\title{
Psychological interventions for parents of children and adolescents with chronic illness (Review)
}

Law E, Fisher E, Eccleston C, Palermo TM

Law E, Fisher E, Eccleston C, Palermo TM.

Psychological interventions for parents of children and adolescents with chronic illness.

Cochrane Database of Systematic Reviews 2019, Issue 3. Art. No.: CD009660.

DOI: 10.1002/14651858.CD009660.pub4.

www.cochranelibrary.com

Psychological interventions for parents of children and adolescents with chronic illness (Review) 
TABLE OF CONTENTS

HEADER

ABSTRACT

PLAIN LANGUAGE SUMMARY

SUMMARY OF FINDINGS

BACKGROUND

OBJECTIVES

METHODS

RESULTS

Figure 1.

Figure 2.

Figure 3.

Figure 4.

Figure 5.

Figure 6.

Figure 7.

DISCUSSION

AUTHORS' CONCLUSIONS

ACKNOWLEDGEMENTS

REFERENCES

CHARACTERISTICS OF STUDIES

DATA AND ANALYSES

Analysis 1.1. Comparison 1: Asthma post-treatment, Outcome 1: Parenting behavior

Analysis 1.2. Comparison 1: Asthma post-treatment, Outcome 2: Parent mental health

Analysis 1.3. Comparison 1: Asthma post-treatment, Outcome 3: Child mental health

Analysis 1.4. Comparison 1: Asthma post-treatment, Outcome 4: Child symptoms

Analysis 1.5. Comparison 1: Asthma post-treatment, Outcome 5: Family functioning

Analysis 2.1. Comparison 2: Asthma follow-up, Outcome 1: Parent mental health

Analysis 2.2. Comparison 2: Asthma follow-up, Outcome 2: Child symptoms

Analysis 2.3. Comparison 2: Asthma follow-up, Outcome 3: Family functioning

Analysis 3.1. Comparison 3: Cancer post-treatment, Outcome 1: Parenting behavior

Analysis 3.2. Comparison 3: Cancer post-treatment, Outcome 2: Parent mental health

Analysis 4.1. Comparison 4: Cancer follow-up, Outcome 1: Parenting behavior

Analysis 4.2. Comparison 4: Cancer follow-up, Outcome 2: Parent mental health

Analysis 5.1. Comparison 5: Chronic pain conditions post-treatment, Outcome 1: Parenting behavior

Analysis 5.2. Comparison 5: Chronic pain conditions post-treatment, Outcome 2: Parent mental health

Analysis 5.3. Comparison 5: Chronic pain conditions post-treatment, Outcome 3: Child behavior/disability

Analysis 5.4. Comparison 5: Chronic pain conditions post-treatment, Outcome 4: Child mental health

Analysis 5.5. Comparison 5: Chronic pain conditions post-treatment, Outcome 5: Child symptoms

Analysis 6.1. Comparison 6: Chronic pain conditions follow-up, Outcome 1: Parenting behavior

Analysis 6.2. Comparison 6: Chronic pain conditions follow-up, Outcome 2: Parent mental health

Analysis 6.3. Comparison 6: Chronic pain conditions follow-up, Outcome 3: Child behavior/disability

Analysis 6.4. Comparison 6: Chronic pain conditions follow-up, Outcome 4: Child mental health

Analysis 6.5. Comparison 6: Chronic pain conditions follow-up, Outcome 5: Child symptoms

Analysis 7.1. Comparison 7: Diabetes post-treatment, Outcome 1: Parenting behavior

Analysis 7.2. Comparison 7: Diabetes post-treatment, Outcome 2: Parent mental health

Analysis 7.3. Comparison 7: Diabetes post-treatment, Outcome 3: Child mental health

Analysis 7.4. Comparison 7: Diabetes post-treatment, Outcome 4: Child symptoms

Analysis 7.5. Comparison 7: Diabetes post-treatment, Outcome 5: Family functioning

Analysis 8.1. Comparison 8: Diabetes follow-up, Outcome 1: Parenting behavior

Analysis 8.2. Comparison 8: Diabetes follow-up, Outcome 2: Parent mental health 
Analysis 8.4. Comparison 8: Diabetes follow-up, Outcome 4: Child symptoms

Analysis 8.5. Comparison 8: Diabetes follow-up, Outcome 5: Family functioning

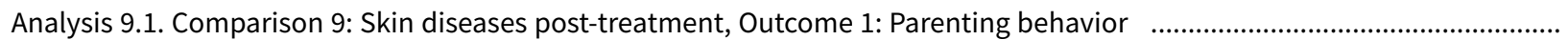

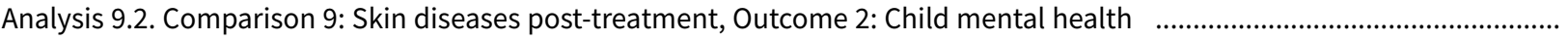

Analysis 9.3. Comparison 9: Skin diseases post-treatment, Outcome 3: Child symptoms

Analysis 9.4. Comparison 9: Skin diseases post-treatment, Outcome 4: Family functioning

Analysis 10.1. Comparison 10: Skin diseases follow-up, Outcome 1: Parenting behavior

Analysis 10.2. Comparison 10: Skin diseases follow-up, Outcome 2: Child mental health

Analysis 10.3. Comparison 10: Skin diseases follow-up, Outcome 3: Child symptoms

Analysis 10.4. Comparison 10: Skin diseases follow-up, Outcome 4: Family functioning

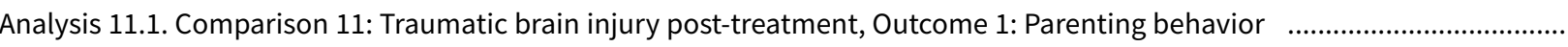

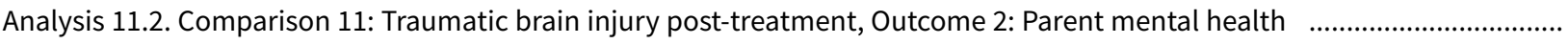

Analysis 11.3. Comparison 11: Traumatic brain injury post-treatment, Outcome 3: Child behavior/disability ...........................

Analysis 11.4. Comparison 11: Traumatic brain injury post-treatment, Outcome 4: Child mental health

Analysis 11.5. Comparison 11: Traumatic brain injury post-treatment, Outcome 5: Family functioning

Analysis 12.1. Comparison 12: Traumatic brain injury follow-up, Outcome 1: Parenting behavior

Analysis 12.2. Comparison 12: Traumatic brain injury follow-up, Outcome 2: Parent mental health

Analysis 12.3. Comparison 12: Traumatic brain injury follow-up, Outcome 3: Child behavior/disability

Analysis 12.4. Comparison 12: Traumatic brain injury follow-up, Outcome 4: Child mental health

Analysis 12.5. Comparison 12: Traumatic brain injury follow-up, Outcome 5: Family functioning

Analysis 13.1. Comparison 13: Cognitive-behavioral therapy post-treatment, Outcome 1: Parenting behavior ........................

Analysis 13.2. Comparison 13: Cognitive-behavioral therapy post-treatment, Outcome 2: Parent mental health ......................

Analysis 13.3. Comparison 13: Cognitive-behavioral therapy post-treatment, Outcome 3: Child behavior/disability .................

Analysis 13.4. Comparison 13: Cognitive-behavioral therapy post-treatment, Outcome 4: Child mental health ........................

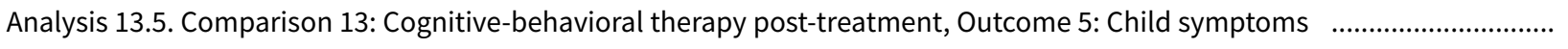

Analysis 13.6. Comparison 13: Cognitive-behavioral therapy post-treatment, Outcome 6: Family functioning ..........................

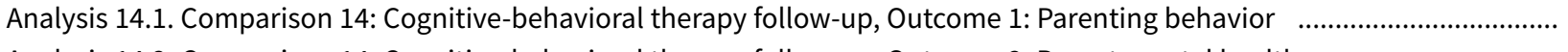

Analysis 14.2. Comparison 14: Cognitive-behavioral therapy follow-up, Outcome 2: Parent mental health $\quad$..............................

Analysis 14.3. Comparison 14: Cognitive-behavioral therapy follow-up, Outcome 3: Child behavior/disability .........................

Analysis 14.4. Comparison 14: Cognitive-behavioral therapy follow-up, Outcome 4: Child mental health ................................

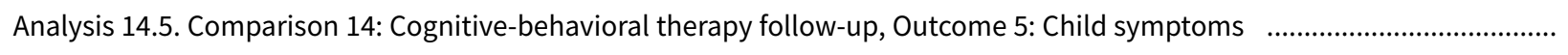

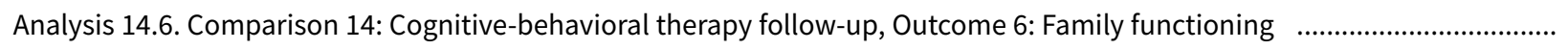

Analysis 15.1. Comparison 15: Family therapy post-treatment, Outcome 1: Parent mental health

Analysis 15.2. Comparison 15: Family therapy post-treatment, Outcome 2: Child mental health

Analysis 15.3. Comparison 15: Family therapy post-treatment, Outcome 3: Child symptoms

Analysis 15.4. Comparison 15: Family therapy post-treatment, Outcome 4: Family functioning

Analysis 16.1. Comparison 16: Family therapy follow-up, Outcome 1: Parent mental health

Analysis 16.2. Comparison 16: Family therapy follow-up, Outcome 2: Child symptoms

Analysis 16.3. Comparison 16: Family therapy follow-up, Outcome 3: Family functioning

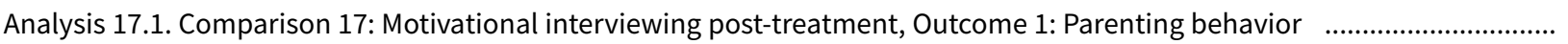

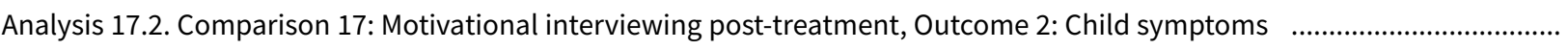

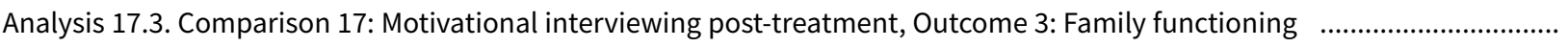

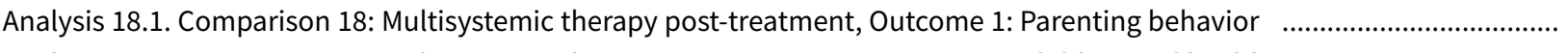

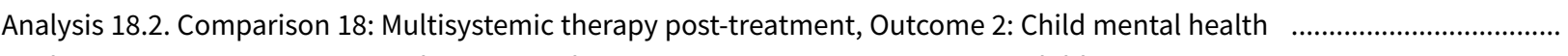

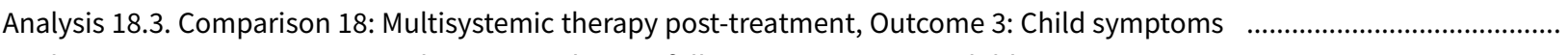

Analysis 19.1. Comparison 19: Multisystemic therapy follow-up, Outcome 1: Child symptoms

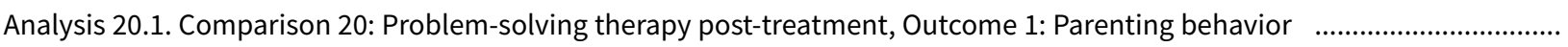

Analysis 20.2. Comparison 20: Problem-solving therapy post-treatment, Outcome 2: Parent mental health

Analysis 20.3. Comparison 20: Problem-solving therapy post-treatment, Outcome 3: Child behavior/disability .......................

Analysis 20.4. Comparison 20: Problem-solving therapy post-treatment, Outcome 4: Child mental health

Analysis 20.5. Comparison 20: Problem-solving therapy post-treatment, Outcome 5: Child symptoms

Analysis 20.6. Comparison 20: Problem-solving therapy post-treatment, Outcome 6: Family functioning 
Analysis 21.1. Comparison 21: Problem-solving therapy follow-up, Outcome 1: Parenting behavior

Analysis 21.2. Comparison 21: Problem-solving therapy follow-up, Outcome 2: Parent mental health

Analysis 21.3. Comparison 21: Problem-solving therapy follow-up, Outcome 3: Child behavior/disability

Analysis 21.4. Comparison 21: Problem-solving therapy follow-up, Outcome 4: Child mental health

Analysis 21.5. Comparison 21: Problem-solving therapy follow-up, Outcome 5: Child symptoms

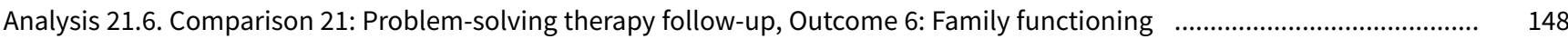

ADDITIONAL TABLES

APPENDICES

WHAT'S NEW

HISTORY

CONTRIBUTIONS OF AUTHORS

DECLARATIONS OF INTERES

SOURCES OF SUPPORT 
[Intervention Review]

\title{
Psychological interventions for parents of children and adolescents with chronic illness
}

Emily Law ${ }^{1}$, Emma Fisher 2 , Christopher Eccleston³ ${ }^{3}$ Tonya M Palermo ${ }^{1}$

1 Anesthesiology and Pain Medicine, University of Washington, Seattle, Washington, USA. ${ }^{2}$ Cochrane Pain, Palliative and Supportive Care Group, Pain Research Unit, Churchill Hospital, Oxford, UK. ${ }^{3}$ Centre for Pain Research, University of Bath, Bath, UK

Contact address: Anna Erskine, anna.erskine@ouh.nhs.uk.

Editorial group: Cochrane Pain, Palliative and Supportive Care Group.

Publication status and date: Stable (no update expected for reasons given in 'What's new'), published in Issue 6, 2021.

Citation: Law E, Fisher E, Eccleston C, Palermo TM. Psychological interventions for parents of children and adolescents with chronic illness. Cochrane Database of Systematic Reviews 2019, Issue 3. Art. No.: CD009660. DOI: 10.1002/14651858.CD009660.pub4.

Copyright $@ 2019$ The Cochrane Collaboration. Published by John Wiley \& Sons, Ltd.

\begin{abstract}
A B S T R A C T
Background

Psychological therapies for parents of children and adolescents with chronic illness aim to improve parenting behavior and mental health, child functioning (behavior/disability, mental health, and medical symptoms), and family functioning.
\end{abstract}

This is an updated version of the original Cochrane Review (2012) which was first updated in 2015.

\section{Objectives}

To evaluate the efficacy and adverse events of psychological therapies for parents of children and adolescents with a chronic illness.

\section{Search methods}

We searched CENTRAL, MEDLINE, Embase, PsycINFO, and trials registries for studies published up to July 2018.

\section{Selection criteria}

Included studies were randomized controlled trials (RCTs) of psychological interventions for parents of children and adolescents with a chronic illness. In this update we included studies with more than 20 participants per arm. In this update, we included interventions that combined psychological and pharmacological treatments. We included comparison groups that received either non-psychological treatment (e.g. psychoeducation), treatment as usual (e.g. standard medical care without added psychological therapy), or wait-list.

\section{Data collection and analysis}

We extracted study characteristics and outcomes post-treatment and at first available follow-up. Primary outcomes were parenting behavior and parent mental health. Secondary outcomes were child behavior/disability, child mental health, child medical symptoms, and family functioning. We pooled data using the standardized mean difference (SMD) and a random-effects model, and evaluated outcomes by medical condition and by therapy type. We assessed risk of bias per Cochrane guidance and quality of evidence using GRADE.

\section{Main results}

We added 21 new studies. We removed 23 studies from the previous update that no longer met our inclusion criteria. There are now 44 RCTs, including 4697 participants post-treatment. Studies included children with asthma (4), cancer (7), chronic pain (13), diabetes (15), inflammatory bowel disease (2), skin diseases (1), and traumatic brain injury (3). Therapy types included cognitive-behavioural therapy (CBT; 21), family therapy (4), motivational interviewing (3), multisystemic therapy (4), and problem-solving therapy (PST; 12). We rated risk of bias as low or unclear for most domains, except selective reporting bias, which we rated high for 19 studies due to incomplete 
outcome reporting. Evidence quality ranged from very low to moderate. We downgraded evidence due to high heterogeneity, imprecision, and publication bias.

\section{Evaluation of parent outcomes by medical condition}

Psychological therapies may improve parenting behavior (e.g. maladaptive or solicitous behaviors; lower scores are better) in children with cancer post-treatment and follow-up (SMD -0.28 , 95\% confidence interval (Cl) -0.43 to -0.13 ; participants $=664$; studies $=3$; SMD $-0.21,95 \% \mathrm{Cl}-0.37$ to -0.05 ; participants $=625$; studies $=3 ; 12=0 \%$, respectively, low-quality evidence), chronic pain post-treatment and follow-up (SMD $-0.29,95 \% \mathrm{Cl}-0.47$ to -0.10 ; participants $=755$; studies $=6$; SMD $-0.35,95 \% \mathrm{Cl}-0.50$ to -0.20 ; participants $=678$; studies $=5$, respectively, moderate-quality evidence), diabetes post-treatment (SMD $-1.39,95 \% \mathrm{Cl}-2.41$ to -0.38 ; participants $=338$; studies $=5$, very low-quality evidence), and traumatic brain injury post-treatment (SMD $-0.74,95 \% \mathrm{Cl}-1.25$ to -0.22 ; participants $=254$; studies $=3$, very low-quality evidence). For the remaining analyses data were insufficient to evaluate the effect of treatment.

Psychological therapies may improve parent mental health (e.g. depression, anxiety, lower scores are better) in children with cancer posttreatment and follow-up (SMD $-0.21,95 \% \mathrm{Cl}-0.35$ to -0.08 ; participants $=836$, studies $=6$, high-quality evidence; $\mathrm{SMD}-0.23,95 \% \mathrm{Cl}-0.39$ to -0.08 ; participants $=667$; studies $=4$, moderate-quality evidence, respectively), and chronic pain post-treatment and follow-up (SMD $-0.24,95 \% \mathrm{Cl}-0.42$ to -0.06 ; participants $=490$; studies $=3$; SMD $-0.20,95 \% \mathrm{Cl}-0.38$ to -0.02 ; participants $=482 ;$ studies $=3$, respectively, low-quality evidence). Parent mental health did not improve in studies of children with diabetes post-treatment (SMD $-0.24,95 \% \mathrm{Cl}-0.90$ to 0.42 ; participants $=211$; studies $=3$, very low-quality evidence). For the remaining analyses, data were insufficient to evaluate the effect of treatment on parent mental health.

\section{Evaluation of parent outcomes by psychological therapy type}

CBT may improve parenting behavior post-treatment (SMD $-0.45,95 \% \mathrm{Cl}-0.68$ to -0.21 ; participants $=1040$; studies $=9$, low-quality evidence), and follow-up (SMD $-0.26,95 \% \mathrm{Cl}-0.42$ to -0.11 ; participants $=743$; studies $=6$, moderate-quality evidence). We did not find evidence for a beneficial effect for CBT on parent mental health at post-treatment or follow-up (SMD $-0.19,95 \% \mathrm{Cl}-0.41$ to 0.03 ; participants $=811$; studies $=8 ;$ SMD $-0.07,95 \% \mathrm{Cl}-0.34$ to 0.20 ; participants $=592$; studies $=5$; respectively, very low-quality evidence). PST may improve parenting behavior post-treatment and follow-up (SMD $-0.39,95 \% \mathrm{Cl}-0.64$ to -0.13 ; participants $=947$; studies $=7$, low-quality evidence; SMD $-0.54,95 \% \mathrm{Cl}-0.94$ to -0.14 ; participants $=852$; studies $=6$, very low-quality evidence, respectively), and parent mental health posttreatment and follow-up (SMD $-0.30,95 \% \mathrm{Cl}-0.45$ to -0.15 ; participants $=891$; studies $=6$; SMD $-0.21,95 \% \mathrm{Cl}-0.35$ to -0.07 ; participants $=800$; studies $=5$, respectively, moderate-quality evidence). For the remaining analyses, data were insufficient to evaluate the effect of treatment on parent outcomes.

\section{Adverse events}

We could not evaluate treatment safety because most studies (32) did not report on whether adverse events occurred during the study period. In six studies, the authors reported that no adverse events occurred. The remaining six studies reported adverse events and none were attributed to psychological therapy. We rated the quality of evidence for adverse events as moderate.

\section{Authors' conclusions}

Psychological therapy may improve parenting behavior among parents of children with cancer, chronic pain, diabetes, and traumatic brain injury. We also found beneficial effects of psychological therapy may also improve parent mental health among parents of children with cancer and chronic pain. CBT and PST may improve parenting behavior. PST may also improve parent mental health. However, the quality of evidence is generally low and there are insufficient data to evaluate most outcomes. Our findings could change as new studies are conducted.

\section{PLAIN LANGUAGE SUMMARY}

\section{Psychological therapies for parents of children and adolescents with a longstanding or life-threatening physical illness}

\section{Bottom line}

We found that psychological therapies may improve parenting behavior for parents of children with cancer, chronic pain, diabetes or traumatic brain injury, and may improve mental health of parents of children with cancer or chronic pain. Cognitive-behavioral therapy (CBT) and problem-solving therapy (PST) are promising types of therapy. We were not able to answer questions about whether psychological therapies are helpful for parents of children with other medical conditions, or whether other types of therapy are helpful, because there were not enough data. Our findings may have been impacted by differences in measures used across studies. New studies may change the results of this review, and so our findings should be interpreted cautiously.

\section{Background}

We have updated our previously published review of psychological therapies for parents of children with a longstanding or life-threatening physical illness to include studies published through July 2018. 
Parenting a child with a longstanding illness is challenging. Parents may have difficulty balancing caring for their child with other demands and can experience increased stress, sadness, or family conflict. Their children may have emotional or behavioral concerns. Parents can influence their child's adaptation to living with their medical condition. Psychological therapies for parents provide training in skills to modify emotions or behaviors that aim to improve parent, child, and family well-being.

We wanted to understand whether psychological therapies are helpful for parents of children and adolescents (up to age 19) with longstanding illness. We included studies of interventions that were predominantly psychological and delivered to parents compared with non-psychological treatment, treatment as usual, or wait-list. Outcomes were parenting behavior (e.g. protective behaviors), parent mental health, child behavior/disability, child mental health, child medical symptoms, family functioning, and side effects.

\section{Key results}

We added 21 new studies in this update and we removed 23 studies that no longer met our inclusion criteria, resulting in 44 randomized controlled trials (randomized controlled trials, where participants are assigned randomly to either one treatment or a different treatment or no treatment, provide the most reliable evidence) with a total of 4697 participants (average child age $=11$ years). The length of the studies ranged from one day to 24 months. Studies included children with asthma (4), cancer (7), chronic pain (recurrent or persistent pain for more than three months, including two studies of children with inflammatory bowel disease (15)), diabetes (15), skin diseases (1), and traumatic brain injury (3); one study included children with eczema and children with asthma. Therapy types included CBT (21), family therapy (4), motivational interviewing (3), multisystemic therapy (4), and PST (12). Funding sources included federal and local governments, hospitals, universities, and foundations.

We found that parenting behavior improved in studies of children with cancer, chronic pain, diabetes, and traumatic brain injury immediately after treatment, which continued long-term for parents of children with cancer and chronic pain. Parent mental health improved in studies of children with cancer and chronic pain immediately after treatment, which continued long-term. Parent mental health did not improve in studies of children with diabetes. We found that CBT and PST improved parenting behavior immediately after treatment, which continued long-term. PST also improved parent mental health immediately after treatment and long-term, but CBT did not. We could not evaluate whether the other types of psychological therapy were beneficial for parents due to insufficient data. We found that these treatment effects were generally small. We found that most studies (32 studies) did not report on whether side effects occurred. In the few studies that did, none of the participants experienced side effects from psychological therapy.

\section{Quality of evidence}

We rated the quality of the evidence from studies using four levels: very low, low, moderate, or high. Very low-quality evidence means that we are very uncertain about the results. High-quality evidence means that we are very confident in the results. There were not enough data to answer some parts of our review questions. There was sufficient evidence (low to moderate quality) to reach some conclusions about the effects of psychological therapy for parents of children with cancer and chronic pain and the effects of CBT and PST. 


\section{SUMMARY OF FINDINGS}

\section{Summary of findings 1. Cognitive-behavioral therapy for parents of children with a chronic illness (post-treatment)}

Cognitive behavioral therapy compared to any control for parents of children with a chronic illness (post-treatment)

Patient or population: parents of children with chronic illness

Settings: community or medical settings

Intervention: cognitive-behavioural therapy

Comparison: any control

\begin{tabular}{|c|c|c|c|}
\hline Outcomes & $\begin{array}{l}\text { Probable outcome with intervention (ef- } \\
\text { fect sizes are presented as SMDa) }\end{array}$ & $\begin{array}{l}\text { No. of participants } \\
\text { (studies) }\end{array}$ & $\begin{array}{l}\text { Quality of the evi- } \\
\text { dence } \\
\text { (GRADE) }\end{array}$ \\
\hline $\begin{array}{l}\text { Parenting behaviors, post-treat- } \\
\text { ment } \\
\text { Higher scores indicate greater mal- } \\
\text { adaptive parenting behavior }\end{array}$ & $\begin{array}{l}\text { On average maladaptive parenting behaviors } \\
\text { in the intervention groups were } 0.45 \text { lower } \\
(95 \% \mathrm{Cl}-0.68 \text { to }-0.21)\end{array}$ & $\begin{array}{l}1040 \text { participants, } 9 \\
\text { studies }\end{array}$ & $\begin{array}{l}\oplus \oplus \ominus \ominus \\
\text { Lowb,c }\end{array}$ \\
\hline $\begin{array}{l}\text { Parent mental health symptoms, } \\
\text { post-treatment } \\
\text { Higher scores indicate greater mental } \\
\text { health symptoms }\end{array}$ & $\begin{array}{l}\text { On average, parent mental health symptoms } \\
\text { in the intervention groups were } 0.19 \text { lower } \\
(95 \% \mathrm{Cl}-0.41 \text { to }-0.03)\end{array}$ & $\begin{array}{l}811 \text { participants, } 8 \\
\text { studies }\end{array}$ & $\begin{array}{l}\oplus \Theta \Theta \Theta \\
\text { Very lowb,c,d }\end{array}$ \\
\hline $\begin{array}{l}\text { Child behavior/disability, post- } \\
\text { treatment } \\
\text { Higher scores indicate greater disabil- } \\
\text { ity }\end{array}$ & $\begin{array}{l}\text { On average, child disability in the interven- } \\
\text { tion groups was } 0.22 \text { lower }(95 \% \mathrm{Cl}-0.35 \text { to } \\
-0.08)\end{array}$ & $\begin{array}{l}1236 \text { participants, } \\
10 \text { studies }\end{array}$ & $\begin{array}{l}\oplus \oplus \oplus \ominus \\
\text { Moderatec }\end{array}$ \\
\hline $\begin{array}{l}\text { Child mental health symptoms, } \\
\text { post-treatment } \\
\text { Higher scores indicate greater mental } \\
\text { health symptoms }\end{array}$ & $\begin{array}{l}\text { On average, child mental health symptoms in } \\
\text { the intervention groups were } 0.08 \text { lower }(95 \% \\
\mathrm{Cl}-0.19 \text { to } 0.03)\end{array}$ & $\begin{array}{l}1786 \text { participants, } \\
15 \text { studies }\end{array}$ & $\begin{array}{l}\oplus \oplus \oplus \oplus \\
\text { High }\end{array}$ \\
\hline $\begin{array}{l}\text { Child medical symptoms, post- } \\
\text { treatment } \\
\text { Higher scores indicate greater med- } \\
\text { ical symptoms }\end{array}$ & $\begin{array}{l}\text { On average, child medical symptoms in the } \\
\text { intervention groups were } 0.38 \text { lower }(95 \% \mathrm{Cl} \\
-0.71 \text { to }-0.06)\end{array}$ & $\begin{array}{l}1434 \text { participants, } \\
13 \text { studies }\end{array}$ & $\begin{array}{l}\oplus \ominus \ominus \ominus \\
\text { Very lowd,e }\end{array}$ \\
\hline $\begin{array}{l}\text { Family functioning, post-treatment } \\
\text { Higher scores indicate poorer family } \\
\text { functioning }\end{array}$ & $\begin{array}{l}\text { On average, family functioning scores in the } \\
\text { intervention groups were } 0.11 \text { lower }(95 \% \mathrm{Cl} \\
-0.35 \text { to } 0.13)\end{array}$ & $\begin{array}{l}429 \text { participants, } 5 \\
\text { studies }\end{array}$ & $\begin{array}{l}\oplus \ominus \odot \odot \\
\text { Very lowf,g }\end{array}$ \\
\hline
\end{tabular}

CI: confidence interval; SMD: standardized mean difference

GRADE Working Group grades of evidence

High-quality: we are very confident that the true effect lies close to that of the estimate of the effect.

Moderate-quality: we are moderately confident in the effect estimate; the true effect is likely to be close to the estimate of effect, but there is a possibility that it is substantially different. 
Low-quality: our confidence in the effect estimate is limited; the true effect may be substantially different from the estimate of the effect.

Very low-quality: we have very little confidence in the effect estimate; the true effect is likely to be substantially different from the estimate of effect.

aSMD: standardized mean difference, interpreted as $0.2=$ small, $0.5=$ moderate, $0.7=$ large (Cohen 1988).

bDowngraded once for heterogeneity.

CDowngraded once for high probability of publication bias.

dDowngraded once for imprecision (wide confidence intervals).

eDowngraded twice for heterogeneity.

fDowngraded once for imprecision (small sample size).

gDowngraded twice for high probability of publication bias.

\section{Summary of findings 2. Cognitive-behavioral therapy for parents of children with a chronic illness (follow-up)}

\section{Cognitive behavioral therapy compared to any control for parents of children with a chronic illness (follow-up)}

Patient or population: parents of children with chronic illness

Settings: community or medical settings

Intervention: cognitive-behavioural therapy

Comparison: any control

\begin{tabular}{|c|c|c|c|}
\hline Outcomes & $\begin{array}{l}\text { Probable outcome with intervention (effect } \\
\text { sizes are presented as SMDa) }\end{array}$ & $\begin{array}{l}\text { No. of participants } \\
\text { (studies) }\end{array}$ & $\begin{array}{l}\text { Quality of the evi- } \\
\text { dence } \\
\text { (GRADE) }\end{array}$ \\
\hline $\begin{array}{l}\text { Parenting behaviors, follow-up } \\
\text { Higher scores indicate greater mal- } \\
\text { adaptive parenting behavior }\end{array}$ & $\begin{array}{l}\text { On average, maladaptive parenting behav- } \\
\text { iors in the intervention groups were } 0.26 \text { lower } \\
(95 \% \mathrm{Cl}-0.42 \text { to }-0.11)\end{array}$ & $\begin{array}{l}743 \text { participants, } 6 \\
\text { studies }\end{array}$ & $\begin{array}{l}\oplus \oplus \oplus \odot \\
\text { Moderateb }\end{array}$ \\
\hline $\begin{array}{l}\text { Parent mental health symptoms, } \\
\text { follow-up } \\
\text { Higher scores indicate greater men- } \\
\text { tal health symptoms }\end{array}$ & $\begin{array}{l}\text { On average, parent mental health symptoms in } \\
\text { the intervention groups were } 0.07 \text { lower }(95 \% \\
\mathrm{Cl}-0.34 \text { to } 0.20)\end{array}$ & $\begin{array}{l}592 \text { participants, } 5 \\
\text { studies }\end{array}$ & $\begin{array}{l}\oplus \ominus \Theta \Theta \\
\text { Very lowb,c,d }\end{array}$ \\
\hline $\begin{array}{l}\text { Child behavior/disability, fol- } \\
\text { low-up } \\
\text { Higher scores indicate greater dis- } \\
\text { ability }\end{array}$ & $\begin{array}{l}\text { On average, child disability in the intervention } \\
\text { groups was } 0.28 \text { lower }(95 \% \mathrm{Cl}-0.40 \text { to }-0.15 \text { ) }\end{array}$ & $\begin{array}{l}1038 \text { participants, } 8 \\
\text { studies }\end{array}$ & $\begin{array}{l}\oplus \oplus \oplus \ominus \\
\text { Moderate }\end{array}$ \\
\hline $\begin{array}{l}\text { Child mental health symptoms, } \\
\text { follow-up } \\
\text { Higher scores indicate greater men- } \\
\text { tal health symptoms }\end{array}$ & $\begin{array}{l}\text { On average, child mental health symptoms in } \\
\text { the intervention groups were } 0.07 \text { lower }(95 \% \\
\mathrm{Cl}-0.19 \text { to } 0.04)\end{array}$ & $\begin{array}{l}1244 \text { participants, } \\
10 \text { studies }\end{array}$ & $\begin{array}{l}\oplus \oplus \oplus \ominus \\
\text { Moderateb }\end{array}$ \\
\hline $\begin{array}{l}\text { Child medical symptoms, fol- } \\
\text { low-up } \\
\text { Higher scores indicate greater med- } \\
\text { ical symptoms }\end{array}$ & $\begin{array}{l}\text { On average, child medical symptoms in the } \\
\text { intervention groups were } 0.13 \text { lower }(95 \% \mathrm{Cl} \\
-0.32 \text { to } 0.06)\end{array}$ & $\begin{array}{l}1136 \text { participants, } \\
10 \text { studies }\end{array}$ & $\begin{array}{l}\oplus \oplus \ominus \ominus \\
\text { Lowb,c }\end{array}$ \\
\hline
\end{tabular}




\section{Family functioning, follow-up}

Higher scores indicate poorer family functioning
On average, family functioning scores in the intervention groups were 0.04 lower $(95 \% \mathrm{Cl}$ -0.32 to 0.24 )
201 participants, 3 studies

$\oplus \odot \Theta \Theta$

Very lowb,e

CI: confidence interval; SMD: standardized mean difference

GRADE Working Group grades of evidence

High-quality: we are very confident that the true effect lies close to that of the estimate of the effect.

Moderate-quality: we are moderately confident in the effect estimate; the true effect is likely to be close to the estimate of effect, but there is a possibility that it is substantially different.

Low-quality: our confidence in the effect estimate is limited; the true effect may be substantially different from the estimate of the effect.

Very low-quality: we have very little confidence in the effect estimate; the true effect is likely to be substantially different from the estimate of effect.

aSMD: standardized mean difference, interpreted as $0.2=$ small, $0.5=$ moderate, $0.7=$ large (Cohen 1988).

bDowngraded once for high probability of publication bias.

cDowngraded once for heterogeneity.

dDowngraded once for imprecision due to wide confidence intervals.

eDowngraded twice for limitations in study design/implementation.

\section{Summary of findings 3. Problem-solving therapy for parents of children with a chronic illness (post-treatment)}

\section{Problem-solving therapy compared to any control for parents of children with a chronic illness (post-treatment)}

Patient or population: parents of children with chronic illness

Settings: community or medical settings

Intervention: problem-solving therapy

Comparison: any control

\begin{tabular}{|c|c|c|c|}
\hline Outcomes & $\begin{array}{l}\text { Probable outcome with intervention (effect } \\
\text { sizes are presented as SMDa) }\end{array}$ & $\begin{array}{l}\text { No. of participants } \\
\text { (studies) }\end{array}$ & $\begin{array}{l}\text { Quality of the evi- } \\
\text { dence } \\
\text { (GRADE) }\end{array}$ \\
\hline $\begin{array}{l}\text { Parenting behaviors, post-treat- } \\
\text { ment } \\
\text { Higher scores indicate greater mal- } \\
\text { adaptive parenting behavior }\end{array}$ & $\begin{array}{l}\text { On average, maladaptive parenting behav- } \\
\text { iors in the intervention groups were } 0.39 \text { lower } \\
(95 \% \mathrm{Cl}-0.64 \text { to }-0.13)\end{array}$ & $\begin{array}{l}947 \text { participants, } 7 \\
\text { studies }\end{array}$ & $\begin{array}{l}\oplus \oplus \ominus \ominus \\
\text { Lowb }\end{array}$ \\
\hline $\begin{array}{l}\text { Parent mental health symptoms, } \\
\text { post-treatment } \\
\text { Higher scores indicate greater men- } \\
\text { tal health symptoms }\end{array}$ & $\begin{array}{l}\text { On average, parental mental health symptoms } \\
\text { in the intervention groups were } 0.30 \text { lower } \\
(95 \% \mathrm{Cl}-0.45 \text { to }-0.15)\end{array}$ & $\begin{array}{l}891 \text { participants, } 6 \\
\text { studies }\end{array}$ & $\begin{array}{l}\oplus \oplus \oplus \ominus \\
\text { Moderatec }\end{array}$ \\
\hline $\begin{array}{l}\text { Child behavior/disability, post- } \\
\text { treatment } \\
\text { Higher scores indicate greater dis- } \\
\text { ability }\end{array}$ & $\begin{array}{l}\text { On average, child disability in the intervention } \\
\text { groups was } 0.08 \text { greater }(95 \% \mathrm{Cl}-0.18 \text { to } 0.33 \text { ) }\end{array}$ & $\begin{array}{l}247 \text { participants, } 3 \\
\text { studies }\end{array}$ & $\begin{array}{l}\oplus \odot \odot \ominus \\
\text { Very lowd,e }\end{array}$ \\
\hline $\begin{array}{l}\text { Child mental health symptoms, } \\
\text { post-treatment }\end{array}$ & $\begin{array}{l}\text { On average, child mental health symptoms in } \\
\text { the intervention groups was } 0.12 \text { lower }(95 \% \mathrm{Cl} \\
-0.50 \text { to } 0.25)\end{array}$ & $\begin{array}{l}276 \text { participants, } 4 \\
\text { studies }\end{array}$ & $\begin{array}{l}\oplus \Theta \Theta \odot \\
\text { Very low d,f,g }\end{array}$ \\
\hline
\end{tabular}

Psychological interventions for parents of children and adolescents with chronic illness (Review) 
Higher scores indicate greater mental health symptoms

\begin{tabular}{l|lll}
\hline $\begin{array}{l}\text { Child medical symptoms, post- } \\
\text { treatment }\end{array}$ & $\begin{array}{l}\text { On average, child medical symptoms in the in- } \\
\text { tervention groups were equivalent } 0.25 \text { higher } \\
(95 \% \mathrm{Cl}-0.23 \text { to } 0.72)\end{array}$ & $\begin{array}{l}679 \text { participants, } 5 \\
\text { studies }\end{array}$ & $\begin{array}{l}\oplus \ominus \ominus \Theta \\
\text { Very lowb,c }\end{array}$ \\
$\begin{array}{l}\text { Higher scores indicate greater med- } \\
\text { ical symptoms }\end{array}$ & & & \\
\hline $\begin{array}{l}\text { Family functioning, post-treat- } \\
\text { ment }\end{array}$ & $\begin{array}{l}\text { On average, family functioning scores in the } \\
\text { intervention groups were } 0.15 \text { lower }(95 \% \mathrm{Cl}\end{array}$ & $\begin{array}{l}237 \text { participants, } 2 \\
\text { studies }\end{array}$ & $\begin{array}{l}\oplus \Theta \Theta \Theta \\
\text { Very lowd,e }\end{array}$ \\
$\begin{array}{l}\text { Higher scores indicate poorer family } \\
\text { functioning }\end{array}$ & -0.41 to 0.10$)$ & & \\
\hline
\end{tabular}

CI: confidence interval; SMD: standardized mean difference

GRADE Working Group grades of evidence

High-quality: we are very confident that the true effect lies close to that of the estimate of the effect.

Moderate-quality: we are moderately confident in the effect estimate; the true effect is likely to be close to the estimate of effect, but there is a possibility that it is substantially different.

Low-quality: our confidence in the effect estimate is limited; the true effect may be substantially different from the estimate of the effect.

Very low-quality: we have very little confidence in the effect estimate; the true effect is likely to be substantially different from the estimate of effect.

aSMD: standardized mean difference, interpreted as $0.2=$ small, $0.5=$ moderate, $0.7=$ large (Cohen 1988 ). ${ }^{b}$ Downgraded twice for heterogeneity.

cDowngraded once for high probability of publication bias.

dDowngraded once for imprecision due to small sample size.

eDowngraded twice for high probability of publication bias.

fDowngraded once for heterogeneity.

gDowngraded once for imprecision due to wide confidence intervals.

\section{Summary of findings 4. Problem-solving therapy for parents of children with a chronic illness (follow-up)}

\section{Problem-solving therapy compared to any control for parents of children with a chronic illness (follow-up)}

Patient or population: parents of children with chronic illness

Settings: community or medical settings

Intervention: problem-solving therapy

Comparison: any control

\begin{tabular}{|c|c|c|c|}
\hline Outcomes & $\begin{array}{l}\text { Probable outcome with intervention (ef- } \\
\text { fect sizes are presented as SMDa) }\end{array}$ & $\begin{array}{l}\text { No. of participants } \\
\text { (studies) }\end{array}$ & $\begin{array}{l}\text { Quality of the evi- } \\
\text { dence } \\
\text { (GRADE) }\end{array}$ \\
\hline $\begin{array}{l}\text { Parenting behaviors, follow-up } \\
\text { Higher scores indicate more mal- } \\
\text { adaptive parenting behavior }\end{array}$ & $\begin{array}{l}\text { On average, maladaptive parenting behav- } \\
\text { iors in the intervention groups were } 0.54 \text { low- } \\
\text { er }(95 \% \mathrm{Cl}-0.94 \text { to }-0.14)\end{array}$ & $\begin{array}{l}852 \text { participants, } 6 \\
\text { studies }\end{array}$ & $\begin{array}{l}\oplus \ominus \ominus \ominus \\
\text { Very lowb,c }\end{array}$ \\
\hline $\begin{array}{l}\text { Parent mental health symptoms, } \\
\text { follow-up }\end{array}$ & $\begin{array}{l}\text { On average, parent mental health symptoms } \\
\text { in the intervention groups were } 0.21 \text { lower } \\
(95 \% \mathrm{Cl}-0.35 \text { to }-0.07)\end{array}$ & $\begin{array}{l}800 \text { participants, } 5 \\
\text { studies }\end{array}$ & $\begin{array}{l}\oplus \oplus \oplus \ominus \\
\text { Moderated }\end{array}$ \\
\hline
\end{tabular}


Higher scores indicate greater mental health symptoms

\begin{tabular}{|c|c|c|c|}
\hline $\begin{array}{l}\text { Child behavior/disability, follow-up } \\
\text { Higher scores indicate greater disabil- } \\
\text { ity }\end{array}$ & $\begin{array}{l}\text { Analysis not conducted due to lack of avail- } \\
\text { able data. }\end{array}$ & $\begin{array}{l}114 \text { participants, } 2 \\
\text { studies }\end{array}$ & $\begin{array}{l}\oplus \odot \odot \ominus \\
\text { Very lowd,e }\end{array}$ \\
\hline $\begin{array}{l}\text { Child mental health symptoms, fol- } \\
\text { low-up } \\
\text { Higher scores indicate greater mental } \\
\text { health symptoms }\end{array}$ & $\begin{array}{l}\text { On average, child mental health symptoms in } \\
\text { the intervention groups were } 0.59 \text { lower ( } 95 \% \\
\mathrm{Cl}-0.28 \text { to } 1.46)\end{array}$ & $\begin{array}{l}212 \text { participants, } 3 \\
\text { studies }\end{array}$ & $\begin{array}{l}\oplus \ominus \odot \odot \\
\text { Very low } f, g\end{array}$ \\
\hline $\begin{array}{l}\text { Child medical symptoms, follow-up } \\
\text { Higher scores indicate greater med- } \\
\text { ical symptoms }\end{array}$ & $\begin{array}{l}\text { On average, child medical symptoms in the } \\
\text { intervention groups were } 0.25 \text { higher }(95 \% \mathrm{Cl} \\
-0.08 \text { to } 0.59)\end{array}$ & $\begin{array}{l}210 \text { participants, } 3 \\
\text { studies }\end{array}$ & $\begin{array}{l}\oplus \ominus \odot \odot \\
\text { Very lowf,g }\end{array}$ \\
\hline $\begin{array}{l}\text { Family functioning, follow-up } \\
\text { Higher scores indicate poorer family } \\
\text { functioning }\end{array}$ & $\begin{array}{l}\text { Analysis not conducted due to lack of avail- } \\
\text { able data. }\end{array}$ & $\begin{array}{l}101 \text { participants, } 1 \\
\text { study }\end{array}$ & $\begin{array}{l}\oplus \ominus \ominus \ominus \\
\text { Very lowd,e }\end{array}$ \\
\hline
\end{tabular}

CI: confidence interval; SMD: standardized mean difference

GRADE Working Group grades of evidence

High-quality: we are very confident that the true effect lies close to that of the estimate of the effect;

Moderate-quality: we are moderately confident in the effect estimate; the true effect is likely to be close to the estimate of effect, but there is a possibility that it is substantially different;

Low-quality: our confidence in the effect estimate is limited; the true effect may be substantially different from the estimate of the effect;

Very low-quality: we have very little confidence in the effect estimate; the true effect is likely to be substantially different from the estimate of effect.

aSMD: standardized mean difference, interpreted as $0.2=$ small, $0.5=$ moderate, $0.7=$ large (Cohen 1988).

bDowngraded twice for heterogeneity.

cDowngraded once for imprecision due to wide confidence intervals.

dDowngraded once for high probability of publication bias.

eDowngraded twice for imprecision due to small sample size.

fDowngraded once for imprecision due to small sample size.

gDowngraded twice for high probability of publication bias. 


\section{B A C K G R O U N D}

This is an updated version of the original Cochrane Review (Eccleston 2012b), which was first updated in 2015 (Eccleston 2015).

\section{Description of the condition}

Chronic medical conditions in childhood include diseases with a duration of more than three months (e.g. asthma, chronic pain, diabetes mellitus) as well as potentially life-threatening conditions such as cancer. These conditions are common in childhood, impacting up to $27 \%$ of children and adolescents (Van Cleave 2010). Over the past century, the prevalence of chronic conditions in childhood has increased while mortality due to acute conditions has decreased (Halfon 2010; Van Cleave 2010). This shift is attributed to medical advances in the diagnosis, prevention, and treatment of acute conditions in childhood (Liu 2015), as well as changes in environmental risk factors for chronic disease, for example, more sedentary lifestyles and poor dietary habits (Han 2010; Popkin 2012). Worldwide, the number of children with a chronic illness is expected to increase over time (Liu 2015). This is problematic because chronic conditions in childhood can impact every domain of daily life, including children's activity participation, schooling, friendships, and emotional functioning, for example, anxiety, depression, oppositional behavior. Parents and families are also impacted and commonly experience emotional distress (e.g. anxiety, depression), maladaptive parenting behaviors (e.g. increased protective or solicitous parenting responses), and poor family functioning, such as family conflict (Cousino 2013; Pinquart 2013; Price 2016).

Parents and families play a critical role in children's adaptation to chronic illness. Across a variety of pediatric populations, maladaptive parenting behaviors, parental distress, and poor family functioning have been associated with poorer child outcomes including greater problematic behaviors and disability (e.g. poor school attendance, decreased participation in extra curricular activities), anxiety and mood symptoms, and more severe medical symptoms (Cousino 2013; Delamater 2014; Leeman 2016; Palermo 2014; Price 2016; Sultan 2016; Wiebe 2016). These associations are hypothesized to be bi-directional; for example, the severity of children's medical symptoms may impact parental distress and vice-versa (Morawska 2015; Palermo 2014). Providing psychological interventions to parents and families of children with chronic conditions has been increasingly promoted as a viable and potentially beneficial approach for children with chronic conditions and their families (Morawska 2015; Palermo 2014; Price 2016; Wiebe 2016). There is a critical need to understand the evidence base for these interventions in order to inform clinical practice and research that will support the health and well-being of these children, their parents, and their families.

\section{Description of the intervention}

Psychological interventions for parents and families of children with chronic conditions aim to reduce parental distress and maladaptive parenting behaviors, improve family functioning, and promote the child's health and well-being (Law 2014). These interventions may be delivered only to parents or may be combined with psychological treatment that is also delivered to the child, the family system, and others, for example, school staff or medical providers (Law 2014).
For the purpose of this review, psychological interventions are defined as any psychotherapeutic treatment specifically designed to change parental cognition or behavior, or both, with the intention of improving parent or child outcomes, or both. Existing interventions include cognitive-behavioral therapy (CBT) (e.g. Palermo 2016b), motivational interviewing (MI) (e.g. Ellis 2017a), problem-solving therapy (PST) (e.g. Sahler 2002), and systemic treatments such as family therapy (FT) (e.g. Wysocki 2000), and multisystemic therapy (MST) (e.g. Ellis 2005).

\section{How the intervention might work}

Proposed mechanisms of psychological treatments vary depending upon the theoretical orientation and approach of the intervention. Cognitive-behavioral therapy (CBT) is founded in behavioral analysis and operant theory (Bergin1975; Skinner 1953), cognitive theory (Beck 1979), and social learning theory (Bandura 1977). Associations between cognitions, emotions, and behaviors are emphasized and are believed to interact to influence desired outcomes. Thus, treatment is focused on altering maladaptive social/environmental, behavioral, and cognitive factors in order to reduce symptoms and prevent relapse.

Family therapy (FT) is based on family systems theory and emphasizes the role of the family context in an individual's emotional functioning (Bowen 1966). There are several types of FT, including structural FT (Minuchin 1974), strategic FT (Haley 1976), and behavioral systems FT (Robin 1989). Treatment aims to alter maladaptive patterns of interaction within the family in order to improve symptoms.

Motivational interviewing (MI) focuses on the patient's motivation for and commitment to behavior change. Specific strategies include exploring and resolving ambivalence, rolling with resistance, and eliciting and supporting the patient's own arguments for change (Miller 1983; Miller 2013). A unique feature of MI is the focus on the patient's own values and goals, as opposed to imposing external values and strategies for change.

Multisystemic therapy (MST) is an intensive family- and communitybased intervention founded in the social ecological model (Bronfenbrenner 1979), and family systems theory (Bowen 1966; Haley 1976; Minuchin 1974). Treatment targets of MST are broad and include the child, their family, and broader systems such as the child's school or medical team. MST incorporates a wide range of intervention techniques based on the individual needs of the child and family (Henggeler 2003), including cognitive and behavioral skills training, parent operant training, and family therapy.

Problem-solving therapy (PST) is based on the social-problemsolving model (D'Zurilla 1971; D'Zurilla 1982; D'Zurilla 1999), which emphasizes the role of constructive problem-solving attitudes and skills in fostering enhanced social competence and reduced emotional distress. Specific problem-solving skills are taught in sequential steps that typically include defining the problem, generating alternative solutions, decision making, and solution implementation and evaluation (D'Zurilla 2007).

\section{Why it is important to do this review}

Children's adaptation to chronic illness occurs within the context of the parent-child relationship, the family system, and the broader community. There are likely bi-directional relationships between parent functioning (parental behavior, mental health), 
child functioning (child behavior/disability, mental health, medical symptoms) and family functioning (e.g. family conflict/cohesion) that may impact the child's adaptation to, and management of their medical condition. Psychological interventions for parents of children with chronic medical conditions focus on improving parent mental health and well-being of children, and the family system. Establishing the evidence at this stage of development can guide clinical practice and future research development.

\section{O B J E C T IVES}

To evaluate the efficacy and adverse events of psychological therapies for parents of children and adolescents with a chronic illness.

\section{METHODS}

\section{Criteria for considering studies for this review}

\section{Types of studies}

Eligible study designs met the following criteria.

- Randomized controlled trials (RCTs), published in full in a peerreviewed journal

- The primary aim of the study was to evaluate an intervention that was predominantly psychological in nature and that was delivered to parents.

- For this update, in order to enhance the quality of included studies and interpretability of results of the review, studies were required to have at least 20 participants per arm post-treatment or follow-up.

- Reported quantitative outcomes. Exclusively qualitative studies were excluded from this review.

\section{Types of participants}

Eligible participants met the following criteria.

- Parents were operationally defined as primary caregivers who were responsible for parenting the child, including (but not limited to) biological parents, guardians, and other adult family members.

- Children and adolescents, aged three months to 19 years, with one of the following chronic medical conditions that had an expected duration of at least three months:

* asthma;

* cancer (including newly diagnosed patients, patients in active treatment, and survivors);

* chronic pain conditions (including but not limited to arthritis, back pain, complex regional pain syndrome, fibromyalgia, headache, idiopathic pain conditions, irritable bowel syndrome, migraine, recurrent abdominal pain);

* diabetes mellitus;

* gynaecological disorders (e.g. chronic dysmenorrhea, endometriosis);

* inflammatory bowel diseases (IBD);

* skin diseases (e.g. eczema);

* traumatic brain injury (TBI).

We selected chronic illnesses from the list of 'Current Health Conditions and Functional Difficulties' from the National Survey of Children with Special Health Care Needs 2009 to 2010 (Data Resource Center 2010). It was impractical to include all chronic illnesses on this list; therefore we selected the most common. For the purposes of this review, we also included three additional illnesses: cancer, inflammatory bowel diseases and gynaecological disorders. Cancer has a high incidence level, and in the UK alone 1821 children aged 0 to 14 years are diagnosed with cancer each year (Cancer Research UK 2018). In the USA, it is estimated that 15,270 children aged 0 to 19 years are diagnosed with cancer (National Cancer Institute 2018). IBD and gynaecological disorders are also common conditions in childhood and adolescence.

\section{Types of interventions}

We included interventions that were primarily psychological, had credible and recognizable psychological/psychotherapeutic content, and were delivered to parents. In this update, we included interventions that combined psychological and pharmacological treatments. We included comparison groups that received either non-psychological treatment (e.g. psychoeducation), treatment as usual (e.g. standard medical care without added psychological therapy), or wait-list.

We excluded interventions that used parents as 'coaches' to support exclusively child-focused treatments, as well as those that were primarily health promotion interventions (e.g. smoking cessation treatments for parents of children with asthma).

\section{Types of outcome measures}

We extracted means, standard deviations, and numbers used in analyses for all available treatment outcomes post-treatment and at the first-available follow-up. We transcribed adverse events verbatim from the published manuscripts.

When studies reported multiple measures within an outcome domain, we extracted the most generic, reliable, appropriate, and frequently used measure within the field. When both parents and children reported on a measure, we preferentially extracted child self-report data. For measures of family functioning, we preferentially extracted parent-reported data.

\section{Primary outcomes}

Our main outcomes were parenting behavior (e.g. self-report measures of behavioral responses to their child, such as overprotective or solicitous behaviors), and parent mental health (e.g. self-report measures of anxiety, depression).

\section{Secondary outcomes}

Our secondary outcomes were child behavior/disability (e.g. selfreport measures of functional disability, school attendance), child mental health (e.g. self-report measures of anxiety, depression, oppositional behavior), child medical symptoms (e.g. objective measures of medical symptoms, such as HbAlc scores for youth with diabetes), family functioning (e.g. self-report measures of family conflict, family cohesion, family communication), and adverse events.

\section{Search methods for identification of studies}

We have conducted three searches for this review: 1) from inception to March 2012, 2) from March 2012 to July 2014, and 3) from July 
2014 to July 2018. Below, we list all sources searched including databases, trials registers, and other resources.

\section{Electronic searches}

We searched four electronic databases for this update:

- Cochrane Central Register of Controlled Trials (CENTRAL) via CRSO, inception to 16 July 2018;

- MEDLINE via Ovid, 1946 to 17 July 2018;

- Embase via Ovid, 1974 to 16 July 2018;

- PsycINFO via Ovid, 1806 to 16 July 2018.

We adapted the search strategies from the MEDLINE search (for all search strategies see Appendix 1). In order to include only the highest quality studies, we did not impose a language restriction and we did not include unpublished literature or grey material. We included four categories of words in the search strategy: psychological interventions, parents, children and adolescents, and chronic illnesses (as stated above), which were refined by a methodological filter used to identify RCTs according to Cochrane guidance (Lefebvre 2011).

\section{Searching other resources}

We checked reference lists of and performed a citation search for all included studies and relevant meta-analyses and systematic reviews identified via our electronic searches. We searched online trials registries up to July 2018 including metaRegister of controlled trials (mRCT; www.isrctn.com/page/ mrct), ClinicalTrials.gov (clinicaltrials.gov), and the World Health Organization International Clinical Trials Registry Platform (ICTRP; www.who.int/ictrp/en/). Search terms for trials registries included: psychological interventions, parents, children, adolescents, and chronic illness (as stated above). We contacted authors of selected studies and experts in the field for unpublished and ongoing studies.

\section{Data collection and analysis}

\section{Selection of studies}

Two review authors (EF, EL) independently conducted the selection of studies including screening titles and abstracts, and full-text manuscripts. A third author (TP) served as arbiter. We selected studies by reviewing full texts of manuscripts identified from the updated abstract search. We resolved any disagreements by discussion between review authors.

Our included studies met the following criteria.

Participants:

- the title or abstract referred to parents;

- children had one or more of the chronic illnesses listed above;

- children were 3 months to 19 years of age;

- there were 20 or more participants in each arm of the study at immediate post-treatment or follow-up;

- the parent had to be the primary caregiver of the child.

Intervention:

- the intervention was primarily psychological in at least one treatment arm;
- design was a RCT;

- treatment was delivered to one or more parents;

- outcome assessments were completed by the parent, the child, or both.

Comparison groups:

- active, non-psychological treatment (e.g. psychoeducation);

- treatment-as-usual (e.g. usual doctors' appointments and treatment without added psychological therapy);

- wait-list.

Outcomes:

- at least one outcome measure was quantitative.

\section{Data extraction and management}

\section{Data collection process}

Two review authors (EL, EF) independently conducted data extraction using the ProForma we developed for prior versions of this review. We resolved any disagreements by discussion between review authors.

\section{Requests for data}

We contacted authors of studies when data were not reported fully in the published manuscripts. We contacted study authors via email twice during a one-month period.

\section{Data items}

We extracted participant demographics, chronic illness characteristics, therapy characteristics, treatment outcomes, and adverse events (transcribed verbatim from the published manuscripts).

\section{Transformations of data}

We did not conduct any transformations of data. We used means and standard deviations for all meta-analyses of treatment outcomes.

\section{Assessment of risk of bias in included studies}

We assessed risk of bias based on the methods reported in the published manuscripts using the recommended Cochrane guidance (Higgins 2017). We evaluated five of the six suggested 'Risk of bias' categories: random sequence generation (selection bias), allocation concealment (selection bias), blinding of outcome assessment (detection bias), incomplete outcome data (attrition bias) and selective reporting (reporting bias). We excluded the category of 'blinding participants and personnel' because it is not possible to blind personnel who are delivering psychological treatments.

\section{Sequence generation}

We judged studies to have low risk of bias if an adequate random sequence generation method was reported, such as using a random numbers table or a computerized random numbers generator. We judged studies to have unclear risk of bias when sequence generation procedures were not reported in the published manuscript. We judged studies to have high risk of bias when a non-random approach to sequence generation was 
reported, such as assigning participants sequentially or based on date of birth. Stratification of participants (e.g. by age or sex) did not count as biased as long as a random sequence generation method was reported.

\section{Allocation concealment}

We judged studies to have low risk of bias if a third party not involved in participant recruitment/enrollment allocated participants to treatment groups or if an alternative adequate allocation method was described (e.g. use of a locked electronic file to store the allocation sequence, use of sealed opaque envelopes that are sequentially numbered according to the allocation sequence, or use of centralized automated telephonic or computerized assignment systems). We judged studies to have unclear risk of bias if procedures for allocation were not described. We judged studies to have high risk of bias when procedures for allocation concealment were not used (e.g. the person recruiting/ enrolling participants would have been able to foresee treatment group assignments).

\section{Detection bias}

We judged studies to have low risk of bias when outcome assessments were administered by an assessor who was blind to the treatment allocation, or when measures were completed by participants in their homes and submitted either online or via postal mail. We judged studies to have unclear risk of bias if the method for blinding study staff during outcome assessments was not described. We judged studies to have high risk of bias when blinding was not used during outcome assessments (e.g. outcome assessments were administered by the participant's study therapist) or if it was likely that the blinding could have been broken.

\section{Attrition bias}

We assigned a low risk of bias when attrition was reported (e.g. via a participant flow diagram) and when the authors reported that characteristics of participants who completed the study and those who were lost to follow-up did not differ between the treatment groups. We assigned an unclear risk of bias when an inadequate description of attrition was provided (i.e. attrition was reported but comparisons between the treatment groups were not reported) or attrition was not clearly described.

\section{Reporting bias}

We assessed outcome reporting bias based on whether the results of the published manuscript included data for all outcomes described in the Methods. We assigned a low risk of bias when data for all outcomes were fully reported at all time points in the published manuscript (i.e. number of participants, means, standard deviations), an unclear risk of bias when insufficient information was reported to make a judgement, and high risk of bias when outcomes data were not fully reported in the published manuscript. When outcome data were not fully reported, we requested these data from the study authors via email. When data were not fully reported in the manuscript, we assessed reporting bias as high regardless of whether study authors responded to our data request.

\section{Measures of treatment effect}

We extracted data immediately post-treatment (i.e. immediately after the treatment program had finished). When studies had repeated follow-up observations on participants, we extracted data from the first available follow-up time point only, because we considered this to be the most clinically relevant time point, per the guidelines provided in chapter 9 of the Cochrane Handbook for Systematic Reviews of Interventions (9.3.4; Deeks 2017).

We categorized outcomes into one of six outcome domains: parenting behavior, parent mental health, child behavior/disability, child mental health, child symptoms and family functioning. Where studies had more than one comparator group, we chose the 'active control group' over 'standard treatment' or 'wait-list control' groups.

There are four therapies (CBT, FT, PST and MST), eight medical conditions (asthma, cancer, diabetes mellitus, gynecological disorders, inflammatory bowel diseases, painful conditions, skin diseases, and traumatic brain injury), two time points (posttreatment and follow-up) and six possible outcomes (parenting behavior, parent mental health, child behavior/disability, child mental health, child symptoms and family functioning). There are six categories by which we sought to analyze data.

- For each condition, across all types of psychological therapy, what is the efficacy for the six outcomes immediately posttreatment?

- For each condition, across all types of psychological therapy, what is the efficacy for the six outcomes at follow-up?

- For each psychological therapy, across all conditions, what is the efficacy for the six outcomes post-treatment?

- For each psychological therapy, across all conditions, what is the efficacy for the six outcomes at follow-up?

- The interaction between the condition and the efficacy of the psychological therapy

- Investigaton of characteristics of particularly effective treatments

We have presented analyses for each of the six outcomes, however, due to the heterogeneous nature of the conditions and studies, this was not always possible.

\section{Unit of analysis issues}

For all included studies, randomization occurred at the level of the individual. Most studies used parallel-group designs; one study used a cross-over design (Kashikar-Zuck 2012). There were no cluster-randomized trials. There were seven studies that had three study arms (Ellis 2017a; Greenley 2015; Levy 2017; Seid 2010; Wade 2017; Wysocki 1999; Wysocki 2006). For studies with two intervention groups, we combined these for analysis in order to create a single pair-wise comparison per the guidelines and methods provided in Chapter 16.5.4 (Higgins 2011a), and Chapter 7.3.8 (Higgins 2011b), of the Cochrane Handbook for Systematic Reviews of Interventions. For studies with two control groups, we extracted data from the active control condition for analyses.

\section{Dealing with missing data}

We contacted authors of studies where outcome data were not reported fully in publications (i.e. means or standard deviations for 
outcomes were missing). However, when study authors could not provide the data or were not-responsive to emails, we excluded those studies from analyses.

\section{Assessment of heterogeneity}

We used the $\mathrm{I}^{2}$ statistic to assess statistical heterogeneity, per the guidelines provided in Chapter 9.5.2 of the Cochrane Handbook for Systematic Reviews of Interventions (Deeks 2017).

\section{Assessment of reporting biases}

We planned to use funnel plots to assess reporting biases per the guidelines provided in Chapter 10.4 of the Cochrane Handbook for Systematic Reviews of Interventions (Sterne 2017). However, the data were not of sufficient quality or quantity to allow for this assessment.

\section{Data synthesis}

We pooled data using the standardized mean difference (SMD) and a random-effects model. We chose to use a random-effects model due to several potential sources of heterogeneity including inconsistency between studies in types of comparator conditions (i.e. active versus wait-list control conditions), variability between studies in types of outcome assessment measures, inclusion of different therapy types in analyses evaluating the effect of psychological treatments for each medical condition, and inclusion of different medical conditions when evaluating the effect of each psychological therapy type. Cohen's $d$ effect sizes can be interpreted as follows: $0.2=$ small, $0.5=$ medium, $0.8=$ large (Cohen 1988). $P$ values were not corrected for the multiple meta-analytic comparisons conducted in this review. We used Review Manager 5 (RevMan 5) to conduct analyses (Review Manager 2014).

When studies evaluated more than one psychological treatment that met our eligibility criteria (e.g. three-armed RCTs with two treatment arms and one comparator), we averaged outcome data across the two treatment arms. When studies had more than one comparator control condition, we preferentially extracted outcome data from the active comparator control condition over treatment as usual and wait-list control conditions.

\section{Quality of the evidence}

Two review authors (EL, EF) independently rated the quality of the outcomes. We used the GRADE system to rank the quality of the evidence using the RevMan 5 'Summary of findings' table, and the guidelines provided in Chapter 11 of the Cochrane Handbook for Systematic Reviews of Interventions (Schünemann 2017).

The GRADE approach uses five considerations (study limitations, consistency of effect, imprecision and publication bias) to assess the quality of the body evidence for each outcome. Quality level ratings range from high to very low, and are interpreted as follows:

- High: we are very confident that the true effect lies close to that of the estimate of the effect;

- Moderate: we are moderately confident in the effect estimate; the true effect is likely to be close to the estimate of effect, but there is a possibility that it is substantially different;

- Low: our confidence in the effect estimate is limited; the true effect may be substantially different from the estimate of the effect;
- Very low: we have very little confidence in the effect estimate; the true effect is likely to be substantially different from the estimate of effect.

The GRADE system uses the following criteria for assigning a quality level to a body of evidence (Chapter 11, Schünemann 2017).

- High: randomized trials; or double-upgraded observational studies

- Moderate: downgraded randomized trials; or upgraded observational studies

- Low: double-downgraded randomized trials; or observational studies

- Very low: triple-downgraded randomized trials; or downgraded observational studies; or case series/case reports

Factors that may decrease the quality level of a body of evidence are:

- limitations in the design and implementation of available studies suggesting high likelihood of bias;

- indirectness of evidence (indirect population, intervention, control, outcomes);

- unexplained heterogeneity or inconsistency of results (including problems with subgroup analyses);

- imprecision of results (wide confidence intervals);

- high probability of publication bias.

Factors that may increase the quality level of a body of evidence are:

- large magnitude of effect;

- all plausible confounding would reduce a demonstrated effect or suggest a spurious effect when results show no effect;

- dose-response gradient.

For this update, we decreased the grade rating by one (-1) or two (-2) (up to a maximum of -3 to 'very low') if we identified the following.

- Limitations in study design/implementation: we decreased the grade rating by one (-1) when more than $50 \%$ to $75 \%$ of the 'Risk of bias' ratings from the studies in the analysis were 'unclear' or 'high' risk of bias, and by two (-2) when more than $75 \%$ of 'Risk of bias' ratings were 'unclear' or 'high'.

- Indirectness of evidence: we decreased the grade rating by one $(-1)$ when $50 \%$ to $75 \%$ of studies included in the analysis had a wait-list control condition, and by two (-2) when $75 \%$ or more of the studies had a wait-list control condition.

- Heterogeneity/inconsistency of results: we decreased the grade rating by one $(-1)$ when the heterogeneity of the analysis was between $46 \%$ to $65 \%$ and by two $(-2)$ when the heterogeneity was more than $65 \%$.

- Imprecision of results: we decreased the grade rating by one $(-1)$ when the analysis included fewer than 500 participants or if there were wide confidence intervals, and by two $(-2)$ when the number of participants included in the analysis was very low or if confidence intervals were very wide.

- High probability of publication bias: we decreased the grade rating by one $(-1)$ when the outcome domain for the analysis was not assessed in $50 \%$ to $75 \%$ of studies that could have been included in the analysis, and by two (-2) when more than $75 \%$ of studies that could be included in the study did not provide data. 


\section{'Summary of findings' tables}

We have included four 'Summary of Findings' tables to present primary findings from this review reflecting the interventions that are most commonly delivered in clinical practice and therefore potentially most relevant to providers and patients: 1) CBT compared to any control condition for parents of children with chronic medical illness at post-treatment (Summary of findings 1), and follow-up (Summary of findings 2), and 2) PST compared to any control condition for parents of children with chronic medical illness at post-treatment (Summary of findings 3), and follow-up (Summary of findings 4). We included key information concerning the quality of evidence, the magnitude of effect of the interventions examined, and the sum of available data on the outcomes parenting behavior, parent mental health, child behavior/disability, child mental health, child medical symptoms, and family functioning. We report the most important reasons for downgrading in the text and 'Summary of findings' tables.

\section{Subgroup analysis and investigation of heterogeneity}

We investigated heterogeneity by conducting subgroup analyses to compare intervention effects between studies that used an active control condition versus a wait-list control condition. We conducted subgroup analyses only when there were at least 10 studies included in the meta-analysis, per the guidelines provided in Chapter 9.6.5.1 of the Cochrane Handbook for Systematic Reviews of Interventions (Deeks 2017).

\section{Sensitivity analysis}

For analyses with at least 10 studies, we conducted sensitivity analysis by comparing intervention effects between studies with a high risk of selective reporting bias (i.e. outcomes were not fully reported in the published manuscript) versus studies with an unclear or low risk of selective reporting bias. We chose to focus on selective reporting bias for our sensitivity analysis because of the relatively large proportion of published studies in this field with incomplete outcome reporting. Prior versions of this review have consistently identified high selective reporting bias whereas the other types of biases have been rated as low or unclear.

\section{RE S U L T S}

\section{Description of studies}

See Characteristics of included studies and Characteristics of excluded studies for a detailed description of included and excluded studies.

\section{Results of the search}

See Figure 1 for the study flow diagram. 
Figure 1. Study flow diagram

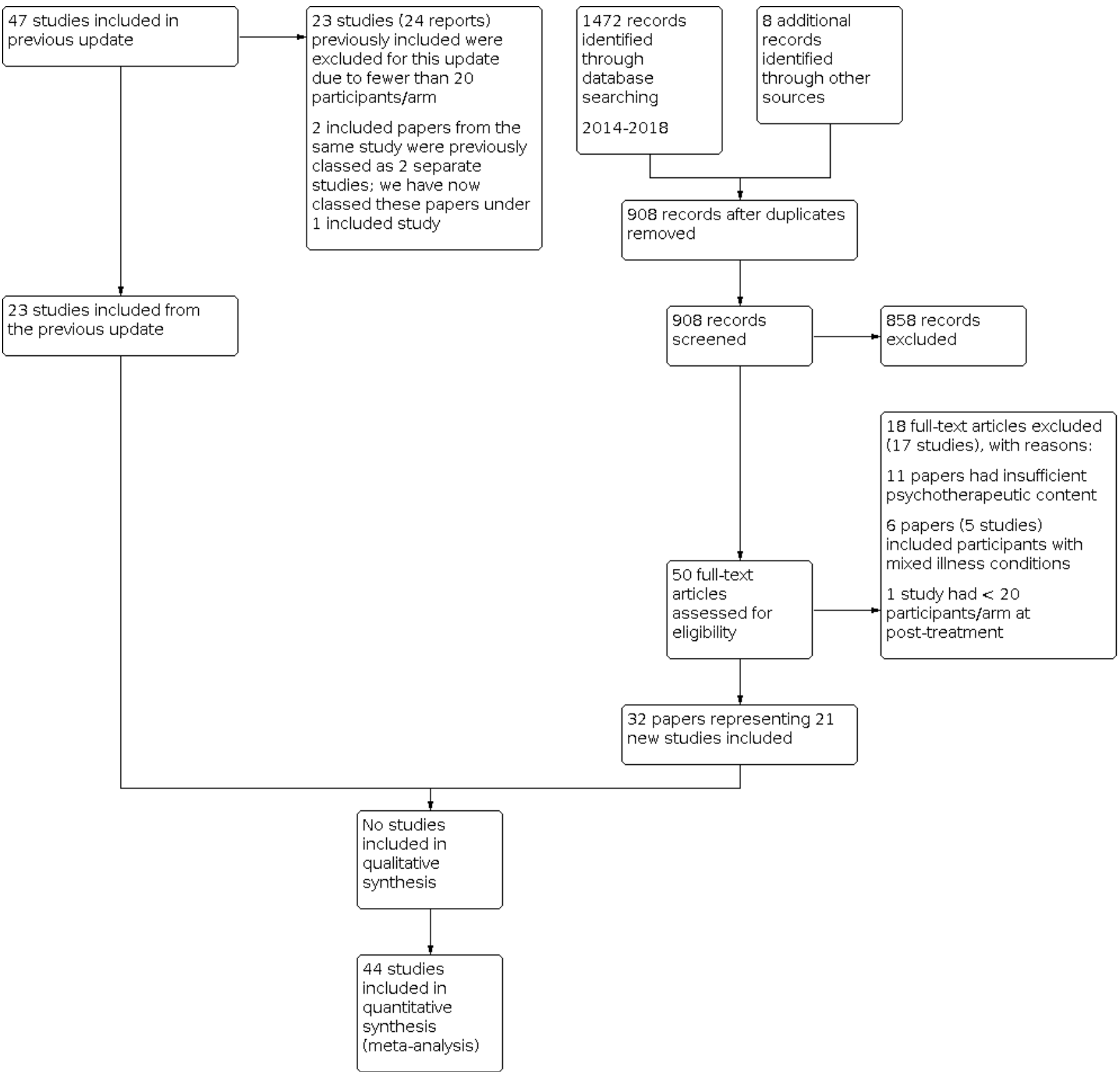

For the initial version of this review, we conducted the first search from inception of databases to March 2012 and identified 35 studies for inclusion. For the first update of the review we conducted a search from March 2012 to July 2014 and identified an additional 13 studies for inclusion. For a detailed description of these searches, see Appendix 2.

This is the second update of this review and we conducted our updated search from July 2014 to July 2018, which yielded 908 unique abstracts that we screened for inclusion. We read 50 papers in full, 18 papers ( 17 studies) of which we excluded. The remaining 32 papers represented 21 new studies which are now included in this update (Bonnert 2017; Daniel 2015; Doherty 2013; Ellis 2017a; Ellis 2017b; Greenley 2015; Husted 2014; Law 2015; Levy 2016; Levy 2017; Mayer-Davis 2015; May 2017; Morawska 2016; Palermo 2016a; Palermo 2016b; Powers 2013; Tsitsi 2017; Wade 2014; Wade
2017; Westrupp 2015; Yeh 2016). Consistent with the change in our protocol, we retained 23 studies from the previous review that had a sample size of more than 20 participants per treatment arm at immediate post-treatment or follow-up (Ambrosino 2008; Ellis 2005; Ellis 2012; Hoekstra-Weebers 1998; Kashikar-Zuck 2012; Kazak 2004; Laffel 2003; Levy 2010; Naar-King 2014; Nansel 2009; Nansel 2012; Palermo 2009; Robins 2005; Sahler 2002; Sahler 2005; Sahler 2013; Sanders 1994; Seid 2010; Stark 2005; Stehl 2009; Wade 2006a; Wysocki 1999; Wysocki 2006). Two manuscripts from one study had previously been analyzed as two separate studies, and for this update both manuscripts were classed into a single study (Sahler 2013). Therefore, this update includes a total of 44 studies.

\section{Included studies}

See Characteristics of included studies for a detailed summary. The 44 included studies randomized 5224 participants, and 4697 
participants completed the immediate post-treatment assessment. Thus, the completion rate for all studies was $85 \%$, and the attrition rate was $15 \%$. The average age of children receiving treatment was 11.5 years (range $=3$ months to 18 years).

As shown in Table 1, the majority of studies evaluated interventions developed for parents of children with cancer (7 studies), chronic pain (13 studies), or diabetes (15 studies). In comparison, very few studies meeting our inclusion criteria evaluated interventions for parents of children with asthma (4 studies), IBD ( 2 studies), skin diseases (1 study), or TBI (3 studies). We did not identify any studies of children with gynecological disorders. We also categorized studies by psychological therapy type. The majority of studies evaluated CBT interventions ( 21 studies) and PST interventions (12 studies). Relatively few studies meeting our inclusion criteria evaluated FT (4 studies), MI (3 studies), or MST (4 studies). Control conditions were primarily treatment-as-usual control conditions (20 studies) and active control conditions (e.g. psychoeducation; 18 studies), with a minority of studies using wait-list control conditions (6 studies). Treatment dose for parents ranged from one to 48 sessions (median $=5$ sessions) and from zero to 48 sessions for children (median $=3$ sessions). The proportion of therapy delivered to parents versus children varied between studies. Most studies delivered an equal amount of treatment to parents and children ( 27 studies); in 12 studies only the parent received therapy.

Treatment was delivered face-to-face with a therapist in 25 studies (see Table 1). There were several studies that used a hybrid approach to treatment delivery including eight studies that delivered treatment face-to-face and via telephone sessions (Daniel 2015; Ellis 2012; Greenley 2015; Nansel 2009; Nansel 2012; Palermo 2016a; Sahler 2002; Stehl 2009). In 10 studies, all treatment sessions were delivered remotely, including eight studies that delivered treatment via the internet (Bonnert 2017; Ellis 2017a; Law 2015; Palermo 2009; Palermo 2016b; Wade 2006a; Wade 2014; Wade 2017), one study that delivered treatment via an audio CD (Tsitsi 2017), and one study that delivered treatment via a selfhelp workbook (Doherty 2013). There was one study that directly compared face-to-face versus telephone-delivery (Levy 2010).

Treatment was delivered to individuals, families, and groups either in outpatient clinics or in participants' homes. Follow-up assessments were conducted in 25 studies; for the majority of studies, the first available follow-up assessments were conducted at three months ( 6 studies) or five to six months (10 studies), with the remaining nine studies at nine to 12 months. Funding sources included federal and state agencies, private foundations, hospitals, and universities. In Table 2, we present a narrative summary of the treatment content for each included study.

\section{Excluded studies}

See Characteristics of excluded studies for a detailed description of 113 excluded studies, including 73 studies (78 papers) that were previously excluded, 23 studies ( 24 papers) from the prior review that did not meet our inclusion criteria primarily due to insufficient sample size, and 17 new studies (18 papers) identified in this update. Judgements about whether to exclude studies were often difficult to make and we resolved them via discussion between review authors. Here we provide our rationale for excluding studies and provide examples of studies that readers may expect to find in this review but were excluded.

- We excluded studies because the intervention had insufficient psychotherapeutic content, including educational interventions, interventions where parents were trained as 'coaches' for their children, and health promotion interventions (e.g. Barrera 2018a; Brown 2014; Canino 2016; Halterman 2014; Manne 2016; Rapoff 2014; Scholten 2015).

- We also excluded studies because the aim of the study was not relevant to the objectives of this review, including feasibility studies and studies of mixed samples of youth that did not report outcomes separately by medical condition (e.g. Fedele 2013; Hommel 2012; Mortenson 2016; Wade 2010; Wysocki 1997).

- For this update, we excluded 23 previously included studies because the sample size per treatment arm was fewer than 20 participants post-treatment or at follow-up (Allen 1998; Antonini 2014; Barakat 2010; Barry 1997; Celano 2012; Connelly 2006; Duarte 2006; Ellis 2004; Gulewitsch 2013; Hicks 2006; Kashikar-Zuck 2005; Lask 1979; Lehmkuhl 2010; Marsland 2013; Mullins 2012; Ng 2008; Niebel 2000; Olivares 1997; Saßman 2012; Shekarabi-Ahari 2012; Tsiouli 2014; Wade 2006b; Wade 2011).

\section{Risk of bias in included studies}

We judged the majority of included studies to have either low or unclear risk of bias across domains except for selective reporting bias, which we judged to be high risk in 19 of the 44 studies (43\%) (Figure 2; Figure 3). A narrative summary is provided below. 
Figure 2. 'Risk of bias' summary: review authors' judgements about each risk of bias item for each included study

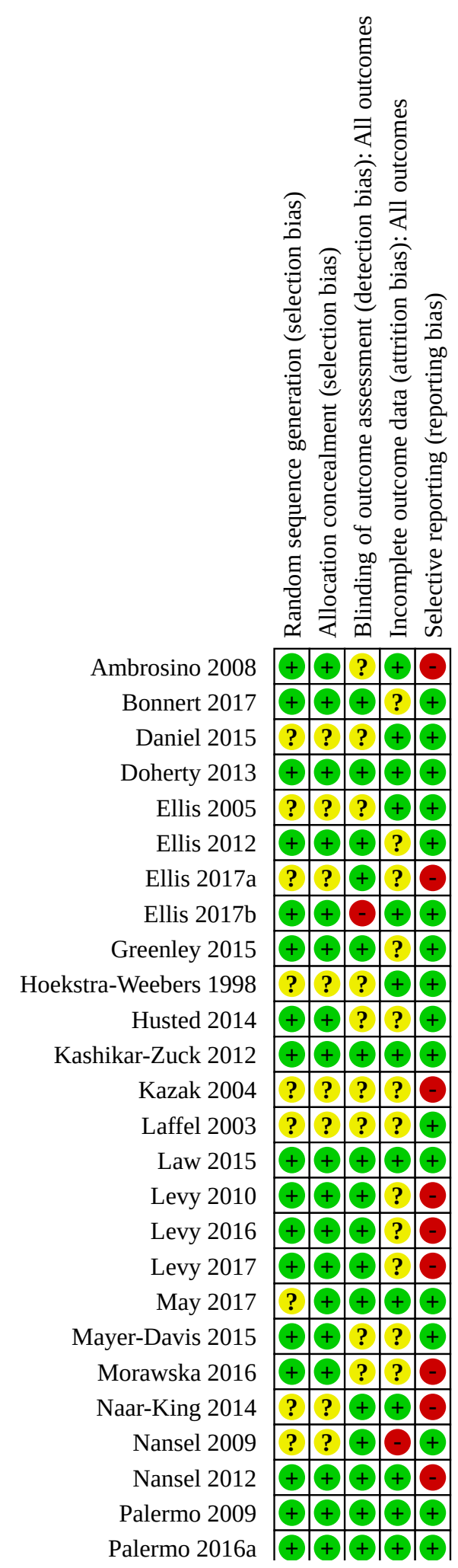


Figure 2. (Continued)

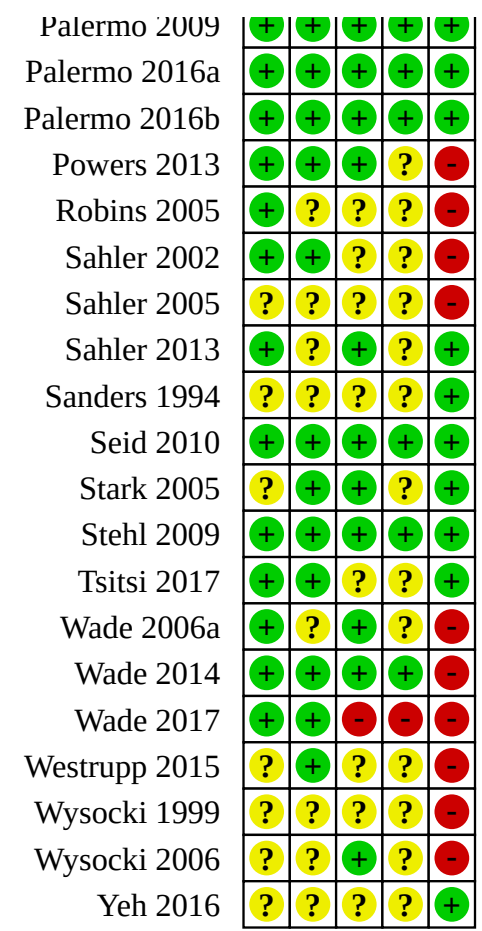

Figure 3. 'Risk of bias' graph: review authors' judgements about each risk of bias item presented as percentages across all included studies

Random sequence generation (selection bias)

Allocation concealment (selection bias)

Blinding of outcome assessment (detection bias): All outcomes

Incomplete outcome data (attrition bias): All outcomes

Selective reporting (reporting bias)
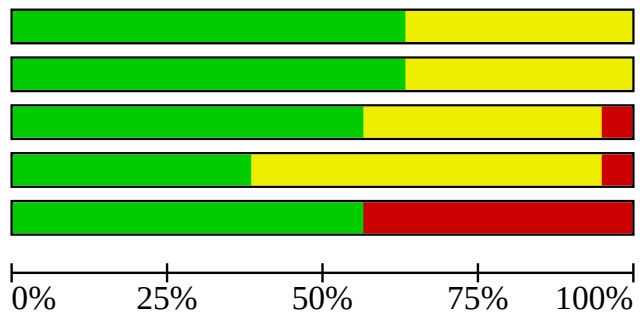

Low risk of bias

Unclear risk of bias

High risk of bias

\section{Allocation}

\section{Random sequence generation}

Twenty-eight studies described a convincing method of randomization and we judged these as low risk of bias. In the remaining 16 studies, selection bias was unclear because they did not provide an adequate description. Due to our inclusion criteria that all studies had to be RCTs, we did not give any studies a rating of high risk of bias for randomization.

\section{Allocation concealment}

For allocation bias, we judged 28 studies to be low risk because they described a convincing method of allocation. The remaining 16 studies did not provide an adequate description and therefore we judged these studies as unclear. We did not rate any studies as having a high risk of allocation bias.

\section{Blinding}

We judged 25 studies to have low risk of detection bias because the study procedures specified that assessments were submitted online or via postal mail, or were completed face-to-face with an outcome assessor who was blinded to treatment allocation. Seventeen studies did not provide an adequate description and we judged these as unclear. We rated two studies as having a high risk of detection bias because the outcome assessor was not blinded to treatment allocation.

We did not assess performance bias because it is not possible to blind personnel who are delivering psychological treatments. 
This means that studies should be presumed to be at risk for performance bias.

\section{Incomplete outcome data}

We judged 16 studies as low risk of attrition bias because they reported attrition, and there were no significant differences between completers and non-completers in the two treatment groups. We rated 25 studies as unclear because the information that they provided was inadequate to allow us to make a judgement (e.g. they reported attrition but did not conduct comparisons between completers and non-completers). We judged two studies as high risk because either they did not report attrition or because they did report attrition and their were differences between completers and non-completers.

\section{Selective reporting}

We judged 25 studies as low risk of selective reporting bias because they presented all of the outcome data required for extraction in the published papers. We rated 19 studies as high risk of selective reporting bias because they did not fully report their data in the published papers. For these studies, we rated selective reporting bias as high regardless of whether the authors responded to our request for data. For 15 of these 19 studies, the authors provided data on request and we included these studies in our analyses (Ambrosino 2008; Ellis 2017a; Levy 2010; Levy 2016; Levy 2017; Morawska 2016; Naar-King 2014; Nansel 2012; Powers 2013; Sahler 2002; Sahler 2005; Wade 2006a; Wade 2014; Wade 2017; Westrupp 2015). We conducted sensitivity analyses to examine the effect of these studies with high risk of selective reporting bias on our findings.

\section{Effects of interventions}

See: Summary of findings 1 Cognitive-behavioral therapy for parents of children with a chronic illness (post-treatment); Summary of findings 2 Cognitive-behavioral therapy for parents of children with a chronic illness (follow-up); Summary of findings 3 Problem-solving therapy for parents of children with a chronic illness (post-treatment); Summary of findings 4 Problem-solving therapy for parents of children with a chronic illness (follow-up)

We conducted two sets of analyses to address the following questions.

- For each medical condition, across all types of psychotherapy, what is the efficacy for each outcome immediately posttreatment and at follow-up?

- For each type of psychological therapy, across all medical conditions, what is the efficacy for each outcome immediately post-treatment and at follow-up?

For analyses, we combined studies of children with IBD with studies of children with chronic pain conditions. There were no studies of children with gynecologic conditions. We included 40 studies (4503 participants post-treatment) in at least one analysis. We were not able to include four studies in any of the analyses because they either did not assess or did not provide means or standard deviations for the outcomes analyzed in this review (Greenley 2015; Kazak 2004; Robins 2005; Stark 2005). Stark 2005 provided outcome data on calcium intake; however, this was heterogeneous with other outcomes we extracted for this condition and therapy type, and therefore we determined that this study was not appropriate to include in the meta-analysis.

\section{Medical conditions across all psychological therapies}

\section{Asthma}

Four studies (506 participants) evaluated the effect of psychological therapies for parents of children with asthma (Morawska 2016; Naar-King 2014; Seid 2010; Yeh 2016). All four studies used active comparator conditions. We were not able to conduct our planned subgroup analyses to investigate heterogeneity due to the small number of studies included in the primary analyses.

- We were not able to draw conclusions about the effects of psychological therapies on parenting behavior or parent mental health post-treatment or at follow-up due to the small number of studies included in the analyses. Only two studies reported parenting behavior post-treatment (209 participants; Morawska 2016; Naar-King 2014), and only one study reported parent mental health post-treatment and at follow-up (65 participants; Yeh 2016). We judged the quality of evidence for parenting behavior and parent mental health to be very low; we downgraded these outcomes twice for imprecision (small number of participants) and once for high probability of publication bias.

- Three studies reported on the effect of psychological therapies on children's asthma symptoms, and results indicated that there was no evidence of a beneficial treatment effect post-treatment (SMD $-0.16,95 \% \mathrm{Cl}-0.63$ to 0.31 ; participants = 337; studies = 3; $12=77 \%$; Analysis 1.4), and there were only two studies at followup (160 participants; Seid 2010; Yeh 2016). We judged the quality of evidence for this outcome as very low at post-treatment and follow-up; we downgraded twice for heterogeneity, and once for imprecision (small number of participants). Heterogeneity was high, indicating that there may be considerable inconsistency in the results between the small number of studies included in these analyses.

- We were unable to draw conclusions about the effect of psychological therapies on other outcomes for children with asthma due to the small number of included studies. No studies reported on child behavior/disability, and only one study reported on child mental health at post-treatment (41 participants; Morawska 2016). We judged the quality of evidence for child outcomes to be very low; we downgraded once for limitations of study design/implementation and twice for imprecision (small number of participants).

- Regarding family functioning, we were not able to draw conclusions due to the small number of studies included in the analyses. Only two studies reported family functioning post-treatment and at follow-up (104 participants; Morawska 2016; Yeh 2016). We judged the quality of evidence for family functioning at both time points to be very low; we downgraded once for limitations of study design/implementation and twice for imprecision (small number of participants).

\section{Cancer}

Seven studies (991 participants) evaluated the effect of psychological therapies for parents of children with cancer; six studies used active control conditions (Hoekstra-Weebers 1998; Sahler 2002; Sahler 2005; Sahler 2013; Stehl 2009; Tsitsi 2017), and one used a wait-list control condition (Kazak 2004). We were 
not able to conduct our planned subgroup analyses to investigate heterogeneity due to the small number of studies included in the primary analyses.

- Psychological therapies had a small beneficial effect on parenting behavior post-treatment (SMD $-0.28,95 \% \mathrm{Cl}-0.43$ to -0.13 ; participants $=664$; studies $=3 ; 1^{2}=0 \%$; Analysis 3.1 ), and this small effect was maintained at follow-up (SMD -0.21 , $95 \% \mathrm{Cl}-0.37$ to -0.05 ; participants $=625$; studies $=3 ; 1^{2}=0 \%$; Analysis 4.1). There was no heterogeneity. We rated the quality of evidence for parenting behavior as low at both time points; we downgraded once due to high probability of publication bias and once for limitations of study design/implementation.

- Parent mental health also improved in response to psychological therapies post-treatment (SMD $-0.21,95 \% \mathrm{Cl}$ -0.35 to -0.08 ; participants $=836$; studies $=6 ; 1^{2}=0 \%$; Analysis 3.2 ), which was a small effect size and this was maintained at follow-up (SMD $-0.23,95 \% \mathrm{Cl}-0.39$ to -0.08 ; participants $=667$; studies $=4 ; 1^{2}=0 \%$; Analysis 4.2 ). There was no heterogeneity. We judged the quality of evidence for parent mental health as high at post-treatment. At follow-up, we judged the quality of evidence as moderate, downgraded once due to limitations of study design/implementation.

- There were no studies of psychological therapies for parents of children with cancer that presented extractable data on child mental health, child behavior/disability, child symptoms, or family functioning post-treatment or at follow-up.

\section{Chronic pain conditions}

Fifteen studies (1595 participants) evaluated the effect of psychological therapies for parents of children with chronic pain conditions (Bonnert 2017; Daniel 2015; Greenley 2015; KashikarZuck 2012; Law 2015; Levy 2010; Levy 2016; Levy 2017; Palermo 2009; Palermo 2016a; Palermo 2016b; Powers 2013; Robins 2005; Sanders 1994; Stark 2005). Four of these studies used waitlist control comparator conditions (Bonnert 2017; Daniel 2015; Greenley 2015; Palermo 2009), and the remaining 11 studies used active control conditions. When there were 10 or more studies included in the primary analysis, we conducted our planned subgroup analyses to investigate heterogeneity by evaluating only studies that used an active control comparator condition. We were not able to conduct our planned subgroup analyses to evaluate only studies with a wait-list control condition due to the small number of available studies. There were four studies with high risk of selective reporting bias that we included in analyses of child behavior and disability (Levy 2010; Levy 2016; Levy 2017; Powers 2013); see 'Sensitivity analyses' below for results from subgroup analyses evaluating the effect of these studies on our findings.

- We found a small beneficial effect of treatment on parenting behavior post-treatment (SMD $-0.29,95 \% \mathrm{Cl}-0.47$ to -0.10 ; participants $=755$; studies $=6 ; 1^{2}=34 \%$; Analysis 5.1), which was maintained at follow-up (SMD $-0.35,95 \% \mathrm{Cl}-0.50$ to -0.20 ; participants $=678$; studies $=5 ;\left.\right|^{2}=1 \%$; Analysis 6.1). We judged the quality of this evidence as moderate. We downgraded evidence once at each time point due to high probability of publication bias.

- Parent mental health also improved in response to psychological therapies post-treatment (SMD $-0.24,95 \% \mathrm{Cl}$ -0.42 to -0.06 ; participants $=490$; studies $=3 ; 1^{2}=0 \%$; Analysis 5.2), and follow-up (SMD $-0.20,95 \% \mathrm{Cl}-0.38$ to -0.02 ; participants $=482$; studies $=3 ; 12=0 \%$; Analysis 6.2), which were small effects. We judged this evidence to be low quality; we downgraded evidence twice at each time point, once due to high probability of publication bias and once due to imprecision (small number of participants).

- Regarding children's treatment outcomes, we found a small beneficial effect of treatment on child behavior/disability at post-treatment (SMD $-0.15,95 \% \mathrm{Cl}-0.28$ to -0.01 ; participants $=1362 ;$ studies $=12 ; 12=33 \%$; Analysis 5.3), and this was maintained at follow-up (SMD $-0.27,95 \% \mathrm{Cl}-0.39$ to -0.15 ; participants $=1099$; studies $=9 ; 1^{2}=0 \%$; Analysis 6.3). We judged this evidence to be high quality at post-treatment and follow-up. We conducted subgroup analysis to investigate heterogeneity at post-treatment. When we included only studies with an active control condition in the analysis, we found that there was no longer evidence of a beneficial effect of treatment and heterogeneity was lower (SMD $-0.13,95 \% \mathrm{Cl}-0.26$ to 0.00 ; participants $=1154$; studies $=9 ;\left.\right|^{2}=18 \%$ ).

- We did not find evidence of a beneficial treatment effect on child mental health post-treatment (SMD $-0.02,95 \% \mathrm{Cl}-0.13$ to 0.09 ; participants $=1314$; studies $=11 ; 1^{2}=0 \%$; Analysis 5.4 ) or at follow-up (SMD $-0.02,95 \% \mathrm{Cl}-0.14$ to 0.09 ; participants $=1108$; studies $=9 ; 1^{2}=0 \%$; Analysis 6.4). We did not conduct subgroup analysis because there was no heterogeneity. We judged this evidence as high quality at post-treatment and follow-up.

- We found a moderate beneficial effect of psychological therapies on children's pain symptoms post-treatment (SMD $-0.44,95 \% \mathrm{Cl}-0.84$ to -0.03 ; participants $=1161$; studies $=10 ; \mathrm{I}^{2}=$ 91\%; Analysis 5.5). Heterogeneity was high. When we conducted subgroup analysis that only included studies with an active control condition, there was no evidence of a beneficial effect of treatment on children's pain symptoms, and heterogeneity was lower (SMD -0.13, 95\% Cl -0.33 to 0.06; participants = 1018; studies $\left.=8 ; 1^{2}=55 \%\right)$. We found that there was not a beneficial effect of psychological therapies on children's pain symptoms at follow-up (SMD $-0.12,95 \% \mathrm{Cl}-0.32$ to 0.09 ; participants = 966; studies $=8 ; 1^{2}=58 \%$; Analysis 6.5). At post-treatment, we judged the quality of this evidence as low, downgraded twice due to heterogeneity. At follow-up, we judged the quality of the evidence as low, downgraded once for heterogeneity and once for imprecision (wide confidence intervals).

- No studies of children with chronic pain conditions presented data on family functioning post-treatment or follow-up.

\section{Diabetes}

Fifteen studies (1488 participants) evaluated the effect of psychological therapies for parents of children with diabetes (Ambrosino 2008; Doherty 2013; Ellis 2005; Ellis 2012; Ellis 2017a; Ellis 2017b; Husted 2014; Laffel 2003; May 2017; Mayer-Davis 2015; Nansel 2009; Nansel 2012; Westrupp 2015; Wysocki 1999; Wysocki 2006). All studies used an active control comparator condition, and therefore we did not conduct our planned subgroup analyses to investigate heterogeneity. There were six studies with high risk of selected reporting bias for child symptoms post-treatment (Ambrosino 2008; Ellis 2017a; Nansel 2012; Westrupp 2015; Wysocki 1999; Wysocki 2006); see 'Sensitivity analyses' below for results from subgroup analyses evaluating the effect of these studies on our findings for that analysis. 
- We found that psychological treatments had a large beneficial effect on parenting behavior post-treatment (SMD -1.39, 95\% $\mathrm{Cl}-2.41$ to -0.38 ; participants $=338$; studies $=5 ; \mathrm{I}^{2}=94 \%$; Analysis 7.1). Heterogeneity was high, indicating that there may have been considerable inconsistency in the results among these studies. Only two studies reported parenting behavior at follow-up (110 participants; Husted 2014; Westrupp 2015); we did not interpret these results due to the small number of studies in the analysis. We judged this evidence as very low at both time points. At post-treatment and follow-up, we downgraded the quality of evidence once for limitation of study design/ implementation and twice for heterogeneity.

- We did not find evidence of a beneficial effect of psychological therapies for parents of children with diabetes on parent mental health post-treatment (SMD $-0.24,95 \% \mathrm{Cl}-0.90$ to 0.42 ; participants $=211$; studies $=3 ; 1^{2}=82 \%$; Analysis 7.2 ). Heterogeneity was high, indicating that there may have been considerable inconsistency in the results among these studies. Only two studies reported parent mental health at follow-up (participants $=130 ;$ Ambrosino 2008; Westrupp 2015), therefore we did not interpret these results. We judged the quality of this evidence as very low at both time points. At post-treatment, we downgraded the quality of evidence twice for heterogeneity and once for imprecision. At follow-up, we downgraded the quality of evidence once for limitation of study design/implementation and twice for imprecision.

- No studies of children with diabetes presented data on child behavior/disability at post-treatment or follow-up.

- For child mental health, we did not find evidence of a beneficial treatment effect post-treatment (SMD $-0.09,95 \% \mathrm{Cl}-0.40$ to 0.21 ; participants $=467$; studies $=6 ; 1^{2}=63 \%$; Analysis 7.3). Heterogeneity was high, indicating there may have been inconsistency in the results among these studies. Only two studies presented data on child mental health at follow-up (participants =110; Husted 2014; Westrupp 2015), and we did not interpret these results due to the small number of studies in the analysis. We judged the quality of this evidence as very low; we downgraded once for limitations of study design/ implementation and twice for imprecision (wide confidence intervals and small number of participants).

- We did not find evidence of a beneficial effect of psychological therapies on diabetes-related medical symptoms post-treatment (SMD $-0.02,95 \% \mathrm{Cl}-0.25$ to 0.21 ; participants $=1339$; studies $=13 ; 1^{2}=75 \%$; Analysis 7.4$)$, or at follow-up (SMD $-0.04,95 \% \mathrm{Cl}-0.35$ to 0.27 ; participants $=518$; studies $=$ $6 ; 1^{2}=67 \%$; Analysis 8.4). Heterogeniety was high indicating that there may be inconsistency in the results of these studies. We judged the quality of this evidence post-treatment to be low, and we further downgraded this rating at follow-up to very low. At post-treatment, we downgraded our quality of evidence rating once due to limitations of study design/implementation, and once for imprecision (wide confidence intervals). At follow-up, we also downgraded our quality of evidence rating once for high probability of publication bias.

- In our analysis of family functioning, we did not find evidence of a beneficial treatment effect at post-treatment (SMD -0.15 , $95 \% \mathrm{Cl}-0.31$ to 0.01 ; participants $=701$; studies $=9 ; 1^{2}=9 \%$; Analysis 7.5 ). Only two studies were available to analyze at follow-up (participants = 158; Ambrosino 2008; Westrupp 2015), therefore we did not interpret these results. At post-treatment, we judged the quality of evidence for family functioning as moderate; we downgraded our quality of evidence rating once due to limitations in study design/implementation. At follow-up, we judged the quality of evidence as very low; we downgraded once due to limitations in study design/implementation and twice for imprecision.

\section{Skin diseases}

We found one study that evaluated the effect of psychological therapies for parents of children with skin diseases, which used active control comparator conditions (participants $=77$; Morawska 2016). In this study, the authors reported on parenting behavior, child mental health, child symptoms, and family functioning at post-treatment and follow-up. Since we only identified one study, we were not able to draw conclusions on the effects of treatment. We judged the quality of this evidence to be very low; we downgraded twice for imprecision (small number of participants), and once for high probability of publication bias.

\section{Traumatic brain injury (TBI)}

We found three studies of psychological therapies for parents of children with TBI, which were conducted by the same author group (participants $=262 ;$ Wade 2006a; Wade 2014; Wade 2017). All three studies used an active control comparator condition. We did not conduct planned subgroup analyses due to the small number of studies.

- We identified a large beneficial effect of treatment on parenting behavior post-treatment (SMD $-0.74,95 \% \mathrm{Cl}-1.25$ to -0.22 ; participants $=254$; studies $=3 ; 1^{2}=71 \%$; Analysis 11.1 ), although heterogeneity was high indicating that there may be inconsistency in the results between these studies. Only one study reported on parenting behavior at follow-up and so we are not able to comment on whether this treatment effect is maintained over time (participants $=113$; Wade 2014). We judged the quality of this evidence to be very low, downgraded twice due to heterogeneity and once due to imprecision (small number of participants).

- We were unable to draw conclusions about the effect of psychological therapies on parent mental health because only two studies presented data on this outcome at post-treatment (participants $=165$; Wade 2006a; Wade 2014) and only one study presented data at follow-up (participants $=113$; Wade 2014). We judged the quality of this evidence to be low post-treatment, downgraded twice due to imprecision (very low number of participants) and very low at follow-up, downgraded twice due to imprecision (very low number of participants) and once for high probability of publication bias.

- We were unable to draw conclusions about the effect of treatment on child behavior/disability because only one study presented data on this outcome at post-treatment and followup (participants =121; Wade 2014). We judged the quality of this evidence to be very low at post-treatment and follow-up, downgraded twice due to imprecision (very low number of participants) and once due to high probability of publication bias.

- We found a moderate beneficial effect of psychological therapies on child mental health at post-treatment (SMD -0.43 , $95 \% \mathrm{Cl}-0.69$ to -0.18 ; participants $=251$; studies $=3 ; 1^{2}=0 \%$; Analysis 11.4). Only one study reported data on child mental health at follow-up and so we are not able to draw conclusions 
about whether this treatment effect is maintained over time (participants $=98$; Wade 2014). We judged the quality of this evidence to be moderate at post-treatment (downgraded once due to imprecision (small number of participants)) and very low at follow-up, downgraded twice due to imprecision (very low number of participants) and once due to high probability of publication bias.

- No studies reported on child medical symptoms post-treatment or follow-up.

- Only one study reported on family functioning at post-treatment and follow-up and so we are not able to draw conclusions (participants $=121$; Wade 2014). We judged the quality of this evidence to be very low at post-treatment and followup, downgraded twice due to imprecision (small number of participants) and once for high probability of publication bias.

\section{Individual psychological therapies across all conditions}

\section{Cognitive-behavioral therapy (CBT)}

We found 21 studies of CBT for parents of children with chronic medical conditions (2070 participants) (Ambrosino 2008; Bonnert 2017; Doherty 2013; Hoekstra-Weebers 1998; KashikarZuck 2012; Laffel 2003; Law 2015; Levy 2010; Levy 2016; Levy 2017; Morawska 2016; Palermo 2009; Palermo 2016b; Powers 2013; Robins 2005; Sanders 1994; Stark 2005; Stehl 2009; Tsitsi 2017; Wade 2017; Westrupp 2015).Two of these studies used wait-list control comparator conditions (Bonnert 2017; Palermo 2009), and the remaining 19 studies used active control conditions. When there were 10 or more studies included in the primary analysis, we conducted our planned subgroup analyses to investigate heterogeneity by evaluating only studies that used an active control comparator condition. We were not able to conduct our planned subgroup analyses using only studies with a wait-list control condition due to the small number of available studies. We rated eight studies as having high risk of selective reporting bias on the outcomes of parent behavior, parent mental health, child behavior, child mental health, and child symptoms post-treatment, and child symptoms at follow-up (Ambrosino 2008; Levy 2010; Levy 2016; Levy 2017; Morawska 2016; Powers 2013; Sanders 1994; Westrupp 2015); see the 'Sensitivity analyses' section below for subgroup analyses evaluating the effect of these studies on our findings for these outcomes.

- We entered 10 studies post-treatment and six studies at followup into an analysis to investigate the effects of CBT across all chronic medical conditions on parenting behavior. We found a moderate beneficial effect of CBT on parenting behavior posttreatment (SMD $-0.45,95 \% \mathrm{Cl}-0.68$ to -0.21 ; participants = $1040 ;$ studies = 10; $\left.\right|^{2}=69 \%$; Analysis 13.1; Figure 4), which was maintained at follow-up (SMD $-0.26,95 \% \mathrm{Cl}-0.42$ to -0.11 ; participants $=743$; studies $=6 ; 1^{2}=9 \%$; Analysis 14.1). We judged the quality of the evidence for CBT on parenting behavior to be low post-treatment, downgraded once for heterogeneity, and once for publication bias, and moderate at follow-up, downgraded once for publication bias (Summary of findings 1; Summary of findings 2). At post-treatment, we were able to examine heterogeneity and found the same pattern of results when the subgroup analysis included only studies with an active control condition (SMD $-0.50,95 \% \mathrm{Cl}-0.74$ to -0.26 ; participants $=992 ;$ studies $\left.=9 ;\left.\right|^{2}=68 \%\right)$.
- Eight studies at post-treatment and five studies at followup presented data on parent mental health. We did not find evidence for a beneficial effect of CBT on parent mental health post-treatment (SMD $-0.19,95 \% \mathrm{Cl}-0.41$ to 0.03 ; participants $=811$; studies $=8 ; 1^{2}=53 \%$; Analysis 13.2; Figure 5), or follow-up (SMD $-0.07,95 \% \mathrm{Cl}-0.34$ to 0.20 ; participants = 592; studies $=5 ; 1^{2}=55 \%$; Analysis 14.2). All of the studies used active control conditions and so we were not able to conduct our planned subgroup analysis to evaluate heterogeneity. We judged the quality of evidence for CBT on parent mental health as very low at post-treatment and follow-up. We downgraded both time points once for heterogeneity, once for imprecision (wide confidence intervals), and once for high probability of publication bias.

- CBT had a small beneficial effect on child behavior/disability post-treatment (SMD $-0.22,95 \% \mathrm{Cl}-0.35$ to -0.08 ; participants $=1236$; studies $=10 ; 1^{2}=25 \%$; Analysis 13.3), which was maintained at follow-up (SMD $-0.28,95 \% \mathrm{Cl}-0.40$ to -0.15 ; participants $=1038$; studies $=8 ; 1^{2}=0 \%$; Analysis 14.3). We judged the quality of evidence as moderate post-treatment and at follow-up, and downgraded once for probability of publication bias. When we conducted our planned subgroup analysis at post-treatment we found that there was still a beneficial effect of treatment and heterogeneity was lower (SMD $-0.18,95 \% \mathrm{Cl}$ -0.31 to -0.05 ; participants $=1093$; studies $=8 ;\left.\right|^{2}=13 \%$ ).

- We did not find evidence of a beneficial effect of CBT on child mental health post-treatment (SMD $-0.08,95 \% \mathrm{Cl}-0.19$ to 0.03 ; participants $=1786$; studies $=15 ; 1^{2}=21 \%$; Analysis 13.4), or at follow-up (SMD $-0.07,95 \% \mathrm{Cl}-0.19$ to 0.04 ; participants $=1244$; studies $=10 ; 1^{2}=0 \%$; Analysis 14.4). We judged this evidence to be high quality at post-treatment, and moderate at follow-up, downgraded once for probability of publication bias. To investigate heterogeneity in the post-treatment analysis, we conducted our planned subgroup analysis and found that there was still no evidence of a beneficial treatment effect and heterogeneity was slightly higher (SMD $-0.09,95 \% \mathrm{Cl}-0.21$ to 0.02 ; participants $=1637$; studies $=13 ; 1^{2}=26 \%$ ).

- For child medical symptoms, we found a beneficial effect of CBT post-treatment (SMD $-0.38,95 \% \mathrm{Cl}-0.71$ to -0.06 ; participants $=1434$; studies $=13 ; \mathrm{I}^{2}=89 \%$, Analysis 13.5), although this was not maintained at follow-up (SMD -0.13 , $95 \% \mathrm{Cl}-0.32$ to 0.06 ; participants $=1136$; studies $=10 ; \mathrm{I}^{2}=$ $60 \%$; Analysis 14.5). We judged this as very low-quality evidence post-treatment and low-quality at follow-up. We downgraded post-treatment time points twice for heterogeneity and once for imprecision (wide confidence intervals). At follow-up, we downgraded once for heterogeneity and once for publication bias. We investigated heterogeneity post-treatment with our planned subgroup analysis, and results indicated that there was no longer evidence of a beneficial treatment effect when only studies with an active control condition were included in the analysis, and heterogeneity was lower (SMD $-0.15,95 \% \mathrm{Cl}-0.32$ to 0.02 ; participants $=1291$; studies $=11 ;\left.\right|^{2}=55 \%$ ).

- We also examined the effect of CBT on family functioning, and we did not find evidence of a beneficial treatment effect posttreatment (SMD $-0.11,95 \% \mathrm{Cl}-0.35$ to 0.13 ; participants $=429$; studies = 5; $1^{2}=37 \%$; Analysis 13.6), or at follow-up (SMD -0.04, $95 \% \mathrm{Cl}-0.32$ to 0.24 ; participants = 201; studies $=3 ; 12=0 \%$; Analysis 14.6). We judged this evidence to be very low quality at both time points. We downgraded post-treatment once for 
and follow-up twice for limitations in study design and once for publication bias.

Figure 4. Forest plot of comparison 13, cognitive-behavioural therapy post-treatment, outcome 13.1: parenting behavior

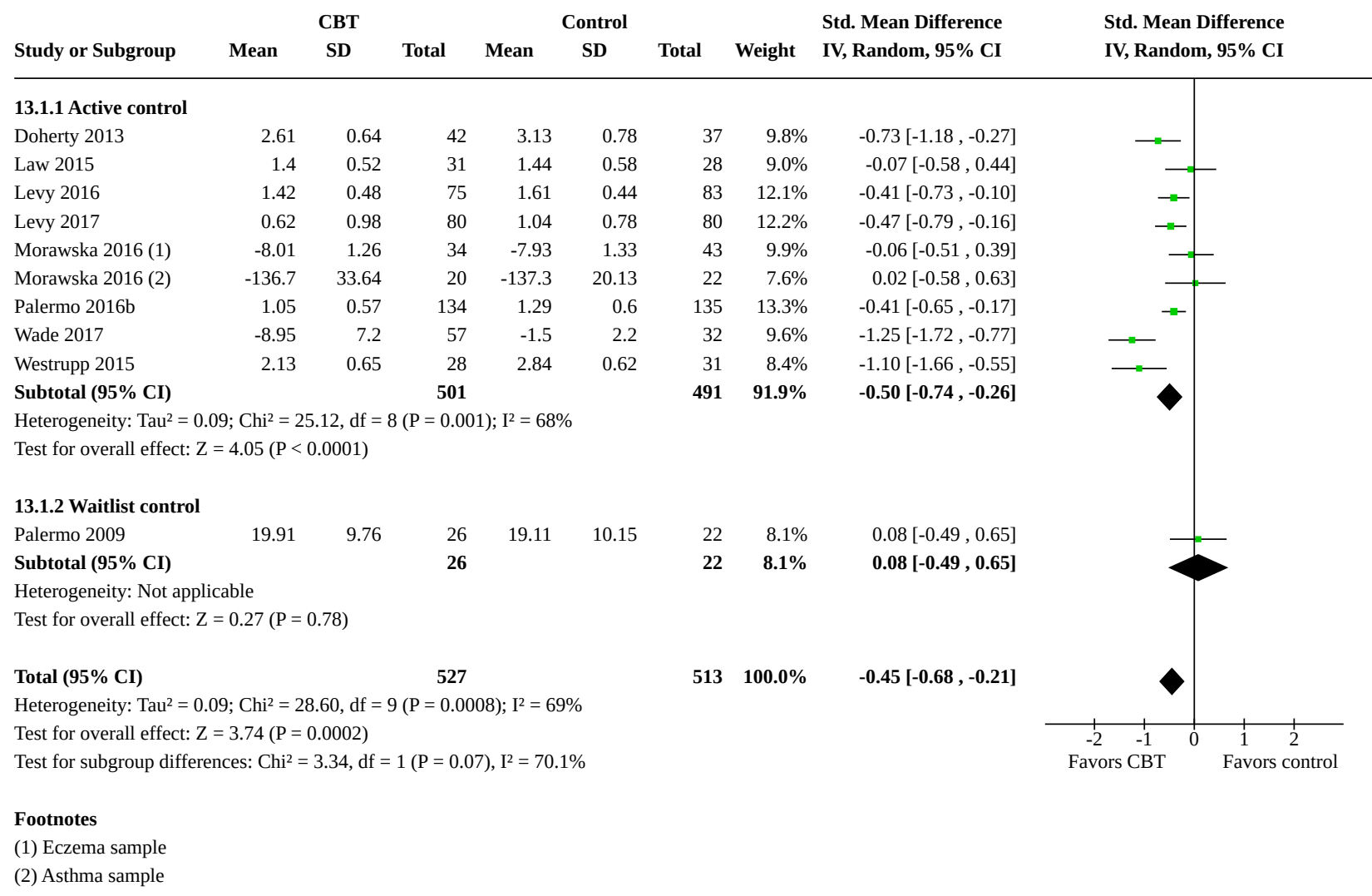

Figure 5. Forest plot of comparison 13, cognitive-behavioural therapy post-treatment, outcome 13.2: parent mental health

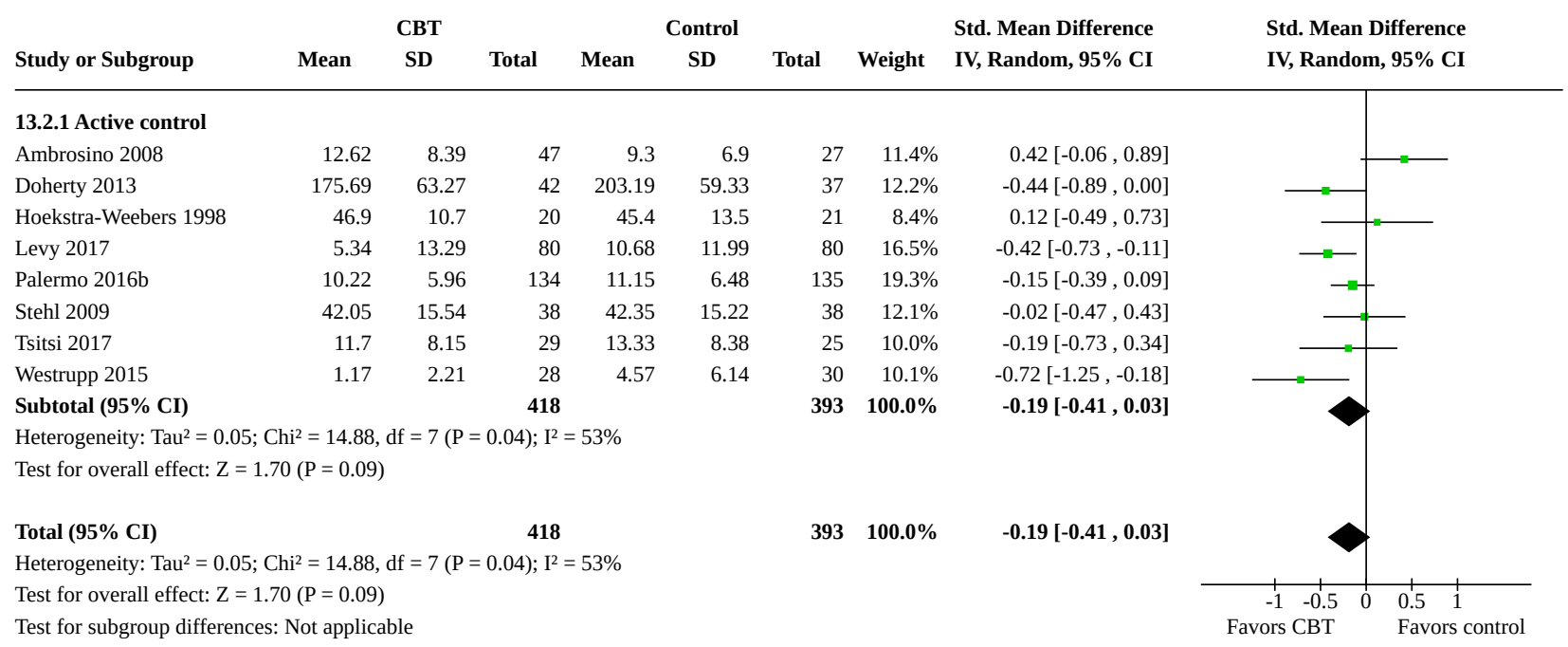




\section{Family therapy (FT)}

Four studies evaluated FT for parents of children with chronic medical conditions (participants = 389; Kazak 2004; Wysocki 1999; Wysocki 2006; Yeh 2016). Only one study used a wait-list control condition (Kazak 2004), and the remaining three studies used active control conditions. We were not able to conduct our planned subgroup analyses to investigate heterogeneity due to the small number of available studies.

- We did not conduct analyses of the effect of FT on parenting behavior post-treatment and follow-up because no studies presented extractable data. Only one study of FT presented data on parent-mental health post-treatment and follow-up (participants $=65$; Yeh 2016), therefore we could not draw any conclusions.

- No studies presented data on the effect of FT on child behavior/ disability post-treatment or follow-up and so we did not conduct analyses.

- Only one study reported the effect of treatment on child mental health and so we were not able to draw conclusions (participants = 74; Wysocki 1999).

- We entered three studies into an analysis of the effects of FT on child symptoms post-treatment and we did not find evidence of a beneficial treatment effect (SMD $-0.18,95 \% \mathrm{Cl}-0.77$ to 0.40 ; participants $=197$; studies $=3 ; 1^{2}=77 \%$; Analysis 15.3). Because only one study presented extractable data on child symptoms at follow-up (participants =65; Yeh 2016), we did not interpret the results.

- We entered three studies into an analysis of the effects of FT on family functioning post-treatment and we did not find evidence of a beneficial treatment effect (SMD $-0.34,95 \% \mathrm{Cl}-0.89$ to 0.21 ; participants $=197$; studies $=3 ; 12=73 \%$; Analysis 15.4). Only one study reported family functioning at follow-up (participants $=65$; Yeh 2016), therefore we were unable to draw any conclusions.

We judged the quality of evidence for family therapy to be very low. Where we were able to conduct meta-analyses, we downgraded evidence twice for heterogeneity and once for imprecision. We judged the studies eligible for inclusion in the remaining analyses to have limitations in study design/implementation, high probability of publication bias, and imprecision due to small sample sizes. Heterogeneity was high for these analyses, indicating that there may have been considerable inconsistency in the results among studies of FT.

\section{Motivational interviewing (MI)}

Three studies evaluated MI for parents of children with chronic medical conditions, and all three used active control comparator conditions (participants = 193; Ellis 2017a; May 2017; Mayer-Davis 2015).

- Two studies evaluated parent $\mathrm{Ml}$ and reported data on parenting behavior post-treatment (participants = 143; Ellis 2017a; May 2017). We did not interpret the results due to the small number of studies in the analysis. No studies presented data on parenting behavior at follow-up, or on parent mental health post-treatment or follow-up.

- No studies of MI presented data on child behavior/disability or child mental health post-treatment or follow-up. Only two studies reported data on the effect of $\mathrm{MI}$ on child medical symptoms post-treatment (participants = 122; Ellis 2017a; Mayer-Davis 2015), therefore we did not interpret the results. No studies presented data on child medical symptoms at follow-up.

- For family functioning, only two studies presented extractable data and we did not interpret the results due to the small number of studies in the analysis (participants =143; Ellis 2017a; May 2017). We did not conduct an analysis evaluating the effect of MI on family functioning at follow-up due to lack of data.

Although we were unable to conduct any meta-analyses for outcomes related to MI, we judged the quality of the evidence for MI as very low. We downgraded evidence once for limitation of study design/implementation and twice for imprecision.

\section{Multisystemic therapy (MST)}

There were four studies (participants $=427$ ) that evaluated MST for parents of children with chronic medical conditions, which were conducted by the same author group (Ellis 2005; Ellis 2012; Ellis 2017b; Naar-King 2014). All four studies used an active control comparator condition.

- Only one study of MST presented extractable data on parenting behavior post-treatment, therefore we were unable to draw any conclusions (participants $=167$; Naar-King 2014). No studies reported on parenting behavior at follow-up. No studies presented extractable data on parent mental health posttreatment or follow-up.

- No studies reported on child behavior/disability at posttreatment or follow-up. Only one study presented data on child mental health post-treatment (participants $=117$; Ellis 2005), and none at follow-up, therefore we could not draw any conclusions.

- We entered four studies into an analysis evaluating child symptoms post-treatment, and we did not find evidence of a beneficial treatment effect (SMD $-0.18,95 \% \mathrm{Cl}-0.45$ to 0.08 ; participants $=477 ;$ studies $=4 ;\left.\right|^{2}=50 \%$; Analysis 18.3. We rated this outcome as very low quality, downgraded twice for imprecision (small number of participants and wide confidence intervals) and once for heterogeneity. Only two studies reported on child symptoms at follow-up (participants = 247; Ellis 2005; Ellis 2012). We did not interpret these results due to the small number of studies in the analysis.

- None of the studies reported family functioning post-treatment or at follow-up.

We judged the quality of evidence for the remaining MST outcomes as very low; we downgraded all outcomes once for imprecision, and twice for high probability of publication bias.

\section{Problem-solving therapy (PST)}

There were 12 studies (participants $=1763$ ), which evaluated PST for parents of children with chronic illness (Daniel 2015; Greenley 2015; Husted 2014; Nansel 2009; Nansel 2012; Palermo 2016a; Sahler 2002; Sahler 2005; Sahler 2013; Seid 2010; Wade 2006a; Wade 2014). Of these, three studies used wait-list control comparator conditions (Daniel 2015; Greenley 2015; Seid 2010), and the remaining used active control conditions. We were not able to conduct our planned subgroup analyses to investigate heterogeneity because there were too few studies included in the primary analyses. 
- PST had a small to moderate beneficial effect on parenting behavior post-treatment (SMD $-0.39,95 \% \mathrm{Cl}-0.64$ to -0.13 ; participants $=947$; studies $=7 ; 1^{2}=67 \%$; Analysis 20.1; Figure 6), which was maintained at follow-up (SMD $-0.54,95 \% \mathrm{Cl}-0.94$ to -0.14 ; participants $=852$; studies $=6 ; 1^{2}=86 \%$; Analysis 21.1 ). We judged the quality of evidence for PST on parenting behavior post-treatment as low, and very low at follow-up (Summary of findings 3; Summary of findings 4). We downgraded the posttreatment and follow-up time points twice for heterogeneity and once more at follow-up for imprecision (wide confidence intervals).

- PST also had a small beneficial effect on parent mental health post-treatment $(\mathrm{SMD}-0.30,95 \% \mathrm{Cl}-0.45$ to -0.15 ; participants = 891; studies = 6; $\left.\right|^{2}=14 \%$; Analysis 20.2; Figure 7), and at followup (SMD $-0.21,95 \% \mathrm{Cl}-0.35$ to -0.07 ; participants $=800$; studies $=5 ; 1^{2}=0 \%$; Analysis 21.2). We judged the quality of evidence for PST on parent mental health post-treatment and at followup as moderate; we downgraded once each for high probability of publication bias.

- We did not find evidence of a beneficial effect of PST on child behavior/disability post-treatment (SMD $0.08,95 \% \mathrm{Cl}-0.18$ to 0.33; participants $=247$; studies $=3 ; 12=0 \%$; Analysis 20.3). We did not interpret the results at follow-up because only two studies were included in the analysis (participants =166; Palermo 2016a; Wade 2014). We rated the quality of evidence post-treatment for PST on child behavior/disability as very low. At post-treatment, we downgraded once for imprecision (small number of participants) and twice for high probability of publication bias. At follow-up, we judged the quality of evidence to be very low; we downgraded twice for imprecision and once for high probability of publication bias.

- We did not find evidence of a beneficial effect of PST on child mental health post-treatment (SMD $-0.12,95 \% \mathrm{Cl}-0.50$ to 0.25 ; participants $=276$; studies $=4 ; 1^{2}=56 \%$; Analysis 20.4), or at follow-up (SMD $0.59,95 \% \mathrm{Cl}-0.28$ to 1.46 ; participants = 212; studies $=3 ; 12=89 \%$; Analysis 21.4). At post-treatment and follow-up, we judged the quality of evidence for PST on child mental health as very low. We downgraded the quality of evidence post-treatment once for heterogeneity and twice for imprecision. We downgraded the quality of evidence at follow-up once for imprecision, and twice for high probability of publication bias.

- We did not find evidence of a beneficial effect of PST on child symptoms post-treatment (SMD $0.25,95 \% \mathrm{Cl}-0.23$ to 0.72 ; participants $=679$; studies $=5 ; 1^{2}=87 \%$; Analysis 20.5) or followup (SMD 0.25, $95 \% \mathrm{Cl}-0.08$ to 0.59 ; participants $=210$; studies $=$ $3 ;\left.\right|^{2}=30 \%$; Analysis 21.5). We rated the post-treatment outcome as very low-quality evidence; we downgraded once for high probability of publication bias and twice for heterogeneity at post-treatment. At follow-up, we downgraded twice for high probability of publication bias and once for imprecision.

- Only two studies presented extractable data on family functioning post-treatment (participants $=237$; Nansel 2009; Wade 2014), and so we did not interpret these results. Only one study of PST presented data on family functioning at followup (participants = 101; Wade 2014), therefore we conducted no analysis. We judged the quality of this evidence to be very low; we downgraded twice for imprecision and once for high probability of publication bias.

Figure 6. Forest plot of comparison 20, problem-solving therapy post-treatment, outcome 20.1: parenting behavior

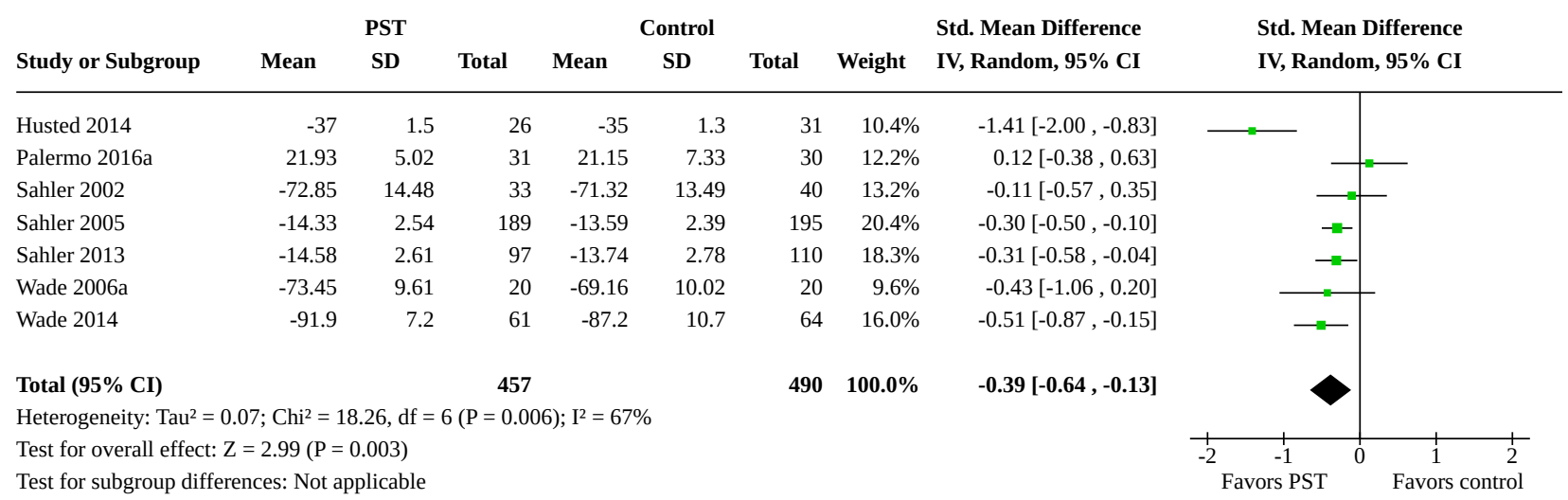


Figure 7. Forest plot of comparison 20, problem-solving therapy post-treatment, outcome 20.2: parent mental health

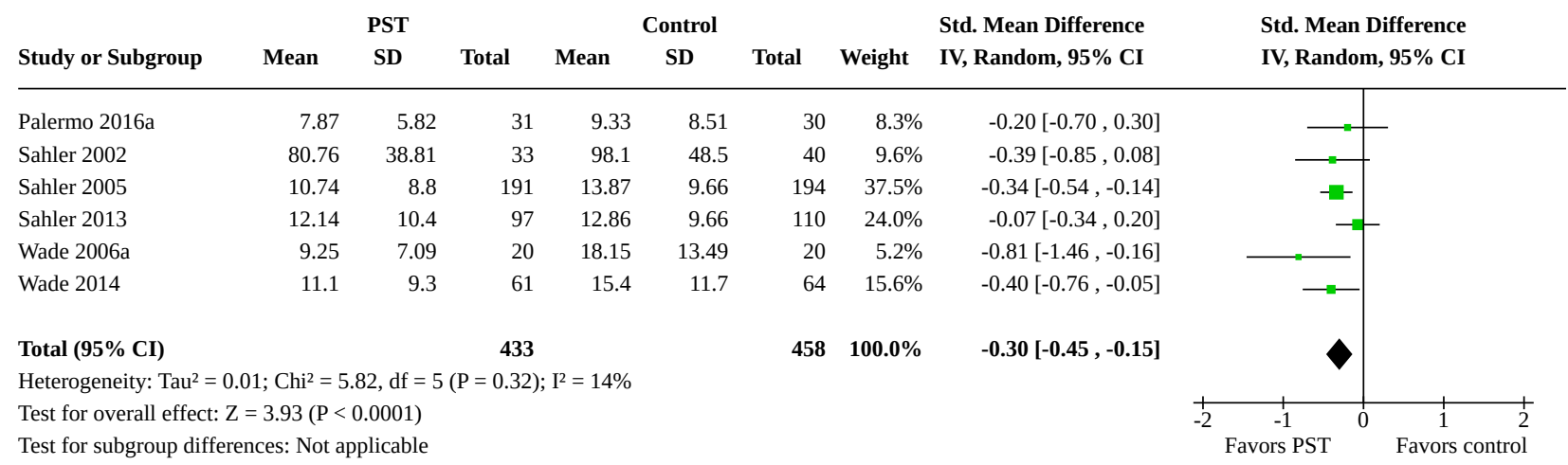

\section{Adverse events}

We found 12 studies that reported on whether or not adverse events occurred during the study period. In six of these studies, the authors reported that there were no adverse events during the study period (Doherty 2013; Ellis 2017b; Law 2015; Levy 2017; Morawska 2016; Nansel 2009). In the remaining six studies, the authors reported that adverse events occurred during the study period although none were attributed to psychological therapies (Ellis 2012; Kashikar-Zuck 2012; Nansel 2009; Powers 2013; Palermo 2016a; Palermo 2016b). In one study (Powers 2013 , participants $=129)$, children reported expected side effects of the study medication amitriptyline (e.g. fatigue, drowsiness, dizziness) as well as respiratory symptoms (e.g. influenza, seasonal allergies), which were reported more frequently by the control group (education + amitriptyline) than the treatment group (CBT + amitriptyline). In two studies, participants reported major life events and stressors during the study period (e.g. parent death, serious illness) as well as self-harm behaviors; the study authors note that these events were not attributed to participation in study procedures (Palermo 2016a, participants $=60$; Palermo 2016b, participants $=258$ ). In another study, the most commonly reported adverse event was infection (e.g. sinus infection, strep throat) and there was one participant who had a psychiatric hospitalization for further assessment of symptoms revealed at the first treatment session (Kashikar-Zuck 2012, participants $=100$ ); the authors reported that these events were not study-related and did not differ between treatment groups. In two studies, the authors reported that rates of diabetes-related events (e.g. hypoglycemia) were the same for the treatment and control groups and these were not attributed to the study procedures (Ellis 2012; participants $=117$; Nansel 2009; participants $=116$ ).

Authors of the remaining 32 studies did not report on whether or not adverse events occurred. Kazak 2004 did not report any adverse events, but reported that participants with higher distress were more likely to drop out of the treatment compared to less distressed participants.

We judged the quality of evidence for adverse events as moderate; we downgraded once for publication bias.

\section{Sensitivity analyses}

We examined the impact of studies with high risk of selective reporting bias by removing the 18 studies where the authors provided missing data on request but did not report these data in the published manuscripts. To minimize the total number of analyses conducted for this review, we conducted sensitivity analyses only when the primary analysis included more than 10 studies.

\section{Chronic pain}

There were four studies with high risk of selective reporting bias that we included in analyses of the effect of treatment on child behavior, child mental health, and child symptoms post-treatment (Levy 2010; Levy 2016; Levy 2017; Powers 2013).

- For child behavior, when we removed studies with high risk of bias, there was no longer evidence for a beneficial effect of the intervention (SMD $-0.10,95 \% \mathrm{Cl}-0.30$ to 0.10 ; participants $=$ 751 ; studies $=8$ ). This is inconsistent with the primary analysis, which found a beneficial effect of treatment when all studies were included regardless of the risk of reporting bias.

- For child mental health, when we removed studies with high risk of bias, there was no evidence for a beneficial effect of the intervention, which is consistent with the primary analysis (SMD $-0.01,95 \% \mathrm{Cl}-0.16$ to 0.14 ; participants $=685$; studies $=7$ ).

- For child symptoms, when we removed studies with high risk of bias, there was no evidence for a beneficial effect of treatment, which is consistent with the primary analysis (SMD $-0.09,95 \% \mathrm{Cl}$ -0.31 to 0.13 ; participants $=565$; studies $=7$ ).

\section{Diabetes}

There were six studies with high risk of selected reporting bias for child symptoms post-treatment (Ambrosino 2008; Ellis 2017a; Nansel 2012; Westrupp 2015; Wysocki 1999; Wysocki 2006).

- When we removed studies with high risk of bias, there was no evidence of a beneficial effect of treatment on child symptoms $(\mathrm{SMD} 0.06,95 \% \mathrm{Cl}-0.35$ to 0.48 ; participants $=641$; studies $=7$ ), which is consistent with the primary analysis.

\section{Cognitive-behavioral therapy}

Among studies of CBT, we rated eight studies as having high risk of selective reporting bias on the outcomes of parent behavior, 
parent mental health, child behavior, child mental health, and child symptoms post-treatment, and child symptoms at follow-up (Ambrosino 2008; Levy 2010; Levy 2016; Levy 2017; Morawska 2016; Powers 2013; Wade 2017; Westrupp 2015).

- For parent behavior post-treatment, there was still evidence of a beneficial effect of treatment (SMD $-0.33,95 \% \mathrm{Cl}-0.63$ to -0.02 ; participants $=455$; studies $=4$ ), which is consistent with the primary analysis.

- For parent mental health post-treatment, there was still no evidence of a beneficial effect of the intervention (SMD -0.16 , $95 \% \mathrm{Cl}-0.33$ to 0.02 ; participants $=519$; studies $=5$ ), which is consistent with the primary analysis.

- For child behavior post-treatment, there was still a beneficial effect of the intervention (SMD $-0.24,95 \% \mathrm{Cl}-0.46$ to -0.02 ; participants $=625$; studies $=6$ ), which is consistent with the primary analysis.

- For child mental health, there was still no evidence of a beneficial effect of the intervention (SMD $-0.11,95 \% \mathrm{Cl}-0.30$ to 0.08 ; participants $=705$; studies $=7$ ), which is consistent with the primary analysis.

- For child symptoms post-treatment, when we removed studies with high risk of bias, there was no longer evidence of a beneficial effect of treatment (SMD $-0.6195 \% \mathrm{Cl}-1.27$ to 0.05 , participants $=703$, studies $=6$ ). This is not consistent with the primary analysis, which found a beneficial effect of treatment on child symptoms when all studies were included regardless of the risk of reporting bias.

- For child symptoms at follow-up, there was still no evidence of a beneficial treatment effect (SMD $-0.20,95 \% \mathrm{Cl}-0.60$ to 0.21 ; participants $=477$; studies $=4$ ), which is consistent with the primary analysis.

\section{DISCUSSION}

This is the second updated version of the original Cochrane Review published in 2012 (Eccleston 2012b), and first updated in 2015 (Eccleston 2015).

\section{Summary of main results}

There were two objectives of this review:

- First, we aimed to evaluate the efficacy of psychological therapies for parents of children with a chronic medical condition including asthma, chronic pain conditions, cancer, diabetes mellitus, gynecologic disorders, IBD, skin diseases, and TBI. We also aimed to evaluate adverse events caused by psychological therapies in these populations.

- Second, we sought to evaluate the risk of bias and quality of evidence for the included studies.

We included 44 studies in this updated review. Children in these studies had asthma, cancer, chronic pain, diabetes mellitus, IBD, skin diseases, and TBI. We did not identify any studies of children with gynecologic disorders. For analyses, we combined the two studies of children with IBD with studies of children with chronic pain. Types of psychotherapy interventions were: cognitivebehavioral therapy (CBT), family therapy (FT), motivational interviewing (MI), multisystemic therapy (MST), and problemsolving therapy (PST). Our primary outcomes were parenting behavior and parent mental health. Our secondary outcomes were child behavior/disability, child mental health, child medical symptoms, family functioning, and adverse events. We conducted two sets of analyses to address the following questions:

- For each medical condition, across all types of psychotherapy, what is the efficacy for each outcome post-treatment and at follow-up?

- For each type of psychological therapy, across all medical conditions, what is the efficacy for each outcome post-treatment and at follow-up?

It should be noted that beneficial treatment effects emerged when there was homogeneity of approach, homogeneity of outcome measurements, and a larger number of participants. In addition, we are not able to make conclusions about whether these beneficial treatment effects could be clinically meaningful.

\section{Combined psychological therapies for each illness condition}

We evaluated the efficacy of all psychological therapies delivered to parents for each medical condition (Table 3). Overall, we found that the pattern of effects for psychological therapies varied by medical condition. Where we did identify evidence for a beneficial effect of treatment, the effect sizes were generally small, indicating that the benefits of treatment may be small. Importantly, the quality of evidence for most of these outcomes was low to very low, with the exception of chronic pain conditions, which we rated from low to high quality, and so these findings should be interpreted cautiously.

Among studies of children with cancer, we found that psychological therapies had beneficial effects on parenting behavior and parent mental health post-treatment and follow-up. We were not able to determine the effect of psychological therapies on child outcomes or family functioning for children with cancer because very few studies evaluated these outcomes.

We identified predominantly beneficial effects for psychological therapies delivered to parents of children with chronic pain. In this group, psychological therapies had a beneficial and longlasting effect on parenting behavior and parent mental health. We also found beneficial effects on child behavior/disability at post-treatment and follow-up, and child medical symptoms at post-treatment, although this was not maintained at follow-up. There was no evidence of a beneficial effect on children's mental health symptoms assessed post-treatment or follow-up. Family functioning was not assessed in any of the studies of children with chronic pain.

Among studies of children with traumatic brain injury, we found that psychological therapies had beneficial effects on parenting behavior and child mental health post-treatment. We were not able to evaluate the long-term maintenance of these treatment effects because very few studies reported on these outcomes at follow-up. We were unable to draw conclusions about the effect of treatment on parent mental health, child behavior/disability, and family functioning because very few studies reported on these outcomes post-treatment or follow-up. Child medical symptoms were not assessed in any of the studies of children with traumatic brain injury.

Among studies of children with diabetes, a different and somewhat less favorable pattern of results emerged. We found that psychological therapies had a beneficial effect on parenting 
behavior post-treatment; it was not possible to assess long-term maintenance because very few of the studies reported on parenting behavior at follow-up. We did not find evidence of a beneficial effect of treatment on parent mental health, child mental health, child medical symptoms, or family functioning post-treatment. For child medical symptoms, we found no evidence of a beneficial effect at follow-up. Too few studies reported on the remaining outcomes at follow-up to understand the potential long-term effects of treatment. None of the studies assessed child behavior/disability and so it was not possible to determine the effect of treatment on this outcome.

We were also able to evaluate the effect of psychological therapies on medical symptoms for children with asthma. Similar to the meta-analysis on medical symptoms for children with diabetes, we did not find evidence for a beneficial effect of psychological therapies on children's asthma symptoms post-treatment although there were too few studies to evaluate the effect of treatment at follow-up. We were not able to determine the effect of psychological therapies on other outcomes for children with asthma due to insufficient data.

Analyses for skin diseases were either not interpreted due to very limited data or not conducted due to lack of data.

\section{Individual psychological therapies for combined illness conditions}

We evaluated the efficacy of each type of psychotherapy across all medical conditions combined (Table 4). Overall, we identified varying patterns of findings by therapy type. These findings should be interpreted with caution as the quality of evidence was predominantly low to very low, indicating that these results could change as more studies are conducted.

\section{Parent outcomes}

The majority of included studies evaluated either CBT or PST, and both psychotherapy types resulted in similar benefits for parenting behavior post-treatment and follow-up. PST was also beneficial for improving parent mental health post-treatment and followup. These effect sizes were generally small indicating modest improvements may be expected from treatment. We found no evidence of a beneficial effect for CBT on parent mental health posttreatment or follow-up. We were not able to determine the effect of FT, MI, and MST on parent outcomes due to insufficient data.

\section{Child and family outcomes}

The pattern of results for child and family outcomes was more variable. For CBT, we found beneficial effects on child behavior/ disability post-treatment and follow-up. We also found a small beneficial effect for CBT on child medical symptoms posttreatment, although this was not maintained at follow-up. There was no evidence of a beneficial effect of CBT on child mental health or family functioning post-treatment or at follow-up. Where beneficial treatment effects were detected, effect sizes were generally small, indicating that modest improvements in child behavior/disability and child medical symptoms may be expected from CBT.

In contrast, there was no evidence for a beneficial effect of PST on any of the three child outcomes post-treatment and we found this was maintained at follow-up for child mental health. There were insufficient data to evaluate the effect of PST on child behavior/disability and medical symptoms at follow-up and on family functioning at either time point.

We were not able to determine the effect of FT and MST on most of the child and family outcomes in this review due to insufficient data. There was no evidence of a beneficial effect of FT or MST on child medical symptoms post-treatment; there were insufficient data to evaluate whether this pattern was maintained at follow-up. For FT, there was no evidence of a beneficial effect of treatment on family functioning post-treatment and too few studies reported family functioning at follow-up. Remaining analyses were not conducted or not interpreted due to insufficient data.

For $\mathrm{Ml}$, there were insufficient data to determine the effect of treatment on any of the outcomes extracted for this review.

\section{Adverse events}

The majority of studies $(n=32)$ did not report whether adverse events due to treatment occurred during the study period. Among those studies that did report adverse events, none found any adverse events due to psychological therapy. Because relatively few studies reported whether or not they encountered adverse events, we are unable to comment on the relevance of adverse events to treatment safety, which is a limitation of this review.

\section{Planned subgroup analyses to evaluate heterogeneity}

In this update, for primary analyses that included more than 10 studies, we conducted planned subgroup analyses to evaluate heterogeneity due to the inclusion of active versus wait-list comparator control conditions. Findings from subgroup analyses indicated that variability between studies may have been due to different types of control comparator conditions (i.e. active versus wait-list), When we included studies with only active control conditions in subgroup analyses, heterogeneity was often lower. It is difficult to interpret differences on treatment efficacy identified in the primary analyses versus the subgroup analyses due to the relatively small number of studies included in the subgroup analyses. This issue should be considered in the next update of this review.

\section{Sensitivity analyses}

We also conducted sensitivity analyses to evaluate the effect of studies with high risk of reporting bias for analyses that included more than 10 studies. For these analyses, we excluded studies where the outcome data were not fully reported in the published manuscript but were provided to us by the authors on request. Results of our sensitivity analyses indicate that we would have identified a different pattern of findings if we had not contacted authors for these missing data. Non-production of data in science is a significant problem (Nature 2009), and our results support prior work indicating that this is a particular concern in psychology research (Wicherts 2006; Wicherts 2011).

\section{Overall completeness and applicability of evidence}

We were unable to identify any studies for children with gynecologic disorders, therefore studies investigating these disorders are still needed. However, for the first time in the history of this review, this update includes several expanded populations including studies of children with IBD (which we included in the chronic pain conditions analysis, Greenley 2015; Levy 2016), and 
studies of MI (Ellis 2017a; Mayer-Davis 2015; May 2017). In our last review we noted that studies of PST were predominantly comprised of parents of children with cancer. PST has now been tested in additional populations including parents of children with chronic pain (Palermo 2016a), and IBD (Greenley 2015).

Many analyses were not interpreted or conducted due to insufficient data. Typically, this occurred because most studies assessed some but not all of the outcome domains extracted for this review. Given our growing understanding of bi-directional relationships between parent, child, and family functioning across a variety of pediatric populations (e.g. Morawska 2015; Palermo 2014), we recommend that parent, child, and family outcomes should be routinely assessed in future studies of psychological interventions for parents of children with chronic illness.

\section{Quality of the evidence}

In general, we judged 'Risk of bias' ratings as low or unclear with the exception of selective reporting bias, which we judged to be high risk for nearly half of the studies due to incomplete reporting of treatment outcome data in the published manuscripts. Although most study authors provided us with these data on request, there is room for improvement in clinical trial reporting practices in this domain. Our evaluation of risk of bias excluded the category of 'blinding participants and personnel' because it is not possible to blind personnel who are delivering psychological treatments; thus, this risk of bias remains.

We judged the quality of the evidence to be generally very low to moderate. Therefore, results from this update should be interpreted with caution as these findings are likely to change as future studies are conducted. Contributing factors to our quality of evidence ratings include high heterogeneity, imprecision, and publication bias. In contrast, we did judge some outcomes as moderate or high quality including some analyses of youth with chronic pain, youth with cancer, cognitive-behavioural therapies, and problem-solving therapies.

\section{Potential biases in the review process}

We searched four large databases as well as other sources (e.g. trials registry search, reference search, citation search). Therefore, we think it is unlikely that potentially eligible studies were not included in this update. There is also a potential for Type I error due to the large number of primary analyses conducted to evaluate the primary aims of this review, in addition to our planned subgroup analyses for heterogeneity and sensitivity. In the future, we may consider dividing this review into two publications to separately study treatment efficacy for each medical condition versus treatment efficacy for each type of psychological therapy.

\section{Agreements and disagreements with other studies or reviews}

\section{Combined psychological therapies for each illness condition}

Prior systematic reviews and meta-analyses have evaluated the efficacy of psychological interventions for youth with asthma (Pai 2014), cancer (Pai 2006), chronic pain conditions (Anie 2012; Fisher 2014; Fisher 2018; Rutten 2015), diabetes (Armour 2005; McBroom 2009), and TBI (Brown 2013). In general, our results are consistent with these prior reviews.
For children with asthma, our findings were inconsistent with a prior meta-analysis, which found evidence for improvements in children's medical symptoms in response to psychological treatment (Pai 2014). For children with cancer, a prior meta-analysis also found no evidence of a beneficial effect of psychological interventions on child behavior or child mental health, but positive treatment effects for parent mental health and parenting behavior (Pai 2006). Our results for children with chronic pain conditions are consistent with two previous meta-analyses that reported beneficial effects on children's disability and medical symptoms and no evidence of a beneficial effect on child mental health (Fisher 2014; Fisher 2018). Agreement with prior reviews for children with diabetes was consistent on the outcome of child medical symptoms (Armour 2005), but inconsistent on the outcome of family functioning (Delamater 2014; McBroom 2009). For children with skin diseases, findings from our review and a prior review were both inconclusive due to lack of data (Ersser 2014). Finally, for children with TBI, our analyses were consistent with a prior systematic review that identified improvements in parenting behavior and emotional adjustment as well as children's behavioral and emotional functioning (Brown 2013).

Disagreements between the present meta-analysis and previous reviews may be due to differences in methodology (e.g. where the prior review was a systematic review but did not include a metaanalysis), as well as differences in inclusion criteria, selection of outcome measures, and/or selection of comparator group.

\section{Individual psychological therapies for combined illness conditions}

In this update, we were able to evaluate the effect of CBT and PST on our primary outcomes of parenting behavior and parent mental health. We found beneficial effects of PST on parenting behavior and parent mental health, which is consistent with the prior version of this systematic review and others (Eccleston 2015; Law 2014). However, we also identified beneficial effects of $C B T$ on parenting behavior, whereas prior reviews have reported no evidence for a beneficial effect of CBT on this outcome (Eccleston 2015; Law 2014). Consistent with other meta-analyses, we did not find evidence for beneficial effects of CBT on parent mental health (Eccleston 2015; Law 2014). Sample sizes for these analyses were substantially larger in this update compared to prior reviews, which may have increased our ability to detect beneficial treatment effects. For example, the analysis of the effect of CBT on parenting behavior in this update included 1040 participants whereas the same analysis in the prior version of this review included only 166 participants (Eccleston 2015). It is important to note that our confidence in these estimates is moderate, which means a different pattern of findings may emerge as additional studies are conducted.

We were also able to evaluate the effect of CBT on some child outcomes and family functioning, and identified a beneficial effect of treatment on child behavior/disability and medical symptoms (e.g. pain intensity), but found no evidence for a beneficial treatment effect on family functioning. For PST, data were available for child mental health, child behavior/disability, and medical symptoms at post-treatment and results indicated there was no evidence for a beneficial treatment effect on these child outcomes. This is generally consistent with prior reviews, which have also identified mixed treatment effects for child and family outcomes across populations of youth with chronic medical conditions (Eccleston 2015; Law 2014; Sansom-Daly 2012). 
Importantly, in this update we were not able to evaluate the effect of FT, MST, and MI on most outcomes due to lack of available data. Similar limitations have been encountered in prior reviews (Eccleston 2015; Law 2014). Studies of MI were included for the first time in this update. A recent systematic review and metaanalysis of MI for pediatric health behavior change (Gayes 2014), found that $\mathrm{MI}$ had a small beneficial effect on a range of child health behaviors for children with a variety of conditions, including some of those evaluated in the present update (e.g. asthma, diabetes). Relevent to this update, MI was found to be most beneficial when both parents and children received treatment compared to when the intervention was delivered to children alone (Gayes 2014).

\section{AUTHORS' CONCLUSIONS}

\section{Implications for practice}

\section{Implications for parents of children with a chronic illness}

There is little evidence available to guide parents as to the most effective psychological intervention expected to improve their own mental health or behavioral functioning. We found that cognitive-behavioral therapy (CBT) and problem-solving therapy (PST) improved parenting behavior, and PST improved parental mental health. In addition, our findings suggest that CBT is beneficial for improving children's behavior/disability and their medical symptoms (e.g. pain). However, these findings should be interpreted cautiously because they may change as new studies are conducted.

\section{Implications for clinicians}

Overall, we judged the evidence as very low to moderate quality. Therefore, results from this update should be interpreted with caution as these findings are likely to change as future studies are conducted.

\section{Findings regarding problem-solving therapy}

- PST is the only therapy included in this review that was routinely delivered only to parents and that was expressly developed to reduce parent distress. We found that PST improved parenting behavior and parent mental health, although these results should be interpreted cautiously because they may change as new studies are conducted.

- We did not find evidence for a beneficial effect of PST on child mental health and too few studies were available to understand the effect of PST on other child outcomes or family functioning.

- Studies of PST were predominantly delivered to parents of children with cancer, but PST has also been evaluated in parents of children with chronic pain, IBD, and TBI.

\section{Findings regarding cognitive-behavioral therapy}

- CBT was typically delivered to both children and parents, and led to improvements in parenting behavior but not parent mental health.

- In contrast to PST, CBT led to improvements in some child outcomes (behavior/disability, medical symptoms).

- These results should also be interpreted cautiously because they may change as new studies are conducted.

- We did not find evidence for a beneficial effect of CBT on children's mental health or family functioning.
Findings regarding family therapy, motivational interviewing, and multisystemic therapy

- This update includes a very small number of studies of family therapy (FT), (motivational interviewing) MI, and multisystemic therapy (MST) which limits our ability to make conclusions about these therapy types.

\section{Implications for policy makers and funders of the interventions}

It is surprising how few studies have targeted parenting behavior or mental health, given the ample evidence demonstrating the bidirectional effects of child and parent functioning in the context of chronic illness. When combining all therapies for parenting outcomes, we concluded that the quality of evidence was mostly low to very low, meaning further research is likely to change the estimates of effects. This is primarily due to the small number of studies that reported parent outcomes, particularly for therapy types other than CBT and PST. Thus, additional clinical studies are needed to understand the most effective interventions to implement with parents of youth with chronic health conditions.

\section{Implications for research}

\section{General design}

Research is needed to determine the best way to deliver parent interventions, including the optimal dose, whether interventions should be delivered by trained professionals or paraprofessionals, and whether alternative modes of intervention delivery such as through eHealth or mHealth technologies impacts treatment feasibility and efficacy in clinical settings. At present, it is unknown whether parent interventions delivered alone or in combination with child and/or family/systems treatments are more efficacious. For example, there are some psychotherapy types that are typically delivered only to parents (e.g. PST) whereas other therapy types are delivered to parents and children (e.g. CBT). Research designs that allow for testing of child only, parent only, and parent/child/ family interventions will advance this field. Further research to understand how to maximize the effects of parent interventions singly or in combination with specific child interventions is needed.

Given the small sample sizes of many studies in this field, we encourage multi-site investigations to obtain larger samples. Moreover, considerations in research designs are needed for maximizing retention of parents and families in studies through to follow-up assessment points.

At present, there is limited understanding of moderators or mediators of parent interventions. Studies should incorporate consideration of baseline patient, parent or family characteristics that may moderate the effects of treatment and be adequately powered to test these hypotheses. Further, the plausible treatment mechanisms for parent interventions need to be further conceptualized and studied in studies. Measurement of possible mechanisms should occur prior to outcome assessment (such as mid-treatment) in order to test mediation pathways.

\section{Measurement}

We found that multiple measurement tools were often used to evaluate one outcome domain in a single study. This practice was particularly problematic for studies that did not identify a-priori the primary outcome. A posteriori selection of outcome measures 
is a problem and can increase bias. To address this concern, we recommend that editorial boards implement standards for trial registration and reporting that includes a-priori decisions regarding outcome measurement.

In addition, there was heterogeneity in the measures used to evaluate most of the outcome domains across studies. Work is needed to establish consensus within the field for recommended or appropriate measurement tools to evaluate a given outcome within and across illness groups. Given the inherent challenges in establishing consensus across illness groups, researchers may consider using a combination of disease-specific measures to enhance sensitivity as well as general measures to enhance generalizability.

Finally, we were surprised by the number of studies that did not assess parent or family outcomes even though all of the interventions included in this review were developed to be delivered to parents or families. We recommend that future studies routinely assess parent and family outcomes when parents are directly targeted in treatment.

\section{Other}

Since the first version of this review (which included only 13 studies), there has been a large increase in studies and interest in improving parental mental health and parenting behavior among families of children and adolescents with chronic illness. Studies identified in the updated search for this review had several strengths, including more routine use of CONSORT guidelines (Schulz 2010), and relatively larger sample sizes. The next generation of studies should take into account additional limitations identified in this review, including the following.

- Very few studies of FT, MI, and MST met the inclusion criteria for this review. Additional, larger studies of these therapies for children and adolescents with a broad range of illness conditions are needed.

- Replication studies for interventions that have been evaluated by only one research team, such as MST for families of children with diabetes and PST for families of children with TBI.

- There are several subpopulations that have been underrepresented in most studies, particularly those of low socioeconomic or minority status, as well as fathers. Research is needed to understand the efficacy of psychological therapies for these groups.

- Research is needed to understand the evidence-base for studies that aim to intervene with mixed samples of youth with chronic illness. We may consider including these studies in a future version of this review.

- Research is needed to understand the feasibility and efficacy of these interventions in developing countries, particularly given predictions that the prevalence of childhood chronic illness will continue to increase worldwide (Liu 2015).

- In this updated search, we found more routine use of CONSORT reporting guidelines and trials registries compared to prior versions of this review. That being said, these practices were not universal across studies and this is an area that deserves attention from study authors and journal editors. Study authors are encouraged to report complete details about their intervention and how it was delivered, including making treatment manuals publicly available. Many journals now have policies requiring trial registry and use of CONSORT guidelines, and we encourage editors to enforce these policies.

- We had some trouble with incomplete reporting of data in published manuscripts. Complete data were available to extract from 25 of 44 studies included in this review. Additionally, authors of 16 studies provided data to us on request, which were missing from the published manuscripts. We rated these studies as having high risk of reporting bias, and our sensitivity analyses indicate that excluding these studies may have changed the findings of our meta-analyses. We support the general move toward central registries for all study data and treatment manuals.

- Finally, piecemeal and repeat publication is an ongoing concern. There were several included studies identified from our updated search where multiple manuscripts were published from the same study. Such practices are unhelpful, create confusion and increase unnecessary labour (American Psychological Association 2011). Many journals now have policies regarding publication of multiple manuscripts from the same study, including a detailed description of previous publications from that study and a statement regarding the unique contribution of the present manuscript (e.g. Drotar 2010). Editors play a crucial role in enforcing these policies, and need to take a proactive approach to identifying such papers during the review process (Committee on Publication Ethics 2011; World Association of Medical Editors 2012).

\section{ACKNOWLEDGEMENTS}

We would like to thank Dr Zeinab Mousavi, Dr Gerrit Hirschfeld, Dr Anna Huguet, Dr Rikard Wicksell, Dr Jordi Miro, Megan Walker, and Dr Nils Niederstrasser for their time in helping to translate papers and extract data.

We would like to thank all study authors who responded to emails requesting further studies or data.

We would also like to thank Jane Hayes and Joanne Abbot for all their help designing and carrying out the search strategies.

We would like to thank Jessica Bartlett for contributing to an earlier version of this review. We would also like to thank Sade Rodriguez, and Aly Sonnen for their assistance with data extraction and data entry for this update.

We thank the peer reviewers for this update: Esther Coren and Rosanna Fennessy.

Cochrane Review Group funding acknowledgement: this project was supported by the National Institute for Health Research, via Cochrane Infrastructure funding to the Cochrane Pain, Palliative and Supportive Care Review Group (PaPaS). The views and opinions expressed therein are those of the authors and do not necessarily reflect those of the Systematic Reviews Programme, NIHR, NHS or the Department of Health. 


\section{R E F E R E N C E S}

\section{References to studies included in this review}

Ambrosino 2008 \{published data only\}

* Ambrosino JM, Fennie K, Whittemore R, Jaser S, Dowd MF, Grey M. Short-term effects of coping skills training in school-age children with type 1 diabetes. Pediatric Diabetes 2008;9(3 Part 2):74-82.

Grey M, Whittermore R, Jaser S, Ambrosino J, Lindemann E, Liberti L, et al. Effects of coping skills training in school-age children with type 1 diabetes. Research in Nursing \& Health 2009;32(4):405-18.

\section{Bonnert 2017 \{published data only\}}

Bonnert M, Olén O, Lalouni M, Benninga MA, Battai M, Engelbrektsson J, et al. Internet-delivered cognitive behavior therapy for adolescents with irritable bowel syndrome: a randomized controlled trial. American Journal of Gastroenterology 2017;112:152-62.

\section{Daniel 2015 \{published data only\}}

Daniel LC, Li Y, Smith K, Tarazi R, Robinson R, Patterson CA, et al. Lessons learned from a randomized controlled trial of a family-based intervention to promote school functioning for school-age children with sickle cell disease. Journal of Pediatric Psychology 2015;40(10):1085-94.

\section{Doherty 2013 \{published data only\}}

Doherty FM, Calam R, Sanders MR. Positive Parenting Program (Triple $P$ ) for families of adolescents with type 1 diabetes: a randomized controlled trial of self-directed teen Triple $P$. Journal of Pediatric Psychology 2013;38(8):846-58.

\section{Ellis 2005 \{published data only\}}

* Ellis DA, Frey MA, Naar-King S, Templin T, Cunningham P, Cakan N. The effects of multisystemic therapy on diabetes stress among adolescents with chronically poorly controlled type 1 diabetes: findings from a randomized, controlled trial. Pediatrics 2005;116(6):e826-32.

Ellis DA, Frey MA, Naar-King S, Templin T, Cunningham P, Cakan N. Use of multisystemic therapy to improve regimen adherence among adolescents with type 1 diabetes in chronic poor metabolic control. Diabetes Care 2005;28(7):1604-10.

Ellis DA, Templin T, Naar-King S, Frey MA, Cunningham PB, Podolski CL, et al. Multisystemic therapy for adolescents with poorly controlled type 1 diabetes: stability of treatment effects in a randomized controlled trial. Journal of Consulting and Clinical Psychology 2007;75(1):168-74.

Ellis DA, Yopp J, Templin T, Naar-King S, Frey MA, Cunningham PB, et al. Family mediators and moderators of treatment outcomes among youths with poorly controlled type 1 diabetes: results from a randomized controlled trial. Journal of Pediatric Psychology 2007;32(2):194-205.

Naar-King S, Ellis DA, Idalski A, Frey MA, Cunningham P. Multisystemic therapy decreases parental overestimation of adolescent responsibility for type 1 diabetes management in urban youth. Families, Systems \& Health 2007;25(2):178-89.
Ellis 2012 \{published data only\}

Ellis DA, Naar-King S, Chen X, Moltz K, Cunningham P, IdalskiCarcone A. Multisystemic therapy compared to telephone support for youth with poorly controlled diabetes: findings from a randomized controlled trial. Annals of Behavioural Medicine 2012;44(2):207-15.

\section{Ellis 2017a \{published data only\}}

Ellis DA, Carcone Al, Ondersma SJ, Naar-King S, Dekelbab B, Moltz K. Brief computer-delivered intervention to increase parental monitoring in families of African American adolescents with type 1 diabetes: a randomized controlled trial. Telemedicine Journal and E-health 2017;23(6):493-502.

Ellis 2017b \{published data only\}

Ellis DA, Carcone Al, Naar-King S, Rajkumar D, Palmisano G, Moltz K. Adaptation of an evidence-based diabetes management intervention for delivery in community settings: findings from a pilot randomized effectiveness trial. Journal of Pediatric Psychology 2017 [Epub ahead of print]:1-16.

\section{Greenley 2015 \{published data only\}}

Greenley RN, Gumidyala AP, Nguyen E, Plevinsky JM, Poulopoulos N, Thomason MM. Can you teach a teen new tricks? Problem solving skills training improves oral medication adherence in pediatric patients with inflammatory bowel disease participating in a randomized trial. Inflammatory Bowel Diseases 2015;21(11):2649-57.

\section{Hoekstra-Weebers 1998 \{published data only\}}

Hoekstra-Weebers JE, Heuvel F, Jaspers JP, Kamps WA, Klip EC. Brief report: an intervention program for parents of pediatric cancer patients: a randomized controlled trial. Journal of Pediatric Psychology 1998;23(3):207-14.

\section{Husted 2014 \{published data only\}}

Husted GR, Thorsteinsson B, Appel-Esbensen B, Gluud C, Winkel $P$, Hommel E. Effect of guided self-determination youth intervention integrated into outpatient visits versus treatment as usual on glycemic control and life skills: a randomized clinical trial in adolescents with type 1 diabetes. Trials 2014;15(321):321. [DOI: 10.1186/1745-6215-15-321]

Kashikar-Zuck 2012 \{published data only\}

Kashikar-Zuck S, Ting TV, Arnold LM, Bean J, Powers SW, Graham TB, et al. Cognitive behavioral therapy for the treatment of juvenile fibromyalgia. Arthritis and Rheumatism 2012;64(1):297-305.

\section{Kazak 2004 \{published data only\}}

Kazak AE, Alderfer MA, Streisand R, Simms S, Rourke MT, Barakat LP, et al. Treatment of posttraumatic stress symptoms in adolescent survivors of childhood cancer and their families: a randomized clinical trial. Journal of Family Psychology 2004;18(3):493-504.

\section{Laffel 2003 \{published data only\}}

Laffel LM, Vangsness L, Connell A, Goebel-Fabbri A, Butler D, Anderson BJ. Impact of ambulatory, family-focused teamwork 
intervention on glycemic control in youth with type 1 diabetes. Journal of Pediatrics 2003;142(4):409-16.

\section{Law 2015 \{published data only\}}

Law EF, Beals-Erickson SE, Noel M, Claar R, Palermo TM. Pilot randomized controlled trial of internet-delivered cognitivebehavioral treatment for pediatric headache. Headache 2015;55(10):1410-25.

\section{Levy 2010 \{published data only\}}

* Levy RL, Langer SL, Walker LS, Romano JM, Christie DL, Youssef N, et al. Cognitive-behavioral therapy for children with functional abdominal pain and their parents decreases pain and other symptoms. American Journal of Gastroenterology 2010;105(4):946-56.

Levy RL, Langer SL, Walker LS, Romano JM, Christie DL, Youssef $\mathrm{N}$, et al. Twelve-month follow-up of cognitive behavioural therapy for children with functional abdominal pain. JAMA Pediatric 2013;167(2):178-84.

\section{Levy 2016 \{published data only\}}

Levy RL, Van Tilburg MA, Langer SL, Romano JM, Walker LS, Mancl LA, et al. Effects of a cognitive behavioral therapy intervention trial to improve disease outcomes in children with inflammatory bowel disease. Inflammatory Bowel Diseases 2016;22(9):2134-48

\section{Levy 2017 \{published data only\}}

Levy RL, Langer SL, Van Tilburg MAL, Romano JM, Murphy TB, Walker LS, et al. Brief telephone-delivered cognitive behavioral therapy targeted to parents of children with functional abdominal pain: a randomized controlled trial. Pain 2017;158(4):618-28.

\section{May 2017 \{published data only\}}

May DK, Ellis DA, Cano A, Dekelbab B. Improving diabetesrelated parent-adolescent communication with individualized feedback. Journal of Pediatric Psychology 2017;42(10):1114-22. [DOI: 10.1093/jpepsy/jsx070]

\section{Mayer-Davis 2015 \{published data only\}}

Mayer-Davis EJ, Seid M, Crandell J, Dolan L, Lagarde WH, Letourneau L, et al. Flexible Lifestyles for Youth (FL3X) behavioural intervention for at-risk adolescents with type 1 diabetes: a randomized pilot and feasibility trial. Diabetic Medicine 2015;32(6):829-33.

\section{Morawska 2016 \{published data only\}}

Morawska A, Mitchell AE, Burges S, Fraser J. Effects of Triple P parenting intervention on child health outcomes for childhood asthma and eczema: randomised controlled trial. Behavior Research and Therapy 2016;83:35-44.

\section{Naar-King 2014 \{published data only\}}

Ellis DA, King P, Naar-King S, Lam P, Cunningham PB, Secord E. Effects of family treatment on parenting beliefs among caregivers of youth with poorly controlled asthma. Journal of Developmental and Behavioral Pediatrics 2014;35(8):846-93.

* Naar-King S, Ellis D, King PS, Lam P, Cunningham P, Secord E, et al. Multisystemic therapy for high-risk African American adolescents with asthma: a randomized clinical trial. Journal of Consulting and Clinical Psychology 2014;82(3):536-45.

Nansel 2009 \{published data only\}

Nansel TR, Anderson BJ, Laffel LM, Simons-Morton BG, Weissberg-Benchell J, Wysocki T, et al. A multi-site trial of a clinic-integrated intervention for promoting family management of pediatric type 1 diabetes: feasibility and design. Pediatric Diabetes 2009;10(2):105-15.

Nansel 2012 \{published data only\}

Nansel TR, Iannotti RJ, Liu A. Clinic-integrated behavioural intervention for families of youth with type 1 diabetes: randomized clinical trial. Pediatrics 2012;129(4):1-8.

\section{Palermo 2009 \{published data only\}}

Palermo TM, Wilson AC, Peters M, Lewandowski A, Somhegyi H. Randomized controlled trial of an internet delivered family cognitive behavioral therapy intervention for children and adolescents with chronic pain. Pain 2009;146(1-2):205-13.

\section{Palermo 2016a \{published data only\}}

Palermo TM, Law EF, Bromberg M, Fales J, Eccleston C, Wilson AC. Problem-solving skills training for parents of children with chronic pain: a pilot randomized controlled trial. Pain 2016;157(6):1213-23.

\section{Palermo 2016b \{published data only\}}

Palermo TM, Law EF, Fales J, Bromberg MH, Jessen-Fiddick T, Tai G. Internet-delivered cognitive-behavioral treatment for adolescents with chronic pain and their parents: a randomized controlled multicenter trial. Pain 2016;157(1):174-85.

\section{Powers 2013 \{published data only\}}

Powers SW, Kashikar-Zuck SM, Allen JR, LeCates SL, Slater SK, Zafar M, et al. Cognitive behavioral therapy plus amitriptyline for chronic migraine in children and adolescents: a randomized clinical trial. JAMA 2013;310(24):2622-30.

\section{Robins 2005 \{published data only\}}

Robins PM, Smith SM, Glutting JJ, Bishop CT. A randomized controlled trial of a cognitive-behavioral family intervention for pediatric recurrent abdominal pain. Journal of Pediatric Psychology 2005;30(5):397-408.

\section{Sahler 2002 \{published data only\}}

Sahler OJ, Varni JW, Fairclough DL, Butler RW, Noll RB, Dolgin MJ, et al. Problem-solving skills training for mothers of children with newly diagnosed cancer: a randomized trial. Developmental and Behavioural Pediatrics 2002;23(2):77-86.

\section{Sahler 2005 \{published data only\}}

Sahler OJ, Fairclough DL, Phipps S, Mulhern RK, Dolgin MJ, Noll RB, et al. Using problem-solving skills training to reduce negative affectivity in mothers of children with newly diagnosed cancer: report of a multi-site randomized trial. Journal of Consulting and Clinical Psychology 2005;73(2):272-83.

Sahler 2013 \{published data only\}

Askins MA, Sahler OJ, Sherman SA, Fairclough DL, Butler RW, Katz ER, et al. Report from a multi-institutional randomized 
clinical trial examining computer-assisted problem-solving skills training for English-and Spanish-speaking mothers of children with newly diagnosed cancer. Journal of Pediatric Psychology 2008;34(5):551-63.

* Sahler OJ, Dolgin MJ, Phipps S, Fairclough DL, Askins MA, Katz ER, et al. Specificity of problem solving skills training in mothers of children newly diagnosed with cancer: results of a multi-site randomized clinical trial. Journal of Clinical Oncology 2013;31(10):1329-35.

\section{Sanders 1994 \{published data only\}}

Sanders MR, Shepherd RW, Cleghorn G, Woolford H. The treatment of recurrent abdominal pain in children: a controlled comparison of cognitive-behavioral family intervention and standard pediatric care. Journal of Consulting and Clinical Psychology 1994;62(2):306-14.

\section{Seid 2010 \{published data only\}}

Seid M, Varni JW, Gidwani P, Gelhard LR, Slymen DJ. Problemsolving skills training for vulnerable families of children with persistent asthma: report of a randomized trial on healthrelated quality of life outcomes. Journal of Pediatric Psychology 2010;35(10):1133-43.

\section{Stark 2005 \{published data only\}}

Stark LJ, Davis AM, Janicke DM, Mackner LM, Hommel KA, Bean JA, et al. A randomized clinical trial of dietary calcium to improve bone accretion in children with juvenile rheumatoid arthritis. Pediatrics 2006;148(4):501-7. [DOI: 10.1016/ jpeds.2005.11.043]

* Stark LJ, Janicke D, McGrath AM, Mackner L, Hommel KA, Lovell D. Prevention of osteoporosis: a randomized clinical trial to increase calcium intake in children with juvenile rheumatoid arthritis. Journal of Pediatric Psychology 2005;30(5):377-86.

\section{Stehl 2009 \{published data only\}}

Stehl ML, Kazak AE, Alderfer MA, Rodriguez A, Hwang WT, Pai AL, et al. Conducting a randomized clinical trial of a psychological intervention for parents/caregivers of children with cancer shortly after diagnosis. Journal of Pediatric Psychology 2009;34(8):803-16.

\section{Tsitsi 2017 \{published data only\}}

Tsitsi T, Andreas C, Evridiki P, Raftopoulos V. Effectiveness of a relaxation intervention (progressive muscle relaxation and guided imagery techniques) to reduce anxiety and improve mood of parents of hospitalized children with malignancies: a randomized controlled trial in Republic of Cyprus and Greece. European Journal of Oncology Nursing 2017;26:9-18.

\section{Wade 2006a \{published data only\}}

Wade SL, Carey J, Wolfe CR. An online family intervention to reduce parental distress following pediatric brain injury. Journal of Consulting and Clinical Psychology 2006;74(3):445-54

* Wade SL, Carey J, Wolfe CR. The efficacy of an online cognitive-behavioral family intervention in improving child behavior and social competence following pediatric brain injury. Rehabilitation Psychology 2006;51(3):179-89.

\section{Wade 2014 \{published data only\}}

Narad M, Minich N, Gerry-Taylor H, Kirkwood M, MainesBrown T, Stancin T, et al. Effects of a web-based intervention on family functioning following pediatric traumatic brain injury. The Journal of Development and Behavioral Pediatrics 2015;36(9):700-7.

Petranovich CL, Wade SL, Gerry-Taylor H, Cassedy A, Stancin T, Kirkwood MW, et al. Long-term caregiver mental health outcomes following a predominately online intervention for adolescents with complicated mild to severe traumatic brain injury. Journal of Pediatric Psychology 2015;40(7):680-8.

Tlustos SJ, Kirkwood MW, Gerry-Taylor H, Stancin T, Brown TM, Wade SL. A randomized problem-solving trial for adolescent brain injury: changes in social competence. Rehabilitation Psychology 2016;61(4):347-57.

Wade SL, Gerry-Taylor H, Cassedy A, Zhang N, Kirkwood MW, Brown TM, et al. Long-term behavioral outcomes after a randomized, clinical trial of counselor-assisted problem solving for adolescents with complicated mild-to-severe traumatic brain injury. Journal of Neurotrauma 2015;32:967-75.

Wade SL, Kurowski BG, Kirkwood MW, Zhang N, Cassedy A, Brown TM, et al. Online problem-solving therapy after traumatic brain injury: a randomized controlled trial. Pediatrics 2015;135(2):487-95.

* Wade SL, Stancin T, Kirkwood M, Maines-Brown T, McMullen KM, Taylor HG. Counselor-assisted problem solving (CAPS) improves behavioral outcomes in older adolescents with complicated mild to severe TBI. Journal of Head Trauma Rehabilitation 2014;29(3):198-207.

\section{Wade 2017 \{published data only\}}

Wade SL, Cassedy AE, Shultz EL, Zang H, Zhang N, Kirkwood MW, et al. Randomized clinical trial of online parent training for behavior problems after early brain injury. Journal of the American Academy of Child and Adolescent Psychiatry 2017;56(11):930-9.

\section{Westrupp 2015 \{published data only\}}

Westrupp EM, Northam E, Lee KJ, Scratch SE, Cameron F. Reducing and preventing internalizing and externalizing behavior problems in children with type 1 diabetes: a randomized controlled trial of the Triple P-Positive Parenting Program. Pediatric Diabetes 2014;16:554-63.

\section{Wysocki 1999 \{published data only\}}

Wysocki T, Greco P, Harris MA, Bubb J, White NH. Behavior therapy for families of adolescents with diabetes: maintenance of treatment effects. Diabetes Care 2001;24(3):441-6.

Wysocki T, Harris MA, Greco P, Bubb J, Danda CE, Harvey LM, et al. Randomized, controlled trial of behavior therapy for families of adolescents with insulin-dependent diabetes mellitus. Journal of Pediatric Psychology 2000;25(1):23-33.

* Wysocki T, Miller KM, Greco P, Harris MA, Harvey LM, Taylor A, et al. Behavior therapy for families of adolescents with diabetes: effects on directly observed family interactions. Behavior Therapy 1999;30:507-25. 
Wysocki 2006 \{published data only\}

Wysocki T, Harris MA, Buckloh LM, Mertlich D, Lochrie AS, Mauras N, et al. Randomized trial of behavioral family systems therapy for diabetes: maintenance of effects on diabetes outcomes in adolescents. Diabetes Care 2007;30(3):555-60.

* Wysocki T, Harris MA, Buckloh LM, Mertlich D, Lochrie AS, Taylor A, et al. Effects of behavioral family systems therapy for diabetes on adolescents' family relationships, treatment adherence, and metabolic control. Journal of Pediatric Psychology 2006;31(9):928-38.

Wysocki T, Harris MA, Buckloh LM, Mertlich D, Lochrie AS, Taylor A, et al. Randomized, controlled trial of behavioral family systems therapy for diabetes: maintenance and generalization of effects on parent-adolescent communication. Behavior Therapy 2008;39:33-46.

\section{Yeh 2016 \{published data only\}}

Yeh HY, Ma WF, Huang JL, Hsueh KC, Chiang LC. Evaluating the effectiveness of a family empowerment program on family function and pulmonary function of children with asthma: a randomized control trial. International Journal of Nursing Studies 2016;60:133-44.

\section{References to studies excluded from this review}

\section{Aleman 1992 \{published data only\}}

Aleman Mendez S, Palacios AS. An integrated approach to the psychological features of the asthmatic child [Un adordaje integral de los aspectos psicologicos del niño asmatico]. Allergologia et Immunopathologia 1992;20(6):240-5.

\section{Allen 1998 \{published data only\}}

Allen KD, Shriver MD. Role of parent-mediated pain behavior management strategies in biofeedback treatment of childhood migraines. Behaviour Therapy 1998;29:477-90.

\section{Anderson 1999 \{published data only\}}

Anderson BJ, Ho J, Brackett J, Laffel LMB. An office-based intervention to maintain parent-adolescent teamwork in diabetes management: impact on parent involvement, family conflict, and subsequent glycemic control. Diabetes Care 1999;22(7):713-21.

\section{Antonini 2014 \{published data only\}}

Antonini TN, Raj SP, Oberjohn KS, Cassedy A, Makoroff KL, Fouladi $\mathrm{M}$, et al. Pilot randomized trial of an online parenting skills program for pediatric traumatic brain injury: improvements in parenting and child behavior. Behavior Therapy 2014;45(4):455-68.

\section{Barakat 2010 \{published data only\}}

Barakat LP, Schwartz LA, Salaom KS, Radcliffe J. A family-based randomized controlled trial of pain intervention for adolescents with sickle cell disease. Journal of Pediatric Hematology Oncology 2010;32(7):540-7.

\section{Barrera 2018a \{published data only\}}

Barrera M, Atenagu EG, Sung L, Bartels U, Schulte F, Chung J, et al. A randomized control intervention trial to improve social skills and quality of life in pediatric brain tumor survivors. Psycho-Oncology 2018;27(1):91-8. [DOI: 10.1002/pon.4385]

Barrera 2018b \{published data only\}

Barrera M, Atenafu EG, Schulte F, Nathan PC, Hancock K, Saleh A. A randomized controlled trial of a group intervention for siblings of children with cancer: changes in symptoms of anxiety in siblings of caregivers. Psycho-oncology 2018;27(6):1629-34.

Barry 1997 \{published data only\}

Barry J, Von Baeyer CL. Brief cognitive-behavioral group treatment for child's headache. Clinical Journal of Pain 1997;13(3):215-20.

Bellin 2013 \{published data only\}

Bellin MH, Kub J, Frick KD, Bollinger ME, Tsoukleris M, Walker J, et al. Stress and quality of life in caregivers of inner-city minority children with poorly controlled asthma. Journal of Pediatric Health Care 2013;27(2):127-34.

\section{Betancourt 2004 \{published data only\}}

Betancourt GP, Gutierrez de Pineres Scarpetta C. Psychological intervention pre-postsurgical program for cardiovascular pediatric patients. Saludarte 2004;3(11):19-34.

\section{Borhani 2011 \{published data only\}}

Borhani F, Najafi MK, Rabori ED, Sabzevari S. The effect of family-centred empowerment model on quality of life of schoolaged children with thalassemia major. Iranian Journal of Nursing Midwifery Research 2011;16(4):292-8.

\section{Braga 2005 \{published data only\}}

Braga L, Da Paz A Jr, Ylvisaker M. Direct clinician-delivered versus indirect family-supported rehabilitation of children with traumatic brain injury: a randomized controlled trial. Brain Injury 2005;19(10):819-31.

\section{Brown 2014 \{published data only\}}

Brown FL, Whittingham K, Boyd RN, McKinlay L, Sofronoff K. Does Stepping Stones Triple P plus Acceptance and Commitment Therapy improve parent, couple, and family adjustment following paediatric acquired brain injury? A randomised controlled trial. Behavior and Research Therapy 2015;73:58-66.

* Brown FL, Whittingham K, Boyd RN, McKinlay L, Sofronoff K. Improving child and parenting outcomes following paediatric acquired brain injury: a randomised controlled trial of Stepping Stones Triple P plus Acceptance and Commitment Therapy. Journal of Child Psychology and Psychiatry 2014;55(10):1172-83.

\section{Bruzzese 2008 \{published data only\}}

Bruzzese J, Unikel L, Gallagher R, Evans D, Colland V. Feasilbility and impact of a school-based intervention for families of urban adolescents with asthma: results from a randomized pilot trial. Family Process 2008;47(1):95-113.

\section{Burke 1997 \{published data only\}}

Burke SO, Handley-Derry MH, Costello EA, Kauffmann E, Dillon MC. Stress-point intervention for parents of repeatedly 
hospitalized children with chronic conditions. Research in Nursing \& Health 1997;20(6):475-85.

\section{Burke 2001 \{published data only\}}

Burke SO, Harrison MB, Kauffmann E, Wong C. Effects of stresspoint intervention with families of repeatedly hospitalized children. Journal of Family Nursing 2001;7(2):128-58.

\section{Cakan 2007 \{published data only\}}

Cakan N, Ellis DA, Templin T, Frey M, Naar-King S. The effects of W8 status on treatment outcomes in a randomized clinical trial of multisystemic therapy for adolescents with type 1 diabetes and chronically poor metabolic control. Pediatric Diabetes 2007;8(4):206-13.

\section{Canino 2008 \{published data only\}}

Canino G, Vila D, Normand ST, Acosta-Perez E, Ramirez R, Garcia P, et al. Reducing asthma health disparities in poor Puerto Rican children: the effectiveness of a culturally tailored family intervention. Journal of Allergy \& Clinical Immunology 2008;121(3):665-70.

\section{Canino 2016 \{published data only\}}

Canino G, Shrout PE, Vila D, Ramírez R, Rand C. Effectiveness of a multi-level asthma intervention in increasing controller medication use: a randomized control trial. Journal of Asthma 2016;53(3):301-10.

\section{Carey 2008 \{published data only\}}

Carey JC, Wade SL, Wolfe CR. Lessons learned: the effect of prior technology use on web-based interventions. Cyber Psychology \& Behavior 2008;11(2):188-95.

\section{Celano 2012 \{published data only\}}

Celano MP, Holsey CN, Kobrynski LJ. Home-based family intervention for low-income children with asthma: a randomized controlled pilot study. Journal of Family Psychology 2012;26(2):171-8.

\section{Cernvall 2015 \{published data only\}}

Cernvall M, Carlbring P, Ljungman L, Ljungman G, von Essen L. Internet-based guided self-help for parents of children on cancer treatment: a randomized controlled trial. PsychoOncology 2015;24:1152-8.

\section{Chen 2013 \{published data only\}}

Chen SH, Huang JL, Yeh KW, Tsai YF. Interactive support interventions for caregivers of asthmatic children. Journal of Asthma 2013;50(6):649-57.

\section{Chernoff 2002 \{published data only\}}

Chernoff RG, Ireys HT, DeVet KA, Kim YJ. A randomized, controlled trial of a community-based support program for families of children with chronic illness: pediatric outcomes. Archives of Pediatrics and Adolescent Medicine 2002;156(6):533-9.

\section{Chiang 2009 \{published data only\}}

Chiang L, Ma W, Huang J, Tseng L, Hsueh K. Effect of relaxationbreathing training on anxiety and asthma signs/symptoms of children with moderate-to-severe asthma: a randomized controlled trial. International Journal of Nursing Studies 2009;46(8):1061-70.

\section{Christie 2016 \{published data only\}}

Christie D, Thompson R, Sawtell M, Allen E, Cairns J, Smith F, et al. Effectiveness of a structured educational intervention using psychological delivery methods in children and adolescents with poorly controlled type 1 diabetes: a cluster-randomized controlled trial of the CASCADE intervention. BMJ Open Diabetes Research and Care 2016;4(1):1. [DOI: 10.1136/ bmjdrc-2015-000165]

\section{Churchill 2018 \{published data only\}}

Churchill SS, Kieckhefer GM. One year follow-up of outcomes from the RCT of the building on family strengths program. Maternal and Child Health Journal 2018;22(6):913-21.

\section{Connelly 2006 \{published data only\}}

Connelly M, Rapoff MA, Thompson N, Connelly W. Headstrong: a pilot study of a CD-ROM intervention for recurrent pediatric headache. Journal of Pediatric Psychology 2006;31(7):737-47.

\section{Duarte 2006 \{published data only\}}

Duarte MA, Penna FJ, Andrade EM, Cancela CS, Neto JC, Barbosa TF. Treatment of nonorganic recurrent abdominal pain: cognitive-behavioral family intervention. Journal of Pediatric Gastroenterology and Nutrition 2006;43(1):59-64.

\section{Ellis 2004 \{published data only\}}

Ellis DA, Naar-King S, Frey M, Templin T, Rowland M, Greger N. Use of multisystemic therapy to improve regimen adherence among adolescents with type 1 diabetes in poor metabolic control: a pilot investigation. Journal of Clinical Psychology in Medical Settings 2004;11(4):315-24.

Ellis 2007 \{published data only\}

Ellis DA, Naar-King S, Templin T, Frey MA, Cunningham PB. Improving health outcomes among youth with poorly controlled type 1 diabetes: the role of treatment fidelity in a randomized clinical trial of multisystemic therapy. Journal of Family Psychology 2007;21(3):363-71.

\section{Ellis 2008 \{published data only\}}

Ellis D, Naar-King S, Templin T, Frey M, Cunningham P, Sheidow A, et al. Multisystemic therapy for adolescents with poorly controlled type 1 diabetes: reduced diabetic ketoacidosis admissions and related costs over 24 months. Diabetes Care 2008;31(9):1746-7.

\section{Evans 1999 \{published data only\}}

Evans R, Gergen PJ, Mitchell H, Kattan M, Kercsmar C, Crain E, et al. A randomized clinical trial to reduce asthma morbidity among inner-city children: results of the national cooperative inner-city asthma study. Journal of Pediatrics 1999;135(3):332-8.

Fedele 2013 \{published data only\}

Fedele DA, Hullmann SE, Chaffin M, Kenner C, Fisher MJ, Kirk K, et al. Impact of a parent-based interdiscplinary intervention for mothers on adjustment in children newly diagnosed with cancer. Journal of Pediatric Psychology 2013;38(5):531-40. 
Field 1998 \{published data only\}

Field T, Henteleff T, Hernandez-Reif M, Martinez E, Mavunda K, Kuhn C, et al. Children with asthma have improved pulmonary functions after massage therapy. Journal of Pediatrics 1998;132(5):854-8.

\section{Forsander 1995 \{published data only\}}

Forsander G, Persson B, Sundelin J, Berglund E, Snellman K, Hellström R. Metabolic control in children with insulindependent diabetes mellitus $5 y$ after diagnosis. Early detection of patients at risk for poor metabolic control. Acta Paediatrica 1998;87(8):857-64.

* Forsander G. Family attitudes to different management regimens in diabetes mellitus. Practical Diabetes International 1995;12(2):80-5.

Forsander GA, Sundelin J, Persson B. Influence of the initial management regimen and family social situation on glycemic control and medical care in children with type I diabetes mellitus. Acta Paediatrica 2000;89(12):1462-8.

Forsander GA, Sundelin J. Comparison of two therapeutic regimes for diabetes-stricken children. Social and mental resources of the family are often crucial for the prognosis [Två behandlingsregimer vid diabetesdebut hos barn jämförda: Familjens sociala och mentalaresurser avgör ofta prognosen]. Lakartidningen 2001;98(48):5484-9.

Sundelin JG, Forsander G, Mattson SE. Family-oriented support at the onset of diabetes mellitus: a comparison of two group conditions during 2 years following diagnosis. Acta Paediatrica 1996;85(1):49-55.

\section{Forsander 2003 \{published data only\}}

Forsander G, Malmodin B, Eklund C, Persson B. Relationship between dietary intake in children with diabetes mellitus type I, their management at diagnosis, social factors, anthropometry and glycaemic control. Scandinavian Journal of Nutrition/ Naringsforskning 2003;47(2):75-84.

\section{Garbutt 2010 \{published data only\}}

Garbutt JM, Banister C, Highstein G, Sterkel R, Epstein J, Bruns J, et al. Telephone coaching for parents of children with asthma: impact and lessons learned. Archives of Pediatrics and Adolescent Medicine 2010;164(7):625-30.

\section{Gerber 2010 \{published data only\}}

* Gerber W, Petermann F, Gerber-von Müller G, Dollwet M, Darabaneanu S, Niederberger U, et al. MIPAS-family-evaluation of a new multi-modal behavioral training program for pediatric headaches: clinical effects and the impact on quality of life. Journal of Headache Pain 2010;11(3):215-25.

Gerber WD, Muller GG, Petermann U, Niederberger U, Petermann F. Do behavioral medicine approaches have an effect on the quality of life and everyday competence of children suffering from chronic headaches? [Verbessern verhaltensmedizinische behandlungsstrategien die lebensqualitat bei kindern mit chronischen kopfschmerzen?]. Zeitschrift fur Klinische Psychologie und Psychotherapie 2009;38(4):231-9.
Gerber WD, Petermann F, Müller G, Niederberger U, Rentmeister B, Siniatchkin M, et al. MIPAS-family: development and evaluation of a behavioural medicine programme for the treatment of chronic paediatric headaches. Verhaltenstherapie 2008;18(4):247-55.

Giallo 2008 \{published data only\}

Giallo R, Gavidia-Payne S. Evaluation of a family-based intervention for siblings of children with a disability or chronic illness. Australian e-Journal for the Advancement of Mental Health 2008;7(2):1-13.

Glang 2007 \{published data only\}

Glang A, McLaughlin K, Schroeder, S. Using interactive multimedia to teach parent advocacy skills: an exploratory study. Journal of Head Trauma Rehabilitation 2007;22(3):196-203.

\section{Grey 2011 \{published data only\}}

Grey M, Jaser SS, Whittemore R, Jeon S, Lindemann E. Coping skills training for parents of children with type 1 diabetes. Nursing Research 2011;60(3):173-81.

\section{Groß 2013 \{published data only\}}

Groß M, Warschburger P. Chronic abdominal pain: psychosocial strain and treatment-associated changes in coping. Verhaltenstherapie 2013;23:80-9.

* Groß M, Warschburger P. Evaluation of a cognitivebehavioural pain management program for children with chronic abdominal pain: a randomized controlled study. International Journal of Behavioral Medicine 2013;20:434-43.

\section{Gulewitsch 2012 \{published data only\}}

Gulewitsch MD, Schauer JS, Hautzinger M, Schlarb AA. Therapy of functional stomach ache in children. Concept, acceptance and first pilot results of a hypnotherapeutic- behavioral brief intervention [Therapie funktioneller Bauchschmerzenbei KindernKonzept, Akzeptanz und erste Pilotergebnisse einer hypnotherapeutisch-behavioralen Kurzintervention]. Der Schmerz 2012;26(2):160-7.

\section{Gulewitsch 2013 \{published data only\}}

Gulewitsch MD, Müller J, Hautzinger M, Schlarb AA. Brief hypnotherapeutic-behavioural intervention for functional abdominal pain and irritable bowel syndrome in childhood: a randomized controlled trial. European Journal of Pediatrics 2013;172(8):1043-51.

\section{Gustafsson 1986 \{published data only\}}

Gustafsson PA, Kjellman M, Cederblad M. Family therapy in the treatment of severe childhood asthma. Journal of Psychosomatic Research 1986;30(3):369-74.

\section{Halterman 2014 \{published data only\}}

Halterman JS, Fagno M, Tremblay PJ, Fisher SG, Wang H, Rand C, et al. Prompting asthma intervention in Rochesteruniting parents and providers (PAIR-UP) a randomized trial. JAMA 2014;168(10):10. [DOI: 10.1001/jamapediatrics.2014.1983] 
Harris 2001 \{published data only\}

Harris MA, Greco P, Wysocki T, White TH. Family therapy with adolescents with diabetes: a litmus test for clinically meaningful change. Families, Systems \& Health 2001;19:159-68.

\section{Haus 1976 \{published data only\}}

Haus BF, Thompson S. The effect of nursing intervention on a program of behavior modification by parents in the home. Journal of Psychiatric Nursing and Mental Health Services 1976;14(8):9-16.

\section{Hernandez 1998 \{published data only\}}

Hernandez NE, Kolb S. Effects of relaxation on anxiety in primary caregivers of chronically ill children. Pediatric Nursing 1998;24(1):51-6.

\section{Hicks 2006 \{published data only\}}

Hicks CL, Von Baeyer CL, McGrath PJ. Online psychological treatment for pediatric recurrent pain: a randomized evaluation. Journal of Pediatric Psychology 2006;31(7):724-36.

\section{Hommel 2012 \{published data only\}}

Hommel KA, Hente EA, Odell S, Herzer M, Ingerski LM, Guilfoyle SM, et al. Evaluation of a group-based behavioral intervention to promote adherence in adolescents with inflammatory bowel disease. European Journal of Gastroenterology and Hepatology 2012;24(1):64-9.

\section{Hovell 1994 \{published data only\}}

Hovell MF, Meltzer SB, Zakarian JM, Wahlgren DR, Emerson JA, Hofstetter CR, et al. Reduction of environmental tobacco smoke exposure among asthmatic children: a controlled trial. Chest 1994;106(2):440-6.

\section{Humphreys 2000 \{published data only\}}

Humphreys PA, Gevirtz RN. Treatment of recurrent abdominal pain: components analysis of 4 treatment protocols. Journal of Pediatric Gastroenterology and Nutrition 2000;31(1):47-51.

Ireys 1996 \{published data only\}

Ireys HT, Sills EM, Kolodner KB, Walsh BB. A social support intervention for parents of children with juvenile rheumatoid arthritis: results of a randomized trial. Journal of Pediatric Psychology 1996;21(5):633-41.

Ireys 2001 \{published data only\}

Ireys HT, Chernoff R, DeVet KA, Kim Y. Maternal outcomes of a randomized controlled trial of a community-based support program for families of children with chronic illnesses. Archives of Pediatrics and Adolescent Medicine 2001;155(7):771-7.

\section{Jay 1990 \{published data only\}}

Jay SM, Elliott $\mathrm{CH}$. A stress inoculation program for parents whose children are undergoing painful medical procedures. Journal of Consulting and Clinical Psychology 1990;58(6):799-804.

\section{Johnson 1987 \{published data only\}}

Johnson MR, Whitt JK, Martin B. The effect of fantasy facilitation of anxiety in chronically ill and healthy children. Journal of Pediatric Psychology 1987;12(2):273-84.
Kamps 2008 \{published data only\}

Kamps JL, Rapoff MA, Roberts MC, Varela RE, Barnard M, Olson $\mathrm{N}$. Improving adherence to inhaled corticosteroids in children with asthma: a pilot of a randomized clinical trial. Children's Health Care 2008;37(4):261-77.

Kashikar-Zuck 2005 \{published data only\}

Kashikar-Zuck S, Swain N, Jones BA, Graham TB. Efficacy of cognitive-behavioral intervention for juvenile primary fibromyalgia syndrome. Journal of Rheumatology 2005;32(8):1594-602.

\section{Kaslow 2000 \{published data only\}}

Kaslow NJ, Collins MH, Rashid FL, Baskin ML, Griffith JR, Hollins $L$, et al. The efficacy of a pilot family psychoeducational intervention for pediatric sickle cell disease. Families, Systems, \& Health 2000;18(4):381-404.

Katz 2014 \{published data only\}

Katz ML, Volkening LK, Butler DA, Anderson BJ, Laffel LM. Family-based psychoeducation and care ambassador intervention to improve glycemic control in youth with type 1 diabetes: a randomized trial. Pediatric Diabetes 2014;15(2):142-50.

\section{Kazak 1996 \{published data only\}}

Kazak AE, Penati B, Boyer BA, Himelstein B, Brophy P, Waibel K, et al. A randomized controlled prospective outcome study of a psychological and pharmacological intervention protocol for procedural distress in pediatric leukemia. Journal of Pediatric Psychology 1996;21(5):615-31.

\section{Kazak 2005 \{published data only\}}

Kazak AE, Simms S, Alderfer MA, Rourke MT, Crump T, McClure K, et al. Feasibility and preliminary outcomes from a pilot study of a brief psychological intervention for families of children newly diagnosed with cancer. Journal of Pediatric Psychology 2005;30(8):644-55.

\section{Ketchen 2006 \{published data only\}}

Ketchen B, Hazzard A, Lassiter S, Barber N, Armistead L, Mentz R, et al. STARBRIGHT world: a pilot study of a homebased sickle cell psychoeducational intervention. Children's Health Care 2006;35(4):321-38.

\section{Klinnert 2005 \{published data only\}}

Klinnert MD, Liu AH, Pearson MR, Ellison M, Budhiraja N, Robinson JL. Short-term impact of a randomized multifaceted intervention for wheezing infants in low-income families. Archives of Pediatric Adolescent Medicine 2005;159(1):75-82.

\section{Klinnert 2007 \{published data only\}}

Klinnert MD, Liu AH, Pearson MR, Tong S, Strand M, Luckow A, et al. Outcome of a randomized multifaceted intervention with low-income families of wheezing infants. Archives of Pediatrics and Adolescent Medicine 2007;161(8):783-90.

\section{Kroner-Herwig 1998 \{published data only\}}

Kroner-Herwig B, Mohn U, Pothmann R. Comparison of biofeedback and relaxation in the treatment of pediatric 
headache and the influence of parent involvement on outcome. Applied Psychophysiology and Biofeedback 1998;23(3):143-57.

\section{Kupfer 2010 \{published data only\}}

Kupfer J, Gieler U, Diepgen TL, Fartasch M, Lob-Corzilius T, Ring J, et al. Structured education program improves the coping with atopic dermatitis in children and their parents - a multicenter, randomized controlled trial. Journal of Psychosomatic Research 2010;68(4):353-8.

Kurowski 2013 \{published data only\}

* Kurowski BG, Wade SL, Kirkwood MW, Brown TM, Stancin T, Taylor G. Online problem-solving therapy for executive dysfunction after child traumatic brain injury. Pediatrics 2013;132(1):158-65.

Kurowski BG, Wade SL, Kirkwood MW, Brown TM, Stancin T, Taylor HG. Long-term benefits of an early online problem solving intervention for executive dysfunction after traumatic brain injury in children. JAMA Pediatrics 2014;168(6):523-31.

Wade SL, Karver CL, Taylor GH, Cassedy A, Stancin T, Kirkwood MW, et al. Counselor-assisted problem solving improves caregiver efficacy following adolescent brain injury. Rehabilitation Psychology 2014;59(1):1-9.

Lasecki 2008 \{published data only\}

Lasecki K, Olympia D, Clark E, Jenson W, Heathfield LT. Using behavioral interventions to assist children with type 1 diabetes manage blood glucose levels. School Psychology Quarterly 2008;23(3):389-406.

Lask 1979 \{published data only\}

Lask B, Matthew D. Childhood asthma. A controlled trial of family psychotherapy. Archives of Disease in Childhood 1979;54(2):116-9.

\section{Lehmkuhl 2010 \{published data only\}}

Lehmkuhl HD, Storch EA, Cammarata C, Meyer K, Rahman O, Silverstein J, et al. Telehealth behavior therapy for the management of type 1 diabetes in adolescents. Journal of Diabetes Science and Technology 2010;4(1):199-208.

\section{Logan 1997 \{published data only\}}

Logan S. Emotionally focused therapy improves marital adjustment in parents of children with chronically ill children. Child: Care, Health and Development 1997;23(6):479-80.

\section{Lyon 2013 \{published data only\}}

Lyon ME, Jacobs S, Briggs L, Cheng YI, Wang J. A longitudinal, randomized, controlled trial of advance care planning for teens with cancer: anxiety, depression, quality of life, advance directives, spirituality. Journal of Adolescent Health 2014;54(6):710-7.

* Lyon ME, Jacobs S, Briggs L, Cheng YI, Wang J. Familycentered advance care planning for teens with cancer. JAMA Pediatrics 2013;167(5):460-7.

\section{Manne 2016 \{published data only\}}

Manne S, Mee L, Bartell A, Sands S, Kashy DA. A randomized clinical trial of a parent-focused social-cognitive processing intervention for caregivers of children undergoing hematopoetic stem cell transplantation. Journal of Consulting and Clinical Psychology 2016;84(5):389-401.

Marsland 2013 \{published data only\}

Marsland AL, Long KA, Howe C, Thompson, AL, Tersak J, Ewing LW. A pilot trial of a stress management intervention for primary caregivers of children newly diagnosed with cancer: preliminary evidence that perceived social support moderates the psychosocial benefit of intervention. Journal of Pediatric Psychology 2013;38(4):449-61.

Mendez 1997 \{published data only\}

Mendez FJ, Belendez M. Effects of a behavioral intervention on treatment adherence and stress management in adolescents with IDDM. Diabetes Care 1997;20(9):1370-5.

\section{Mortenson 2016 \{published data only\}}

Mortenson P, Singhal A, Hengel AR, Purtzki J. Impact of early follow-up intervention on parent-reported postconcussion pediatric symptoms: a feasibility study. Journal of Head Trauma Rehabilitation 2016;31(6):E23-32.

Mowla 2017 \{published data only\}

Mowla F, Khanjari S, Inanlou M. Contribution of Benson's relaxation technique and brief psycho-educational intervention on quality of life of primary caregivers of Iranian children with chronic diseases. Journal of Pediatric Nursing 2017;35:65-71.

\section{Mullins 2012 \{published data only\}}

Mullins LL, Fedele DA, Chaffin M, Hullmann SE, Kenner C, Eddington AR, et al. A clinic-based interdisciplinary intervention for mothers of children newly diagnosed with cancer: a pilot study. Journal of Pediatric Pscyhology 2012;37(10):1104-15.

\section{Murphy 2012 \{published data only\}}

Murphy HR, Wadham C, Hassler-Hurst J, Rayman G, Skinner TC. Randomized trial of a diabetes self-management education and family teamwork intervention in adolescents with type 1 diabetes. Diabetic Medicine 2012;29(8):249-53.

\section{Nelson 2011 \{published data only\}}

Nelson KA, Highstein GR, Garbutt J, Trinkaus K, Fisher E, Smith SR, et al. A randomized controlled trial of parental asthma coaching to improve outcomes among urban minority children. Archives of Pediatric Adolescent Medicine 2011;165(6):520-6.

\section{Ng 2008 \{published data only\}}

Ng SM, Li AM, Lou VW, Tso IF, Wan PY, Chan DF. Incorporating family therapy into asthma group intervention: a randomized waitlist-controlled trial. Family Process 2008;47(1):115-30.

\section{Niebel 2000 \{published data only\}}

Niebel G, Kallweit C, Lange I, Fölster-Holst R. Direct versus video-aided parent education in atopic eczema in childhood as a supplement to specialty physician treatment. A controlled pilot study [Direkte versus videover-mittelte elternschulung bei atopishchem ekzem in kinderslater als erganzung facharztlicher behandlung: eine kontrollierte pilotstudie]. Hautarzt 2000;51(6):401-11. 
Olivares 1997 \{published data only\}

Olivares J, Mendez FX, Ros M, Bermejo RM. Effects of a training program for parents with diabetic children with obstacles to comply with therapy [El cuidado de la diabetes mellitus insulino-dependiente: Efectos de un programa de modificacion de conducta en padres]. Psicologia Conductual 1997;5(2):219-35.

\section{Pérez 1999 \{published data only\}}

Pérez MG, Feldman L, Caballero F. Effects of a self-management educational program for the control of childhood asthma. Patient Education and Counseling 1999;36(1):47-55.

\section{Rapoff 2014 \{published data only\}}

Rapoff MA, Connelly M, Bickel JL, Powers SW, Hershey AD, Allen JR, et al. Headstrong intervention for pediatric migraine headache: a randomized clinical trial. The Journal of Headache and Pain 2014;15(12):12. [DOI: 10.1186/1129-2377-15-12]

\section{Rasoli 2008 \{published data only\}}

Rasoli R, Etemadi A, Shafidabadi A, Delavar A. Comparing effectiveness of individual and marital emotionally focused intervention based on decreasing relationship distress of couples with chronically ill children. Journal of Family Research 2008;3(3):683-96.

\section{Rice 2015 \{published data only\}}

Rice JL, Matlack KM, Simmons MD, Steinfeld J, Laws MA, Dovey ME. LEAP: a randomized-controlled trial of a layeducator inpatient asthma education program. Patient Education and Counseling 2015;98:1585-91.

\section{Sanders 1989 \{published data only\}}

Sanders MR, Rebgetz M, Morrison M, Bor W, Gordon A, Dadds M, et al. Cognitive-behavioral treatment of recurrent nonspecific abdominal pain in children: an analysis of generalization, maintenance, and side effects. Journal of Consulting and Clinical Psychology 1989;57(2):294-300.

\section{Sanders 1996 \{published data only\}}

Sanders MR, Cleghorn G, Shepherd RW, Patrick M. Predictors of clinical improvement in children with recurrent abdominal pain. Behavioural and Cognitive Psychotherapy 1996;24:27-38.

\section{Saßman 2012 \{published data only\}}

Saßmann H, Hair M, Danne T, Lange K. Reducing stress and supporting positive relations in families of young children with type 1 diabetes: a randomized controlled study for evaluating the effects of the DELFIN parenting program. BMC Pediatrics 2012;12(152):2-11.

\section{Satin 1989 \{published data only\}}

Satin W, La Greca AM, Zigo MA, Skyler JS. Diabetes in adolescence: effects of multifamily group intervention and parent simulation of diabetes. Journal of Pediatric Psychology 1989;14(2):259-75.

\section{Scholten 2011 \{published data only\}}

Scholten L, Willemen AM, Grootenhuis MA, Maurice-Stam H, Schuengel C, Last BF. A cognitive behavioral based group intervention for children with a chronic illness and their parents: a multicentre randomized controlled trial. $B M C$ Pediatrics 2011;11(65):1-8.

Scholten 2015 \{published data only\}

Scholten L, Willemen AM, Napoleone E, Maurice-Stam H, Last BF, Van Dijk-Lokkart EM, et al. Moderators of the efficacy of a psychosocial group intervention for children with chronic illness and their parents: what works for whom? Journal of Pediatric Psychology 2015;40(2):214-27.

Shekarabi-Ahari 2012 \{published data only\}

Shekarabi-Ahari G, Younesi J, Borjali A, Ansari-Damavandi S. The effectiveness of group hope therapy on hope and depression of mothers with children suffering from cancer in Tehran. Iranian Journal of Cancer Prevention 2012;5(4):183-8.

Sieberg 2011 \{published data only\}

Sieberg CB, Flannery-Schroeder E, Plante W. Children with comorbid recurrent abdominal pain and anxiety disorders: results from a multiple-baseline intervention study. Journal of Child Health Care 2011;15(2):126-39.

Staab 2002 \{published data only\}

Staab D, Van Rueden U, Kehrt R, Erhart M, Wenninger K, Kamtsiuris $\mathrm{P}$, et al. Evaluation of a parental training program for the management of childhood atopic dermatitis. Pediatric Allergy and Immunology 2002;13(2):84-90.

\section{Sullivan-Bolyai 2010 \{published data only\}}

Sullivan-Bolyai S, Bova C, Leung K, Trudeau A, Lee M, Gruppuso P. Social support to empower parents (STEP): an intervention for parents of young children newly diagnosed with type 1 diabetes. Diabetes Educator 2010;36(1):88-97.

\section{Sullivan-Bolyai 2015 \{published data only\}}

Sullivan-Bolyai S, Crawford S, Bova C, Lee M, Quintos JB, Johnson K, et al. PETS-D: impact on diabetes management outcomes. Diabetes Educator 2015;41(5):537-49.

\section{Szczepanski 2010 \{published data only\}}

Szczepanski R, Jaeschke R, Spindler T, Ihorst G, Forster J, ASEV Study Group. Preschoolers' and parents' asthma education trial (P2AET) - a randomized controlled study. European Journal of Pediatrics 2010;169(9):1051-60.

\section{Szigethy 2014 \{published data only\}}

Szigethy E, Bujoreanu SI, Youk AO, Weisz J, Benhayon D, Fairclough D. Randomized efficacy trial of two psychotherapies for depression in youth with inflammatory bowel disease. Journal of the American Acadamy of Child and Adolescent Psychiatry 2014;53(7):726-35.

Tsiouli 2014 \{published data only\}

Tsiouli E, Pavlopoulos V, Alexopoulos EC, Chrousos G, Darviri C. Short-term impact of a stress management and health promotion program on perceived stress, parental stress, health locus of control and cortisol levels in parents of children and adolescents with diabetes type 1: a pilot randomized controlled trial. Explore 2014;10(2):88-98. 
Van der Veek 2013 \{published data only\}

Van der Veek SMC, Derkx BHF, Benninga MA, Boer F, De Haan E. Cognitive behaviour therapy for pediatric functional abdominal pain: a randomized controlled trial. Pediatrics 2013;132(5):1163-72.

\section{Van Dijk-Lokkart 2016 \{published data only\}}

Van Dijk-Lokkart EM, Braam KI, Van Dulmen-den Broeder E, Kaspers GJL, Takken T, Grootenhuis MA, et al. Effects of a combined physical and psychosocial intervention program for childhood cancer patients on quality of life and psychosocial functioning: results of the QLIM randomized clinical trial. Psycho-oncology 2016;25:815-22.

\section{Wade 2006b \{published data only\}}

Wade SL, Michaud L, Brown TM. Putting the pieces together: preliminary efficacy of a family problem-solving intervention for children with traumatic brain injury. Journal of Head Trauma Rehabilitation 2006;21(1):59-67.

Wade 2010 \{published data only\}

Wade SL, Walz NC, Carey J, Williams KM, Cass J, Herren L, et al. A randomized trial of teen online problem solving for improving executive function deficits following pediatric traumatic brain injury. Journal of Head Trauma Rehabilitation 2010;25(6):409-15.

Wade 2011 \{published data only\}

Wade SL, Walz NC, Carey J, McMullen KM, Cass J, Mark E, et al. A randomized trial of teen online problem solving: efficacy in improving caregiver outcomes after brain injury. Health Psychology 2012;31(6):767-76.

* Wade SL, Walz NC, Carey J, McMullen KM, Cass J, Mark E, et al. Effect on behavior problems of teen online problemsolving for adolescent traumatic brain injury. Pediatrics 2011;128(4):e947-53.

Walders 2006 \{published data only\}

Walders N, Kercsmar C, Schluchter M, Redline S, Lester Kirchner H, Drotar D. An interdisciplinary intervention for undertreated pediatric asthma. Chest 2006;129(2):292-9.

Walker 1996 \{published data only\}

Walker JG, Johnson S, Manion I, Cloutier P. Emotionally focused marital intervention for couples with chronically ill children. Journal of Consulting and Clinical Psychology 1996;64(5):1029-36.

\section{Warner 2011 \{published data only\}}

Warner CM, Ludwig K, Sweeney C, Spillane C, Hogan L, Ryan J, et al. Treating persistent distress and anxiety in parents of children with cancer: an initial feasibility trial. Journal of Pediatric Oncology Nursing 2011;28(4):224-30.

\section{Wysocki 1997 \{published data only\}}

Wysocki T, McDonell K, Harris MA, Elder Danda CL, Greco P, Bubb J, et al. Social validity of support group and behavior therapy interventions for families of adolescents with insulindependent diabetes mellitus. Journal of Pediatric Psychology 1997;22(5):635-49.

\section{Additional references}

\section{American Psychological Association 2011}

American Psychological Association. Publication Manual of the American Psychological Association. Washington: American Psychological Association, 2011.

\section{Anie 2012}

Anie KA, Green J. Psychological therapies for sickle cell disease and pain. Cochrane Database of Systematic Reviews 2012, Issue 2. Art. No: CD001916. [DOI: 10.1002/14651858.CD001916.pub2]

\section{Armour 2005}

Armour TA, Norris SL, Jack Jr L, Zhang X, Fisher L. The effectiveness of family interventions in people with diabetes mellitus: a systematic review. Diabetic Medicine 2005;22(10):1295-305.

\section{Bandura 1977}

Bandura A. Social Learning Theory. New Jersey: Prentice-Hall, 1977.

\section{Beck 1979}

Beck AR, Rush AJ, Shaw B, Emery G. Cognitive Therapy of Depression. New York: Guilford Press, 1979.

\section{Bergin1975}

Bergin AE, Suinn RM. Individual psychotherapy and behavior therapy. Annual Review of Psychology 1975;26:509-56.

\section{Bowen 1966}

Bowen, MDM. The use of family theory in clinical practice. Comprehensive Psychiatry 1966;7(5):345-74.

\section{Bronfenbrenner 1979}

Bronfenbreener $\mathrm{U}$. The ecology of human development: experiments and design and nature. Massachusetts: Harvard University, 1979.

\section{Brown 2013}

Brown FL, Whittingham K, Boyd R, Sofronoff K. A systematic review of parenting interventions for traumatic brain injury: child and parent outcomes. Journal of Head Trauma Rehabilitation 2013;28(5):349-60.

\section{Cancer Research UK 2018}

Cancer Research UK. Childhood cancer key stats. www.cancerresearchuk.org/health-professional/cancerstatistics/childrens-cancers (acessed 16 October 2018).

\section{Cohen 1988}

Cohen J. Statistical Power Analysis for the Behavioral Sciences. Hillsdale, New Jersey: Erlbaum, 1988.

Committee on Publication Ethics 2011

Committee on Publication Ethics. Code of conduct and best practice guidelines for journal editors. publicationethics.org/ (accessed 22 March 2012). 


\section{Cousino 2013}

Cousino MK, Hazen RA. Parenting stress among caregivers of children with chronic illness: a systematic review. Journal of Pediatric Psychology 2013;38(8):809-28.

\section{D'Zurilla 1971}

D'Zurilla TJ, Goldfried MR. Problem solving and behavior modification. Journal of Abnormal Psychology 1971;78(1):107-26.

\section{D'Zurilla 1982}

D'Zurilla TJ, Nezu AM. Social problem solving in adults. In: Kendall PC, editors(s). Advances in Cognitive-Behavioral Research and Therapy. New York: Academic Press, 1982:202-74.

\section{D'Zurilla 1999}

D'Zurilla TJ, Nezu AM. Problem-Solving Therapy: A Social Competence Approach to Clinical Intervention. New York: Springer-Verlag, 1999

\section{D'Zurilla 2007}

D'Zurilla TJ, Nezu AM. Problem-Solving Therapy. A Positive Approach to Clinical Intervention. New York: Springer, 2007.

\section{Data Resource Center 2010}

Data Resource Center. National survey of children with special health care needs: current health conditions and functional difficulties. childhealthdata.org/docs/cshcn/conditionsdifficulties-09cshcn_feb-2-2012.pdf (accessed 5 April 2015).

\section{Deeks 2017}

Deeks JJ, Higgins JPT, Altman DG (editors) on behalf of the Cochrane Statistical Methods Group. Chapter 9: Analysing data and undertaking meta-analyses. In: Higgins JPT, Churchill R, Chandler J, Cumpston MS (editors), Cochrane Handbook for Systematic Reviews of Interventions version 5.2.0 (updated June 2017), Cochrane, 2017. Available from www.training.cochrane.org/handbook.

\section{Delamater 2014}

Delamater AM, de Wit M, McDarby V, Malik J, Acerini CL. Psychological care of children and adolescents with type 1 diabetes. Pediatric Diabetes 2014;15:232-44.

\section{Drotar 2010}

Drotar D. Editorial: Guidance for submission and review of multiple publications derived from the same study. Journal of Pediatric Psychology 2010;35(3):225-30.

\section{Ersser 2014}

Ersser SJ, Cowdell F, Latter S, Gardiner E, Flohr C, Thompson AR, et al. Psychological and educational interventions for atopic eczema in children. Cochrane Database of Systematic Reviews 2014, Issue 1. Art. No: CD004054. [DOI: 10.1002/14651858.CD004054.pub3]

\section{Fisher 2014}

Fisher E, Heathcote L, Palermo TM, Williams AC, Lau J, Eccleston C. Systematic review and meta-analysis: psychological therapies for children with chronic pain. Journal of Pediatric Psychology 2014;39(8):1-20.

\section{Fisher 2018}

Fisher E, Law E, Dudeney J, Palermo TM, Steward G, Eccleston C. Psychological therapies for the management of chronic and recurrent pain in children and adolescents. Cochrane Database of Systematic Reviews 2018, Issue 9. Art. No: CD003968. [DOI: 10.1002/14651858.CD003968.pub5]

\section{Gayes 2014}

Gayes LA, Steele RC. A meta-analysis of motivational interviewing interventions for pediatric health behavior change. Journal of Consulting and Clinical Psychology 2014;82(3):521-35.

\section{Haley 1976}

Haley J. Problem Solving Therapy. San Francisco: Jossey-Bass, 1976.

\section{Halfon 2010}

Halfon N, Newackeck PW. Evolving notions of childhood chronic illness. JAMA 2010;303(7):665-6.

\section{Han 2010}

Han JC, Lawlor DA, Kimm SY. Childhood obesity. Lancet 2010;375(9727):1737-48.

\section{Henggeler 2003}

Henggeler SW, Lee T. Multisystemic treatment of serious clinical problems. In: Kazdin E, Weisz JR, editors(s). Evidence-Based Psychotherapies for Children and Adolescents. New York: Guilford Press, 2003:301-24.

\section{Higgins 2011a}

Higgins JP, Deeks JJ, Altman DG (editors). Chapter 16: Special topics in statistics. In: Higgins JPT, Green S (editors), Cochrane Handbook for Systematic Reviews of Interventions Version 5.1.0 (updated March 2011). The Cochrane Collaboration, 2011. Available from www.handbook.cochrane.org.

\section{Higgins 2011b}

Higgins JP, Deeks JJ (editors). Chapter 7: Selecting studies and collecting data. In: Higgins JPT, Green S (editors), Cochrane Handbook for Systematic Reviews of Interventions Version 5.1.0 (updated March 2011). The Cochrane Collaboration, 2011. Available from www.handbook.cochrane.org.

\section{Higgins 2017}

Higgins JP, Altman DG, Sterne JA (editors). Chapter 8: Assessing risk of bias in included studies. In: Higgins JPT, Churchill R, Chandler J, Cumpston MS (editors), Cochrane Handbook for Systematic Reviews of Interventions version 5.2.0 (updated June 2017), Cochrane, 2017. Available from www.training.cochrane.org/handbook.

\section{Law 2014}

Law EF, Fisher E, Fales J, Noel M, Eccleston C. Systematic review and meta-analysis of parent and family-based interventions for children and adolescents with chronic medical conditions. Journal of Pediatric Psychology 2014;39(8):866-86.

\section{Leeman 2016}

Leeman J, Crandell JL, Lee A, Bai J, Sandelowski M, Knafl K. Family functioning and the well-being of children with chronic 
conditions: a meta-analysis. Research in Nursing \& Health 2016;39:229-43.

\section{Lefebvre 2011}

Lefebvre C, Manheimer E, Glanville J. Chapter 6: Searching for studies. In: Higgins JPT, Green S (editors). Cochrane Handbook for Systematic Reviews of Interventions Version 5.1.0 (updated March 2011). The Cochrane Collaboration, 2011. Available from www.handbook.cochrane.org.

\section{Liu 2015}

Liu L, Oza S, Hogan D, Perin J, Rudan I, Lawn JE, et al. Global, regional, and national causes of child mortality in 2000-13, with projections to inform post-2015 priorities: an updated systematic analysis. Lancet 2015;385(9966):430-40.

\section{McBroom 2009}

McBroom LA, Enriquez M. Review of family-centered interventions to enhance the health outcomes of children with type 1 diabetes. Diabetes Educator 2009;35(3):428-38.

\section{Miller 1983}

Miller WR. Motivational interviewing with problem drinkers. Behavioural Psychotherapy 1983;11:147-72.

\section{Miller 2013}

Miller WM, Rollnick S. Motivational Interviewing: Helping People Change. 3 edition. New York: The Guilford Press, 2013.

\section{Minuchin 1974}

Minuchin S. Families \& Family Therapy. Massachusetts: Harvard University, 1974.

\section{Morawska 2015}

Morawska A, Calam R, Fraser J. Parenting interventions for childhood chronic illness: a review and recommendations for intervention design and delivery. Journal of Child Health Care 2015;19(1):5-17.

\section{National Cancer Institute 2018}

National Cancer Institute at the National Institutes of Health. Cancer in children and adolescents. www.cancer.gov/types/ childhood-cancers/child-adolescent-cancers-fact-sheet\#q1 (accessed 16 October 2018).

\section{Nature 2009}

Nature Editorial. Data's shameful neglect. Nature 2009;461(7261):145.

\section{Pai 2006}

Pai AL, Drotar D, Zebracki K, Moore M, Youngstorm E. A metaanalysis of the effects of psychological interventions in pediatric oncology on outcomes of psychological distress and adjustment. Journal of Pediatric Psychology 2006;31(9):978-88.

\section{Pai 2014}

Pai A, McGrady M. Systematic review and meta-analysis of psychological interventions to promote treatment adherence in children, adolescents, and young adults with chronic illness. Journal of Pediatric Psychology 2014;39(8):918-31.

\section{Palermo 2014}

Palermo TM, Valrie CR, Karlson CW. Family and parent influences on pediatric chronic pain: a developmental perspective. American Psychologist 2014;69(2):142-52.

\section{Pinquart 2013}

Pinquart M. Do the parent-child relationship and parenting behaviors differ between families with a child with and without chronic illness? A meta-analysis. Journal of Pediatric Psychology 2013;38(7):708-21.

\section{Popkin 2012}

Popkin BM, Adair LS, Ng SW. Global nutrition transition and the pandemic of obesity in developing countries. Nutrition Reviews 2012; 70(4):256

\section{Price 2016}

Price J, Kassam-Adams N, Alderfer MA, Christofferson J, Kazak AE. Systematic review: a reevaluation and update of the integrative (trajectory) model of pediatric medical traumatic stress. Journal of Pediatric Psychology 2016;41(1):86-97.

\section{Review Manager 2014 [Computer program]}

Nordic Cochrane Centre, The Cochrane Collaboration Review Manager 5 (RevMan 5). Version 5.3. Copenhagen: Nordic Cochrane Centre, The Cochrane Collaboration, 2014.

\section{Robin 1989}

Robin AL, Foster SL. Negotiating Parent Adolescent Conflict: A Behavioral-Family Systems Approach. New York: Guilford, 1989.

\section{Rutten 2015}

Rutten J, Korterink JJ, Venmans L, Benninga MA, Tabbers MM. Nonpharmacologic treatment of functional abdominal pain disorders: a systematic review. Pediatrics 2015;135(3):522.

\section{Sansom-Daly 2012}

Sansom-Daly UM, Peate M, Wakefield CE, Bryant RA, Cohn RJ. A systematic review of psychological interventions for adolescents and young adults living with chronic illness. Health Psychology 2012;31(3):380-93. [DOI: 10.1037/a0025977]

\section{Schulz 2010}

Schulz KF, Altman DG, Moher D, for the CONSORT Group. CONSORT 2010 Statement: updated guidelines for reporting parallel group randomised trials. BMJ 2010;340:698-702.

\section{Schünemann 2011}

Schünemann HJ, Oxman AD, Vist GE, Higgins JP, Deeks JJ, Glasziou P, et al. Chapter 12: Interpreting results and drawing conclusions. In: Higgins JPT, Green S (editors), Cochrane Handbook for Systematic Reviews of Interventions Version 5.1.0 (updated March 2011). The Cochrane Collaboration, 2011. Available from www.handbook.cochrane.org.

\section{Schünemann 2017}

Schünemann HJ, Oxman AD, Higgins JP, Vist GE, Glasziou P, Akl $E$, et al, on behalf of the Cochrane GRADEing Methods Group and the Cochrane Statistical Methods Group. Chapter 11: Completing 'Summary of findings' tables and grading the confidence in or quality of the evidence. In: Higgins JPT, 
Churchill R, Chandler J, Cumpston MS (editors), Cochrane Handbook for Systematic Reviews of Interventions version 5.2.0 (updated June 2017). Cochrane, 2017. Available from www.training.cochrane.org/handbook.

\section{Skinner 1953}

Skinner BF. Chapter 5: Operant behavior. In: Science and Human Behaviour. Toronto: The Macmillan Company, 1953.

\section{Sterne 2017}

Sterne JA, Egger M, Moher D, Boutron I (editors). Chapter 10: Addressing reporting biases. In: Higgins JPT, Churchill R, Chandler J, Cumpston MS (editors), Cochrane Handbook for Systematic Reviews of Interventions version 5.2.0 (updated June 2017), Cochrane, 2017. Available from www.training.cochrane.org/handbook.

\section{Sultan 2016}

Sultan S, Leclair L, Rondeau E, Burns W, Abate C. A systematic review on factors and consequences of parental distress as related to childhood cancer. European Journal of Cancer Care 2016;25:616-37.

\section{Van Cleave 2010}

Van Cleave J, Gortmaker SL, Perrin JM. Dynamics of obesity and chronic health conditions among children and youth. JAMA 2010;303(7):623-30.

\section{Wicherts 2006}

Wicherts JM, Borsboom D, Kats J, Molenaar D. The poor availability of psychological research data for reanalysis. American Psychologist 2006;61(7):726-8.

\section{Wicherts 2011}

Wicherts JM, Bakker M, Molenaar D. Willingness to share research data is related to the strength of the evidence and quality of reporting of statistical results. PLOS ONE 2011;6(11):e26828.

\section{Wiebe 2016}

Weibe DJ, Helgeson V, Berg CA. The social context of managing diabetes across the life span. American Psychologist 2016;71(7):526-38.

CHARACTERISTICS OF STUDIES

Characteristics of included studies [ordered by study ID]

\section{World Association of Medical Editors 2012}

World Association of Medical Editors. Publication ethics policies for medical journals. www.wame.org (accessed 22 March 2012).

\section{Wysocki 2000}

Wysocki T, Harris MA, Greco P, Bubb J, Danda CE, Harvey LM, et al. Randomized, controlled trial of behavior therapy for families of adolescents with insulin-dependent diabetes mellitus. Journal of Pediatric Psychology 2000;25(1):23-33.

\section{Yates 2005}

Yates SL, Morley S, Eccleston C, Williams A. A scale for rating the quality of psychological trials for pain. Pain 2005;117(3):314-25.

\section{References to other published versions of this review \\ Eccleston 2012a}

Eccleston C, Palermo TM, Fisher E, Law E. Psychological interventions for parents of children and adolescents with chronic illness. Cochrane Database of Systematic Reviews 2012, Issue 2. Art. No: CD009660. [DOI: 10.1002/14651858.CD009660]

\section{Eccleston 2012b}

Eccleston C, Palermo TM, Fisher E, Law E. Psychological interventions for parents of children and adolescents with chronic illness. Cochrane Database of Systematic Reviews 2012, Issue 8. Art. No: CD009660. [DOI: 10.1002/14651858.CD009660.pub2]

\section{Eccleston 2015}

Eccleston C, Fisher E, Law E, Bartlett J, Palermo TM. Psychological interventions for parents of children and adolescents with chronic illness. Cochrane Database of Systematic Reviews 2015, Issue 4. Art. No: CD009660. [DOI: 10.1002/14651858.CD009660.pub3]

* Indicates the major publication for the study

Ambrosino 2008

\section{Study characteristics}

Methods RCT. 2 arms. Outcomes assessed at pre-treatment, immediate post-treatment, 3-month, 6-month and 12-month follow-up

Participants End of treatment $n=87$, 3-month follow-up $n=79,6$-month follow-up $n=72,12$-month follow-up $n=72$ Start of treatment $n=87$

Child sex: 34 M, 53 F 
Ambrosino 2008 (Continued)

Parent sex: $5 \mathrm{M}, 82 \mathrm{~F}$

Child age (mean, SD): $9.91 \pm 1.44$ years

Parent age (mean, SD): $40.01 \pm 5.40$ years

Source: hospital

Medical condition: type 1 diabetes

Illness duration (mean): 3.71 years

\begin{tabular}{l} 
Interventions \\
"Group Education" \\
Mode of delivery: face-to-face, group \\
Intervention delivered by: mental health professional \\
Training: not reported \\
Duration of intervention (child): $6 \times 1.5$-h sessions $=9 \mathrm{~h}$ \\
Duration of intervention (parent): $6 \times 1.5$-h sessions $=9 \mathrm{~h}$ \\
\hline
\end{tabular}

Outcomes ${ }^{\star}$ Extracted outcome measures used in the analyses

\section{Child measures}

$\mathrm{HbA} 1 \mathrm{c}^{*}$

Children's Depression Inventory ${ }^{\star}$

Issues in Coping with IDDM - Child scale

Self-Efficacy for Diabetes Scale

Diabetes Quality of Life Scale for Youth

Diabetes Family Behavior Scale

\section{Parent measures}

Center for Epidemiologic Depression Scale*

Family Adaptability and Cohesion Scale*

Issues in Coping with IDDM - Parent scale

Diabetes Responsibility and Conflict scale

Notes

Funding: "This study was supported by grants funded by the National Institute for Nursing Research (National Institute of Health, 1\&2R01NR004009)"

COI: no conflict of interest statement was included in this manuscript

\section{Risk of bias}

\begin{tabular}{lll}
\hline Bias & Authors' judgement & Support for judgement \\
\hline $\begin{array}{ll}\text { Random sequence genera- } \\
\text { tion (selection bias) }\end{array}$ & Low risk & $\begin{array}{l}\text { Quote: "Participants were randomized initially by a sealed envelope technique } \\
\text { and later by computer to either the coping skills therapy of group eduction." } \\
\end{array}$ \\
& \\
& \\
\hline
\end{tabular}


Ambrosino 2008 (Continued)

Allocation concealment Low risk Quote: "Participants were randomized initially by a sealed envelope technique (selection bias) and later by computer to either the coping skills therapy of group eduction."
Comment: probably done

Quote: "All follow-up data were collected by trained research assistants."

Comment: blinding unclear, probably not done

Blinding of outcome as- Unclear risk sessment (detection bias)

All outcomes

Attrition was reported, there were no significant differences between com-

Incomplete outcome data Low risk

(attrition bias)

pleters and non-completers

All outcomes

Selective reporting (re- High risk porting bias)

Pre-specified outcomes identified in the Methods were not fully reported in the Results. The study authors provided these data on request

Bonnert 2017

\section{Study characteristics}

Methods

Participants
RCT. 2 arms. Outcomes assessed at pre-treatment, immediate post-treatment, and 6-month follow-up for the treatment group only

End of treatment $n=95,6$-month follow-up $n=42$ (treatment group only)

Start of treatment $\mathrm{n}=101$

Child sex: 39 M, $62 \mathrm{~F}$

Parent sex: not reported

Child age (mean, SD): $15.54 \pm 1.56$ years

Parent age: not reported

Source: primary care, hospital, community

Medical condition: IBS

Illness duration (mean): 5.12 years

Interventions

"Exposure-based Internet Cognitive Behavioral Therapy"

"Waitlist"

Mode of delivery: remote-internet, individual

Intervention delivered by: internet + clinical psychologists

Training: CBT training

Duration of intervention (child): 10 modules over 10 weeks

Duration of intervention (parent): 5 modules over 10 weeks

Outcomes

${ }^{\star}$ Extracted outcome measures used in the analyses

\section{Child measures}

Gastrointestinal Symptom Rating Scale-IBS 
Faces Pain Scale-revised ${ }^{\star}$

Pain frequency

Pediatric Quality of Life Inventory

Pediatric Quality of Life Inventory-Gastro

IBS-behavioral responses questionnaires

Visceral Sensitivity Index

Perceived Stress Scale

Spence Children's Anxiety Scale*

\section{Parent measures}

Children's Somatization Inventory

Pediatric Quality of Life Inventory

Pediatric Quality of Life Inventory - Gastro

School absences due to pain ${ }^{\star}$

Medication use

Spence Childhood Anxiety Scale - Parent report the Swedish Research Council (521-2013-2846), the Kempe-Carlgren Foundation, the Ruth and Richard Julin Foundation (2012 Juli0048), the Majblomman Foundation, the Ishizu Matsumurais Donation, the Ihre Foundation (SLS-331861), the Ihre fellowship in Gastroenterology, the Gadelius Foundation, the Samariten Foundation, the Värkstadsstift elsen Foundation, the Swedish Research Council for Health, Working life and Welfare (2014-4052), the Swedish Society of Medicine (SLS-331681 SLS-410501), and the Stockholm County Council (ALF). Financial support was also provided through the regional agreement on medical training and clinical research between Stockholm County Council and Karolinska Institutet (20130129). None of the funding bodies had any influence on study design, implementation, data analysis, or interpretation."

COI: "Potential Competing Interests: None"

\section{Risk of bias}

Bias Authors' judgement Support for judgement

Random sequence genera- Low risk tion (selection bias)
Quote: "The randomization was conducted by an independent researcher, who received lists with anonymous study ID numbers and used a random number service (www.random.org) to allocate participants."

Comment: probably done
Low risk (selection bias)
Quote: "The randomization was conducted by an independent researcher, who received lists with anonymous study ID numbers and used a random number service (www.random.org) to allocate participants."

Comment: probably done 
Bonnert 2017 (Continued)

Incomplete outcome data Unclear risk Attrition was reported but differences between completers and non-com(attrition bias) pleters were not reported

All outcomes

Selective reporting (re- Low risk Outcomes data were fully reported porting bias)

\section{Daniel 2015}

\section{Study characteristics}

\begin{tabular}{|c|c|}
\hline Methods & RCT. 2 arms. Outcomes assessed pre-treatment and immediate post-treatment \\
\hline \multirow[t]{9}{*}{ Participants } & End of treatment $n=62$ \\
\hline & Start of treatment $\mathrm{n}=83$ \\
\hline & Child sex: $42 \mathrm{M}, 41 \mathrm{~F}$ \\
\hline & Parent sex: not reported \\
\hline & Child age (mean, SD): $8.48 \pm 2.11$ years \\
\hline & Parent age: not reported \\
\hline & Source: hospital \\
\hline & Medical condition: sickle cell \\
\hline & Illness duration: lifetime \\
\hline \multirow[t]{7}{*}{ Interventions } & "Families Taking Control" \\
\hline & "Delayed Intervention Control" \\
\hline & Mode of delivery: face-to-face + remote-telephone, group/individual/family \\
\hline & Intervention delivered by: doctoral and masters students and peer patient navigator \\
\hline & $\begin{array}{l}\text { Training: training in sickle cell disease, PST, and cultural considerations in working with African-Ameri- } \\
\text { can families }\end{array}$ \\
\hline & $\begin{array}{l}\text { Duration of intervention (child): 1-day workshop }(7 \mathrm{~h})+3 \times 30 \text {-min booster phone calls over } 6 \text { months }= \\
9.5 \mathrm{~h}\end{array}$ \\
\hline & $\begin{array}{l}\text { Duration of intervention (parent): } 1 \text {-day workshop }(7 \mathrm{~h})+3 \times 30 \text {-min booster phone calls over } 6 \\
\text { months }=9.5 \mathrm{~h}\end{array}$ \\
\hline
\end{tabular}

Outcomes

${ }^{\star}$ Extracted outcome measures used in the analyses

\section{Child measures}

Pediatric Quality of Life Inventory School Subscale - Child report*

Woodcock Johnson III (WJ-III)

\section{Parent measures}

Pediatric Quality of Life Inventory School Subscale- Parent report 
Daniel 2015 (Continued)

Notes

Funding: "NHLBI (U54 HL070585) to M.S. (PI), BTRP to LPB (PI); and NCMHD (1RC1MD004418) to L.P.B.

(PI)."

COI: "Conflicts of interest: None declared."

\section{Risk of bias}

\begin{tabular}{lll}
\hline Bias & Authors' judgement & Support for judgement \\
\hline $\begin{array}{ll}\text { Random sequence genera- } \\
\text { tion (selection bias) }\end{array}$ & Unclear risk & $\begin{array}{l}\text { Quote: "Randomization (stratified by gender in blocks of 10) was concealed } \\
\text { from the family and the study team until after completing the baseline assess- } \\
\text { ment when an envelope with randomization status was opened and the family } \\
\text { was informed of next steps." } \\
\end{array}$ \\
& $\begin{array}{l}\text { Comment: insufficient information about the sequence generation process to } \\
\text { permit judgement }\end{array}$
\end{tabular}

Allocation concealment Unclear risk
(selection bias)

Quote: "Randomization (stratified by gender in blocks of 10) was concealed from the family and the study team until after completing the baseline assessment when an envelope with randomization status was opened and the family was informed of next steps."

Comment: insufficient information about allocation concealment provided to permit judgement; it is unclear if envelopes were sequentially numbered, opaque, and sealed

\begin{tabular}{|c|c|c|}
\hline $\begin{array}{l}\text { Blinding of outcome as- } \\
\text { sessment (detection bias) }\end{array}$ & Unclear risk & $\begin{array}{l}\text { Insufficient information to permit judgement; no statement about whether or } \\
\text { not blinding of outcome assessment occurred }\end{array}$ \\
\hline
\end{tabular}

All outcomes

\begin{tabular}{|c|c|c|}
\hline $\begin{array}{l}\text { Incomplete outcome data } \\
\text { (attrition bias) }\end{array}$ & Low risk & $\begin{array}{l}\text { Attrition was reported, no significant differences between completers and } \\
\text { non-completers are reported }\end{array}$ \\
\hline
\end{tabular}

All outcomes

Selective reporting (re- Low risk Outcomes data were fully reported
porting bias)

porting bias)

Doherty 2013

\section{Study characteristics}

\begin{tabular}{ll}
\hline Methods & RCT. 2 arms. Outcomes assessed at pre-treatment and immediate post-treatment \\
\hline Participants & End of treatment $n=54$ \\
& Start of treatment $n=90$ \\
& Child sex: $45 \mathrm{M}, 34 \mathrm{~F}$ \\
& Parent sex: $1 \mathrm{M}, 78 \mathrm{~F}$ \\
& Child age (mean): 13 years \\
& Parent age: 43.5 years \\
& Source: community \\
Medical condition: type 1 diabetes
\end{tabular}


Doherty 2013 (Continued)

Illness duration (mean): 5.17 years

Interventions
"Uriple P Diabetes"
"Usual Care"
Mode of delivery: remote-self-guided book, individual
Intervention delivered by: self-guided book
Training: not reported
Duration of intervention (child): none
Duration of intervention (parent): $10 \times 1$ - $\mathrm{h}$ modules $=10 \mathrm{~h}$

${ }^{*}$ Extracted outcome measures used in th
Parent measures
Revised Diabetes Family Conflict Scale*
Pediatric Inventory for Parents*
Eyberg Child Behavior Inventory*
Parenting Scale*
Parenting Sense of Competence Scale

Notes

Funding: "This study was supported by a small research grant as part of the University of Manchester Doctorate in Clinical Psychology (F.D.)."

COI: "M.S. is the founder and lead author of the Triple P - Positive Parenting Program, and is consultant to Triple P International."

\section{Risk of bias}

Bias Authors' judgement Support for judgement

Random sequence genera- Low risk tion (selection bias)
Quote: "A computerized block randomization program ensured equal allocation of participants to one of two groups."

Comment: probably done
Allocation concealment Low risk (selection bias)
Quote: "Blocks consisted of hidden, predetermined sequence of numbers from a computerized random number database prepared by an individual not involved in data collection. Researchers were blind to block size to avoid bias and maintain allocation concealment. Participants had group allocation confirmed after completion of baseline questionnaires. A University employee who constructed the Web site, but was not directly involved with the research project, generated the random allocation sequence."

Comment: probably done

\begin{tabular}{lll}
$\begin{array}{l}\text { Blinding of outcome as- } \\
\begin{array}{l}\text { sessment (detection bias) } \\
\text { All outcomes }\end{array}\end{array}$ & Low risk & $\begin{array}{l}\text { Quote: "Detection bias was minimized by using web-administered question- } \\
\text { naires that were self-reported via the Web site...or posted paper-based ques- } \\
\text { tionnaires where requested." } \\
\text { Comment: probably done }\end{array}$ \\
\hline $\begin{array}{l}\text { Incomplete outcome data } \\
\text { (attrition bias) }\end{array}$ & Low risk & $\begin{array}{l}\text { Attrition was reported and no significant differences between completers and } \\
\text { non-completers were detected }\end{array}$ \\
\hline
\end{tabular}

Psychological interventions for parents of children and adolescents with chronic illness (Review)

Copyright $\odot 2019$ The Cochrane Collaboration. Published by John Wiley \& Sons, Ltd. 
Doherty 2013 (Continued)

All outcomes

Selective reporting (re- Low risk $\quad$ Outcomes data were fully reported
porting bias)

Selective reporting (re- Low risk Outcomes data were fully reported
porting bias)

\section{Ellis 2005}

\section{Study characteristics}

\begin{tabular}{|c|c|}
\hline Methods & RCT. 2 arms. Outcomes assessed pre-treatment, immediate post-treatment, 12-month follow-up \\
\hline \multirow[t]{9}{*}{ Participants } & End of treatment $n=110,12$-month follow-up $=85$ \\
\hline & Start of treatment $n=127$ children and their families \\
\hline & Child sex: $62 \mathrm{M}, 65 \mathrm{~F}$ \\
\hline & Parent sex: not reported \\
\hline & Child age (mean, SD): $13.25 \pm 1.95$ years \\
\hline & Parent age: $38.8 \pm 6.8$ years \\
\hline & Source: hospital \\
\hline & Medical condition: type 1 diabetes \\
\hline & Illness duration (mean): 5.3 years \\
\hline \multirow[t]{7}{*}{ Interventions } & "Multisystemic Therapy" \\
\hline & "Standard Care Control" \\
\hline & Mode of delivery: face-to-face, family \\
\hline & Intervention delivered by: therapist \\
\hline & Training: not reported \\
\hline & Duration of intervention (child): mean 48 sessions over 5.7 months \\
\hline & Duration of intervention (parent): mean 48 sessions over 5.7 months \\
\hline \multirow[t]{6}{*}{ Outcomes } & *Extracted outcome measures used in the analyses \\
\hline & Child measures \\
\hline & $\mathrm{HbAlc}{ }^{\star}$ \\
\hline & Diabetes Stress Questionnaire* \\
\hline & Frequency of Blood Glucose Testing from blood glucose meter \\
\hline & Health Service Use per Medical Chart Review \\
\hline \multirow[t]{2}{*}{ Notes } & $\begin{array}{l}\text { Funding: "This project was supported by grant Ro1 DK59067 from the National Institute of Diabetes and } \\
\text { Digestive and Kidney Diseases" }\end{array}$ \\
\hline & COI: "No conflict of interest declared" \\
\hline
\end{tabular}

\section{Risk of bias}

Psychological interventions for parents of children and adolescents with chronic illness (Review) 
Ellis 2005 (Continued)

\section{Bias Authors' judgement Support for judgement}

Random sequence genera- Unclear risk tion (selection bias)
Quote: "Random assignment to treatment group was completed after baseline data collection."

Comment: no method described

\begin{tabular}{|c|c|c|}
\hline $\begin{array}{l}\text { Allocation concealment } \\
\text { (selection bias) }\end{array}$ & Unclear risk & $\begin{array}{l}\text { Quote; "To ensure equivalence across treatment conditions, random assign- } \\
\text { ment was stratified according to HbA1c level at the baseline visit." }\end{array}$ \\
\hline $\begin{array}{l}\text { Blinding of outcome as- } \\
\text { sessment (detection bias) } \\
\text { All outcomes }\end{array}$ & Unclear risk & $\begin{array}{l}\text { No description found in text } \\
\text { Comment: probably not done }\end{array}$ \\
\hline $\begin{array}{l}\text { Incomplete outcome data } \\
\text { (attrition bias) } \\
\text { All outcomes }\end{array}$ & Low risk & $\begin{array}{l}\text { Attrition was reported, there were no significant differences between com- } \\
\text { pleters and non-completers }\end{array}$ \\
\hline $\begin{array}{l}\text { Selective reporting (re- } \\
\text { porting bias) }\end{array}$ & Low risk & Outcomes data were fully reported \\
\hline
\end{tabular}

Ellis 2012

\section{Study characteristics}

\begin{tabular}{|c|c|}
\hline Methods & RCT. 2 arms. Assessed at pre-treatment, 7 months post-treatment, 6-month follow-up \\
\hline \multirow[t]{9}{*}{ Participants } & End of treatment $n=117,6$-month follow-up $=117$ \\
\hline & Start of treatment $n=146$ \\
\hline & Child sex: 64 M, 82 M \\
\hline & Parent sex: not reported \\
\hline & Child age (mean, SD): $14.2 \pm 2.3$ years \\
\hline & Parent age: not reported \\
\hline & Source: hospital \\
\hline & Medical condition: type 1 diabetes \\
\hline & Illness duration (mean): 4.7 years \\
\hline \multirow[t]{7}{*}{ Interventions } & "Multisystemic therapy" \\
\hline & "Telephone support" \\
\hline & Mode of delivery: face-to-face + remote-telephone, family \\
\hline & Intervention delivered by: masters-level therapists \\
\hline & Training: 5-day training, phone consultation with MST expert, follow-up booster \\
\hline & Duration of intervention (child, hours): minimum 2 meetings/week for 6 months \\
\hline & Duration of intervention (parent, hours): minimum 2 meetings/week for 6 months \\
\hline Outcomes & ${ }^{\star}$ Extracted outcome measures used in the analyses \\
\hline
\end{tabular}

Psychological interventions for parents of children and adolescents with chronic illness (Review) 
Ellis 2012 (Continued)

\section{Child measures}

$\mathrm{HbA} 1 \mathrm{c}^{*}$

Diabetes Management Scale

Notes $\quad$ Funding: "This project was supported by grant \#RO1DK59067 from the National institute of Diabetes, Digestive and Kidney diseases"

COI: "Conflict of interest statement: three of the authors are board members of Evidence Based Services, which has a licensing agreement with MST Services, which has a licensing agreement with MST Services, LLC, for dissemination of multisystemic therapy treatment technology. There are no other potential author conflicts of interest"

\section{Risk of bias}

\begin{tabular}{lll}
\hline Bias & Authors' judgement & Support for judgement \\
\hline $\begin{array}{ll}\text { Random sequence genera- } \\
\text { tion (selection bias) }\end{array}$ & Low risk & $\begin{array}{l}\text { Quote: "Participants were randomized in a 1:1 ratio to MST or telephone sup- } \\
\text { port. Randomization occurred immediately after baseline data collection us- } \\
\text { ing a permuted block algorithm to ensure equivalence across treatment condi- } \\
\text { tion..." }\end{array}$ \\
& Comment: probably done \\
\hline
\end{tabular}

\begin{tabular}{ll}
\hline $\begin{array}{l}\text { Allocation concealment } \\
\text { (selection bias) }\end{array}$ & $\begin{array}{l}\text { Quote: "The project statistician generated the randomization sequence and } \\
\text { participants were notified of their randomization status by the project manag- } \\
\text { er." }\end{array}$ \\
Comment: probably done
\end{tabular}

\begin{tabular}{|c|c|c|}
\hline \multirow[t]{2}{*}{$\begin{array}{l}\text { Blinding of outcome as- } \\
\text { sessment (detection bias) } \\
\text { All outcomes }\end{array}$} & Low risk & $\begin{array}{l}\text { Quote: "All measures were collected by a trained research assistant in the par- } \\
\text { ticipants' homes. The research assistant was blind to treatment assignment to } \\
\text { the extent possible in a behavioral trial." }\end{array}$ \\
\hline & & Comment: probably done \\
\hline
\end{tabular}

Incomplete outcome data Unclear risk (attrition bias)

Attrition was reported, but no data were presented describing equivalence beAll outcomes tween completers and non-completers

\begin{tabular}{ll}
\hline $\begin{array}{l}\text { Selective reporting (re- Low risk } \\
\text { porting bias) }\end{array}$ & Outcomes data fully reported
\end{tabular}

\section{Ellis 2017a}

\section{Study characteristics}

\begin{tabular}{ll}
\hline Methods & RCT. 3 arms. Assessed pre-treatment and 1-month follow-up (7 months post-baseline) \\
\hline Participants & End of treatment $n=56$ \\
& Start of treatment $n=67$ \\
& Child sex: not reported \\
& Parent sex: 28 M, $36 \mathrm{~F}$ \\
Child age (mean, SD): $12.1 \pm 1.3$ years
\end{tabular}


Ellis 2017a (Continued)

Parent age (mean, SD): $38.3 \pm 6.6$ years

Source: hospital

Medical condition: type 1 diabetes

Illness duration (mean): 4.6 years

Interventions 3 Ms diabetes"
"Attention Control Intervention"
Mode of delivery: arm 1: remote-internet, individual/arm 2: remote-internet, individual
Intervention delivered by: both arms, internet
Training: not reported
Duration of intervention (child): arm 1, 3 sessions of motivational interviewing/arm 2, 3 sessions of psy-
choeducation
Duration of intervention (parent): arm 1, 3 sessions of motivational interviewing/arm 2, 3 sessions of
motivational interviewing

Outcomes $\quad$ Extracted outcome measures used in the analyses

\section{Child measures}

$\mathrm{HbA1c}$ *

Parent-Adolescent Relationship Questionnaire*

\section{Parent measures}

Knowledge of need to monitor adolescent diabetes management

Rollnick's Readiness Ruler

Parental Monitoring of Diabetes Care Scale-Revised*

Notes

Funding: "This work was supported, in part, by funding from the National Institutes of Diabetes, Digestive and Kidney Disease (Grant No. R21 DK089238-01) -Dr. Ellis-PI."

COI: "Dr. Ondersma is part owner of Interva, a company that markets the CIAS intervention authoring tool used to develop the intervention for this study."

\section{Risk of bias}

\begin{tabular}{|c|c|c|}
\hline Bias & Authors' judgement & Support for judgement \\
\hline \multirow[t]{2}{*}{$\begin{array}{l}\text { Random sequence genera- } \\
\text { tion (selection bias) }\end{array}$} & Unclear risk & $\begin{array}{l}\text { Quote: "Families enrolled were randomly assigned to one of } 3 \text { treatment } \\
\text { arms." }\end{array}$ \\
\hline & & $\begin{array}{l}\text { Comment: insufficient information is provided about the sequence generation } \\
\text { to permit judgement }\end{array}$ \\
\hline \multirow[t]{2}{*}{$\begin{array}{l}\text { Allocation concealment } \\
\text { (selection bias) }\end{array}$} & Unclear risk & $\begin{array}{l}\text { Quote: "Families enrolled were randomly assigned to one of } 3 \text { treatment } \\
\text { arms." }\end{array}$ \\
\hline & & $\begin{array}{l}\text { Comment: insufficient information is provided about the method of conceal- } \\
\text { ment to permit judgement }\end{array}$ \\
\hline $\begin{array}{l}\text { Blinding of outcome as- } \\
\text { sessment (detection bias) }\end{array}$ & Low risk & $\begin{array}{l}\text { Quote: "All data collection measures and the intervention content were admin- } \\
\text { istered using Internet-based software on a touch screen tablet computer." }\end{array}$ \\
\hline
\end{tabular}

Psychological interventions for parents of children and adolescents with chronic illness (Review) 
Ellis 2017a (Continued)

All outcomes

Comment: probably done
Incomplete outcome data Unclear risk (attrition bias)

All outcomes
Attrition was reported but differences between completers and non-completers were not reported
Selective reporting (reporting bias)
High risk
Pre-specified outcomes identified in the Methods were not fully reported in the Results. The study authors provided these data on request

\section{Ellis 2017b}

\section{Study characteristics}

\begin{tabular}{|c|c|}
\hline Methods & RCT. 2 arms. Assessed baseline and post-treatment \\
\hline \multirow[t]{9}{*}{ Participants } & End of treatment $n=44$ \\
\hline & Start of treatment $n=50$ \\
\hline & Child sex: $18 \mathrm{M}, 29 \mathrm{~F}$ \\
\hline & Parent sex: 2 M, $45 \mathrm{~F}$ \\
\hline & Child age (mean, SD): $14.3 \pm 2.4$ years \\
\hline & Parent age: $41.7 \pm 7.5$ years \\
\hline & Source: hospital \\
\hline & Medical condition: type 1 diabetes \\
\hline & Illness duration (mean): 6.7 years \\
\hline \multirow[t]{7}{*}{ Interventions } & "REACH for control" \\
\hline & "Standard medical care" \\
\hline & Mode of delivery: face-to-face, family \\
\hline & Intervention delivered by: community health workers \\
\hline & $\begin{array}{l}\text { Training: CHW competency training by Michigan Community Health Worker Alliance plus protocol-spe- } \\
\text { cific training in an 80-h, 2-week-long training period }\end{array}$ \\
\hline & Duration of intervention (child): twice weekly $30-90-$ min sessions for 20 weeks \\
\hline & Duration of intervention (parent): twice weekly $30-90$-min sessions for 20 weeks \\
\hline \multirow[t]{7}{*}{ Outcomes } & ${ }^{\star}$ Extracted outcome measures used in the analyses \\
\hline & Child measures \\
\hline & $\mathrm{HbA} 1 \mathrm{c}^{\star}$ \\
\hline & Diabetes Management Scale \\
\hline & Diabetes Quality of Life-Youth Scale \\
\hline & Parent measures \\
\hline & Diabetes Management Scale \\
\hline
\end{tabular}


Ellis 2017b (Continued)

Notes

Funding: "This work was supported by funding from the National Institute of Diabetes Digestive and Kidney Disease of the National Institutes of Health (R34 DK102091-01, PI)."

COI: "Conflicts of interest: None declared."

\section{Risk of bias}

\begin{tabular}{lll}
\hline Bias & Authors' judgement & Support for judgement \\
\hline $\begin{array}{l}\text { Random sequence genera- } \\
\text { tion (selection bias) }\end{array}$ & Low risk & $\begin{array}{l}\text { Quote: "Participants were randomized in a 1:1 ratio to RFC [REACH for Control] } \\
\text { plus standard medical care or standard medical care alone. Randomization } \\
\text { occurred immediately after baseline data collection using a permuted block } \\
\text { algorithm with blocks of varying size to ensure equivalence across treatment } \\
\text { condition and was conducted by the project co investigator using a computer- } \\
\text { ized software package (http://randomization.com)" }\end{array}$ \\
& & $\begin{array}{l}\text { Quote: "...was conducted by the project co investigator using a computerized } \\
\text { software package (http://randomization.com)...treatment assignment was } \\
\text { then provided to the research assistant collecting the data who informed the } \\
\text { family of their status....The research assistant was not blind to treatment as- } \\
\text { signment because of the need to complete exit interviews to assess treatment } \\
\text { satisfaction with treatment families." }\end{array}$ \\
\hline
\end{tabular}

\begin{tabular}{lll}
\hline $\begin{array}{l}\text { Blinding of outcome as- } \\
\text { sessment (detection bias) }\end{array}$ & High risk & $\begin{array}{l}\text { Quote: "To minimize bias, data collection was conducted by research assis- } \\
\text { tants hired by the university research partner rather than the } \mathrm{CHW} \text { interven- } \\
\text { All outcomes }\end{array}$ \\
& $\begin{array}{l}\text { tionists....The research assistant was not blind to treatment assignment be- } \\
\text { cause of the need to complete exit interviews to assess treatment satisfaction } \\
\text { with treatment families." }\end{array}$
\end{tabular}

\begin{tabular}{ll}
\hline $\begin{array}{l}\text { Incomplete outcome data } \\
\text { (attrition bias) }\end{array}$ & Low risk
\end{tabular}

All outcomes

Selective reporting (re- Low risk $\quad$ Outcomes data were fully reported
porting bias)

\section{Greenley 2015}

\section{Study characteristics}

\begin{tabular}{ll}
\hline Methods & $\begin{array}{l}\text { RCT. } 3 \text { arms. Assessed pre-treatment, after initial treatment (12 weeks), after additional treatment (20 } \\
\text { weeks) }\end{array}$ \\
\hline Participants & End of initial treatment (12 weeks) $n=65$, end of additional treatment (20 weeks) $n=65$ \\
& Child sex: $46 \mathrm{M}, 30 \mathrm{~F}$ \\
& Parent sex: not reported \\
& Child age (mean, SD): $14.5 \pm 1.8$ years \\
& Parent age: not reported \\
& Source: hospital \\
Medical condition: IBD
\end{tabular}


Illness duration: not reported

Interventions
"Problem Solving Skills Training Irritable Bowel Disease"
Mode of delivery: arm 1: face-to-face + remote-telephone, family. Arm 2: face-to-face + remote-tele-
phone, family
Intervention delivered by: graduate students in psychology
Training: 10 h of PSST training
Duration of intervention (child): arm 1, 2 sessions; arm 2, 4 sessions (session 1: 75 mins, other sessions:
45 mins)
Duration of intervention (parent): arm 1, 2 sessions; arm 2: 4 sessions (session 1: 75 mins, other ses-
sions: 45 mins)

\begin{tabular}{ll} 
Outcomes & *Extracted outcome measures used in the analyses \\
Child measures & MEMS Track Caps electronic monitor \\
& Pediatric Quality of Life Inventory (PedsQL) \\
\hline Notes & Funding: "Supported by the Crohn's and Colitis Foundation of America (Senior Research Award \#2838; \\
PI: Greenley)." & COI: "The authors have no conflicts of interest to disclose."
\end{tabular}

\section{Risk of bias}

\begin{tabular}{|c|c|c|}
\hline Bias & Authors' judgement & Support for judgement \\
\hline \multirow[t]{2}{*}{$\begin{array}{l}\text { Random sequence genera- } \\
\text { tion (selection bias) }\end{array}$} & Low risk & $\begin{array}{l}\text { Quote: "The randomization sequence was generated by a biostatistician using } \\
\text { Windows version } 6.0 \text { of randomization program 'Rand.exe.'" }\end{array}$ \\
\hline & & Comment: probably done \\
\hline \multirow[t]{2}{*}{$\begin{array}{l}\text { Allocation concealment } \\
\text { (selection bias) }\end{array}$} & Low risk & $\begin{array}{l}\text { Quote: "The random allocation sequence was stored electronically in a pass- } \\
\text { word-protected file accessible only to the research assistant in charge of in- } \\
\text { forming participants of randomization outcomes. Research assistants en- } \\
\text { rolling participants and those conducting assessment visits were blind to par- } \\
\text { ticipant intervention condition." }\end{array}$ \\
\hline & & Comment: probably done \\
\hline \multirow[t]{2}{*}{$\begin{array}{l}\text { Blinding of outcome as- } \\
\text { sessment (detection bias) } \\
\text { All outcomes }\end{array}$} & Low risk & $\begin{array}{l}\text { Quote: "All assessments were conducted in participants' homes... Research as- } \\
\text { sistants...conducting assessment visits were blind to participant intervention } \\
\text { condition." }\end{array}$ \\
\hline & & Comment: probably done \\
\hline $\begin{array}{l}\text { Incomplete outcome data } \\
\text { (attrition bias) } \\
\text { All outcomes }\end{array}$ & Unclear risk & $\begin{array}{l}\text { Attrition was reported but differences between completers and non-com- } \\
\text { pleters were not reported }\end{array}$ \\
\hline $\begin{array}{l}\text { Selective reporting (re- } \\
\text { porting bias) }\end{array}$ & Low risk & Outcomes data were fully reported \\
\hline
\end{tabular}




\section{Study characteristics}

\begin{tabular}{|c|c|}
\hline Methods & RCT. 2 arms. Pre-treatment (at diagnosis), post-treatment, 6-month follow-up \\
\hline \multirow[t]{9}{*}{ Participants } & End of treatment and 6-month follow-up $n=81$ \\
\hline & Start of treatment $\mathrm{n}=120$ \\
\hline & Parent sex: 40 M, $41 \mathrm{~F}$ \\
\hline & Child sex: $23 \mathrm{M}, 18 \mathrm{~F}$ \\
\hline & Child age (mean, SD): $6.4 \pm 4.7$ years \\
\hline & Parent age: $36.6 \pm 5.4$ years \\
\hline & Source: hospital \\
\hline & Medical condition: cancer \\
\hline & Illness duration (range): 2-21 days post diagnosis \\
\hline \multirow[t]{7}{*}{ Interventions } & "Psychoeducational and Cognitive-Behavioral Intervention" \\
\hline & "Standard Care Control" \\
\hline & Mode of delivery: face-to-face, individual \\
\hline & Intervention delivered by: psychologist \\
\hline & Training: not reported \\
\hline & Duration of intervention (child): 0 \\
\hline & Duration of intervention (parent): 8 sessions $\times 90$ mins $=12 \mathrm{~h}$ \\
\hline \multirow[t]{7}{*}{ Outcomes } & ${ }^{*}$ Extracted outcome measures used in the analyses \\
\hline & Parent measures \\
\hline & Symptom Check List (SCL) \\
\hline & State-Trait Anxiety Inventory-State ${ }^{\star}$ \\
\hline & Goldberg General Health Questionnaire \\
\hline & Social Support List-Discrepancies \\
\hline & Intensity of emotions list \\
\hline \multirow[t]{2}{*}{ Notes } & $\begin{array}{l}\text { Funding: "This study has been funded by the Dutch Cancer Society and the Pediatric Oncology Founda- } \\
\text { tion Groningen" }\end{array}$ \\
\hline & COI: no conflict of interest statement included in the manuscript \\
\hline
\end{tabular}

\section{Risk of bias}

\section{Bias}

Random sequence generation (selection bias)

\section{Authors' judgement Support for judgement}

Unclear risk

Quote: "Parents were randomly assigned.... parents drew one of two envelopes in which a letter indicated in which group they were placed." 


\begin{tabular}{|c|c|c|}
\hline $\begin{array}{l}\text { Allocation concealment } \\
\text { (selection bias) }\end{array}$ & Unclear risk & $\begin{array}{l}\text { Quote: "Parents were randomly assigned.... parents drew one of two en- } \\
\text { velopes in which a letter indicated in which group they were placed." } \\
\text { Comment: probably done but unsure whether envelopes were sealed or num- } \\
\text { bered }\end{array}$ \\
\hline $\begin{array}{l}\text { Blinding of outcome as- } \\
\text { sessment (detection bias) } \\
\text { All outcomes }\end{array}$ & Unclear risk & $\begin{array}{l}\text { No description found in text } \\
\text { Comment: probably not done }\end{array}$ \\
\hline $\begin{array}{l}\text { Incomplete outcome data } \\
\text { (attrition bias) } \\
\text { All outcomes }\end{array}$ & Low risk & $\begin{array}{l}\text { Attrition was reported, there were no significant differences between com- } \\
\text { pleters and non-completers }\end{array}$ \\
\hline $\begin{array}{l}\text { Selective reporting (re- } \\
\text { porting bias) }\end{array}$ & Low risk & Outcomes data were fully reported \\
\hline
\end{tabular}

\section{Husted 2014}

\section{Study characteristics}

\begin{tabular}{|c|c|}
\hline Methods & RCT. 2 arms. Assessed pre-treatment, post-treatment, 6-month follow-up \\
\hline \multirow[t]{9}{*}{ Participants } & End of treatment $n=57,12$-month follow-up $n=53$ \\
\hline & Start of treatment $n=71$ \\
\hline & Child sex: $28 \mathrm{M}, 43 \mathrm{~F}$ \\
\hline & Parent sex: not reported \\
\hline & Child age (mean, SD): $14.8 \pm 1.4$ years \\
\hline & Parent age: not reported \\
\hline & Source: hospital/primary care \\
\hline & Medical condition: type 1 diabetes \\
\hline & Illness duration (mean): 5.7 years \\
\hline \multirow[t]{7}{*}{ Interventions } & "Self-determination Diabetes" \\
\hline & "Treatment as usual" \\
\hline & Mode of delivery: face-to-face, individual/family \\
\hline & $\begin{array}{l}\text { Intervention delivered by: pediatric physicians, pediatric diabetes nurses, dieticians, and reflection } \\
\text { sheets }\end{array}$ \\
\hline & Training: not reported \\
\hline & Duration of intervention (child): 8 sessions $x 1 \mathrm{~h}=8 \mathrm{~h}$ \\
\hline & Duration of intervention (parent): 8 sessions $x 1 \mathrm{~h}=8 \mathrm{~h}$ \\
\hline \multirow[t]{2}{*}{ Outcomes } & ${ }^{\star}$ Extracted outcome measures used in the analyses \\
\hline & Child measures \\
\hline
\end{tabular}


Husted 2014 (Continued)

$\mathrm{HbA} 1 c^{\star}$

Perceived Competence in Diabetes Scale

Health Care Climate Questionnaire

Treatment Self-Regulation Questionnaire

Problem Areas in Diabetes

World Health Organization-5 scale*

Perception of Parents Scale*

Notes

Funding: "This trial was supported by grants from the Research Foundation at Hillerød Hospital, the Novo Nordisk Foundation, the Lundbeck Foundation, the Sahva Foundation, the Tryg Foundation, the Foundation of Senior Lieutenant Harald Jensen and Wife, the Pediatric Department at Hillerød Hospital, the Research Foundation of the Capital Region of Denmark, the Foundation of Mrs. Lily Benthine Lund, the Axel Muusfeldt Foundation, the Foundation of Master Cabinetmaker Sophus Jacobsen and his wife Astrid Jacobsen, the Ville Heise Foundation, the Beckett Foundation, and the Health Insurance Foundation. GRH received the grants."

COI: "Competing interests: None declared."

\section{Risk of bias}

Bias Authors' judgement Support for judgement

Random sequence genera- Low risk tion (selection bias)
Quote: "The adolescents were randomized using opaque sealed envelopes containing a twice-folded piece of paper indicating the group assignment; these assignments were prepared in blocks of 4, each comprising two GSD-Y intervention assignments and two usual-care assignments. The 4 envelopes in each block were randomly mixed and then consecutively numbered from one to 4 by GRH (primary author)."

Comment: probably done
Quote: "The adolescents were randomized using opaque sealed envelopes containing a twice-folded piece of paper indicating the group assignment; these assignments were prepared in blocks of 4, each comprising two GSD-Y intervention assignments and two usual-care assignments. The 4 envelopes in each block were randomly mixed and then consecutively numbered from one to 4 by GRH (primary author)."

Comment: probably done

\begin{tabular}{|c|c|c|}
\hline $\begin{array}{l}\text { Blinding of outcome as- } \\
\text { sessment (detection bias) } \\
\text { All outcomes }\end{array}$ & Unclear risk & $\begin{array}{l}\text { Quote: "The scales were compiled into one questionnaire and completed by } \\
\text { the adolescents in the clinic at baseline, before randomization, at the end of } \\
\text { the experimental period, and after a } 6 \text {-month follow-up period." }\end{array}$ \\
\hline & & $\begin{array}{l}\text { Comment: insufficient information provided about detection bias to permit } \\
\text { judgement }\end{array}$ \\
\hline
\end{tabular}

Incomplete outcome data Unclear risk (attrition bias)

All outcomes
Attrition is reported but differences between completers and non-completers are not reported

Selective reporting (re- Low risk Outcomes data were fully reported
porting bias)


Kashikar-Zuck 2012

\section{Study characteristics}

Methods

Participants
RCT, cross-over design. 2 arms. Assessed pre-treatment, post-treatment, 6-month follow-up

End of treatment $n=100,12$-month follow-up $n=100$

Start of treatment $\mathrm{n}=114$

Child sex: 9 M, $105 \mathrm{~F}$

Parent sex: not reported

Child age (mean, SD): $15.0 \pm 1.8$ years

Parent age: not reported

Source: hospital

Medical condition: juvenile fibromyalgia

Illness duration (mean): 2 years

Interventions

"Cognitive behavioral therapy"

"Fibromyalgia education"

Mode of delivery: face-to-face, individual

Intervention delivered by: psychology post-doctoral fellows

Training: 6- to 8-h training + ongoing supervision

Duration of intervention (child): 8 sessions $\times 45 \mathrm{~min}=6 \mathrm{~h}$

Duration of intervention (parent): 3 sessions $x 45 \mathrm{~min}=2 \mathrm{~h}, 15 \mathrm{mins}$
*Extracted outcome measures used in the analyses

\section{Child measures}

Child Depression Inventory ${ }^{\star}$

Functional Disability Inventory*

Pain severity-visual analogue scale*

Sleep quality-visual analogue scale

Pediatric Quality of Life Inventory

Tender point sensitivity using dolorimetry

Physician's global assessment

Notes

Funding: "Supported by the NIH (National Institute of Arthritis and Musculoskeletal and Skin Diseases grant R01-AR-050028 to Dr. Kashikar-Zuck)."

COI: "Dr. Passo has received consulting fees, speaking fees, and /or honoraria from Pfizer (less than $\$ 10,000)$."

\section{Risk of bias}


Kashikar-Zuck 2012 (Continued)

\section{Bias Authors' judgement Support for judgement}

Random sequence genera- Low risk tion (selection bias)
Quote: "Eligible patients were randomly assigned to 1 of the 2 treatment arms based upon a computer-generated randomization list. Randomisation was stratified by site."

Comment: probably done

\begin{tabular}{|c|c|c|}
\hline $\begin{array}{l}\text { Allocation concealment } \\
\text { (selection bias) }\end{array}$ & Low risk & $\begin{array}{l}\text { Quote: "When a patient was enrolled, the study therapist contacted the bio- } \\
\text { statistician to obtain the subject identification number and treatment alloca- } \\
\text { tion." }\end{array}$ \\
\hline & & Comment: probably done \\
\hline
\end{tabular}

\begin{tabular}{|c|c|c|}
\hline \multirow[t]{2}{*}{$\begin{array}{l}\text { Blinding of outcome as- } \\
\text { sessment (detection bias) } \\
\text { All outcomes }\end{array}$} & Low risk & $\begin{array}{l}\text { Quote: "The principle investigator, study physicians, study coordinator, } \\
\text { and assessment staff were all blinded to the patients' treatment condition } \\
\text { throughout the trial. Patients were asked not to divulge what treatment they } \\
\text { were receiving to the study physician." }\end{array}$ \\
\hline & & Comment: probably done \\
\hline
\end{tabular}

$\begin{array}{ll}\begin{array}{l}\text { Incomplete outcome data } \\ \text { (attrition bias) }\end{array} & \text { Low risk }\end{array}$

All outcomes completers and non-completers

Selective reporting (re- Low risk Outcomes data were fully reported
porting bias)

\section{Kazak 2004}

\section{Study characteristics}

\begin{tabular}{ll}
\hline Methods & RCT. 2 arms. Assessed pre-treatment and 3-5 months post-treatment \\
\hline Participants & End of treatment $n=116$ children \\
& Start of treatment $n=150$ children \\
& Child sex: $73 \mathrm{M}, 77 \mathrm{~F}$ \\
& Parent sex: $106 \mathrm{M}, 146 \mathrm{~F}$ \\
& Child age (mean, SD): $14.61 \pm 2.4$ years \\
& Parent age: not reported \\
& Source: hospital \\
& Medical condition: cancer \\
Illness duration (mean): 5.3 years & "Surviving Cancer Competently Intervention Program (SCCIP)" \\
"Wait-list Control" \\
Mode of delivery: face-to-face, group \\
Intervention delivered by: nurses, social workers, psychologists, graduate and post-doctoral psycholo- \\
gy trainees
\end{tabular}


Kazak 2004 (Continued)

Training: 12-h training including didactics, readings, role play, observation

Duration of intervention (child): 1-day workshop $=7 \mathrm{~h}$

Duration of intervention (parent): 1-day workshop $=7 \mathrm{~h}$

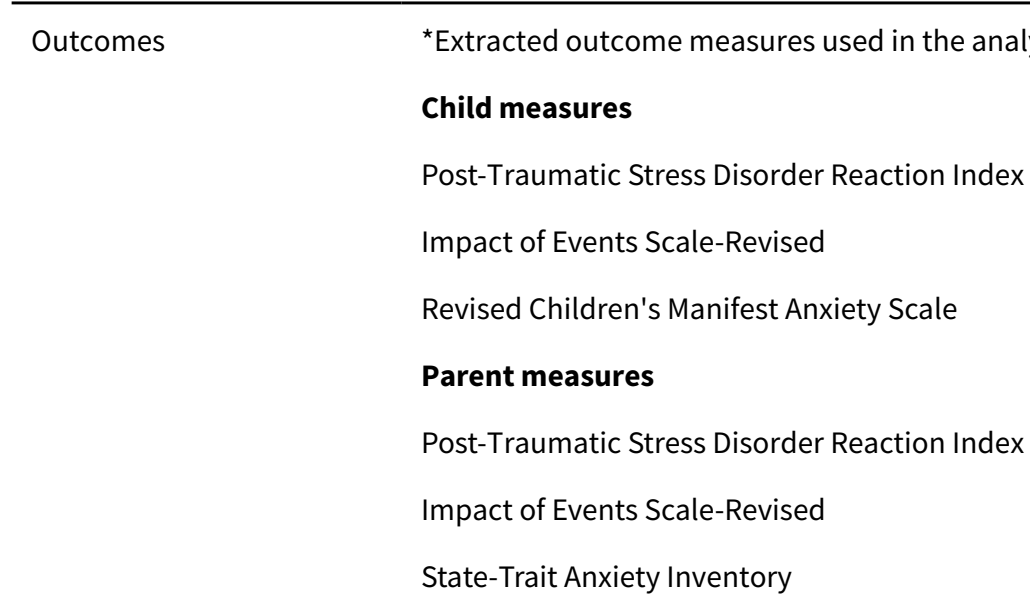

Notes $\quad$ Funding: "This research was funded by a grant from the National Cancer Institute (CA63930) and a grant from the Abramson Cancer Center of The University of Pennsylvania (CA15488)"

COI: no conflict of interest statement included in the manuscript

\section{Risk of bias}

Bias Authors' judgement Support for judgement

Random sequence genera- Unclear risk tion (selection bias)
Quote: "Families were randomized to the treatment or wail-list control condition."

Comment: method not described

\begin{tabular}{|c|c|c|}
\hline $\begin{array}{l}\text { Allocation concealment } \\
\text { (selection bias) }\end{array}$ & Unclear risk & $\begin{array}{l}\text { No description found in text } \\
\text { Comment: probably not done }\end{array}$ \\
\hline
\end{tabular}

Blinding of outcome as- Unclear risk sessment (detection bias)

All outcomes

No description found in text

Comment: probably not done
Incomplete outcome data Unclear risk Attrition was reported, but no data were presented describing equivalence be(attrition bias) tween completers and non-completers

All outcomes
Selective reporting (re- High risk porting bias)
Pre-specified outcomes identified in the Methods were not fully reported in the Results. The study authors did not provide these data when requested

\section{Laffel 2003}

\section{Study characteristics}

\begin{tabular}{ll}
\hline Methods & RCT. 2 arms. Assessed at pre-treatment and 1 year \\
\hline Participants & End of treatment $n=100$ children \\
\hline
\end{tabular}

Psychological interventions for parents of children and adolescents with chronic illness (Review) 
Laffel 2003 (Continued)

\author{
Start of treatment $\mathrm{n}=105$ \\ Child sex: 53 M, $47 \mathrm{~F}$ \\ Parent sex: not reported \\ Child age (mean, SD): $12.1 \pm 2.3$ years \\ Parent age: not reported \\ Source: hospital \\ Medical condition: type 1 diabetes \\ Illness duration (mean): 2.7 years
}

Interventions
"Teamwork Intervention"
"Standard Care"
Mode of delivery: face-to-face, family
Intervention delivered by: research assistant
Training: not reported
Duration of intervention (child): 4 sessions over 1 year (h not reported)
Duration of intervention (parent): 4 sessions over 1 year (hours not reported)

Outcomes * Extracted measures used in the analysesExtracted outcome measures used in the analyses

\title{
Child measures
}

$\mathrm{A} 1 \mathrm{c}^{*}$

Diabetes Family Conflict Scale

Clinician Report of Adherence to Diabetes Management Tasks

Diabetes Family Responsibility Questionnaire

Joint structured interview to assess parental involvement in diabetes management tasks

Pediatric Quality of Life Inventory

\section{Parent measures}

Diabetes Family Conflict Scale*

Diabetes Family Responsibility Questionnaire

Joint structured interview to assess parental involvement in diabetes management tasks ney Diseases, the Charles H. Hood Foundation, and the Katherine Adler Astrove Youth Education Fund"

COI: no conflict of interest statement included in the manuscript

\section{Risk of bias}

\begin{tabular}{lll}
\hline Bias & Authors' judgement & Support for judgement \\
\hline $\begin{array}{l}\text { Random sequence genera- } \\
\text { tion (selection bias) }\end{array}$ & Unclear risk & $\begin{array}{l}\text { "Patients were randomly assigned according to age and duration." Comment: } \\
\text { method not described }\end{array}$ \\
\hline
\end{tabular}


Laffel 2003 (Continued)

$\begin{aligned} & \text { Allocation concealment } \\ & \text { (selection bias) }\end{aligned} \quad$ Unclear risk No description found in text. Comment: probably not done

(selection bia

Blinding of outcome as-

Unclear risk

No description found in text. Comment: probably not done

sessment (detection bias)

All outcomes

Incomplete outcome data Unclear risk Attrition was reported but was not adequately described to make a judgement
(attrition bias)
All outcomes

Selective reporting (re- Low risk $\quad$ Outcomes data were fully reported
porting bias)

\section{Law 2015}

\section{Study characteristics}

\begin{tabular}{|c|c|}
\hline Methods & RCT. 2 arms. Assessed at pre-treatment, post-treatment (8-10 weeks), 4-month follow-up \\
\hline \multirow[t]{9}{*}{ Participants } & End of treatment $n=59,6$-month follow-up $n=49$ \\
\hline & Start of treatment $n=83$ \\
\hline & Child sex: $15 \mathrm{M}, 68 \mathrm{~F}$ \\
\hline & Parent sex: not reported \\
\hline & Child age (mean, SD): $14.5 \pm 1.7$ years \\
\hline & Parent age: not reported \\
\hline & Source: hospital \\
\hline & Medical condition: headache \\
\hline & Illness duration: not reported \\
\hline \multirow[t]{7}{*}{ Interventions } & "Web-based Management of Adolescent Pain (Web-MAP)" \\
\hline & "Specialized Headache Clinic" \\
\hline & Mode of delivery: remote-internet, individual \\
\hline & Intervention delivered by: internet + PhD-level psychology postdoctoral fellow \\
\hline & Training: not reported \\
\hline & Duration of intervention (child): 8 modules $\times 30 \mathrm{~min}=4 \mathrm{~h}$ \\
\hline & Duration of intervention (parent): 8 modules $\times 30 \mathrm{~min}=4 \mathrm{~h}$ \\
\hline \multirow[t]{5}{*}{ Outcomes } & ${ }^{\star}$ Extracted outcome measures used in the analyses \\
\hline & Child measures \\
\hline & Headache Frequency* \\
\hline & Pain Intensity (11-point numerical rating scale) \\
\hline & Child Activity Limitation Interview-21* \\
\hline
\end{tabular}


Law 2015 (Continued)

Revised Children's Manifest Anxiety Scale, Second Edition

Children's Depression Inventory*

Actiwatch 64

\section{Parent measures}

Adult Responses to Children's Symptoms*

\section{Notes}

Funding: "This research was supported by Grant K24HD060068 from the National Institutes of Health/ National Institute of Child Health and Human Development (PI: Palermo)."

COI: "Conflict of interest statement: No conflicts."

\section{Risk of bias}

Bias Authors' judgement Support for judgement

Random sequence genera- Low risk

Quote: "Blocked randomization with blocks of 10 was used to assign participants to one of the two treatment conditions. An online number generator was used to produce the blocked randomization. Participants were allocated in a 1:1 ratio."

Comment: probably done

\section{Allocation concealment Low risk} (selection bias)

Quote: "Group assignments were identified by ID number in an excel spreadsheet that was password protected and accessible only to a research coordinator who was blinded to participant recruitment, screening, and informed consent. Following completion of all pre-treatment assessments, the research coordinator accessed the excel spreadsheet to reveal the group assignment. This information was then programmed into the Web-MAP system, which generated a message on the web site to each study participant revealing the instructions for their treatment assignment."

Comment: probably done

\begin{tabular}{lll}
\hline $\begin{array}{l}\text { Blinding of outcome as- } \\
\begin{array}{l}\text { sessment (detection bias) } \\
\text { All outcomes }\end{array}\end{array}$ & Low risk & $\begin{array}{l}\text { Quote: "A research coordinator who was blinded to group status conducted all } \\
\text { assessment procedures that occurred in the clinic." }\end{array}$ \\
\hline $\begin{array}{l}\text { Incomplete outcome data } \\
\text { (attrition bias) } \\
\text { All outcomes }\end{array}$ & Low risk & $\begin{array}{l}\text { Attrition was reported and there were no differences between completers and } \\
\text { non-completers }\end{array}$ \\
\hline $\begin{array}{l}\text { Selective reporting (re- } \\
\text { porting bias) }\end{array}$ & Low risk & Outcomes data were fully reported \\
\hline
\end{tabular}

Levy 2010

\section{Study characteristics}

\begin{tabular}{ll}
\hline Methods & RCT. 2 arms. Assessed at pre-treatment, post-treatment, 3-month follow-up, 6-month follow-up \\
\hline Participants & End of treatment $n=168,3$-month follow-up $n=143,6$-month follow-up $n=154$ \\
& Start of treatment $n=200$
\end{tabular}


Levy 2010 (Continued)

Child sex: 55 M, 145 F

Parent sex: $12 \mathrm{M}, 188 \mathrm{~F}$

Child age (mean, SD): $11.2 \pm 2.6$ years

Parent age (mean, SD) $=43.8 \pm 6.4$ years

Source: hospital

Medical condition: functional abdominal pain

Illness duration: not reported

Interventions
"Cognitive-behavioral treatment"
"Educational intervention"
Mode of delivery: face-to-face, family
Intervention delivered by: master's-level therapist
Training: not reported
Duration of intervention (child): 3 sessions $\times 75$ min $=4 \mathrm{~h}$
Duration of intervention (parent): 3 sessions $\times 75$ min $=4 \mathrm{~h}$

Outcomes $\quad$ Extracted outcome measures used in the analyses

\section{Child measures}

Functional Disability Inventory*

Faces Pain Scale-Revised *

Child Depression Inventory ${ }^{\star}$

Child Somatization Inventory

Multidimensional Anxiety Scale for Children

\section{Parent measures}

Functional Disability Inventory

Faces Pain Scale-Revised

Child Somatization Inventory

Notes

Funding: "This study was supported by grant number 5R01HD036069 from the National Institutes of Health - National Institute of Child Health and Human Development."

COI: "Potential competing interests: William E. Whitehead is a member of the Board of Directors of the Rome Foundation. Nader Youssef is currently the Director of Clinical Research at AstraZeneca LP. At the time the study was conducted, however, he was not affiliated with this company and contributed to this project by his appointment at Goryeb Children's Hospital."

\section{Risk of bias}

\begin{tabular}{lll}
\hline Bias & Authors' judgement & Support for judgement \\
\hline $\begin{array}{l}\text { Random sequence genera- } \\
\text { tion (selection bias) }\end{array}$ & Low risk & $\begin{array}{l}\text { Quote: "Randomisation was then performed by a different researcher using a } \\
\text { computerized random-number generator, stratifying by age." }\end{array}$
\end{tabular}


Levy 2010 (Continued)

Comment: probably done

\begin{tabular}{ll}
\hline $\begin{array}{l}\text { Allocation concealment } \\
\text { (selection bias) }\end{array}$ & Low risk
\end{tabular}$\quad \begin{aligned} & \text { Quote: "Randomisation was then performed by a different researcher using a } \\
& \text { computerized random-number generator, stratifying by age." }\end{aligned}$

Comment: probably done

\begin{tabular}{|c|c|c|}
\hline $\begin{array}{l}\text { Blinding of outcome as- } \\
\text { sessment (detection bias) }\end{array}$ & Low risk & $\begin{array}{l}\text { Quote: "Nurse assessors were blind to the treatment assignment of the chil- } \\
\text { dren." }\end{array}$ \\
\hline All outcomes & & Comment: probably done \\
\hline
\end{tabular}

\begin{tabular}{lll}
\hline $\begin{array}{l}\text { Incomplete outcome data } \\
\text { (attrition bias) } \\
\text { All outcomes }\end{array}$ & Unclear risk & $\begin{array}{l}\text { Attrition was reported, but no data were presented describing equivalence be } \\
\text { tween completers and non-completers }\end{array}$ \\
\hline $\begin{array}{l}\text { Selective reporting (re- } \\
\text { porting bias) }\end{array}$ & High risk & $\begin{array}{l}\text { Pre-specified outcomes identified in the Methods were not fully reported in } \\
\text { the Results. The study authors provided these data on request }\end{array}$ \\
\hline
\end{tabular}

Levy 2016

\section{Study characteristics}

\begin{tabular}{|c|c|}
\hline Methods & $\begin{array}{l}\text { RCT. } 2 \text { arms. Assessed pre-treatment, } 1 \text { week post-treatment, 3-month follow-up, 6-month follow-up, } \\
\text { 12-month follow-up }\end{array}$ \\
\hline \multirow[t]{9}{*}{ Participants } & $\begin{array}{l}\text { End of treatment } n=150,3 \text {-month follow-up } n=139,6 \text {-month follow-up } n=141,12 \text {-month follow-up } n \\
=138\end{array}$ \\
\hline & Start of treatment $\mathrm{n}=185$ \\
\hline & Child sex: $98 \mathrm{M}, 87 \mathrm{~F}$ \\
\hline & Parent sex: $18 \mathrm{M}, 167 \mathrm{~F}$ \\
\hline & Child age (mean, SD): $13.5 \pm 2.7$ years \\
\hline & Parent age (mean, SD): $44.4 \pm 6.9$ years \\
\hline & Source: hospital \\
\hline & Medical condition: IBD \\
\hline & Illness duration: not reported \\
\hline \multirow[t]{7}{*}{ Interventions } & "Social Learning Cognitive Behavioral Therapy Irritable Bowel Disease (SLCBT IBD)" \\
\hline & "Educational Support" \\
\hline & Mode of delivery: face-to-face, individual/family \\
\hline & Intervention delivered by: master's-level therapist \\
\hline & Training: not reported \\
\hline & Duration of intervention (child): 3 sessions $\times 75 \mathrm{~min}=4 \mathrm{~h}$ \\
\hline & Duration of intervention (parent): 3 sessions $\times 75 \mathrm{~min}=4 \mathrm{~h}$ \\
\hline
\end{tabular}


Levy 2016 (Continued)

\author{
Child measures \\ Pain Response Inventory \\ Pain Beliefs Questionaire \\ IMPACT-III (IBD Quality of Life) \\ Child Depression Inventory ${ }^{\star}$ \\ Multidimensional Anxiety Scale for Children \\ Functional Disability Inventory*
}

\title{
Parent measures
}

Adults' Responses to Children's Symptoms*

Pain Response Inventory

Pain Beliefs Questionnaire

Number of hospital stays and doctor's visits for IBD

Days of school missed due to Gl symptoms

Functional Disability Inventory

Notes

Funding: "Supported by a grant from the Eunice Kennedy Shriver National Institute of Child Health and Human Development (award number R01HD050345 to R. L. Levy)."

COI: "The authors have no conflict of interest to disclose."

\section{Risk of bias}

\begin{tabular}{|c|c|c|}
\hline Bias & Authors' judgement & Support for judgement \\
\hline $\begin{array}{l}\text { Random sequence genera- } \\
\text { tion (selection bias) }\end{array}$ & Low risk & $\begin{array}{l}\text { Quote: "Randomization was then performed by a different researcher using a } \\
\text { computerized random-number generator" } \\
\text { Comment: probably done }\end{array}$ \\
\hline $\begin{array}{l}\text { Allocation concealment } \\
\text { (selection bias) }\end{array}$ & Low risk & $\begin{array}{l}\text { Quote: "Randomization was then performed by a different researcher using a } \\
\text { computerized random-number generator" } \\
\text { Comment: probably done }\end{array}$ \\
\hline $\begin{array}{l}\text { Blinding of outcome as- } \\
\text { sessment (detection bias) } \\
\text { All outcomes }\end{array}$ & Low risk & $\begin{array}{l}\text { Quote: "At all assessment points, parents completed questionnaires online or } \\
\text { by mail (whichever modality they preferred). Children completed assessments } \\
\text { through a scheduled telephone call with a highly trained research nurse who } \\
\text { was blinded to the participant's treatment assignment." } \\
\text { Comment: probably done }\end{array}$ \\
\hline $\begin{array}{l}\text { Incomplete outcome data } \\
\text { (attrition bias) } \\
\text { All outcomes }\end{array}$ & Unclear risk & $\begin{array}{l}\text { Attrition was reported, but no data were presented describing equivalence be- } \\
\text { tween completers and non-completers }\end{array}$ \\
\hline $\begin{array}{l}\text { Selective reporting (re- } \\
\text { porting bias) }\end{array}$ & High risk & $\begin{array}{l}\text { Pre-specified outcomes identified in the Methods were not fully reported in } \\
\text { the Results. The study authors provided these data on request }\end{array}$ \\
\hline
\end{tabular}


Levy 2017

\section{Study characteristics}

Methods

RCT. 3 arms. Assessed pre-treatment, 1 week post-treatment, 3-month follow-up, 6-month follow-up

Participants

End of treatment $n=243$, 3-month follow-up $n=235,6$-month follow-up $n=234$

Start of treatment $\mathrm{n}=316$

Child sex: 112 M, 204 F

Parent sex: $16 \mathrm{M}, 300 \mathrm{~F}$

Child age (mean, SD): $9.4 \pm 1.7$ years

Parent age (mean, SD): $39.9 \pm 7.4$ years

Source: hospital

Medical condition: functional abdominal pain

Illness duration: not reported

Interventions

"Social Learning and Cognitive Behavioral Therapy Functional Abdomnial Pain (SLCBT FAP)"

"Social Learning and Cognitive Behavioral Therapy Remote (SLCBT Remote), education or support"

Mode of delivery: arm 1, face-to-face, individual. Arm 2, remote-telephone, individual

Intervention delivered by: both arms, advanced clinical psychology graduate students, or master's-level social workers

Training: treatment manual + training including didactics, observation, role play

Duration of intervention (child): none

Duration of intervention (parent): 3 sessions $\times 60 \mathrm{~min}=3 \mathrm{~h}$

\section{Outcomes}

*Extracted outcome measures used in the analyses

\section{Child measures}

Abdominal Pain Index*
Pain Response Inventory
Children's Somatization Inventory
Pediatric Quality of Life Inventory
Functional Disability Inventory

Parent measures

Adults' Responses to Children's Symptoms*

Pain Beliefs Questionnaire

Pain Catastrophizing Scale-Parent self-report*

Functional Disability Inventory

Number of hospital stays and doctor's visits

Days of school missed 
Levy 2017 (Continued)

Pain Behavior Check List

Children's Somatization Inventory

Pediatric Quality of Life Inventory

Notes

Funding: "This study was supported by award R01HD36069-0981 from the Eunice Kennedy Shriver National Institute of Child Health and Human Development (R.L.L.)."

COI: "Conflict of interest statement: The authors have no conflicts of interest relevant to this article to disclose."

\section{Risk of bias}

\begin{tabular}{|c|c|c|}
\hline Bias & Authors' judgement & Support for judgement \\
\hline \multirow[t]{2}{*}{$\begin{array}{l}\text { Random sequence genera- } \\
\text { tion (selection bias) }\end{array}$} & Low risk & $\begin{array}{l}\text { Quote: "Randomization using a computer-generated randomization sequence } \\
\text { occurred after baseline assessments" }\end{array}$ \\
\hline & & Comment: probably done \\
\hline \multirow[t]{2}{*}{$\begin{array}{l}\text { Allocation concealment } \\
\text { (selection bias) }\end{array}$} & Low risk & $\begin{array}{l}\text { Quote: "Recruiters and physicians were blind to treatment assignment. After } \\
\text { enrolment and completion of baseline assessments, the study coordinator } \\
\text { queried the randomization database for treatment assignment" }\end{array}$ \\
\hline & & Comment: probably done \\
\hline \multirow[t]{2}{*}{$\begin{array}{l}\text { Blinding of outcome as- } \\
\text { sessment (detection bias) } \\
\text { All outcomes }\end{array}$} & Low risk & $\begin{array}{l}\text { Quote: "Parents completed questionnaires online or by mail ( } 90.5 \% \text { online). } \\
\text { Children completed assessments through a telephone call with a trained inter- } \\
\text { viewer blinded to study hypotheses and treatment assignment." }\end{array}$ \\
\hline & & Comment: probably done \\
\hline $\begin{array}{l}\text { Incomplete outcome data } \\
\text { (attrition bias) } \\
\text { All outcomes }\end{array}$ & Unclear risk & $\begin{array}{l}\text { Attrition was reported, but no data were presented describing equivalence be- } \\
\text { tween completers and non-completers }\end{array}$ \\
\hline $\begin{array}{l}\text { Selective reporting (re- } \\
\text { porting bias) }\end{array}$ & High risk & $\begin{array}{l}\text { Pre-specified outcomes identified in the Methods were not fully reported in } \\
\text { the Results. The study authors provided these data on request }\end{array}$ \\
\hline
\end{tabular}

May 2017

\section{Study characteristics}

\begin{tabular}{ll}
\hline Methods & RCT. 2 arms. Assessed pre-treatment and post-treatment (same day as intervention) \\
\hline Participants & End of treatment $n=79$ \\
& Child sex: $35 \mathrm{M}, 44 \mathrm{~F}$ \\
& Parent sex: $11 \mathrm{M}, 68 \mathrm{~F}$ \\
& Child age (mean, SD): $14.9 \pm 1.5$ years \\
Parent age: not reported & Source: hospital
\end{tabular}


May 2017 (Continued)

Medical condition: type 1 diabetes

Illness duration (mean): 8.8 years

"Motivational Interviewing"
"Education"
Mode of delivery: face-to-face, individual
Intervention delivered by: clinical psychology doctoral student
Training: quarterly supervision from a paediatric psychologist
Duration of intervention (child): none
Duration of intervention (parent): $1 \times 30$-min session

Outcomes

*Extracted outcome measures used in the analyses

\section{Child measures}

Inclusion of Others in the Self scale (IOS)*

Measure of Intimate Events (MIE)

Observed communication

\section{Parent measures}

Inclusion of Others in the Self scale (IOS)

Measure of Intimate Events (MIE)

Observed communication*

Notes

Funding: "Financial support provided by Wayne State University and Beaumont Health Systems HIC \#2013 0 470."

COI: "Conflicts of interest: None declared."

\section{Risk of bias}

\section{Bias}

Random sequence genera- Unclear risk tion (selection bias)

\section{Authors' judgement Support for judgement}

Quote: "Families were then randomized to intervention or control using a flip book with a pre assigned randomization number (to ensure that the interventionist remained blind to the dyads' group assignments during the initial rating of communication skills)."

Comment: randomization probably done but flip book method is unclear

Allocation concealment $\quad$ Low risk
(selection bias)

Quote: "Families were then randomized to intervention or control using a flip book with a pre-assigned randomization number (to ensure that the interventionist remained blind to the dyads' group assignments during the initial rating of communication skills)."

Comment: probably done

\begin{tabular}{|c|c|c|}
\hline $\begin{array}{l}\text { Blinding of outcome as- } \\
\text { sessment (detection bias) }\end{array}$ & Low risk & $\begin{array}{l}\text { Quote: "Both discussion tasks were video-recorded for later coding by inde- } \\
\text { pendent, blinded coders." }\end{array}$ \\
\hline
\end{tabular}

Comment: probably done 
May 2017 (Continued)

Incomplete outcome data Low risk Attrition was reported; there was no participant dropout (attrition bias)

All outcomes

Selective reporting (re- Low risk Outcomes data were fully reported
porting bias)

Mayer-Davis 2015

\section{Study characteristics}

\begin{tabular}{|c|c|}
\hline Methods & RCT. 2 arms. Assessed pre-treatment and 1-month follow-up (4 months post-baseline) \\
\hline \multirow[t]{9}{*}{ Participants } & End of treatment $\mathrm{n}=58$ \\
\hline & Start of treatment $n=61$ \\
\hline & Child sex: not reported \\
\hline & Parent sex: not reported \\
\hline & Child age (mean, SD): $13.9 \pm 1.4$ years \\
\hline & Parent age: not reported \\
\hline & Source: hospital \\
\hline & Medical condition: type 1 diabetes \\
\hline & Illness duration (mean): 7.4 years \\
\hline \multirow[t]{7}{*}{ Interventions } & "FL3X Diabetes" \\
\hline & "Usual care" \\
\hline & Mode of delivery: face-to-face, individual \\
\hline & Intervention delivered by: pediatric diabetes clinicians/educators \\
\hline & $\begin{array}{l}\text { Training: 2-day motivational interviewing training and 2-day recruitment and intervention workshop, } \\
\text { continuous training and supervision calls weekly }\end{array}$ \\
\hline & Duration of intervention (child): 3 sessions +2 optional sessions $(40-60$ min each) $=3-5 \mathrm{~h}$ \\
\hline & Duration of intervention (parent): 3 sessions +2 optional sessions $(40-60 \mathrm{~min}$ each $)=3-5 \mathrm{~h}$ \\
\hline \multirow[t]{5}{*}{ Outcomes } & ${ }^{*}$ Extracted outcome measures used in the analyses \\
\hline & Child measures \\
\hline & $\mathrm{HbA} 1 c^{*}$ \\
\hline & Pediatric Diabetes Quality of Life \\
\hline & Pediatric Quality of Life 4.0 \\
\hline \multirow[t]{2}{*}{ Notes } & $\begin{array}{l}\text { Funding: "Funding was received from the National Institutes of Health (R21-DK085483; to E.J.M.-D. and } \\
\text { M.S.)." }\end{array}$ \\
\hline & COI: "Competing interests: None declared." \\
\hline
\end{tabular}


Mayer-Davis 2015 (Continued)

Risk of bias

\begin{tabular}{|c|c|c|}
\hline Bias & Authors' judgement & Support for judgement \\
\hline $\begin{array}{l}\text { Random sequence genera- } \\
\text { tion (selection bias) }\end{array}$ & Low risk & $\begin{array}{l}\text { Quote: "Participants were randomized, within each clinical site, electronically } \\
\text { via a predetermined allocation embedded within the study web site" } \\
\text { Comment: probably done }\end{array}$ \\
\hline $\begin{array}{l}\text { Allocation concealment } \\
\text { (selection bias) }\end{array}$ & Low risk & $\begin{array}{l}\text { Quote: "Participants were randomized, within each clinical site, electronically } \\
\text { via a predetermined allocation embedded within the study web site" } \\
\text { Comment: probably done }\end{array}$ \\
\hline $\begin{array}{l}\text { Blinding of outcome as- } \\
\text { sessment (detection bias) } \\
\text { All outcomes }\end{array}$ & Unclear risk & $\begin{array}{l}\text { Quote: "Baseline and 4-month end-of-study measures were collected in per- } \\
\text { son." } \\
\text { Comment: insufficient information provided on detection bias to permit } \\
\text { judgement }\end{array}$ \\
\hline $\begin{array}{l}\text { Incomplete outcome data } \\
\text { (attrition bias) } \\
\text { All outcomes }\end{array}$ & Unclear risk & $\begin{array}{l}\text { Attrition was reported, but no data were presented describing equivalence be- } \\
\text { tween completers and non-completers }\end{array}$ \\
\hline $\begin{array}{l}\text { Selective reporting (re- } \\
\text { porting bias) }\end{array}$ & Low risk & Outcomes data were fully reported \\
\hline
\end{tabular}

Morawska 2016

\section{Study characteristics}

\begin{tabular}{ll}
\hline Methods & RCT. 2 arms. Assessed pre-treatment, post-treatment (4 weeks), 6-month follow-up \\
\hline Participants & End of treatment $n=83,6$-month follow-up $n=75$ \\
& Start of treatment $n=107$ \\
& Child sex: $56 \mathrm{M}, 51 \mathrm{~F}$ \\
& Parent sex: not reported \\
& Child age (mean, SD): $5.0 \pm 2.2$ years \\
& Parent age: 37.3 years \\
& Source: hospital, community \\
& Medical condition: asthma, eczema \\
Illness duration (mean): 4.1 years (eczema), 2.3 years (asthma) \\
"Triple P Asthma/Eczema" \\
"Care as usual" \\
Mode of delivery: face-to-face, group \\
Intervention delivered by: psychologists or nurses \\
Training: all study therapists had Triple P accreditation \\
\hline Interventions
\end{tabular}


Morawska 2016 (Continued)

Duration of intervention (child): none

Duration of intervention (parent): 2 sessions $\times 2 h=4 h$

\begin{tabular}{|c|c|}
\hline \multirow[t]{11}{*}{ Outcomes } & *Extracted outcome measures used in the analyses \\
\hline & Parent measures \\
\hline & Parents' Self-Efficacy with Eczema Care Index ${ }^{\star}$ \\
\hline & Asthma Parent Tasks Checklist* \\
\hline & Eczema Behavior Checklist* \\
\hline & Asthma Behavior Checklist* \\
\hline & Pediatric Quality of Life 4.0 \\
\hline & PedsQL Family Impact Module* \\
\hline & Patient-Oriented Eczema Measure* \\
\hline & Asthma episode frequency and severity* \\
\hline & Observed at-home medical management \\
\hline \multirow[t]{2}{*}{ Notes } & Funding: "This research was supported by the Australian Research Council DP110102449." \\
\hline & $\begin{array}{l}\text { COI: "The Triple P - Positive Parenting Program is owned by The University of Queensland. The Uni- } \\
\text { versity, through its main technology transfer company, UniQuest Pty Ltd, has licensed Triple P Inter- } \\
\text { national Pty Ltd to publish and disseminate the program worldwide. Royalties stemming from pub- } \\
\text { lished Triple P resources are distributed in accordance with the University's intellectual property policy } \\
\text { and flow to the Parenting and Family Support Centre, School of Psychology, Faculty of Health and be- } \\
\text { havioral Sciences, and contributory authors. No author has any share or ownership in Triple P Interna- } \\
\text { tional Pty Ltd. Alina Morawska is an author of various Triple P resources including that reported in this } \\
\text { study. Amy Mitchell is a staff member employed at the Parenting and Family Support Centre. The oth- } \\
\text { er authors have no potential conflicts of interest or financial relationships relevant to this article to dis- } \\
\text { close." }\end{array}$ \\
\hline
\end{tabular}

Risk of bias

Bias Authors' judgement Support for judgement

Random sequence genera- Low risk tion (selection bias)
Quote: "Allocation was by block randomization, using computer-generated randomly-selected block sizes (4, 6 , or 8 participants per block) and random group allocation within each block. An external researcher generated random allocation sequences, and prepared sequentially-numbered opaque envelopes to conceal group allocation. Envelopes were assigned by a research assistant in the order families completed T1 assessment."

Comment: probably done
Quote: "Allocation was by block randomization, using computer-generated randomly-selected block sizes (4, 6, or 8 participants per block) and random group allocation within each block. An external researcher generated random allocation sequences, and prepared sequentially-numbered opaque envelopes to conceal group allocation. Envelopes were assigned by a research assistant in the order families completed T1 assessment."

Comment: probably done

\begin{tabular}{|c|c|c|}
\hline $\begin{array}{l}\text { Blinding of outcome as- } \\
\text { sessment (detection bias) }\end{array}$ & Unclear risk & $\begin{array}{l}\text { Quote: "Prior to randomization, participants completed T1 assessment, con- } \\
\text { sisting of: parent-reported questionnaires, in online }(n=95) \text { or hardcopy }(n=\end{array}$ \\
\hline
\end{tabular}

Psychological interventions for parents of children and adolescents with chronic illness (Review) Copyright $\odot 2019$ The Cochrane Collaboration. Published by John Wiley \& Sons, Ltd. 
Morawska 2016 (Continued)

All outcomes
12) format depending on parent preference; two weeks of symptom monitoring; and participation in an observation of a typical home treatment session."

Comment: insufficient information provided on detection bias to permit judgement, particularly on observation of home management

Incomplete outcome data Unclear risk (attrition bias)

Attrition was reported, but no data were presented describing equivalence beAll outcomes tween completers and non-completers

\section{Selective reporting (re- High risk} porting bias)

Pre-specified outcomes identified in the Methods were not fully reported in the Results. The study authors provided these data on request

Naar-King 2014

\section{Study characteristics}

\begin{tabular}{|c|c|}
\hline Methods & $\mathrm{RCT}, 2$ arms. Assessed at pre-treatment, post-treatment $=7$ months after baseline data collection \\
\hline \multirow[t]{9}{*}{ Participants } & End of treatment $n=153$ \\
\hline & Start of treatment $\mathrm{n}=170$ \\
\hline & Child sex: $102 \mathrm{M}, 65 \mathrm{~F}$ \\
\hline & Parent sex: not reported \\
\hline & Child age (mean, SD): $13.5 \pm 1.3$ years \\
\hline & Parent age: not reported \\
\hline & Source: hospital \\
\hline & Medical condition: asthma \\
\hline & Illness duration: not reported \\
\hline \multirow[t]{7}{*}{ Interventions } & "Multisystemic Therapy-Health Care" \\
\hline & "Family support" \\
\hline & Mode of delivery: face-to-face, family \\
\hline & Intervention delivered by: master's-level therapist \\
\hline & Training: 5-day training, weekly consultation with MST expert, quarterly booster training \\
\hline & Duration of intervention (child): mean 31 sessions, range $0-62$ \\
\hline & Duration of intervention (parent): mean 31 sessions, range 0-62 \\
\hline
\end{tabular}

Outcomes

*Extracted outcome measures used in the analyses

\section{Child measures}

Rollnicks Readiness Ruler

Family Asthma Management System Scale*

Adherence to daily corticosteroid medication 
Naar-King 2014 (Continued)

$$
\text { Lung function (FEV1) * }
$$

Notes $\quad$ Funding: "This research was supported by a grant from the National Institute of Health (1R01AA022891-01)"

COI: "Philip Cunningham is co-owner of Evidence Based Services."

\section{Risk of bias}

Bias Authors' judgement Support for judgement

Random sequence genera- Unclear risk tion (selection bias)

Quote: "Randomization was stratified based on (1) severity of asthma complications as indicated by the number of recent hospitalizations.... (2) receipt of asthma specialty care (...)."

Comment: method not described

\begin{tabular}{lll}
\hline $\begin{array}{l}\text { Allocation concealment } \\
\text { (selection bias) }\end{array}$ & Unclear risk & $\begin{array}{l}\text { No description found in text } \\
\text { Comment: probably not done }\end{array}$ \\
\hline $\begin{array}{l}\text { Blinding of outcome as- } \\
\text { sessment (detection bias) } \\
\text { All outcomes }\end{array}$ & Low risk & $\begin{array}{l}\text { Quote: "Baseline data collection, including spirometry, subsequently occurred } \\
\text { in the home by trained research assistants. All data collectors were blind to the } \\
\text { participant's study condition." }\end{array}$ \\
& Comment: probably done
\end{tabular}

\begin{tabular}{|c|c|c|}
\hline $\begin{array}{l}\text { Incomplete outcome data } \\
\text { (attrition bias) }\end{array}$ & Low risk & $\begin{array}{l}\text { Attrition was reported and data were presented describing equivalence be- } \\
\text { tween completers and non-completers }\end{array}$ \\
\hline
\end{tabular}

All outcomes

Selective reporting (re- High risk porting bias)

Pre-specified outcomes identified in the Methods were not fully reported in the Results. The study authors provided these data on request

Nansel 2009

\section{Study characteristics}

\begin{tabular}{ll}
\hline Methods & RCT, 2 arms. Assessed at pre-treatment, 3 weeks after last clinic visit post-treatment \\
\hline Participants & End of treatment $n=116$ \\
& Start of treatment $n=122$ \\
& Child sex: not reported \\
& Parent sex: not reported \\
& Child age (mean): 11.5 years \\
& Parent age: not reported \\
Source: hospital & Medical condition: type 1 diabetes \\
Illness duration: 5.8 years
\end{tabular}


Nansel 2009 (Continued)
"Usual Care Comparison"
Mode of delivery: face-to-face + remote-telephone, family
Intervention delivered by: health advisors (college graduates)
Training: not reported
Duration of intervention (child): 3 sessions and 9 phone calls
Duration of intervention (parent): 3 sessions and 9 phone calls

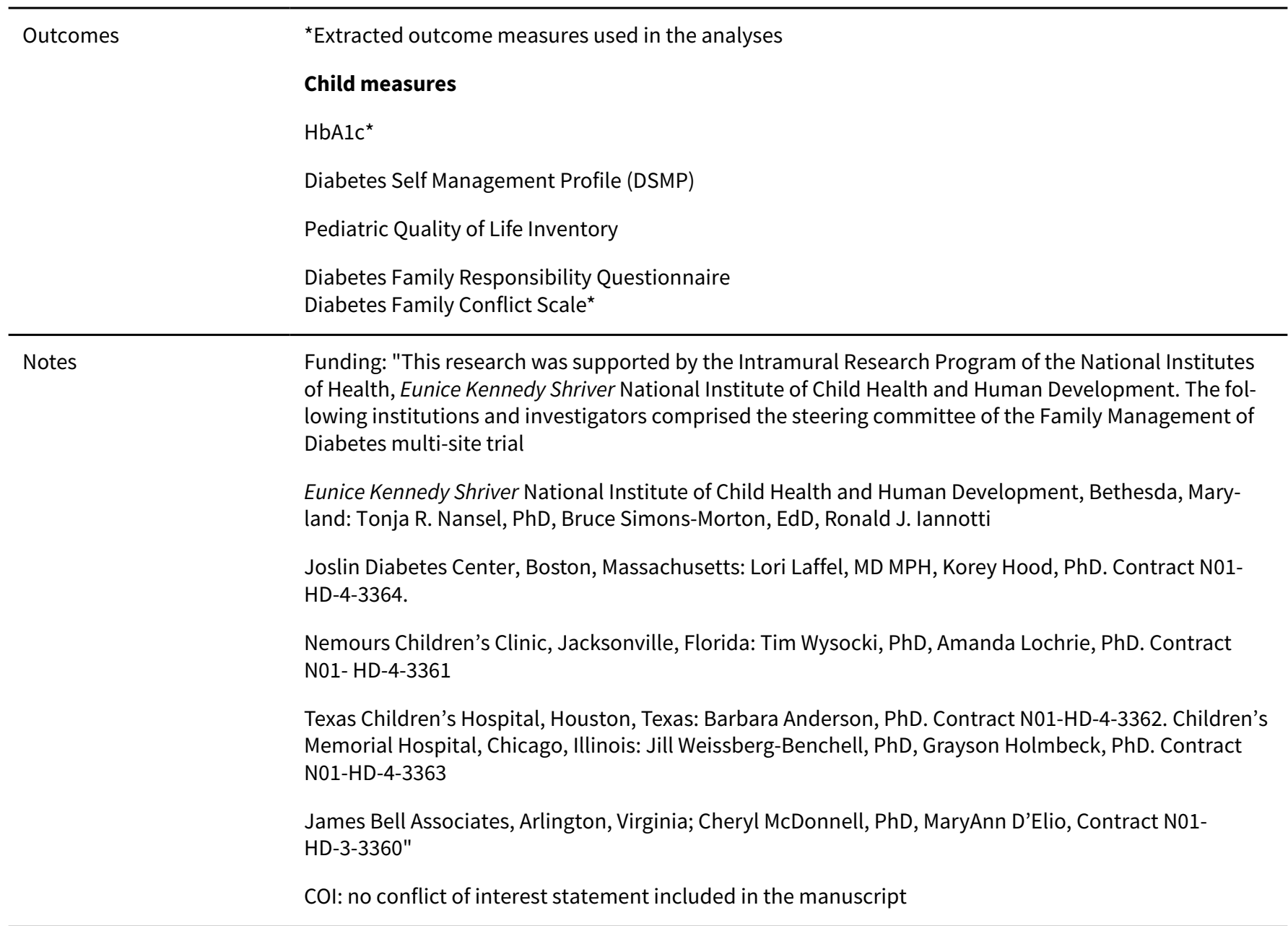

\section{Risk of bias}

\begin{tabular}{lll}
\hline Bias & Authors' judgement & Support for judgement \\
\hline $\begin{array}{l}\text { Random sequence genera- } \\
\text { tion (selection bias) }\end{array}$ & Unclear risk & $\begin{array}{l}\text { Quote: "30 to 32 families (total of 122) meeting the eligibility criteria were re- } \\
\text { cruited and randomized into intervention or usual care groups." No method } \\
\text { given } \\
\text { Comment: method not described }\end{array}$ \\
\hline $\begin{array}{l}\text { Allocation concealment } \\
\text { (selection bias) }\end{array}$ & Unclear risk & No description found in text \\
\hline $\begin{array}{l}\text { Blinding of outcome as- } \\
\text { sessment (detection bias) }\end{array}$ & Low risk & \begin{tabular}{l} 
Comment: probably not done \\
\hline
\end{tabular}
\end{tabular}

Psychological interventions for parents of children and adolescents with chronic illness (Review) 
Nansel 2009 (Continued)

All outcomes visits at baseline and follow-up by trained interviewers not employed by the clinic."

Comment: probably done

$\begin{array}{ll}\text { Incomplete outcome data High risk } & \text { Attrition was not reported } \\ \text { (attrition bias) }\end{array}$

All outcomes

Selective reporting (re- Low risk Outcomes data were fully reported
porting bias)

Nansel 2012

\section{Study characteristics}

\begin{tabular}{|c|c|}
\hline Methods & RCT. 2 arms. Assessed at pre-treatment, 24 months post-treatment \\
\hline \multirow[t]{9}{*}{ Participants } & End of treatment $n=331$ \\
\hline & Start of treatment $\mathrm{n}=390$ \\
\hline & Child sex: 192 M, 198 F \\
\hline & Parent sex: not reported \\
\hline & Child age (mean, SD): $12.5 \pm 1.8$ years \\
\hline & Parent age: not reported \\
\hline & Source: hospital \\
\hline & Medical condition: type 1 diabetes \\
\hline & Illness duration (mean): 4.9 years \\
\hline \multirow[t]{7}{*}{ Interventions } & "WECAN intervention" \\
\hline & "Usual Care Comparison" \\
\hline & Mode of delivery: face-to-face + remote-telephone, family \\
\hline & Intervention delivered by: health advisor \\
\hline & $\begin{array}{l}\text { Training: 2-day workshop including didactics, modelling, and practice, weekly conference calls, annual } \\
\text { in-person training }\end{array}$ \\
\hline & Duration of intervention (child, hours): 6 sessions +18 phone calls \\
\hline & Duration of intervention (parent, hours): 6 sessions +18 phone calls \\
\hline \multirow[t]{5}{*}{ Outcomes } & ${ }^{\star}$ Extracted outcome measures used in the analyses \\
\hline & Child measures \\
\hline & $\mathrm{HbAlc}{ }^{*}$ \\
\hline & Diabetes Self-Management Profile \\
\hline & Blood glucose meter data \\
\hline
\end{tabular}


Nansel 2012 (Continued)

Notes
Funding: "Supported by the intramural research program of the National Institutes of Health, Eunice Kennedy Shriver National Institute of Child Health and Human Development, under the following contracts: N01-HD-4-3364, Joslin Diabetes Center, Boston, Massachusetts; N01-HD-4-3361, Nemours Children's Clinic, Jacksonville, Florida; N01-HD-4-3362, Texas Children's Hospital, Houston, Texas; N01HD-4-3363, Children's Memorial Hospital, Chicago, Illinois; and N01-HD-3-3360, James Bell Associates, Arlington, Virginia. Funded by the National Institutes of Health (NIH)"

COI: "Financial Disclosure: The authors have indicated that they have no financial relationships relevant to this article to disclose."

\section{Risk of bias}

\begin{tabular}{|c|c|c|}
\hline Bias & Authors' judgement & Support for judgement \\
\hline $\begin{array}{l}\text { Random sequence genera- } \\
\text { tion (selection bias) }\end{array}$ & Low risk & $\begin{array}{l}\text { Quote: "A system of random permuted blocks within strata was prepared by } \\
\text { the study coordinating center by a person not involved with data collection." } \\
\text { Comment: probably done }\end{array}$ \\
\hline $\begin{array}{l}\text { Allocation concealment } \\
\text { (selection bias) }\end{array}$ & Low risk & $\begin{array}{l}\text { Quote: "A separate randomization list was prepared for each strata; lists were } \\
\text { transferred to a sequence of sealed envelopes, each containing the assign- } \\
\text { ment of intervention or usual care. Persons conducting assessments were } \\
\text { blinded to study assignment." } \\
\text { Comment: probably done }\end{array}$ \\
\hline $\begin{array}{l}\text { Blinding of outcome as- } \\
\text { sessment (detection bias) } \\
\text { All outcomes }\end{array}$ & Low risk & $\begin{array}{l}\text { Quote: "Persons conducting assessments were blinded to study assignment." } \\
\text { Comment: probably done }\end{array}$ \\
\hline $\begin{array}{l}\text { Incomplete outcome data } \\
\text { (attrition bias) } \\
\text { All outcomes }\end{array}$ & Low risk & $\begin{array}{l}\text { Attrition was reported, there were no significant differences between com- } \\
\text { pleters and non-completers }\end{array}$ \\
\hline $\begin{array}{l}\text { Selective reporting (re- } \\
\text { porting bias) }\end{array}$ & High risk & $\begin{array}{l}\text { Pre-specified outcomes identified in the Methods were not fully reported in } \\
\text { the Results. The study authors provided these data on request }\end{array}$ \\
\hline
\end{tabular}

Palermo 2009

\section{Study characteristics}

\begin{tabular}{ll}
\hline Methods & RCT. 2 arms. Assessed at pre-treatment, post-treatment and 3-month follow-up \\
\hline Participants & End of treatment $\mathrm{n}=44$ \\
Start of treatment $\mathrm{n}=48$ \\
Child sex: $13 \mathrm{M}, 35 \mathrm{~F}$ \\
Parent sex: $7 \mathrm{M}, 41 \mathrm{~F}$ \\
Child age (mean, SD): $14.8 \pm 2.0$ years \\
Parent age: not reported \\
Source: hospital \\
Medical condition: chronic pain
\end{tabular}


Palermo 2009 (Continued)

Illness duration (mean): 30 months

Interventions $\quad$ Web-based Management of Adolescent Pain (Web-MAP)"
"Wait list control group"
Mode of delivery: remote-internet, individual
Intervention delivered by: internet + psychology postdoctoral fellow
Training: 1 year of experience delivering face-to-face CBT to children with chronic pain
Duration of intervention (child): 8 modules $\times 30$ min $=4 \mathrm{~h}$
Duration of intervention (parent): 8 modules $\times 30 \mathrm{~min}=4 \mathrm{~h}$

Outcomes $\quad$ Extracted outcome measures used in the analyses

\section{Child measures}

Pain intensity (11-point numerical rating scale)*

Child Activity Limitations Interview*

Revised Child Anxiety and Depression Scale*

\section{Parent measures}

Adult Responses to Children's Symptoms*

Notes

Funding: "This research was supported by Grant HD050674 from the National Institutes of Health/National Institute of Child Health and Human Development (PI: Palermo) and by a grant from the Doernbecher Foundation"

COI: "Conflict of interests: The present manuscript is submitted exclusively to Pain and is not under consideration in any other journal. There are no financial relationships that might lead to a conflict of interest."

\section{Risk of bias}

\begin{tabular}{|c|c|c|}
\hline Bias & Authors' judgement & Support for judgement \\
\hline \multirow[t]{2}{*}{$\begin{array}{l}\text { Random sequence genera- } \\
\text { tion (selection bias) }\end{array}$} & Low risk & $\begin{array}{l}\text { Quote: "A fixed allocation randomization scheme was used. Specifically, we } \\
\text { used blocked randomization with blocks of } 10 \text { to assign participants to the two } \\
\text { treatment conditions during the course of randomization. An online random } \\
\text { number generator was used to produce the blocked randomization." }\end{array}$ \\
\hline & & Comment: probably done \\
\hline \multirow[t]{2}{*}{$\begin{array}{l}\text { Allocation concealment } \\
\text { (selection bias) }\end{array}$} & Low risk & $\begin{array}{l}\text { Quote: "Group assignments were identified by ID number in sealed envelopes. } \\
\text { Following completion of all pre-treatment assessments, a research coordina- } \\
\text { tor opened the sealed envelope to reveal the group assignment." }\end{array}$ \\
\hline & & Comment: probably done \\
\hline
\end{tabular}

Blinding of outcome as-
sessment (detection bias) $\quad$ Low risk Participants completed questionnaires online

All outcomes

$\begin{array}{ll}\begin{array}{l}\text { Incomplete outcome data } \\ \text { (attrition bias) }\end{array} & \text { Low risk } \\ \text { All outcomes } & \text { Attrition was reported, no significant differences between completers and } \\ \end{array}$


Palermo 2009 (Continued)

Selective reporting (re- Low risk Outcomes data were fully reported porting bias)

Palermo 2016a

\section{Study characteristics}

\begin{tabular}{|c|c|}
\hline Methods & RCT. 2 arms. Assessed at pre-treatment, post-treatment, 3-month follow-up \\
\hline \multirow[t]{9}{*}{ Participants } & End of treatment $n=60,3$-month follow-up $n=59$ \\
\hline & Start of treatment $n=61$ \\
\hline & Child sex: $12 \mathrm{M}, 49 \mathrm{~F}$ \\
\hline & Parent sex: $1 \mathrm{M}, 60 \mathrm{~F}$ \\
\hline & Child age (mean, SD) $=14.3 \pm 1.9$ years \\
\hline & Parent age: not reported \\
\hline & Source: hospital \\
\hline & Medical condition: chronic pain \\
\hline & Illness duration (mean): 2 years \\
\hline \multirow[t]{7}{*}{ Interventions } & "Problem-Solving Skills Training" \\
\hline & "Treatment as usual" \\
\hline & Mode of delivery: face-to-face or remote-telephone, individual \\
\hline & Intervention delivered by: psychology postdoctoral fellows, licensed clinical psychologists \\
\hline & Training: didactic training, role play, weekly cross-site supervision with a licensed clinical psychologist \\
\hline & Duration of intervention (child): none \\
\hline & Duration of intervention (parent): $4-6$ sessions $x 1 \mathrm{~h}=4-6 \mathrm{~h}$ \\
\hline
\end{tabular}

Outcomes $\quad$ Extracted outcome measures used in the analyses

\section{Child measures}

Pain intensity (11-point numerical rating scale)*

Bath Adolescent Pain Questionnaire-Physical Functioning Subscale, Depression Subscale*

\section{Parent measures}

The Brief Symptom Inventory-18

Beck Depression Inventory-II*

Profile of Mood States-Standard

Bath Adolescent Pain-Parental Impact Questionnaire-Parent Behavior Subscale*

Pain Catastrophizing Scale

Short Form Health Survey 12 
Palermo 2016a (Continued)

Parenting Stress Index-Short Form

Helping for Health Inventory

Social Problem-Solving Skills Inventory-Revised

Notes

Funding: "Research reported in this publication was supported by the Eunice Kennedy Shriver National Institute of Child Health \& Human Development of the National Institutes of Health under Award Number R21HD065180 (PI: T. M. P.)."

COI: "Conflict of interest statement: None of the authors have any conflicts of interest."

\section{Risk of bias}

\section{Bias Authors' judgement Support for judgement}

Random sequence genera- Low risk tion (selection bias)

Quote: "A fixed allocation randomization scheme was used. The order of randomization to the 2 treatment conditions was generated separately for each site with an online program (randomizer.org). A blocked method design was used, with blocks of 4 for each identification number"

Comment: probably done

Allocation concealment Low risk
(selection bias)

Quote: "Only the research coordinator had the password to the randomization table. Group assignment was concealed by formatting the document to block out group assignment until the time of randomization."

Comment: probably done

\begin{tabular}{|c|c|c|}
\hline \multirow[t]{2}{*}{$\begin{array}{l}\text { Blinding of outcome as- } \\
\text { sessment (detection bias) } \\
\text { All outcomes }\end{array}$} & Low risk & $\begin{array}{l}\text { Quote: "All study assessments were self-report measures completed in partic- } \\
\text { ipants' homes through mailings; children and parents were instructed to com- } \\
\text { plete the measures independently." }\end{array}$ \\
\hline & & Comment: probably done \\
\hline
\end{tabular}

$\begin{array}{ll}\begin{array}{l}\text { Incomplete outcome data } \\ \text { (attrition bias) }\end{array} & \text { Low risk } \\ \text { All outcomes } & \begin{array}{l}\text { Attrition was fully reported and there were no differences between completers } \\ \text { and non-completers }\end{array}\end{array}$

Selective reporting (re- Low risk Outcomes data were fully reported
porting bias)

\section{Palermo 2016b}

\section{Study characteristics}

\begin{tabular}{ll}
\hline Methods & RCT. 2 arms. Assessed at pre-treatment, post-treatment, 6-month follow-up \\
\hline Participants & End of treatment $n=258,6$-month follow-up $n=257$ \\
& Child sex: $68 \mathrm{M}, 205 \mathrm{~F}$ \\
& Parent sex: $16 \mathrm{M}, 257 \mathrm{~F}$ \\
Child age (mean, $\mathrm{SD})=14.7 \pm 1.6$ & Parent age: not reported
\end{tabular}


Palermo 2016b (Continued)

Source: hospital

Medical condition: chronic pain

Illness duration: not reported

Interventions $\quad$ Web-based Management of Adolescent Pain (Web-MAP)"
"Internet Education"
Mode of delivery: remote-internet, individual
Intervention delivered by: internet + master's degree or psychology postdoctoral fellows
Training: online coach manual + standard series training tasks (readings, role play, and supervision)
Duration of intervention (child): 8 modules $\times 30$ min $=4 \mathrm{~h}$
Duration of intervention (parent): 8 modules $\times 30$ min $=4 \mathrm{~h}$

Outcomes $\quad$ Extracted outcome measures used in the analyses

\section{Child measures}

Child Activity Limitations Interview*

Pain Intensity (11-point numerical rating scale)*

Bath Adolescent Pain Questionnaire-Depression Subscale*

Adolescent Sleep Wake Scale

Helping for Health Inventory

\section{Parent measures}

Adult Responses to Children's Symptoms*

Helping for Health Inventory

Bath Adolescent Pain-Parent Impact Questionnaire-Depression Subscale* tute of Child Health \& Human Development of the National Institutes of Health under Award Number R01HD062538 (T.M.P. [principal investigator])."

COI: "Conflict of interest statement: None of the authors have any conflicts of interest."

\section{Risk of bias}

\begin{tabular}{lll}
\hline Bias & Authors' judgement & Support for judgement \\
\hline $\begin{array}{l}\text { Random sequence genera- } \\
\text { tion (selection bias) }\end{array}$ & Low risk & $\begin{array}{l}\text { Quote: "Randomization was implemented using a computer-generated ran- } \\
\text { domization schedule to derive a randomization assignment to } 2 \text { treatment } \\
\text { conditions in blocks of } 4 \text { for each ID number." } \\
\text { Comment: probably done }\end{array}$ \\
\hline $\begin{array}{l}\text { Allocation concealment } \\
\text { (selection bias) }\end{array}$ & Low risk & $\begin{array}{l}\text { Quote: "The randomization assignment was programmed into the Web-MAP2 } \\
\text { system. After pretreatment assessments, the group assignment was provided } \\
\text { to each participant on the Web site with instructions on how to proceed during } \\
\text { the treatment phase." } \\
\text { Comment: probably done }\end{array}$ \\
& &
\end{tabular}


Palermo 2016b (Continued)

Blinding of outcome assessment (detection bias)

All outcomes
Low risk Quote: "Assessments were completed online through our secure, password-protected Web site independently by adolescents and parents (using separate login procedures) at baseline before randomization, after completion of the 8 to 10 week intervention (immediately after treatment) and at 2 longerterm follow-up periods ( 6 and 12 months). Because all study assessments were completed independently online, there was no possible examiner bias in outcome assessments."

Comment: probably done

Attrition was fully reported and study authors report that there were no differences between completers and non-completers
Incomplete outcome data Low risk (attrition bias)

All outcomes

Selective reporting (re- Low risk Outcomes data were fully reported

porting bias)

Powers 2013

\title{
Study characteristics
}

\begin{tabular}{|c|c|}
\hline Methods & $\begin{array}{l}\text { RCT. } 2 \text { arms. Assessed at pre-treatment, post-treatment ( } 20 \text { weeks), 3-month follow-up, 6-month fol- } \\
\text { low-up, 9-month follow-up, } 12 \text {-month follow-up }\end{array}$ \\
\hline \multirow[t]{9}{*}{ Participants } & $\begin{array}{l}\text { End of treatment } n=129,3 \text {-month follow-up } n=129,6 \text {-month follow-up } n=129,9 \text {-month follow-up } n= \\
129,12 \text {-month follow-up } n=124\end{array}$ \\
\hline & Start of treatment $n=135$ \\
\hline & Child sex: $28 \mathrm{M}, 107 \mathrm{~F}$ \\
\hline & Parent sex: $129 \mathrm{M}, 131 \mathrm{~F}$ \\
\hline & Child age (mean): 14.4 years \\
\hline & Parent age: not reported \\
\hline & Source: hospital \\
\hline & Medical condition: chronic migraine \\
\hline & Illness duration: not reported \\
\hline
\end{tabular}

Interventions

\author{
"Cognitive Behavioral Therapy + amitriptyline" \\ "Education + amitriptyline" \\ Mode of delivery: face-to-face, individual \\ Intervention delivered by: postdoctoral psychology fellows \\ Training: training and supervision by a licensed clinical psychologist with specialised experience in \\ pain management \\ Duration of intervention (child): 8 sessions $x 1 \mathrm{~h}+5$ booster sessions \\ Duration of intervention (parent): 3 sessions $x 1 \mathrm{~h}+5$ booster sessions
}

Outcomes $\quad$ Extracted outcome measures used in the analyses


Powers 2013 (Continued)

\author{
Child measures \\ Headache frequency* \\ Pediatric Migraine Disability Assessment Scale* \\ Children's Depression Inventory*
}

Funding: "Funding was provided by grant R01NS05036 from the National Institute of Neurological Dis-
orders and Stroke (Dr Powers), grant 8 UL1 TR000077 from the National Center for Research Resources
and the National Center for Advancing Translational Sciences, and grant T32DK063929 from the Na-
tional Institute of Diabetes and Digestive and Kidney Diseases for some of the postdoctoral fellows who
contributed to the trial (Dr Powers, program director). Amitriptyline, which was provided without cost
to participants, was purchased using National Institutes of Health grant funds and managed by the in-
vestigational pharmacy at Cincinnati Children's Hospital Medical Center."
COI: "Conflict of interest disclosures: The authors have completed and submitted the ICMJE Form for
Disclosure of Potential Conflicts of Interest and none were reported."

\title{
Risk of bias
}

\begin{tabular}{lll}
\hline Bias & Authors' judgement & Support for judgement \\
\hline $\begin{array}{ll}\text { Random sequence genera- } \\
\text { tion (selection bias) }\end{array}$ & Low risk & $\begin{array}{l}\text { Quote: "Block randomization (with varying block sizes of 4-10) was used, and } \\
\text { participants were stratified by age. Randomization was computer generat- } \\
\text { ed and supplied via secure e-mail to the study therapist" Comment: probably } \\
\text { done }\end{array}$ \\
&
\end{tabular}

\begin{tabular}{ll}
\hline $\begin{array}{l}\text { Allocation concealment } \\
\text { (selection bias) }\end{array}$ & Low risk \\
& $\begin{array}{l}\text { Quote: "Randomization was computer generated and supplied via secure e- } \\
\text { mail to the study therapist." Comment: probably done }\end{array}$
\end{tabular}

\begin{tabular}{lll}
\hline $\begin{array}{l}\text { Blinding of outcome as- } \\
\begin{array}{l}\text { sessment (detection bias) } \\
\text { All outcomes }\end{array}\end{array}$ & Low risk & $\begin{array}{l}\text { Quote: "Outcome assessments were conducted by blinded study personnel." } \\
\text { Comment: probably done }\end{array}$ \\
\hline $\begin{array}{l}\text { Incomplete outcome data } \\
\text { (attrition bias) } \\
\text { All outcomes }\end{array}$ & Unclear risk & $\begin{array}{l}\text { Attrition was reported, however significant differences between completers } \\
\text { and non-completers were not described }\end{array}$ \\
\hline $\begin{array}{l}\text { Selective reporting (re- } \\
\text { porting bias) }\end{array}$ & High risk & $\begin{array}{l}\text { Pre-specified outcomes identified in the Methods were not fully reported in } \\
\text { the Results. The authors provided these data on request }\end{array}$ \\
\hline
\end{tabular}

Robins 2005

\section{Study characteristics}

\begin{tabular}{ll}
\hline Methods & RCT. 2 arms. Assessed pre-treatment, post-treatment and 6-12 months following study entry \\
\hline Participants & End of treatment $n=69,6$-month follow-up $=69$ \\
& Start of treatment $n=86$ \\
& Child sex: 30 M, $39 \mathrm{~F}$ \\
& Parent sex: not reported \\
& Child age (mean, SD): $11.3 \pm 2.4$ years \\
& Parent age: not reported \\
\hline
\end{tabular}


Robins 2005 (Continued)

Source: hospital, primary care

Medical condition: recurrent abdominal pain

Illness duration: not reported

"Standard Medical Care plus Short-Term Cognitive-Behavioral Family Treatment"
"Standard Medical Care"
Mode of delivery: face-to-face, individual
Intervention delivered by: psychology post-doctoral fellow or pre-doctoral intern
Training: not reported
Duration of intervention (child): 5 sessions $\times 40$ mins $=3 \mathrm{~h} 20 \mathrm{mins}$
Duration of intervention (parent): 3 sessions $\times 40$ mins $=2 \mathrm{~h}$

Outcomes

${ }^{\star}$ Extracted outcome measures used in the analyses

\section{Child measures}

Abdominal Pain Index

Child Somatization Inventory

Functional Disability Inventory-Child Version

School Absences obtained from school attendance records

\section{Parent measures}

Abdominal Pain Index

Child Somatization Inventory

Clinician measures

Health service use obtained from physician offices

Notes $\quad$ Funding: "This study was supported in part by a grant through the Nemours Research Programs, awarded to the first author"

COI: no conflict of interest statement included in the manuscript

\section{Risk of bias}

\begin{tabular}{lll}
\hline Bias & Authors' judgement & Support for judgement \\
\hline $\begin{array}{l}\text { Random sequence genera- } \\
\text { tion (selection bias) }\end{array}$ & Low risk & $\begin{array}{l}\text { Quote: "The remaining sample of } 86 \text { were randomly assigned using a coin-flip } \\
\text { method." } \\
\text { Comment: probably done }\end{array}$ \\
\hline $\begin{array}{l}\text { Allocation concealment } \\
\text { (selection bias) }\end{array}$ & Unclear risk & No description found in text \\
\hline $\begin{array}{l}\text { Blinding of outcome as- } \\
\text { sessment (detection bias) } \\
\text { All outcomes }\end{array}$ & Unclear risk & Comment: probably not done \\
\hline
\end{tabular}


Robins 2005 (Continued)

Incomplete outcome data Unclear risk Attrition was reported, but no data were presented on significant differences (attrition bias) between completers and non-completers

All outcomes

\begin{tabular}{|c|c|c|}
\hline $\begin{array}{l}\text { Selective reporting (re- } \\
\text { porting bias) }\end{array}$ & High risk & $\begin{array}{l}\text { Pre-specified outcomes identified in the Methods were not fully reported in } \\
\text { the Results. The study authors did not provide these data when requested }\end{array}$ \\
\hline
\end{tabular}

\section{Sahler 2002}

\section{Study characteristics}

\begin{tabular}{|c|c|}
\hline Methods & RCT. 2 arms. Assessed pre-treatment, post-treatment and 3-month follow-up \\
\hline \multirow[t]{9}{*}{ Participants } & End of treatment $n=81$ \\
\hline & Start of treatment $\mathrm{n}=92$ \\
\hline & Child sex: not reported \\
\hline & Parent sex: $0 \mathrm{M}, 92 \mathrm{~F}$ \\
\hline & Child age (mean, SD): $8.3 \pm 5.5$ years \\
\hline & Parent age (mean, SD): $35.4 \pm 6.6$ years \\
\hline & Source: hospital \\
\hline & Medical condition: cancer \\
\hline & Illness duration: $2-16$ weeks \\
\hline \multirow[t]{7}{*}{ Interventions } & "Problem solving therapy" \\
\hline & "Standard psychosocial care" \\
\hline & Mode of delivery: face-to-face + remote-telephone, individual \\
\hline & Intervention delivered by: master's-level mental health professional or psychology graduate student \\
\hline & Training: 3-day workshop, regular supervision \\
\hline & Duration of intervention (child): 0 \\
\hline & Duration of intervention (parent): 8 sessions $x 1 \mathrm{~h}=8 \mathrm{~h}$ \\
\hline
\end{tabular}

Outcomes $\quad$ Extracted outcome measures used in the analyses

\section{Parent measures}

Social Problem-Solving Inventory-Cancer*

Profile of Mood States*

\section{Notes}

Funding: "This work was supported by Grant R25 CA 65520 from the National Cancer Institute, National Institutes of Health"

COI: no conflict of interest statement included in the manuscript

\section{Risk of bias}


Sahler 2002 (Continued)

\section{Bias Authors' judgement Support for judgement}

Random sequence genera- Low risk tion (selection bias)
Quote: "Randomisation was performed centrally, after stratification by site, using a two-block technique that produced a unique sequence for each site, delivered as a set of consecutively numbered envelopes specifying each subject's assignment".

Comment: probably done

\begin{tabular}{|c|c|c|}
\hline \multirow[t]{2}{*}{$\begin{array}{l}\text { Allocation concealment } \\
\text { (selection bias) }\end{array}$} & Low risk & $\begin{array}{l}\text { Quote: "Randomisation was performed centrally, after stratification by site, } \\
\text { using a two-block technique that produced a unique sequence for each site, } \\
\text { delivered as a set of consecutively numbered envelopes specifying each sub- } \\
\text { ject's assignment". }\end{array}$ \\
\hline & & Comment: probably done \\
\hline
\end{tabular}

\begin{tabular}{lll}
\hline $\begin{array}{l}\text { Blinding of outcome as- } \\
\text { sessment (detection bias) } \\
\text { All outcomes }\end{array}$ & Unclear risk & $\begin{array}{l}\text { No description found in text } \\
\text { Comment: probably not done }\end{array}$ \\
\hline $\begin{array}{l}\text { Incomplete outcome data } \\
\text { (attrition bias) } \\
\begin{array}{l}\text { All outcomes } \\
\text { Selective reporting (re- }\end{array}\end{array}$ & Unclear risk & Attrition was not adequately described to make a judgement \\
porting bias) & High & $\begin{array}{l}\text { Pre-specified outcomes identified in the Methods were not fully reported in } \\
\text { the Results. The study authors provided these data on request }\end{array}$ \\
\hline
\end{tabular}

\section{Sahler 2005}

\section{Study characteristics}

\begin{tabular}{ll}
\hline Methods & RCT. 2 arms. Assessed pre-treatment, post-treatment and 6 months after baseline \\
\hline Participants & End of treatment $\mathrm{n}=407$ \\
& Start of treatment $\mathrm{n}=430$ \\
& Child sex: $219 \mathrm{M}, 210 \mathrm{~F}$ \\
& Parent sex: 0 M, $429 \mathrm{~F}$ \\
& Child age (mean): 7.6 years \\
& Parent age (mean): 35.5 years \\
& Source: hospital \\
& Medical condition: cancer \\
Illness duration (range): 2-16 weeks & "Bright IDEAS Problem Solving Skills Training" \\
"Usual psychosocial care" \\
Mode of delivery: face-to-face, individual \\
Intervention delivered by: not reported \\
Training: not reported
\end{tabular}


Sahler 2005 (Continued)

Duration of intervention (child): 0

Duration of intervention (parent): 8 sessions $x 1 \mathrm{~h}=8 \mathrm{~h}$

$\begin{array}{ll}\text { Outcomes } & \text { } \text { Parent measures } \\ \text { Profile of Mood States } \\ \text { Beck Depression Inventory-II* } \\ \text { Social Problem-Solving Inventory-Revised }{ }^{*} \\ \text { NEO-Five Factor Inventory } \\ \text { Impact of Event Scale-Revised } \\ \text { Funding: "This project was supported by National Cancer Institute, National Institutes of Health Grant } \\ \text { R25 CA65520" } \\ \text { COI: no conflict of interest statement included in the manuscript }\end{array}$

\section{Risk of bias}

\begin{tabular}{|c|c|c|}
\hline Bias & Authors' judgement & Support for judgement \\
\hline $\begin{array}{l}\text { Random sequence genera- } \\
\text { tion (selection bias) }\end{array}$ & Unclear risk & $\begin{array}{l}\text { Quote: "Randomisation was performed centrally." } \\
\text { Comment: method not described }\end{array}$ \\
\hline $\begin{array}{l}\text { Allocation concealment } \\
\text { (selection bias) }\end{array}$ & Unclear risk & $\begin{array}{l}\text { No description found in text } \\
\text { Comment: probably not done }\end{array}$ \\
\hline $\begin{array}{l}\text { Blinding of outcome as- } \\
\text { sessment (detection bias) } \\
\text { All outcomes }\end{array}$ & Unclear risk & $\begin{array}{l}\text { No description found in text } \\
\text { Comment: probably not done }\end{array}$ \\
\hline $\begin{array}{l}\text { Incomplete outcome data } \\
\text { (attrition bias) } \\
\text { All outcomes }\end{array}$ & Unclear risk & $\begin{array}{l}\text { Attrition was reported, but no data were presented describing equivalence be- } \\
\text { tween completers and non-completers }\end{array}$ \\
\hline $\begin{array}{l}\text { Selective reporting (re- } \\
\text { porting bias) }\end{array}$ & High risk & $\begin{array}{l}\text { Pre-specified outcomes identified in the Methods were not fully reported in } \\
\text { the Results. The study authors provided these data on request }\end{array}$ \\
\hline
\end{tabular}

Sahler 2013

\section{Study characteristics}

\begin{tabular}{ll}
\hline Methods & RCT. 2 arms. Assessed pre-treatment, immediately following intervention post-treatment, 3-month fol- \\
& low-up \\
\hline Participants & End of treatment $\mathrm{n}=204$ \\
& Start of treatment $\mathrm{n}=309$ \\
& Child sex: $165 \mathrm{M}, 144 \mathrm{~F}$ \\
& Parent sex: 0 M, 309 F \\
\hline
\end{tabular}


Sahler 2013 (Continued)

Child age (mean, SD): $8.8 \pm 5.9$ years

Parent age (mean, SD): $37.3 \pm 8.2$ years

Source: hospital

Medical condition: cancer

Illness duration (mean): 2.6 years

Interventions
"Bright IDEAS problem-solving skills training"
"Node of delivery: face-to-face, individual
Intervention delivered by: research assistants with graduate training in clinical or behavioral psycholo-
gy
Training: group training, weekly supervision
Duration of intervention (child): 0
Duration of intervention (parent): 8 sessions $\times 1 \mathrm{~h}=8 \mathrm{~h}$

Outcomes

*Extracted outcome measures used in the analyses

Parent measures

Social Problem Solving Inventory-Revised ${ }^{*}$

Profile of Mood States

Total Mood Distubrance scale

Beck Depression Inventory*

Impact of Event Scale Revised

COI: "Authors' Disclosures of Potential Conflicts of Interest: The author(s) indicated no potential conflicts of interest."

\section{Risk of bias}

\begin{tabular}{|c|c|c|}
\hline Bias & Authors' judgement & Support for judgement \\
\hline \multirow[t]{2}{*}{$\begin{array}{l}\text { Random sequence genera- } \\
\text { tion (selection bias) }\end{array}$} & Low risk & $\begin{array}{l}\text { Quote: "Participants completed baseline }(\mathrm{T} 1) \text { assessment and were randomly } \\
\text { assigned to a treatment arm by using a block design of } 6 \text { stratified by site and } \\
\text { language." }\end{array}$ \\
\hline & & Comment: probably done \\
\hline \multirow{2}{*}{$\begin{array}{l}\text { Allocation concealment } \\
\text { (selection bias) }\end{array}$} & Unclear risk & No description found in text \\
\hline & & Comment: probably not done \\
\hline \multirow{2}{*}{$\begin{array}{l}\text { Blinding of outcome as- } \\
\text { sessment (detection bias) } \\
\text { All outcomes }\end{array}$} & Low risk & Quote: "The reviewers were blinded to treatment condition." \\
\hline & & Comment: probably done \\
\hline $\begin{array}{l}\text { Incomplete outcome data } \\
\text { (attrition bias) }\end{array}$ & Unclear risk & $\begin{array}{l}\text { Attrition was reported, but no data were presented describing equivalence be- } \\
\text { tween completers and non-completers }\end{array}$ \\
\hline
\end{tabular}

Psychological interventions for parents of children and adolescents with chronic illness (Review) 
Sahler 2013 (Continued)

All outcomes

Selective reporting (re- Low risk $\quad$ Outcomes data were fully reported
porting bias)

Selective reporting (reporting bias)

\section{Sanders 1994}

\section{Study characteristics}

\begin{tabular}{|c|c|}
\hline Methods & RCT. 2 arms. Assessed at pre-treatment, post-treatment, 6-month follow-up, 12-month follow-up \\
\hline \multirow[t]{9}{*}{ Participants } & End of treatment $n=44$ \\
\hline & Start of treatment $n=44$ \\
\hline & Child sex: $16 \mathrm{M}, 28 \mathrm{~F}$ \\
\hline & Parent sex: not reported \\
\hline & Child age (mean, SD): $9.2 \pm 1.9$ years \\
\hline & Parent age (mean, SD): $39.3 \pm 4.9$ years \\
\hline & Source: not reported \\
\hline & Medical condition: recurrent abdominal pain \\
\hline & Illness duration (mean): 44 months \\
\hline \multirow[t]{7}{*}{ Interventions } & "Cognitive-behavioral family intervention" (CBT) \\
\hline & "Standard pediatric care" \\
\hline & Mode of delivery: face-to-face, individual \\
\hline & Intervention delivered by: not reported \\
\hline & Training: not reported \\
\hline & Duration of intervention (child): 6 sessions $\times 50$ mins $=5 \mathrm{~h}$ \\
\hline & Duration of intervention (parent): 6 sessions $\times 50$ mins $=5 \mathrm{~h}$ \\
\hline
\end{tabular}

Outcomes

^Extracted outcome measures used in the analyses

\section{Child measures}

Pain intensity*

\section{Parent measures}

Child Behavior Checklist-Internalizing*

Parent observation of pain behaviors ${ }^{\star}$

COI: no conflict of interest statement included in the manuscript

\section{Risk of bias}

Psychological interventions for parents of children and adolescents with chronic illness (Review) 
Sanders 1994 (Continued)

\section{Bias Authors' judgement Support for judgement}

Random sequence genera- Unclear risk Quote: "The study used a randomized group comparison design with two tion (selection bias) treatment conditions."

Comment: method not described

\begin{tabular}{lll}
\hline $\begin{array}{l}\text { Allocation concealment } \\
\text { (selection bias) }\end{array}$ & Unclear risk & $\begin{array}{l}\text { No description found in text } \\
\text { Comment: probably not done }\end{array}$ \\
\hline $\begin{array}{l}\text { Blinding of outcome as- } \\
\text { sessment (detection bias) } \\
\begin{array}{l}\text { All outcomes } \\
\text { Incomplete outcome data }\end{array}\end{array}$ & Unclear risk & No description found in text \\
$\begin{array}{l}\text { (attrition bias) } \\
\text { All outcomes }\end{array}$ & Comment: probably not done \\
\hline $\begin{array}{l}\text { Selective reporting (re- } \\
\text { porting bias) }\end{array}$ & Low risk & Attrition was not adequately described to make a judgement \\
\hline
\end{tabular}

Seid 2010

\section{Study characteristics}

\begin{tabular}{|c|c|}
\hline Methods & RCT. 3 arms. Assessed pre-treatment, post-treatment and 6-month follow-up \\
\hline \multirow[t]{9}{*}{ Participants } & End of treatment $n=204,6$-month follow-up $n=188$ \\
\hline & Start of treatment $n=252$ \\
\hline & Child sex: $154 \mathrm{M}, 98 \mathrm{~F}$ \\
\hline & Parent sex: 9 M, $244 \mathrm{~F}$ \\
\hline & Child age (mean, SD): $7.4 \pm 3.1$ years \\
\hline & Parent age: not reported \\
\hline & Source: primary care, community \\
\hline & Medical condition: asthma \\
\hline & Illness duration (mean): 44 months \\
\hline \multirow[t]{7}{*}{ Interventions } & "Problem-Solving Skills Training + Care Coordination" \\
\hline & "In Home Asthma Education + Care Coordination" \\
\hline & "Standard care wait-list control" \\
\hline & Mode of delivery: face-to-face, family \\
\hline & $\begin{array}{l}\text { Intervention delivered by: master's-level health educator, paraprofessional asthma home visitors (care } \\
\text { co-ordination) }\end{array}$ \\
\hline & Training: 2-week training including didactics, role play, observation \\
\hline & Duration of intervention for "Problem Solving Skills Training + Care Coordination" \\
\hline
\end{tabular}


Seid 2010 (Continued)

Parent $=6$ sessions PSST $\times 60 \mathrm{~min}+5$ sessions Care Coordination $\times 60 \mathrm{~min}=11 \mathrm{~h}$

Child $=6$ sessions PSST $\times 60 \mathrm{~min}+5$ sessions Care Coordination $\times 60 \mathrm{~min}=11 \mathrm{~h}$

\begin{tabular}{|c|c|c|}
\hline \multirow[t]{6}{*}{ Outcomes } & \multicolumn{2}{|c|}{${ }^{\star}$ Extracted outcome measures used in the analyses } \\
\hline & \multicolumn{2}{|l|}{ Child measures } \\
\hline & \multicolumn{2}{|c|}{ Pediatric Quality of Life Inventory Asthma Module Asthma Symptoms Scale* } \\
\hline & \multicolumn{2}{|l|}{ Parent measures } \\
\hline & \multicolumn{2}{|c|}{ Pediatric Quality of Life Inventory } \\
\hline & \multicolumn{2}{|c|}{ Health Service Use self report } \\
\hline \multirow[t]{2}{*}{ Notes } & \multicolumn{2}{|c|}{$\begin{array}{l}\text { Funding: "This research was supported by a grant from the Maternal and Child Health Bureau of the } \\
\text { Health Resources and Services Administration (R40 MC01214/08044)" }\end{array}$} \\
\hline & \multicolumn{2}{|c|}{$\begin{array}{l}\text { COI: "Conflict of Interest: Dr Varni holds the copyright and the trademark for the PedsQL and receives } \\
\text { financial compensation from the Mapi Research Trust, which is a nonprofit research institute that } \\
\text { charges distribution fees to for-profit companies that use the Pediatric Quality of Life Inventory" }\end{array}$} \\
\hline \multicolumn{3}{|l|}{ Risk of bias } \\
\hline Bias & Authors' judgement & Support for judgement \\
\hline \multirow[t]{2}{*}{$\begin{array}{l}\text { Random sequence genera- } \\
\text { tion (selection bias) }\end{array}$} & Low risk & $\begin{array}{l}\text { Quote: "Blocked randomization, stratified by site of care and disease severity } \\
\text { was used. Prepared randomization lists were created by the statistician and } \\
\text { concealed until intervention assignment." }\end{array}$ \\
\hline & & Comment: probably done \\
\hline \multirow[t]{2}{*}{$\begin{array}{l}\text { Allocation concealment } \\
\text { (selection bias) }\end{array}$} & Low risk & $\begin{array}{l}\text { Quote: "Blocked randomization, stratified by site of care and disease severity } \\
\text { was used. Prepared randomization lists were created by the statistician and } \\
\text { concealed until intervention assignment." }\end{array}$ \\
\hline & & Comment: probably done \\
\hline \multirow{2}{*}{$\begin{array}{l}\text { Blinding of outcome as- } \\
\text { sessment (detection bias) } \\
\text { All outcomes }\end{array}$} & Low risk & $\begin{array}{l}\text { Quote: "Bilingual, bicultural research staff, blinded to the intervention group, } \\
\text { administered surveys in English or Spanish in participants' homes." }\end{array}$ \\
\hline & & Comment: probably done \\
\hline $\begin{array}{l}\text { Incomplete outcome data } \\
\text { (attrition bias) } \\
\text { All outcomes }\end{array}$ & Low risk & $\begin{array}{l}\text { Attrition was reported, there were no significant differences between com- } \\
\text { pleters and non-completers }\end{array}$ \\
\hline $\begin{array}{l}\text { Selective reporting (re- } \\
\text { porting bias) }\end{array}$ & Low risk & Data were fully reported \\
\hline
\end{tabular}

Stark 2005

\section{Study characteristics}

Methods RCT. 2 arms. Assessed pre-treatment, 8 weeks after baseline post-treatment

Participants $\quad$ End of treatment $n=49$


Stark 2005 (Continued)

\author{
Start of treatment $\mathrm{n}=65$ \\ Child sex: 9 M, 40 F \\ Parent sex: not reported \\ Child age (mean, SD): $6.5 \pm 2.0$ years \\ Parent age (mean, SD): $36.1 \pm 5.4$ years \\ Source: hospital \\ Medical condition: juvenile rheumatoid arthritis \\ Illness duration: not reported
}

Interventions
"Behavioral Intervention"
"Enhanced Standard of Care"
Intervention delivered by: PHD psychologist for parents, post-doctoral fellow with help of a trained RA
for children
Training: treatment manual review, role play, weekly supervision
Duration of intervention (child): 4 sessions $\times 90$ min $=6 \mathrm{~h}$
Duration of intervention (parent): 4 sessions $\times 90$ min $=6 \mathrm{~h}$

Outcomes $\quad$ Extracted outcome measures used in the analyses

\title{
Parent measures
}

Weighed food diaries

Funding: "This research was supported by a Clinical Science Grant from the Arthritis Foundation, NIH/
NIDDK Grant \#DK59492 to Lori J. Stark, Ph.D., and by USPHS Grant \#MO1 RR 08084 from the General
Clinical Research Centers Program, National Center for Research Resources, NIH."
COI: no conflict of interest statement included in the manuscript

\section{Risk of bias}

\begin{tabular}{lll}
\hline Bias & Authors' judgement & Support for judgement \\
\hline $\begin{array}{ll}\text { Random sequence genera- } \\
\text { tion (selection bias) }\end{array}$ & Unclear risk & $\begin{array}{l}\text { Quote: "Participants were stratified on an estimate of their typical Ca intake at } \\
\text { baseline across the two conditions....After stratification by estimated Ca intake } \\
\text { classification, a block randomization protocol was utilized with a block size of } \\
\text { two within each strata of Ca intake." } \\
\text { Comment: probably done }\end{array}$ \\
& &
\end{tabular}

\begin{tabular}{|c|c|c|}
\hline \multirow[t]{2}{*}{$\begin{array}{l}\text { Allocation concealment } \\
\text { (selection bias) }\end{array}$} & Low risk & $\begin{array}{l}\text { Quote: "The randomization sequence was generated and kept by personnel } \\
\text { separate from the personnel conducting recruitment calls and the interven- } \\
\text { tion." }\end{array}$ \\
\hline & & Comment: probably done \\
\hline
\end{tabular}

Blinding of outcome as- Low risk sessment (detection bias) All outcomes
Quote: "..the first two weekdays and the first weekend day, were analyzed by a registered dietician in the General Clinical Research Center (GCRC), who was unaware of the subject's treatment condition.." 
Stark 2005 (Continued)

Comment: probably done

\begin{tabular}{|c|c|c|}
\hline $\begin{array}{l}\text { Incomplete outcome data } \\
\text { (attrition bias) }\end{array}$ & Unclear risk & $\begin{array}{l}\text { Attrition was reported, there were significant differences between completers } \\
\text { and non-completers }\end{array}$ \\
\hline
\end{tabular}

All outcomes

Attrition was reported, there were significant differences between completers

All outcomes

Selective reporting (re- Low risk Outcomes data were fully reported
porting bias)

Stehl 2009

\section{Study characteristics}

\begin{tabular}{|c|c|}
\hline Methods & RCT. 2 arms. Assessed pre-treatment and 1 month post-treatment \\
\hline \multirow[t]{9}{*}{ Participants } & End of treatment $n=48$ \\
\hline & Start of treatment $n=76$ \\
\hline & Child sex: $41 \mathrm{M}, 35 \mathrm{~F}$ \\
\hline & Parent sex: not reported \\
\hline & Child age (mean): 6 years \\
\hline & Parent age (mean): 36 years \\
\hline & Source: hospital \\
\hline & Medical condition: cancer \\
\hline & Illness duration: not reported \\
\hline \multirow[t]{7}{*}{ Interventions } & "Surviving Cancer Competently Intervention Program-Newly Diagnosed (SCCIP-ND)" \\
\hline & "Standard Psychosocial Care" \\
\hline & Mode of delivery: face-to-face + remote: CD-ROM + telephone, individual \\
\hline & $\begin{array}{l}\text { Intervention delivered by: psychology fellows, psychology intern, master's-level psychologist and doc- } \\
\text { toral-level nurse }\end{array}$ \\
\hline & Training: $18 \mathrm{~h}$ of didactic and experiential training \\
\hline & Duration of intervention (children) $=0$ \\
\hline & Duration of intervention (parents) $=3$ sessions $\times 45$ mins +3 booster sessions $=4.5 \mathrm{~h}$ \\
\hline \multirow[t]{5}{*}{ Outcomes } & *Extracted outcome measures used in the analyses \\
\hline & Parent measures \\
\hline & State Trait Anxiety Inventory* \\
\hline & Impact of Event Scale-Revised \\
\hline & Acute Stress Disorder Scale \\
\hline \multirow[t]{2}{*}{ Notes } & Funding: "This research was supported by a grant from the National Cancer Institute (CA088828)" \\
\hline & COI: "Conflict of interest: None declared" \\
\hline
\end{tabular}


Stehl 2009 (Continued)

\section{Risk of bias}

\begin{tabular}{|c|c|c|}
\hline Bias & Authors' judgement & Support for judgement \\
\hline $\begin{array}{l}\text { Random sequence genera- } \\
\text { tion (selection bias) }\end{array}$ & Low risk & $\begin{array}{l}\text { Quote: "Randomization was completed by a predetermined concealed ran- } \\
\text { dom assignment list maintained by a staff member unaware of patient identi- } \\
\text { ty." } \\
\text { Comment: probably done }\end{array}$ \\
\hline $\begin{array}{l}\text { Allocation concealment } \\
\text { (selection bias) }\end{array}$ & Low risk & $\begin{array}{l}\text { Quote: "Randomization was completed by a predetermined concealed ran- } \\
\text { dom assignment list maintained by a staff member unaware of patient identi- } \\
\text { ty." } \\
\text { Comment: probably done }\end{array}$ \\
\hline $\begin{array}{l}\text { Blinding of outcome as- } \\
\text { sessment (detection bias) } \\
\text { All outcomes }\end{array}$ & Low risk & $\begin{array}{l}\text { Quote: "Add data collection took place at the hospital at a time and location of } \\
\text { convenience for the family and was conducted by research assistants." } \\
\text { Comment: probably done }\end{array}$ \\
\hline $\begin{array}{l}\text { Incomplete outcome data } \\
\text { (attrition bias) } \\
\text { All outcomes }\end{array}$ & Low risk & $\begin{array}{l}\text { Attrition was reported, there were no significant differences between com- } \\
\text { pleters and non-completers }\end{array}$ \\
\hline $\begin{array}{l}\text { Selective reporting (re- } \\
\text { porting bias) }\end{array}$ & Low risk & Outcomes data were fully reported \\
\hline
\end{tabular}

Tsitsi 2017

\section{Study characteristics}

\begin{tabular}{ll}
\hline Methods & RCT. 2 arms. Assessed at pre-treatment and post-treatment (3 weeks) \\
\hline Participants & End of treatment $n=54$ \\
& Start of treatment $n=62$ \\
& Child sex: not reported \\
& Parent sex: not reported \\
& Child age (mean, SD): $9.2 \pm 4.9$ years \\
& Parent age (mean, SD): $42.4 \pm 6.4$ years \\
& Source: hospital \\
& Medical condition: cancer \\
Illness duration (mean): 4 weeks & "Relaxation Cancer" \\
"Standard Psychological Suport" \\
Mode of delivery: remote-audio CD, individual \\
Intervention delivered by: research assistant + digital media player
\end{tabular}


Tsitsi 2017 (Continued)

\author{
Training: not reported \\ Duration of intervention (child): none \\ Duration of intervention (parent): 3 sessions $x 25 \mathrm{~min}+3$ weeks of daily, self-guided sessions
}

\begin{tabular}{ll}
\hline Outcomes & Extracted outcome measures used in the analyses \\
Parent measures & Blood pressure \\
Heart rate & Skin temperature \\
Hamilton's Anxiety Scale* & Profile of Mood States Brief Scale \\
\hline Notes & Funding: not reported \\
COI: "Conflict of interest: None declared."
\end{tabular}

Risk of bias

\begin{tabular}{|c|c|c|}
\hline Bias & Authors' judgement & Support for judgement \\
\hline \multirow[t]{2}{*}{$\begin{array}{l}\text { Random sequence genera- } \\
\text { tion (selection bias) }\end{array}$} & Low risk & $\begin{array}{l}\text { Quote: "Randomization was performed by using a computer-generated se- } \\
\text { quence, concealed in sequentially numbered, sealed, opaque envelopes, (by } \\
\text { an independent person) and kept by the research assistant." }\end{array}$ \\
\hline & & Comment: probably done \\
\hline \multirow[t]{2}{*}{$\begin{array}{l}\text { Allocation concealment } \\
\text { (selection bias) }\end{array}$} & Low risk & $\begin{array}{l}\text { Quote: "Randomization was performed by using a computer-generated se- } \\
\text { quence, concealed in sequentially numbered, sealed, opaque envelopes, (by } \\
\text { an independent person) and kept by the research assistant." }\end{array}$ \\
\hline & & Comment: probably done \\
\hline $\begin{array}{l}\text { Blinding of outcome as- } \\
\text { sessment (detection bias) } \\
\text { All outcomes }\end{array}$ & Unclear risk & No description found in text \\
\hline $\begin{array}{l}\text { Incomplete outcome data } \\
\text { (attrition bias) } \\
\text { All outcomes }\end{array}$ & Unclear risk & $\begin{array}{l}\text { Attrition was reported, but no data were presented on equivalence between } \\
\text { completers and non-completers }\end{array}$ \\
\hline $\begin{array}{l}\text { Selective reporting (re- } \\
\text { porting bias) }\end{array}$ & Low risk & Outcomes data were fully reported \\
\hline
\end{tabular}

Wade 2006a

\title{
Study characteristics
}

\begin{tabular}{ll}
\hline Methods & RCT. 2 arms. Assessed pre-treatment and at session 7 of 8 \\
\hline Participants & $\begin{array}{l}\text { End of treatment } n=40 \\
\text { Start of treatment } n=46\end{array}$
\end{tabular}


Wade 2006a (Continued)

Child sex: $23 \mathrm{M}, 17 \mathrm{~F}$

Parent sex: not reported

Child age (mean, SD): $11.0 \pm 3.3$ years

Parent age: not reported

Source: hospital

Medical condition: TBI

Illness duration (mean): 13.7 months

\begin{tabular}{ll}
\hline Interventions & "Family Problem Solving" (PST) \\
"Internet Resources Control" \\
Mode of delivery: remote-internet + teleconference, family \\
Intervention delivered by: internet + clinical psychology graduate student \\
Training: 2 -month training, treatment manual, weekly supervision \\
Duration of intervention (children): 8 core modules, 6 supplementary modules \\
Duration of intervention (parents): 8 core modules, 6 supplementary modules
\end{tabular}

\begin{tabular}{ll}
\hline Outcomes & *Extracted outcome measures used in the analyses \\
Parent outcomes & \\
Child Behavior Checklist-Total Score* & Social Problem-Solving Index \\
Symptom Checklist-90-Revised \\
Global Severity Index \\
Center for Epidemiologic Studies Depression Scale* \\
Anxiety Inventory
\end{tabular}

Notes $\quad$ Funding: "This work was supported by National Council on Medical

Rehabilitation Research, National Institutes of Health Grant HD40942".

COI: no conflict of interest statement included in the manuscript

\section{Risk of bias}

\begin{tabular}{|c|c|c|}
\hline Bias & Authors' judgement & Support for judgement \\
\hline $\begin{array}{l}\text { Random sequence genera- } \\
\text { tion (selection bias) }\end{array}$ & Low risk & $\begin{array}{l}\text { Quote: "Families were randomly assigned to family problem-solving or Inter- } \\
\text { net resources comparison via a computer programme." } \\
\text { Comment: probably done }\end{array}$ \\
\hline $\begin{array}{l}\text { Allocation concealment } \\
\text { (selection bias) }\end{array}$ & Unclear risk & $\begin{array}{l}\text { No description found in text } \\
\text { Comment: probably not done }\end{array}$ \\
\hline $\begin{array}{l}\text { Blinding of outcome as- } \\
\text { sessment (detection bias) } \\
\text { All outcomes }\end{array}$ & Low risk & $\begin{array}{l}\text { Quote: "Given the nature of the study, neither the participants nor the research } \\
\text { assistant was blind to group assignment. The primary outcome measures were } \\
\text { based on parent and child report and therefore not dependent on the judg- } \\
\text { ments of the research staff." } \\
\text { Comment: probably done }\end{array}$ \\
\hline
\end{tabular}

\begin{tabular}{|c|c|c|}
\hline $\begin{array}{l}\text { Incomplete outcome data } \\
\text { (attrition bias) }\end{array}$ & Unclear risk & $\begin{array}{l}\text { Attrition was not reported, there were no significant differences between com- } \\
\text { pleters and non-completers }\end{array}$ \\
\hline
\end{tabular}

All outcomes pleters and non-completers

\begin{tabular}{|c|c|c|}
\hline $\begin{array}{l}\text { Selective reporting (re- } \\
\text { porting bias) }\end{array}$ & High risk & $\begin{array}{l}\text { Pre-specified outcomes identified in the Methods were not fully reported in } \\
\text { the Results. The study authors provided these data on request }\end{array}$ \\
\hline
\end{tabular}


Wade 2014

\title{
Study characteristics
}

Methods

RCT. 2 arms. Assessed pre-treatment, post-treatment (6 months) 12-month follow-up, 18-month follow-up

Earticipants of treatment $\mathrm{n}=127,12$-month follow-up $\mathrm{n}=112,18$-month follow-up $\mathrm{n}=84$
Start of treatment $\mathrm{n}=132$
Child sex: not reported
Parent sex: not reported
Child age (range): $12-17$ years
Parent age: not reported
Source: hospital
Medical condition: TBI
Illness duration: not reported

Interventions
"Counselor-Assisted Problem Solving "
"Internet Resources Comparison"
Mode of delivery: remote-internet + videoconference, family
Intervention delivered by: internet + clinical psychologists
Training: not reported
Duration of intervention (child): 8 modules, 6 video conferences/max of 4 supplemental family sessions
Duration of intervention (parent): 8 modules, 6 video conferences/max of 4 supplemental family ses-
sions

Outcomes

*Extracted outcome measures used in the analyses

\section{Parent measures}

\author{
Caregiver Self-Efficacy Scale* \\ Center for Epidemiologic Studies Depression Scale* \\ Child and Adolescent Functional Assessment Scale* \\ Child Behavior Checklist* \\ Family Assessment Device* \\ lowa Family Interaction Rating Scale \\ Problem Solving Discussion Rating Scale \\ Symptom Checklist-90
}

\section{Notes}

Funding: "This work was supported in part by 1) NIH grant R01-MH073764 from the National Institute of Mental Health; and 2) a grant from the Colorado Traumatic Brain Injury Trust Fund Research Program, Colorado Department of Human Services, Division of Vocational Rehabilitation, Traumatic Brain Injury Program." 
COI: "We certify that no party having a direct interest in the results of the research supporting this article has or will confer a benefit on us or on any organization with which we are associated."

\section{Risk of bias}

\begin{tabular}{|c|c|c|}
\hline Bias & Authors' judgement & Support for judgement \\
\hline \multirow[t]{2}{*}{$\begin{array}{l}\text { Random sequence genera- } \\
\text { tion (selection bias) }\end{array}$} & Low risk & $\begin{array}{l}\text { Quote: "A SAS program was created using permuted block sizes for each ran- } \\
\text { domization." }\end{array}$ \\
\hline & & Comment: probably done \\
\hline \multirow[t]{2}{*}{$\begin{array}{l}\text { Allocation concealment } \\
\text { (selection bias) }\end{array}$} & Low risk & $\begin{array}{l}\text { Quote: "Group assignment was contained in a sealed envelope that was hand- } \\
\text { ed to the participants at the end of the baseline visit." }\end{array}$ \\
\hline & & Comment: probably done \\
\hline \multirow[t]{2}{*}{$\begin{array}{l}\text { Blinding of outcome as- } \\
\text { sessment (detection bias) } \\
\text { All outcomes }\end{array}$} & Low risk & $\begin{array}{l}\text { Quote: "Group assignment was contained in a sealed envelope that was hand- } \\
\text { ed to the participants at the end of the baseline visit. In this fashion, group as- } \\
\text { signment was concealed from the research coordinators completing the base- } \\
\text { line and follow-up assessments." }\end{array}$ \\
\hline & & Comment: probably done \\
\hline $\begin{array}{l}\text { Incomplete outcome data } \\
\text { (attrition bias) } \\
\text { All outcomes }\end{array}$ & Low risk & $\begin{array}{l}\text { Attrition was reported, there were no significant differences between com- } \\
\text { pleters and non-completers }\end{array}$ \\
\hline $\begin{array}{l}\text { Selective reporting (re- } \\
\text { porting bias) }\end{array}$ & High risk & $\begin{array}{l}\text { Pre-specified outcomes identified in the Methods were not fully reported in } \\
\text { the Results. The study authors provided these data on request }\end{array}$ \\
\hline
\end{tabular}

Wade 2017

\section{Study characteristics}

\begin{tabular}{ll}
\hline Methods & RCT. 3 arms. Assessed baseline, post-treatment, and 6-month follow-up \\
\hline Participants & End of treatment $n=95,6$-month follow-up $n=79$ \\
& Start of treatment $n=117$, \\
& Child sex: $69 \mathrm{M}, 44 \mathrm{~F}$ \\
& Sex of parents: unknown \\
& Child age (mean, SD): $5.4 \pm 2.2$ years \\
& Parent age: not reported \\
& Source: hospital \\
& Medical condition: TBI \\
& Illness duration (mean): 10.8 months \\
\hline Interventions & "I-InTERACT Program" \\
& "I-InTERACT Express" \\
"Internet resource group"
\end{tabular}


Intervention delivered by: licensed psychologists, postdoctoral fellow, advanced clinical psychology graduate students

Training: treatment manual + 3-day training, weekly supervision and fidelity checklists

Duration of intervention (parent + child) I-InTERACT Program $=10$ core modules +4 optional plus weekly videoconferencing

Duration of intervention (parent + child) I-InTERACT Express $=7$ core modules plus weekly videoconferencing

\begin{tabular}{|c|c|}
\hline \multirow[t]{3}{*}{ Outcomes } & $\begin{array}{l}{ }^{\star} \text { Extracted outcome measures used in the analyses } \\
\text { Child \& Parent measures }\end{array}$ \\
\hline & Dyadic Parent-Child Interaction Coding Scheme* \\
\hline & Eyeberg Child Behavior Inventory (child only)* \\
\hline \multirow[t]{2}{*}{ Notes } & $\begin{array}{l}\text { Funding "This study was funded by the National Institute on Disability, Independent Living, and Reha- } \\
\text { bilitation Research, formerly known as the National Institute on Disability and Rehabilitation Research } \\
\text { (grant H133b090010)." }\end{array}$ \\
\hline & $\begin{array}{l}\text { COls: "Drs. Wade, Cassedy, Zhang, Kirkwood, Stancin, Yeates, Taylor, Ms. Shultz and Mr. Zhang report } \\
\text { no biomedical financial interests or potential conflicts of interest" }\end{array}$ \\
\hline
\end{tabular}

\section{Risk of bias}

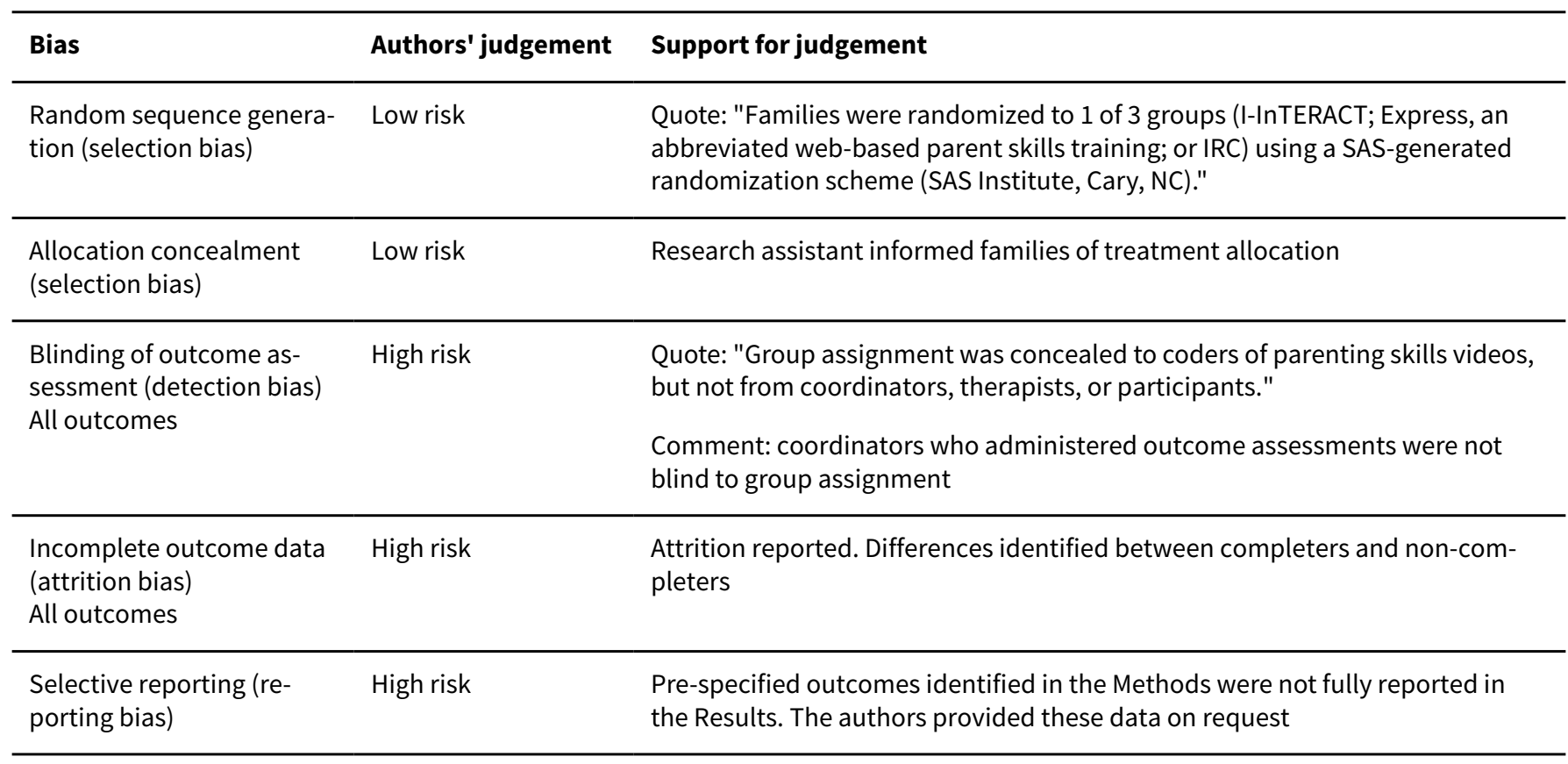

Westrupp 2015

\section{Study characteristics}

Methods

RCT. 2 arms. Assessed pre-treatment, post-treatment (3 months), 6-month follow-up, 12-month follow-up, 24-month follow-up 
Westrupp 2015 (Continued)

Participants
End of treatment $n=60,6$-month follow-up $n=44,12$-month follow-up $=57$

Start of treatment $n=83$

Child sex: 43 M, $33 \mathrm{~F}$

Parent sex: not reported

Child age (mean, SD): $9.0 \pm 2.4$ years

Parent age: not reported

Source: hospital

Medical condition: type 1 diabetes

Illness duration: 3.5 years

"Triple P"

"Standard Care"

Mode of delivery: face-to-face, individual

Intervention delivered by: clinical psychologist

Training: not reported

Duration of intervention (child): none

Duration of intervention (parent): 10 sessions $x 1 \mathrm{~h}=10 \mathrm{~h}$

Outcomes

${ }^{\star}$ Extracted outcome measures used in the analyses

Child measures

$\mathrm{HbA} 1 \mathrm{c}^{*}$

Parent measures

Behavior Assessment System for Children, 2nd Edition*

Depression Anxiety Stress Scale*

Parenting Scale*

Parenting Sense of Competency Scale

Parent Problem Checklist

Eyberg Child Behavior Inventory

Diabetes Family Conflict Scale Revised ${ }^{\star}$

Relationship Quality Index

Notes

Funding: "This study was funded by 3 grants from Eli Lilly, and the Early Development and Disease, and Critical Care and Neurosciences Departments at the Murdoch Childrens Research Institute (MCRI). Research at MCRI is supported by the Victorian Government's Operational Infrastructure Support Program."

COI: "The authors have no other conflicts of interest to declare."

\section{Risk of bias}

Psychological interventions for parents of children and adolescents with chronic illness (Review) 
Westrupp 2015 (Continued)

\section{Bias Authors' judgement Support for judgement}

Random sequence genera- Unclear risk tion (selection bias)

Quote: "Eligible families were randomized sequentially to Triple P or SDC using pre prepared cards (stratified by pre-existing child internalizing or externalizing behavior problems) stored in opaque envelopes generated by an independent statistician."

Comment: method of randomization is not clear

\begin{tabular}{ll}
\hline $\begin{array}{l}\text { Allocation concealment } \\
\text { (selection bias) }\end{array}$ & Low risk \\
& $\begin{array}{l}\text { Quote: "Eligible families were randomized sequentially to Triple P or SDC using } \\
\text { pre prepared cards (stratified by pre-existing child internalizing or externaliz- } \\
\text { ing behavior problems) stored in opaque envelopes generated by an indepen- } \\
\text { dent statistician." }\end{array}$ \\
Comment: probably done
\end{tabular}

Blinding of outcome as- Unclear risk No description found in text

sessment (detection bias)

All outcomes

\begin{tabular}{|c|c|c|}
\hline $\begin{array}{l}\text { Incomplete outcome data } \\
\text { (attrition bias) } \\
\text { All outcomes }\end{array}$ & Unclear risk & $\begin{array}{l}\text { Attrition was reported. Significant differences between participants who start- } \\
\text { ed intervention vs. participants who dropped out after randomization are re- } \\
\text { ported, but differences between remaining completers and non-completers } \\
\text { not reported }\end{array}$ \\
\hline
\end{tabular}

\begin{tabular}{|c|c|c|}
\hline $\begin{array}{l}\text { Selective reporting (re- } \\
\text { porting bias) }\end{array}$ & High risk & $\begin{array}{l}\text { Pre-specified outcomes identified in the Methods were not fully reported in } \\
\text { the Results. The study authors provided these data on request }\end{array}$ \\
\hline
\end{tabular}

Wysocki 1999

\section{Study characteristics}

Methods

RCT. 3 arms. Assessed pre-treatment, 3 months (post-treatment), 6-month follow-up and 12-month follow-up 
Wysocki 1999 (Continued)

Mode of delivery: face-to-face, family

Intervention delivered by: clinical psychologist

Training: $150 \mathrm{~h}$

Duration of intervention (child): 10 sessions, time not reported

Duration of intervention (parents): 10 sessions, time not reported

\begin{tabular}{|c|c|}
\hline \multirow[t]{19}{*}{ Outcomes } & ${ }^{*}$ Extracted outcome measures used in the analy \\
\hline & Child measures \\
\hline & Parent-Adolescent Relationship Questionnaire* \\
\hline & Issues Checklist \\
\hline & 24 Hour Recall Interview of Conflict Situations \\
\hline & Teen Adjustment to Diabetes Scale ${ }^{\star}$ \\
\hline & Diabetes Responsibility and Conflict \\
\hline & 24 Hour Recall Interview of IDDM Self-Care \\
\hline & Self-Care Inventory \\
\hline & Glycated hemoglobin* \\
\hline & Parent measures \\
\hline & Parent-Adolescent Relationship Questionnaire* \\
\hline & Issues Checklist \\
\hline & 24 Hour Recall Interview of Conflict Situations \\
\hline & Teen Adjustment to Diabetes Scale \\
\hline & Diabetes Responsibility and Conflict \\
\hline & 24 Hour Recall Interview of IDDM Self-Care \\
\hline & Self-Care Inventory \\
\hline & Parent-reported health service use \\
\hline
\end{tabular}

Notes

Funding: "This work was supported by grant 1-RO1-DK43802 "Behavior Therapy for Families of Diabetic Adolescents" awarded by the National Institutes of Health to the first author and by the Pediatric and General Clinical Research Centers of Washington University (RR6021 and RR00036)"

COI: no conflict of interest statement included in the manuscript

\section{Risk of bias}

\begin{tabular}{lll}
\hline Bias & Authors' judgement & Support for judgement \\
\hline $\begin{array}{l}\text { Random sequence genera- } \\
\text { tion (selection bias) }\end{array}$ & Unclear risk & $\begin{array}{l}\text { Quote: "The research scientist at the opposing centre randomly assigned each } \\
\text { family, without knowledge of the family's baseline status on any of the out- } \\
\text { come measures to one of three conditions." } \\
\text { Comment: method not fully described }\end{array}$ \\
&
\end{tabular}


Wysocki 1999 (Continued)

$\begin{aligned} & \text { Allocation concealment } \\ & \text { (selection bias) }\end{aligned}$
Unclear risk No description found in text

Blinding of outcome as-

Unclear risk sessment (detection bias)

All outcomes
Quote: "A research assistant administered questionnaires at evaluation sessions; the research assistant completed telephone interviews during the two weeks preceding each of the four evaluations."

Comment: blinding not described

Attrition was reported, but no data were presented on equivalence between

completers and non-completers

Incomplete outcome data Unclear risk

(attrition bias)

All outcomes

Selective reporting (re- High risk porting bias)

Pre-specified outcomes identified in the Methods were not fully reported in the Results. The study authors did not provide these data on request

Wysocki 2006

\section{Study characteristics}

Methods

RCT. 3 arms. Assessed at pre-treatment, 6 months (post-treatment), 12-month follow-up, 18-month follow-up

Participants

End of treatment $n=92,12$-month follow-up $n=88,18$-month follow-up $n=85$

Start of treatment $\mathrm{n}=104$

Child sex: $57 \mathrm{M}, 47 \mathrm{~F}$

Sex of parents: not reported

Child age (mean, SD): $14.2 \pm 1.9$ years

Parent age: not reported

Source: hospital

Medical condition: type 1 diabetes or insulin-treated type 2 diabetes

Illness duration (mean): 5.5 years

Interventions

"Behavioral Family Systems Therapy for Diabetes (BFST-D)"

"Educational Support Group"

"Standard Care"

Mode of delivery: face-to-face, family

Intervention delivered by: clinical psychologist, clinical social worker

Training: not reported

Duration of intervention (child): 12 sessions over 6 months

Duration of intervention (parent): 12 sessions over 6 months

Outcomes

${ }^{\star}$ Extracted outcome measures used in the analyses

\section{Child measures}


Wysocki 2006 (Continued)

Parent-Adolescent Relationship Questionnaire*

$\mathrm{HbA} 1 \mathrm{c}^{\star}$

Diabetes Responsibility and Conflict

Diabetes Self-Management Profile

Family problem-solving discussions coded using Interaction Behavior Code

\section{Parent measures}

Parent-Adolescent Relationship Questionnaire*

Diabetes Responsibility and Conflict

Diabetes Self-Management Profile

Family problem-solving discussions coded using Interaction Behavior Code

Notes

Funding: "this study was supported by NIH grants 1 RO1-DK43802 and K24 DK67128 to the first author; and NIH grants P60 DK20579 and RR00036 which support the Diabetes Research and Training Center and General Clinical Research Center, respectively, at the Washington University School of Medicine"

COI: no conflict of interest statement included in the manuscript

\section{Risk of bias}

\begin{tabular}{|c|c|c|}
\hline Bias & Authors' judgement & Support for judgement \\
\hline $\begin{array}{l}\text { Random sequence genera- } \\
\text { tion (selection bias) }\end{array}$ & Unclear risk & $\begin{array}{l}\text { Quote: "A three-group, randomized treatments design was used." } \\
\text { Comment: method not described fully }\end{array}$ \\
\hline $\begin{array}{l}\text { Allocation concealment } \\
\text { (selection bias) }\end{array}$ & Unclear risk & $\begin{array}{l}\text { Quote: "Families were stratified by } \mathrm{HbAlc".} \\
\text { Comment: no description of concealment described }\end{array}$ \\
\hline $\begin{array}{l}\text { Blinding of outcome as- } \\
\text { sessment (detection bias) } \\
\text { All outcomes }\end{array}$ & Low risk & $\begin{array}{l}\text { Quote: "Raters were unaware of the family's identity or group assignment or of } \\
\text { when the recording was made." } \\
\text { Comment: probably done }\end{array}$ \\
\hline $\begin{array}{l}\text { Incomplete outcome data } \\
\text { (attrition bias) } \\
\text { All outcomes }\end{array}$ & Unclear risk & $\begin{array}{l}\text { Attrition was reported, but no data were presented on equivalence between } \\
\text { completers and non-completers }\end{array}$ \\
\hline $\begin{array}{l}\text { Selective reporting (re- } \\
\text { porting bias) }\end{array}$ & High risk & $\begin{array}{l}\text { Pre-specified outcomes identified in the Methods were not fully reported in } \\
\text { the Results. The study authors did not provide these data on request }\end{array}$ \\
\hline
\end{tabular}

Yeh 2016

\section{Study characteristics}

\begin{tabular}{ll}
\hline Methods & RCT. 2 arms. Assessed pre-treatment, post-treatment (3 months), 12-month follow-up \\
\hline Participants & End of treatment $n=66,12$-month follow-up $n=65$ \\
& Start of treatment $n=76$ \\
\hline
\end{tabular}


Yeh 2016 (Continued)

Child sex: 39 M, $26 \mathrm{~F}$

Parent sex: 9 M, $53 \mathrm{~F}$

Child age: not reported

Parent age: not reported

Source: hospital

Medical condition: asthma

Illness duration: not reported

"Asthma Family Empowerment Program Asthma"

"Self management"

Mode of delivery: face-to-face, family

Intervention delivered by: first study author (discipline not specified)

Training: not reported

Duration of intervention (child): 4 sessions $\times 50 \mathrm{~min}=3 \mathrm{~h} 20 \mathrm{mins}$

Duration of intervention (parent): 4 sessions $\times 50$ min $=3 \mathrm{~h} 20$ mins

Outcomes $\quad$ Extracted outcome measures used in the analyses

\section{Child measures}

FEV1*

Peak expiratory flow

Asthma symptoms

\section{Parent measures}

Parental Stress Index *

Family Environment Scale*

Funding: "this is supported by grants from the National Science Council (no. NSC97-2314-B-039-034MY3)."

COI: "this is a follow-up evaluation study conducted by the researcher without conflict of interest."

\section{Risk of bias}

Bias Authors' judgement Support for judgement

Random sequence genera- Unclear risk tion (selection bias)
Quote: "The eligible families were randomly assigned to one of two groups using sealed opaque envelopes, following computer-generated random serial numbers by the correspondent author (principal investigator)."

Comment: probably done
Quote: "The eligible families were randomly assigned to one of two groups using sealed opaque envelopes, following computer-generated random serial numbers by the correspondent author (principal investigator)." 
Yeh 2016 (Continued)

Comment: probably done, however the principal investigator was the therapist delivering treatment

\begin{tabular}{lll}
\hline $\begin{array}{l}\text { Blinding of outcome as- } \\
\text { sessment (detection bias) }\end{array}$ & Unclear risk & No description found in text \\
$\begin{array}{l}\text { All outcomes } \\
\text { Incomplete outcome data }\end{array}$ & Unclear risk & $\begin{array}{l}\text { Attrition was reported, but no data were presented on equivalence between } \\
\text { completers and non-completers }\end{array}$ \\
$\begin{array}{l}\text { All outcomes } \\
\text { attion bias) }\end{array}$ &
\end{tabular}

Selective reporting (re- Low risk $\quad$ Outcomes data were fully reported
porting bias)

CBT: cognitive-behavioural therapy; CHW: community health worker; COI: conflict of interest; GI: gastrointestinal; IBD: inflammatory bowel disease; IBS: irritable bowel syndrome; IDDM: insulin-dependent diabetes mellitus; MST: multisystemic therapy; $\mathbf{n}$ : number; PSST: problem-solving skills training; PST: problem-solving therapy; RA: research assistant; RCT: randomized controlled trial; SD: standard deviation; TBI: traumatic brain injury

Note: some demographic information such as the sex of participants may not match the number of participants randomized. We have extracted and reported data from studies, however, some studies have missing demographic data.

\section{Characteristics of excluded studies [ordered by study ID]}

\begin{tabular}{|c|c|}
\hline Study & Reason for exclusion \\
\hline Aleman 1992 & Insufficient psychotherapeutic content \\
\hline Allen 1998 & Inadequate $\mathrm{n}$ : the number of participants in any treatment arm was $<20$ \\
\hline Anderson 1999 & Insufficient psychotherapeutic content \\
\hline Antonini 2014 & Inadequate $\mathrm{n}$ : the number of participants in any treatment arm was $<20$ \\
\hline Barakat 2010 & Inadequate $\mathrm{n}$ : the number of participants in any treatment arm was $<20$ \\
\hline Barrera 2018a & Insufficient psychotherapeutic content delivered to parents \\
\hline Barrera 2018b & Insufficient psychotherapeutic content \\
\hline Barry 1997 & Inadequate $\mathrm{n}$ : the number of participants in any treatment arm was $<20$ \\
\hline Bellin 2013 & Insufficient psychotherapeutic content \\
\hline Betancourt 2004 & Identified participants prospectively \\
\hline Borhani 2011 & Aim of study was irrelevant to this review \\
\hline Braga 2005 & Insufficient psychotherapeutic content \\
\hline Brown 2014 & Mixed conditions; data not reported separately for the purpose of this review \\
\hline Bruzzese 2008 & Aim of study was irrelevant to this review \\
\hline Burke 1997 & Insufficient psychotherapeutic content \\
\hline Burke 2001 & Insufficient psychotherapeutic content \\
\hline
\end{tabular}




\begin{tabular}{|c|c|}
\hline Study & Reason for exclusion \\
\hline Cakan 2007 & Aim of study was irrelevant to this review \\
\hline Canino 2008 & Aim of study was irrelevant to this review \\
\hline Canino 2016 & Insufficient psychotherapeutic content \\
\hline Carey 2008 & Aim of study was irrelevant to this review \\
\hline Celano 2012 & Inadequate $\mathrm{n}$ : the number of participants in any treatment arm was $<20$ \\
\hline Cernvall 2015 & Inadequate $\mathrm{n}$ : the number of participants in any treatment arm was $<20$ \\
\hline Chen 2013 & Insufficient psychotherapeutic content \\
\hline Chernoff 2002 & Insufficient psychotherapeutic content \\
\hline Chiang 2009 & Insufficient psychotherapeutic content \\
\hline Christie 2016 & Insufficient psychotherapeutic content \\
\hline Churchill 2018 & Mixed illness conditions \\
\hline Connelly 2006 & Inadequate $\mathrm{n}$ : the number of participants in any treatment arm was $<20$ \\
\hline Duarte 2006 & Inadequate $\mathrm{n}$ : the number of participants in any treatment arm was $<20$ \\
\hline Ellis 2004 & Inadequate $\mathrm{n}$ : the number of participants in any treatment arm was $<20$ \\
\hline Ellis 2007 & Aim of study was irrelevant to this review \\
\hline Ellis 2008 & Aim of study was irrelevant to this review \\
\hline Evans 1999 & Insufficient psychotherapeutic content \\
\hline Fedele 2013 & Aim of study was irrelevant to this review \\
\hline Field 1998 & Insufficient psychotherapeutic content \\
\hline Forsander 1995 & Aim of study was irrelevant to this review \\
\hline Forsander 2003 & Inadequate $\mathrm{n}$ : the number of participants in any treatment arm was $<20$ \\
\hline Garbutt 2010 & Insufficient psychotherapeutic content \\
\hline Gerber 2010 & Aim of study was irrelevant to this review \\
\hline Giallo 2008 & Insufficient psychotherapeutic content \\
\hline Glang 2007 & Insufficient psychotherapeutic content \\
\hline Grey 2011 & Replicated data already included in the review \\
\hline Groß 2013 & Insufficient psychotherapeutic content \\
\hline Gulewitsch 2012 & Aim of study was irrelevant to this review \\
\hline
\end{tabular}




\begin{tabular}{|c|c|}
\hline Study & Reason for exclusion \\
\hline Gulewitsch 2013 & Inadequate $\mathrm{n}$ : the number of participants in any treatment arm was $<20$ \\
\hline Gustafsson 1986 & Inadequate $\mathrm{n}$ : the number of participants in any treatment arm was $<20$ \\
\hline Halterman 2014 & Insufficient psychotherapeutic content \\
\hline Harris 2001 & Aim of study was irrelevant to this review \\
\hline Haus 1976 & Inadequate $\mathrm{n}$ : the number of participants in any treatment arm was $<20$ \\
\hline Hernandez 1998 & Inadequate $\mathrm{n}$ : the number of participants in any treatment arm was $<20$ \\
\hline Hicks 2006 & Inadequate $\mathrm{n}$ : the number of participants in any treatment arm was $<20$ \\
\hline Hommel 2012 & Aim of study was irrelevant to this review \\
\hline Hovell 1994 & Insufficient psychotherapeutic content \\
\hline Humphreys 2000 & Insufficient psychotherapeutic content \\
\hline Ireys 1996 & Insufficient psychotherapeutic content \\
\hline Ireys 2001 & Insufficient psychotherapeutic content \\
\hline Jay 1990 & Aim of study was irrelevant to this review \\
\hline Johnson 1987 & Insufficient psychotherapeutic content \\
\hline Kamps 2008 & Inadequate $\mathrm{n}$ : the number of participants in any treatment arm was $<20$ \\
\hline Kashikar-Zuck 2005 & Inadequate $\mathrm{n}$ : the number of participants in any treatment arm was $<20$ \\
\hline Kaslow 2000 & Insufficient psychotherapeutic content \\
\hline Katz 2014 & Insufficient psychotherapeutic content \\
\hline Kazak 1996 & Insufficient psychotherapeutic content \\
\hline Kazak 2005 & Inadequate $\mathrm{n}$ : the number of participants in any treatment arm was $<20$ \\
\hline Ketchen 2006 & Insufficient psychotherapeutic content \\
\hline Klinnert 2005 & Insufficient psychotherapeutic content \\
\hline Klinnert 2007 & Insufficient psychotherapeutic content \\
\hline Kroner-Herwig 1998 & Inadequate $\mathrm{n}$ : the number of participants in any treatment arm was $<20$ \\
\hline Kupfer 2010 & Insufficient psychotherapeutic content \\
\hline Kurowski 2013 & Aim of study was irrelevant to this review \\
\hline Lasecki 2008 & Inadequate $\mathrm{n}$ : the number of participants in any treatment arm was $<20$ \\
\hline Lask 1979 & Inadequate $\mathrm{n}$ : the number of participants in any treatment arm was $<20$ \\
\hline
\end{tabular}




\begin{tabular}{|c|c|}
\hline Study & Reason for exclusion \\
\hline Lehmkuhl 2010 & Inadequate $\mathrm{n}$ : the number of participants in any treatment arm was $<20$ \\
\hline Logan 1997 & Insufficient psychotherapeutic content \\
\hline Lyon 2013 & Aim of study was irrelevant to this review \\
\hline Manne 2016 & Mixed conditions; data not reported separately for the purpose of this review \\
\hline Marsland 2013 & insufficient $\mathrm{n}$ \\
\hline Mendez 1997 & Insufficient psychotherapeutic content \\
\hline Mortenson 2016 & Insufficient psychotherapeutic content \\
\hline Mowla 2017 & Mixed illness conditions \\
\hline Mullins 2012 & $\mathrm{n}<20$ at post-treatment \\
\hline Murphy 2012 & Insufficient psychotherapeutic content \\
\hline Nelson 2011 & Insufficient psychotherapeutic content \\
\hline Ng 2008 & Inadequate $\mathrm{n}$ : the number of participants in any treatment arm was $<20$ \\
\hline Niebel 2000 & $\mathrm{n}<20$ at post-treatment \\
\hline Olivares 1997 & Inadequate $\mathrm{n}$ : the number of participants in any treatment arm was $<20$ \\
\hline Pérez 1999 & Insufficient psychotherapeutic content \\
\hline Rapoff 2014 & Insufficient psychotherapeutic content delivered to parents \\
\hline Rasoli 2008 & Aim of study was irrelevant to this review \\
\hline Rice 2015 & Insufficient psychotherapeutic content \\
\hline Sanders 1989 & Inadequate $\mathrm{n}$ : the number of participants in any treatment arm was $<20$ \\
\hline Sanders 1996 & Inadequate $\mathrm{n}$ : the number of participants in any treatment arm was $<20$ \\
\hline Saßman 2012 & Inadequate $\mathrm{n}$ : the number of participants in any treatment arm was $<20$ \\
\hline Satin 1989 & Inadequate $\mathrm{n}$ : the number of participants in any treatment arm was $<20$ \\
\hline Scholten 2011 & Aim of study was irrelevant to this review \\
\hline Scholten 2015 & Mixed conditions; data not reported separately for the purpose of this review \\
\hline Shekarabi-Ahari 2012 & insufficient $\mathrm{n}$ \\
\hline Sieberg 2011 & Inadequate $\mathrm{n}$ : the number of participants in any treatment arm was $<20$ \\
\hline Staab 2002 & Insufficient psychotherapeutic content \\
\hline Sullivan-Bolyai 2010 & Insufficient psychotherapeutic content \\
\hline
\end{tabular}




\begin{tabular}{|c|c|}
\hline Study & Reason for exclusion \\
\hline Sullivan-Bolyai 2015 & Insufficient psychotherapeutic content \\
\hline Szczepanski 2010 & Insufficient psychotherapeutic content \\
\hline Szigethy 2014 & Insufficient psychotherapeutic content \\
\hline Tsiouli 2014 & $\mathrm{n}<20$ at post-treatment \\
\hline Van der Veek 2013 & Aim of study was irrelevant to this review \\
\hline Van Dijk-Lokkart 2016 & Insufficient psychotherapeutic content \\
\hline Wade $2006 b$ & $\mathrm{n}<20$ at post-treatment \\
\hline Wade 2010 & Aim of study was irrelevant to this review \\
\hline Wade 2011 & Inadequate $\mathrm{n}$ : the number of participants in any treatment arm was $<20$ \\
\hline Walders 2006 & Insufficient psychotherapeutic content \\
\hline Walker 1996 & Aim of study was irrelevant to this review \\
\hline Warner 2011 & Inadequate $\mathrm{n}$ : the number of participants in any treatment arm was $<20$ \\
\hline Wysocki 1997 & Aim of study was irrelevant to this review \\
\hline
\end{tabular}

n: number

\section{DATA AND ANALYSES}

\section{Comparison 1. Asthma post-treatment}

\begin{tabular}{lllll}
\hline $\begin{array}{l}\text { Outcome or subgroup } \\
\text { title }\end{array}$ & No. of studies & $\begin{array}{l}\text { No. of partici- } \\
\text { pants }\end{array}$ & Statistical method & Effect size \\
\hline 1.1 Parenting behavior & 2 & 209 & $\begin{array}{l}\text { Std. Mean Difference (IV, Random, 95\% } \\
\text { Cl) }\end{array}$ & -0.13 [-0.40, 0.14] \\
\hline 1.2 Parent mental health & 1 & 65 & $\begin{array}{l}\text { Std. Mean Difference (IV, Random, 95\% } \\
\text { Cl) }\end{array}$ & $-0.76[-1.27,-0.26]$ \\
\hline 1.3 Child mental health & 1 & 41 & $\begin{array}{l}\text { Std. Mean Difference (IV, Random, 95\% } \\
\text { Cl) }\end{array}$ & $-0.04[-0.66,0.57]$ \\
\hline 1.4 Child symptoms & 3 & 337 & $\begin{array}{l}\text { Std. Mean Difference (IV, Random, 95\% } \\
\text { Cl) }\end{array}$ & $-0.16[-0.63,0.31]$ \\
\hline 1.5 Family functioning & 2 & 107 & $\begin{array}{l}\text { Std. Mean Difference (IV, Random, 95\% } \\
\text { Cl) }\end{array}$ & $-0.32[-1.49,0.86]$ \\
\hline
\end{tabular}


Analysis 1.1. Comparison 1: Asthma post-treatment, Outcome 1: Parenting behavior

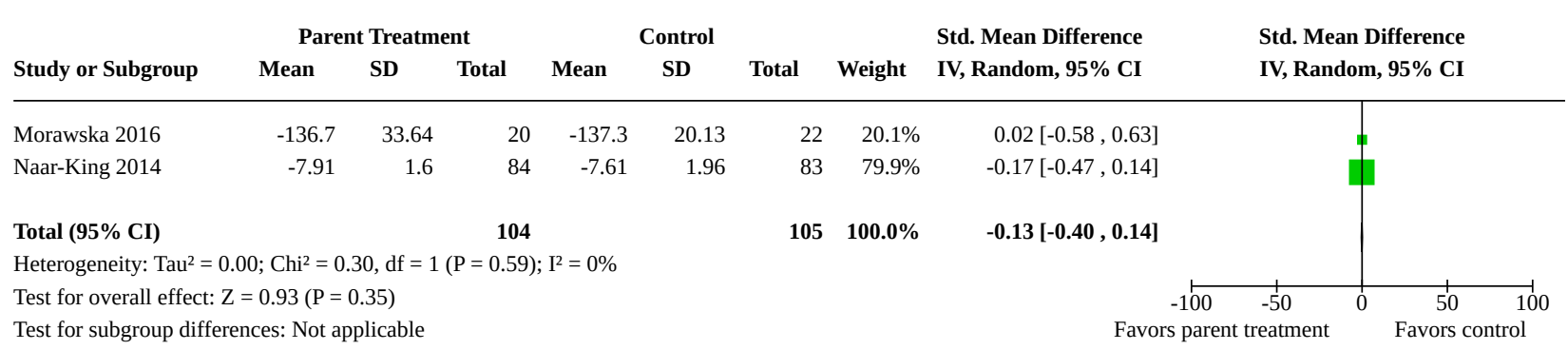

Analysis 1.2. Comparison 1: Asthma post-treatment, Outcome 2: Parent mental health

\begin{tabular}{|c|c|c|c|c|c|c|c|c|c|}
\hline \multirow{2}{*}{ Study or Subroun } & \multicolumn{3}{|c|}{ Parent Treatment } & \multicolumn{3}{|c|}{ Control } & \multirow{2}{*}{\multicolumn{2}{|c|}{$\begin{array}{l}\text { Std. Mean Difference } \\
\text { IV. Random, } 95 \% \text { CI }\end{array}$}} & \multirow{2}{*}{$\begin{array}{l}\text { Std. Mean Difference } \\
\text { IV, Random, } 95 \% \text { CI }\end{array}$} \\
\hline & Mean & SD & Total & Mean & SD & Total & & & \\
\hline
\end{tabular}

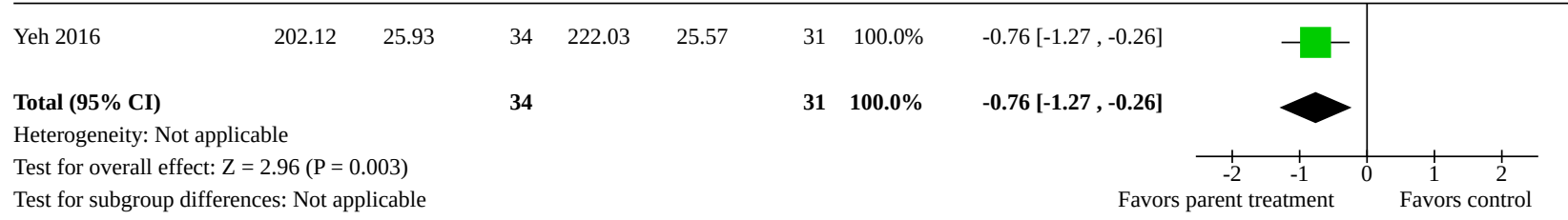

\section{Analysis 1.3. Comparison 1: Asthma post-treatment, Outcome 3: Child mental health}

\begin{tabular}{|c|c|c|c|c|c|c|c|c|c|}
\hline \multirow[b]{2}{*}{ Study or Subgroup } & \multicolumn{3}{|c|}{ Parent Treatment } & \multicolumn{3}{|c|}{ Control } & \multirow[b]{2}{*}{ Weight } & \multirow{2}{*}{$\begin{array}{l}\text { Std. Mean Difference } \\
\text { IV, Random, } 95 \% \text { CI }\end{array}$} & \multirow{2}{*}{$\begin{array}{l}\text { Std. Mean Difference } \\
\text { IV, Random, 95\% CI }\end{array}$} \\
\hline & Mean & SD & Total & Mean & SD & Total & & & \\
\hline Morawska 2016 & 47.3 & 28.3 & 20 & 48.5 & 24.64 & 21 & $100.0 \%$ & $-0.04[-0.66,0.57]$ & \\
\hline Total (95\% CI) & & & 20 & & & 21 & $100.0 \%$ & $-0.04[-0.66,0.57]$ & \\
\hline \multicolumn{10}{|c|}{ Heterogeneity: Not applicable } \\
\hline \multicolumn{4}{|c|}{ Test for overall effect: $\mathrm{Z}=0.14(\mathrm{P}=0.89)$} & & & & & -100 & -50 \\
\hline \multicolumn{4}{|c|}{ Test for subgroup differences: Not applicable } & & & & & Favors pare & Favors control \\
\hline
\end{tabular}

\section{Analysis 1.4. Comparison 1: Asthma post-treatment, Outcome 4: Child symptoms}

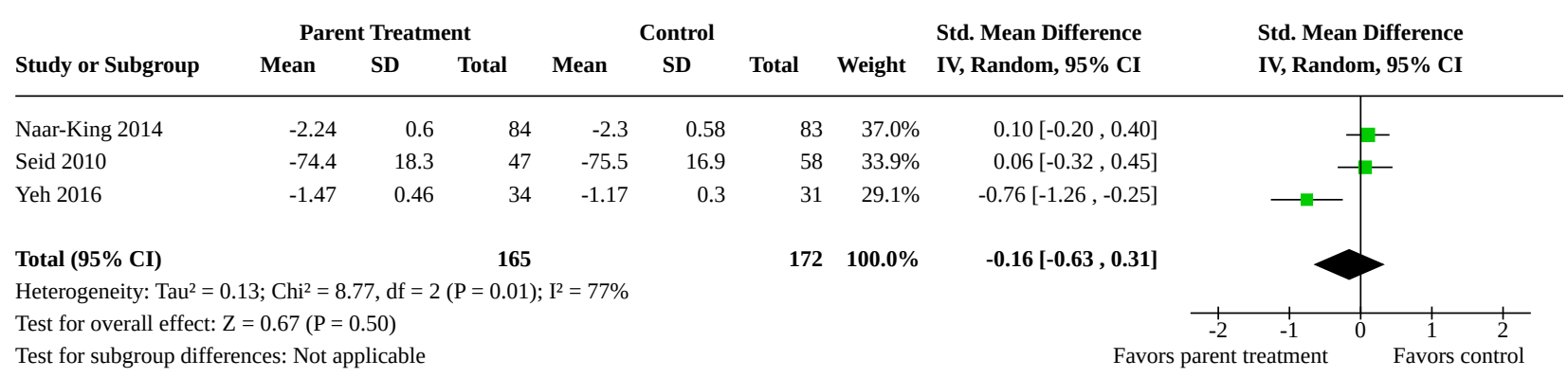




\section{Analysis 1.5. Comparison 1: Asthma post-treatment, Outcome 5: Family functioning}

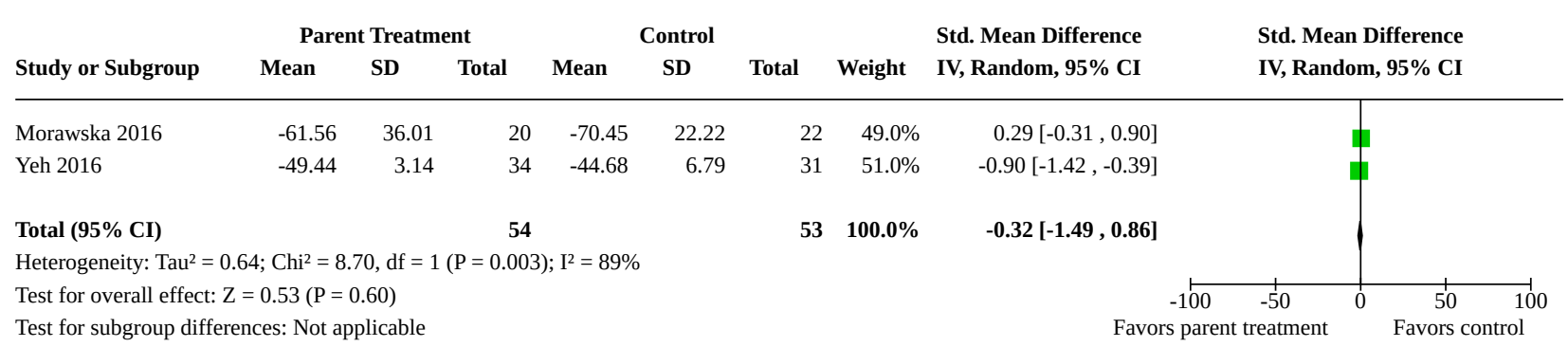

\section{Comparison 2. Asthma follow-up}

\begin{tabular}{lllll}
\hline $\begin{array}{l}\text { Outcome or subgroup } \\
\text { title }\end{array}$ & No. of studies & $\begin{array}{l}\text { No. of partici- } \\
\text { pants }\end{array}$ & Statistical method & Effect size \\
\hline 2.1 Parent mental health & 1 & 65 & $\begin{array}{l}\text { Std. Mean Difference (IV, Random, 95\% } \\
\text { Cl) }\end{array}$ & $-1.30[-1.83,-0.76]$ \\
\hline 2.2 Child symptoms & 2 & 160 & $\begin{array}{l}\text { Std. Mean Difference (IV, Random, 95\% } \\
\text { Cl) }\end{array}$ & $-0.32[-1.25,0.62]$ \\
\hline 2.3 Family functioning & 1 & 65 & $\begin{array}{l}\text { Std. Mean Difference (IV, Random, 95\% } \\
\text { Cl) }\end{array}$ & $-2.71[-3.39,-2.02]$ \\
\hline
\end{tabular}

Analysis 2.1. Comparison 2: Asthma follow-up, Outcome 1: Parent mental health

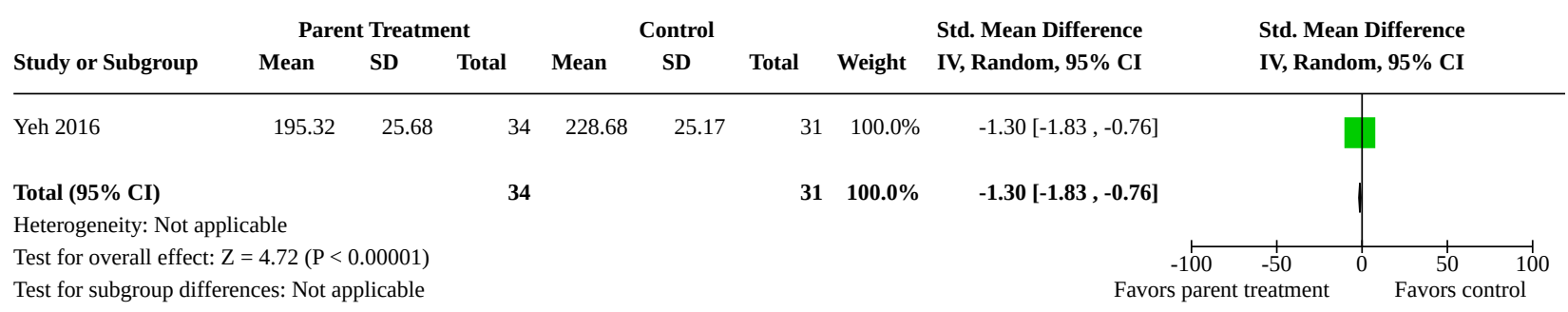

Analysis 2.2. Comparison 2: Asthma follow-up, Outcome 2: Child symptoms

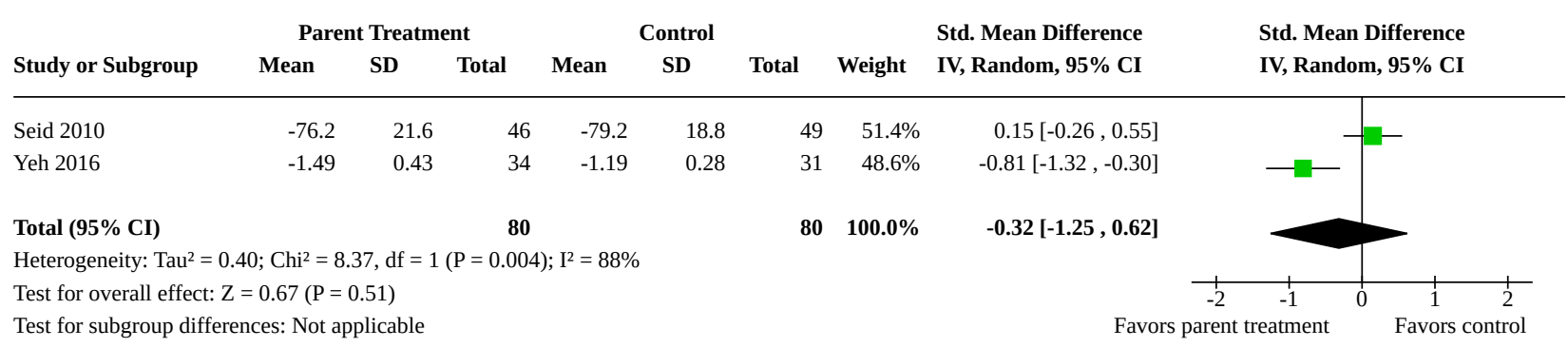




\section{Analysis 2.3. Comparison 2: Asthma follow-up, Outcome 3: Family functioning}

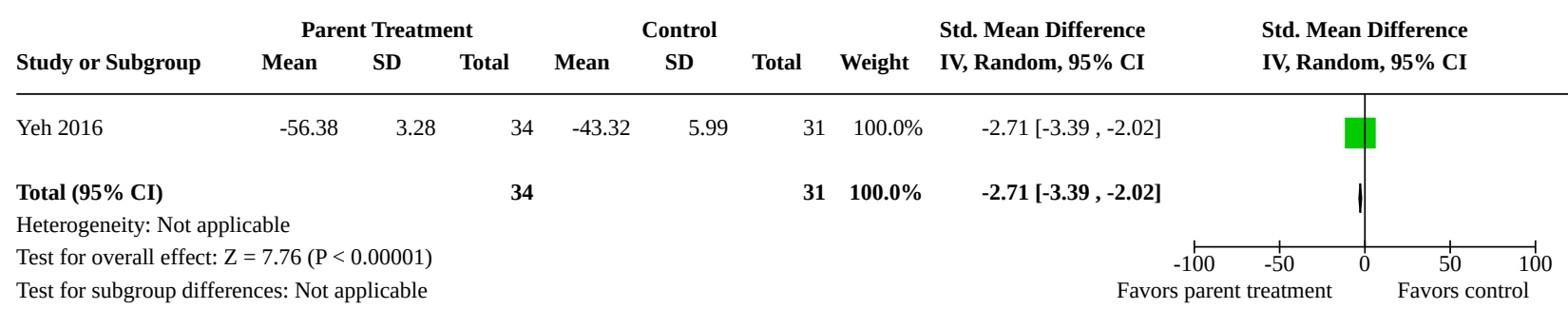

\section{Comparison 3. Cancer post-treatment}

\begin{tabular}{lllll}
\hline $\begin{array}{l}\text { Outcome or subgroup ti- } \\
\text { tle }\end{array}$ & No. of studies & $\begin{array}{l}\text { No. of partici- } \\
\text { pants }\end{array}$ & Statistical method & Effect size \\
\hline 3.1 Parenting behavior & 3 & 664 & $\begin{array}{l}\text { Std. Mean Difference (IV, Random, 95\% } \\
\text { Cl) }\end{array}$ & $-0.28[-0.43,-0.13]$ \\
\hline 3.2 Parent mental health & 6 & 836 & $\begin{array}{l}\text { Std. Mean Difference (IV, Random, 95\% } \\
\text { Cl) }\end{array}$ & $-0.21[-0.35,-0.08]$ \\
\hline
\end{tabular}

\section{Analysis 3.1. Comparison 3: Cancer post-treatment, Outcome 1: Parenting behavior}

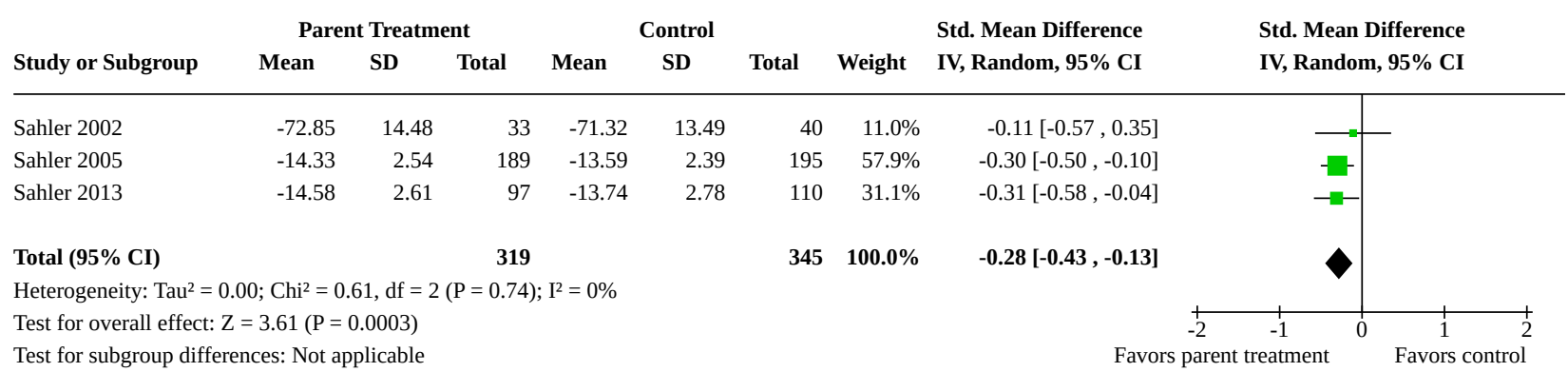

Analysis 3.2. Comparison 3: Cancer post-treatment, Outcome 2: Parent mental health

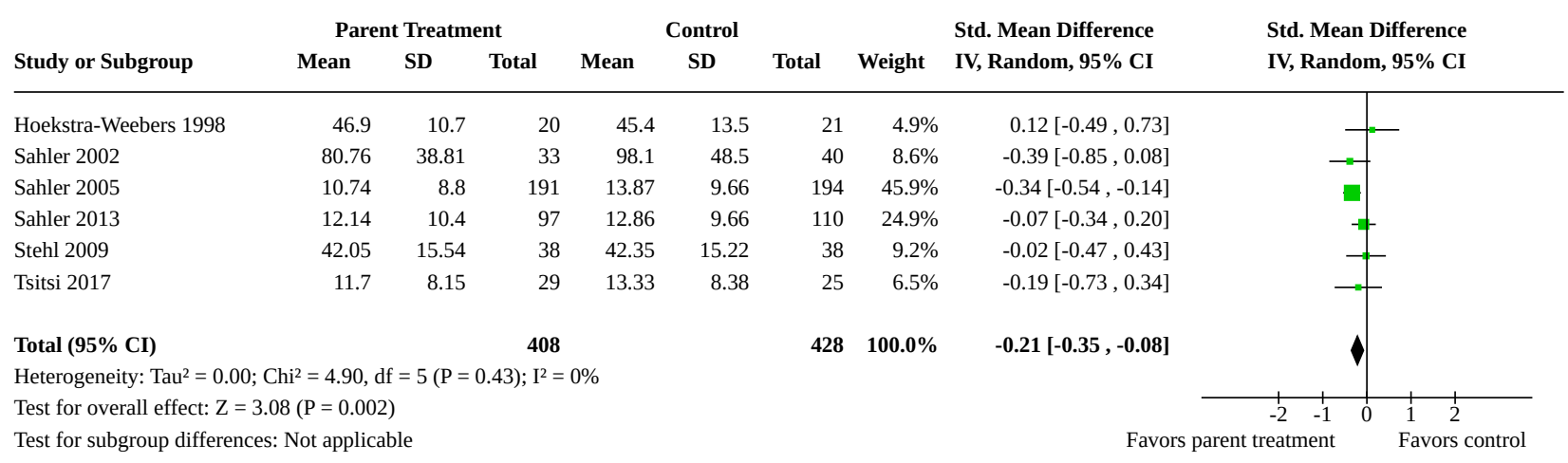




\section{Comparison 4. Cancer follow-up}

\begin{tabular}{lllll}
\hline $\begin{array}{l}\text { Outcome or subgroup ti- } \\
\text { tle }\end{array}$ & No. of studies & $\begin{array}{l}\text { No. of partici- } \\
\text { pants }\end{array}$ & Statistical method & Effect size \\
\hline 4.1 Parenting behavior & 3 & 625 & $\begin{array}{l}\text { Std. Mean Difference (IV, Random, 95\% } \\
\text { Cl) }\end{array}$ & $-0.21[-0.37,-0.05]$ \\
\hline 4.2 Parent mental health & 4 & 667 & $\begin{array}{l}\text { Std. Mean Difference (IV, Random, 95\% } \\
\text { Cl) }\end{array}$ & $-0.23[-0.39,-0.08]$ \\
\hline
\end{tabular}

\section{Analysis 4.1. Comparison 4: Cancer follow-up, Outcome 1: Parenting behavior}

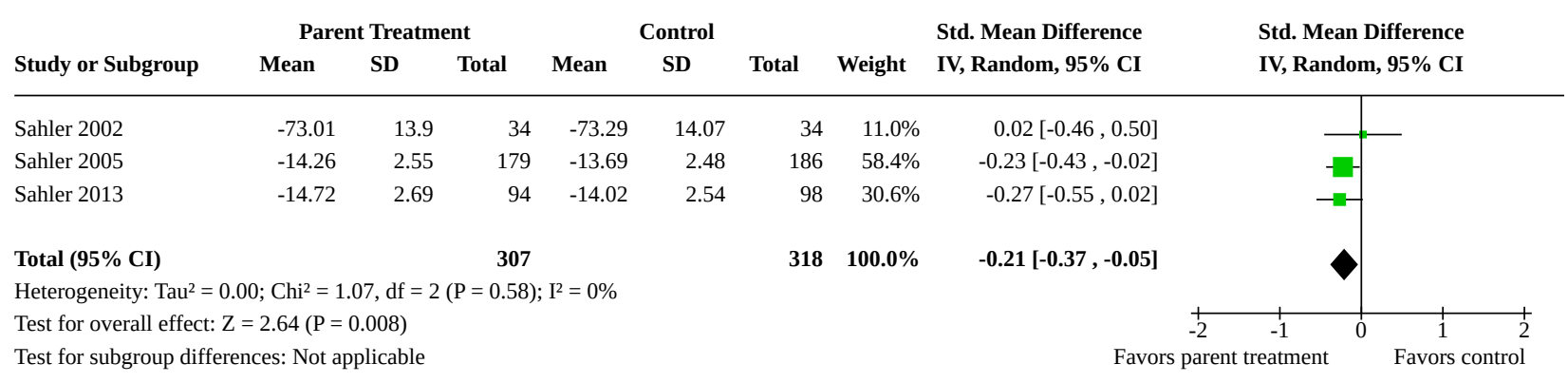

Analysis 4.2. Comparison 4: Cancer follow-up, Outcome 2: Parent mental health

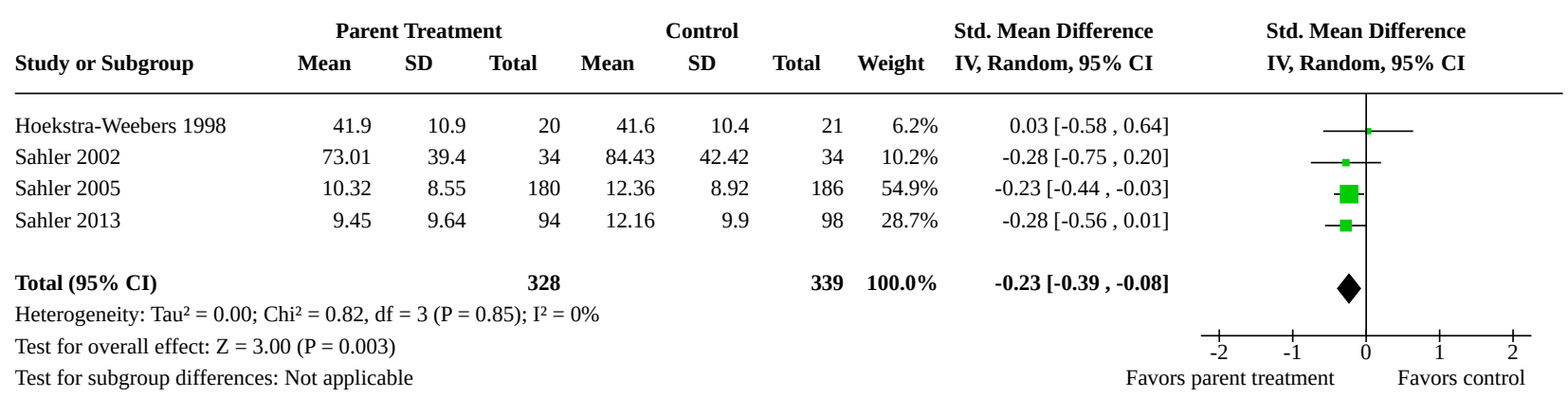

\section{Comparison 5. Chronic pain conditions post-treatment}

\begin{tabular}{|c|c|c|c|c|}
\hline $\begin{array}{l}\text { Outcome or subgroup } \\
\text { title }\end{array}$ & No. of studies & $\begin{array}{l}\text { No. of partici- } \\
\text { pants }\end{array}$ & Statistical method & Effect size \\
\hline 5.2 Parent mental health & 3 & 490 & $\begin{array}{l}\text { Std. Mean Difference (IV, Random, 95\% } \\
\mathrm{CI})\end{array}$ & $-0.24[-0.42,-0.06]$ \\
\hline $\begin{array}{l}5.3 \text { Child behavior/dis- } \\
\text { ability }\end{array}$ & 12 & 1362 & $\begin{array}{l}\text { Std. Mean Difference (IV, Random, 95\% } \\
\mathrm{CI})\end{array}$ & $-0.15[-0.28,-0.01]$ \\
\hline
\end{tabular}




\begin{tabular}{|c|c|c|c|c|}
\hline $\begin{array}{l}\text { Outcome or subgroup } \\
\text { title }\end{array}$ & No. of studies & $\begin{array}{l}\text { No. of partici- } \\
\text { pants }\end{array}$ & Statistical method & Effect size \\
\hline 5.3.1 Active control & 9 & 1154 & $\begin{array}{l}\text { Std. Mean Difference (IV, Random, 95\% } \\
\text { Cl) }\end{array}$ & $-0.13[-0.26,0.00]$ \\
\hline 5.3.2 Waitlist control & 3 & 208 & $\begin{array}{l}\text { Std. Mean Difference (IV, Random, 95\% } \\
\text { CI) }\end{array}$ & $-0.25[-0.76,0.25]$ \\
\hline 5.4 Child mental health & 11 & 1314 & $\begin{array}{l}\text { Std. Mean Difference (IV, Random, 95\% } \\
\text { Cl) }\end{array}$ & $-0.02[-0.13,0.09]$ \\
\hline 5.4.1 Active control & 9 & 1165 & $\begin{array}{l}\text { Std. Mean Difference (IV, Random, 95\% } \\
\text { Cl) }\end{array}$ & $-0.03[-0.16,0.09]$ \\
\hline 5.4.2 Waitlist control & 2 & 149 & $\begin{array}{l}\text { Std. Mean Difference (IV, Random, 95\% } \\
\text { CI) }\end{array}$ & $0.06[-0.27,0.38]$ \\
\hline 5.5 Child symptoms & 10 & 1161 & $\begin{array}{l}\text { Std. Mean Difference (IV, Random, 95\% } \\
\text { Cl) }\end{array}$ & $-0.44[-0.84,-0.03]$ \\
\hline 5.5.1 Active control & 8 & 1018 & $\begin{array}{l}\text { Std. Mean Difference (IV, Random, 95\% } \\
\text { Cl) }\end{array}$ & $-0.13[-0.33,0.06]$ \\
\hline 5.5.2 Waitlist control & 2 & 143 & $\begin{array}{l}\text { Std. Mean Difference (IV, Random, 95\% } \\
\text { CI) }\end{array}$ & $-1.70[-3.94,0.55]$ \\
\hline
\end{tabular}

\section{Analysis 5.1. Comparison 5: Chronic pain conditions post-treatment, Outcome 1: Parenting behavior}

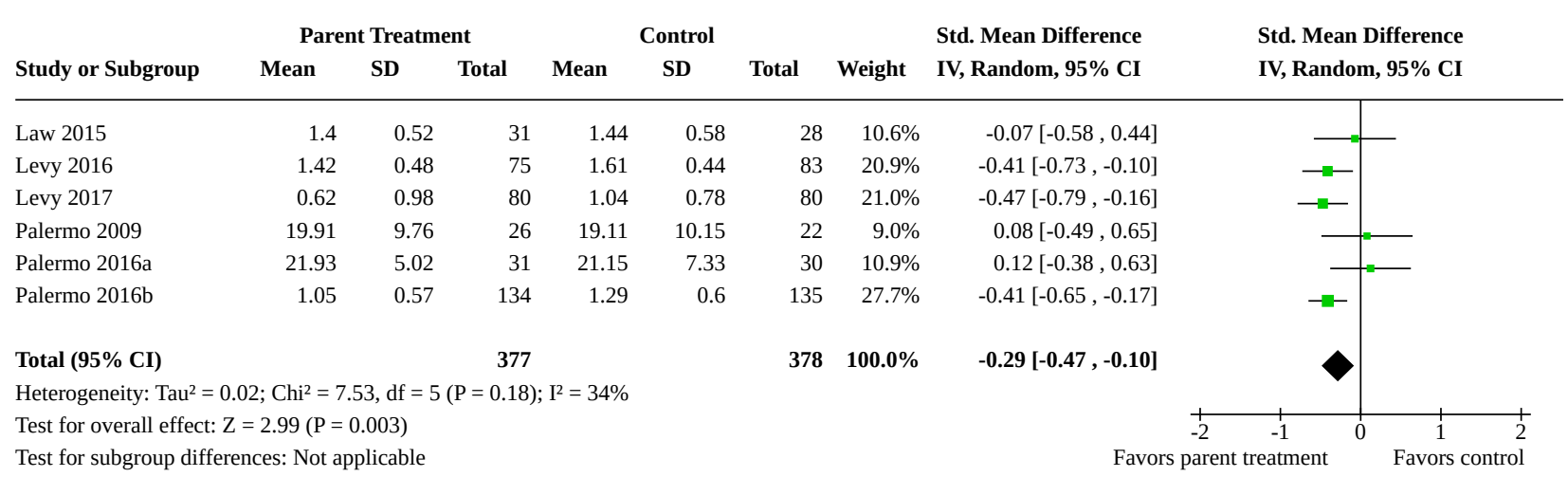

\section{Analysis 5.2. Comparison 5: Chronic pain conditions post-treatment, Outcome 2: Parent mental health}

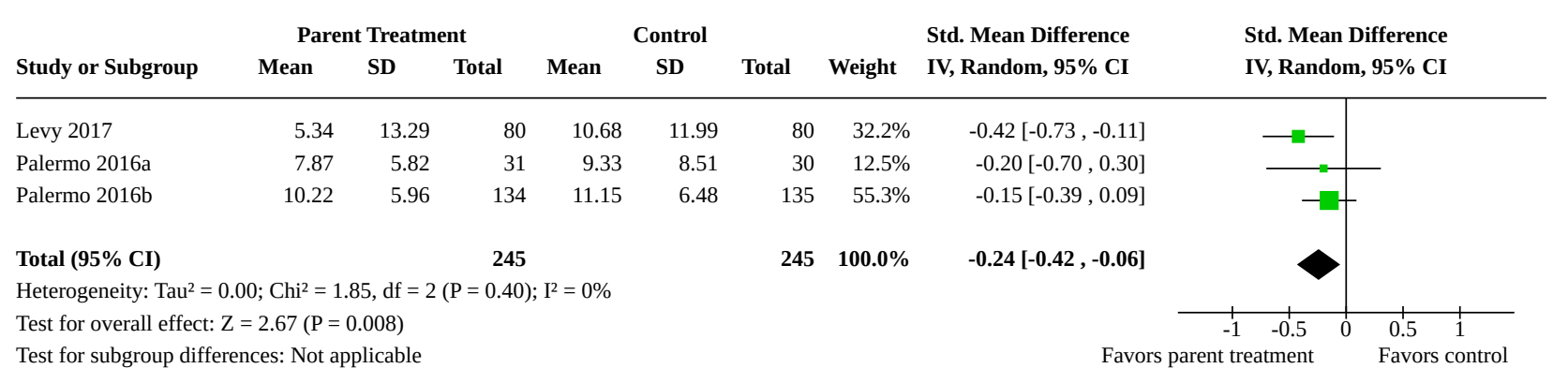


Analysis 5.3. Comparison 5: Chronic pain conditions post-treatment, Outcome 3: Child behavior/disability

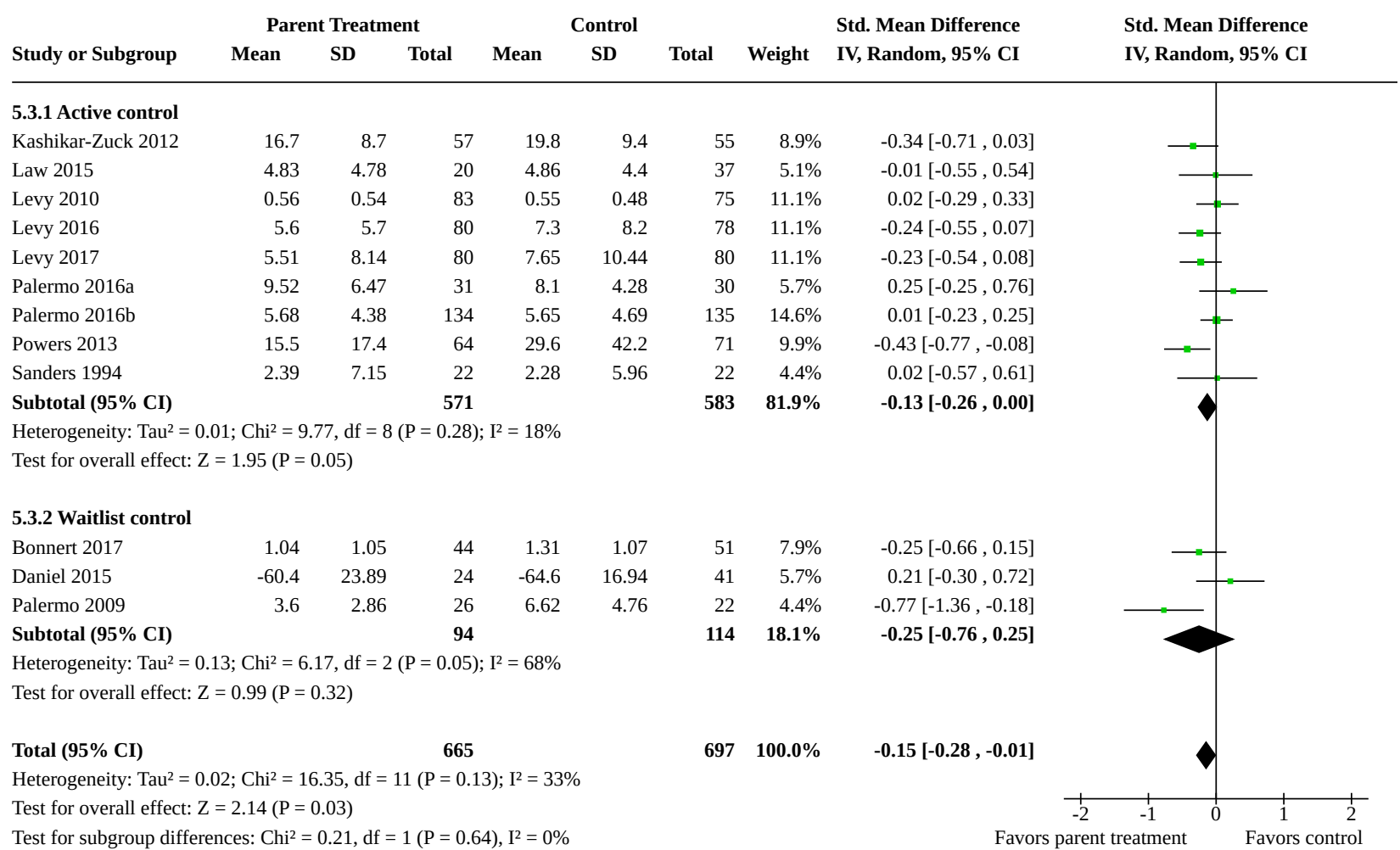

Analysis 5.4. Comparison 5: Chronic pain conditions post-treatment, Outcome 4: Child mental health

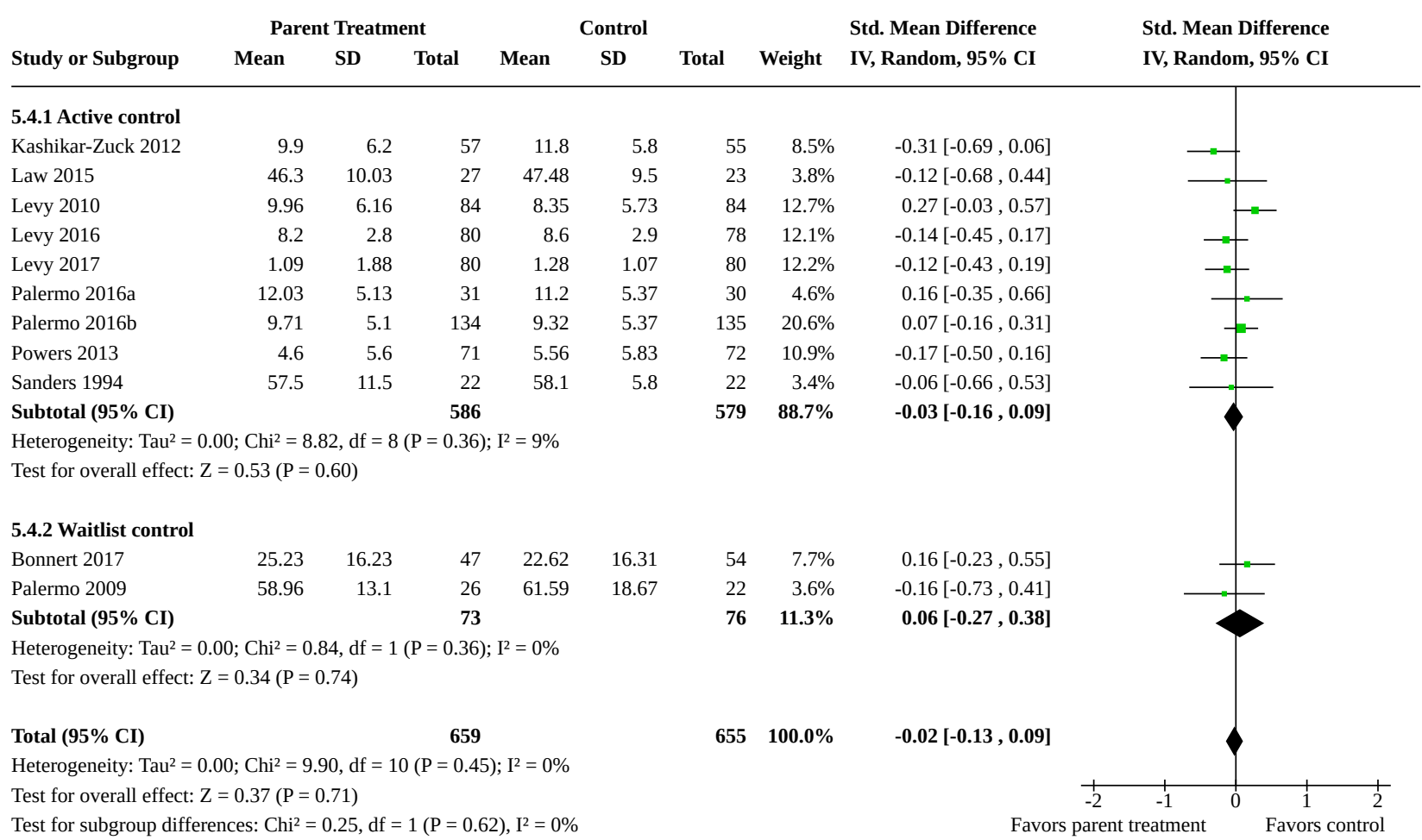




\section{Analysis 5.5. Comparison 5: Chronic pain conditions post-treatment, Outcome 5: Child symptoms}

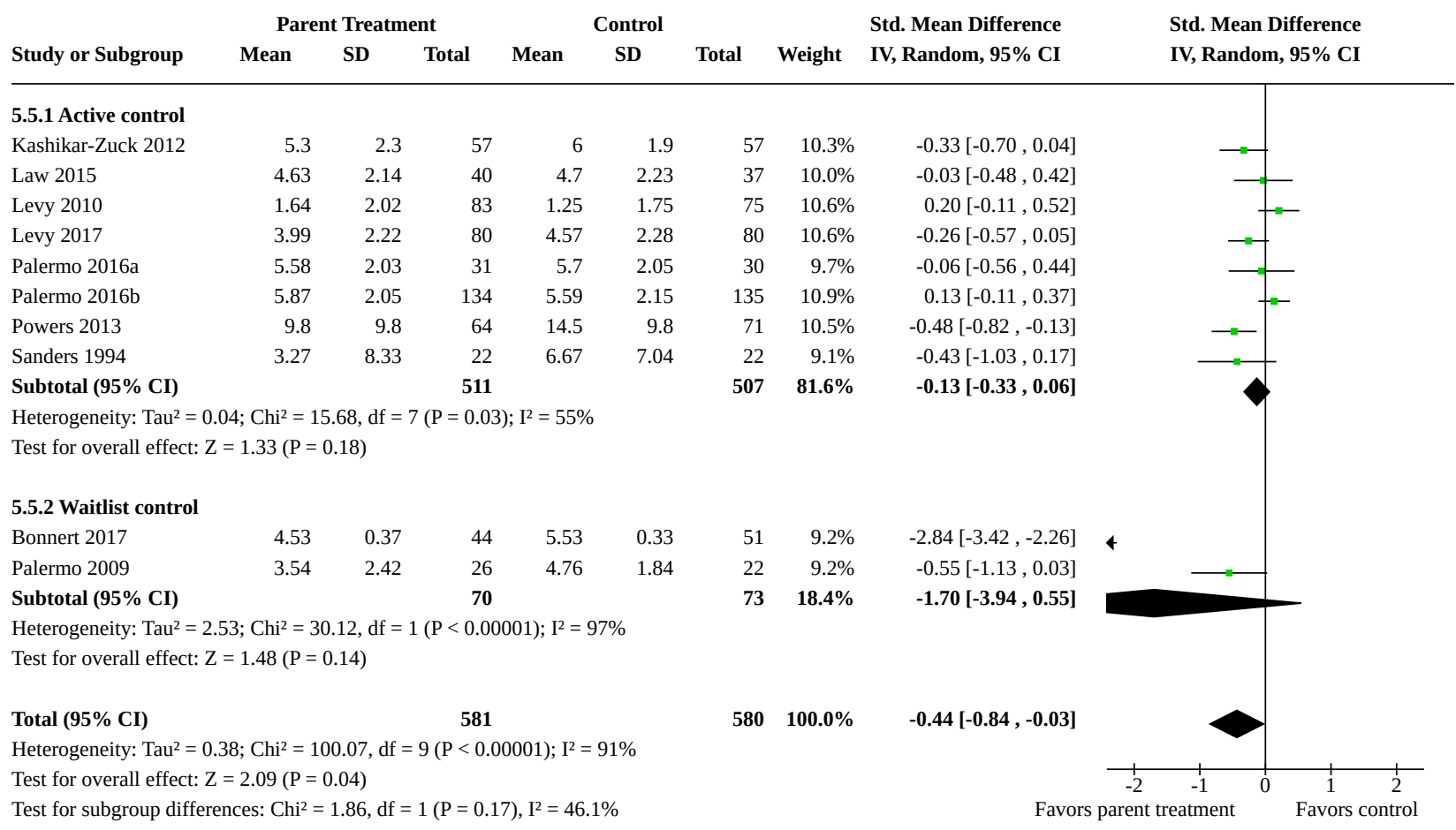

\section{Comparison 6. Chronic pain conditions follow-up}

\begin{tabular}{|c|c|c|c|c|}
\hline $\begin{array}{l}\text { Outcome or subgroup } \\
\text { title }\end{array}$ & No. of studies & $\begin{array}{l}\text { No. of partici- } \\
\text { pants }\end{array}$ & Statistical method & Effect size \\
\hline 6.1 Parenting behavior & 5 & 678 & $\begin{array}{l}\text { Std. Mean Difference (IV, Random, 95\% } \\
\mathrm{CI} \text { ) }\end{array}$ & $-0.35[-0.50,-0.20]$ \\
\hline 6.2 Parent mental health & 3 & 482 & $\begin{array}{l}\text { Std. Mean Difference (IV, Random, 95\% } \\
\text { CI) }\end{array}$ & $-0.20[-0.38,-0.02]$ \\
\hline $\begin{array}{l}6.3 \text { Child behavior/dis- } \\
\text { ability }\end{array}$ & 9 & 1099 & $\begin{array}{l}\text { Std. Mean Difference (IV, Random, 95\% } \\
\mathrm{CI} \text { ) }\end{array}$ & $-0.27[-0.39,-0.15]$ \\
\hline 6.4 Child mental health & 9 & 1108 & $\begin{array}{l}\text { Std. Mean Difference (IV, Random, 95\% } \\
\text { CI) }\end{array}$ & $-0.02[-0.14,0.09]$ \\
\hline 6.5 Child symptoms & 8 & 966 & $\begin{array}{l}\text { Std. Mean Difference (IV, Random, 95\% } \\
\mathrm{CI} \text { ) }\end{array}$ & $-0.12[-0.32,0.09]$ \\
\hline
\end{tabular}


Analysis 6.1. Comparison 6: Chronic pain conditions follow-up, Outcome 1: Parenting behavior

\begin{tabular}{|c|c|c|c|c|c|c|c|c|c|}
\hline & \multicolumn{3}{|c|}{ Parent Treatment } & \multicolumn{3}{|c|}{ Control } & \multicolumn{2}{|r|}{ Std. Mean Difference } & Std. Mean Difference \\
\hline Study or Subgroup & Mean & SD & Total & Mean & SD & Total & Weight & IV, Random, 95\% CI & IV, Random, 95\% CI \\
\hline
\end{tabular}

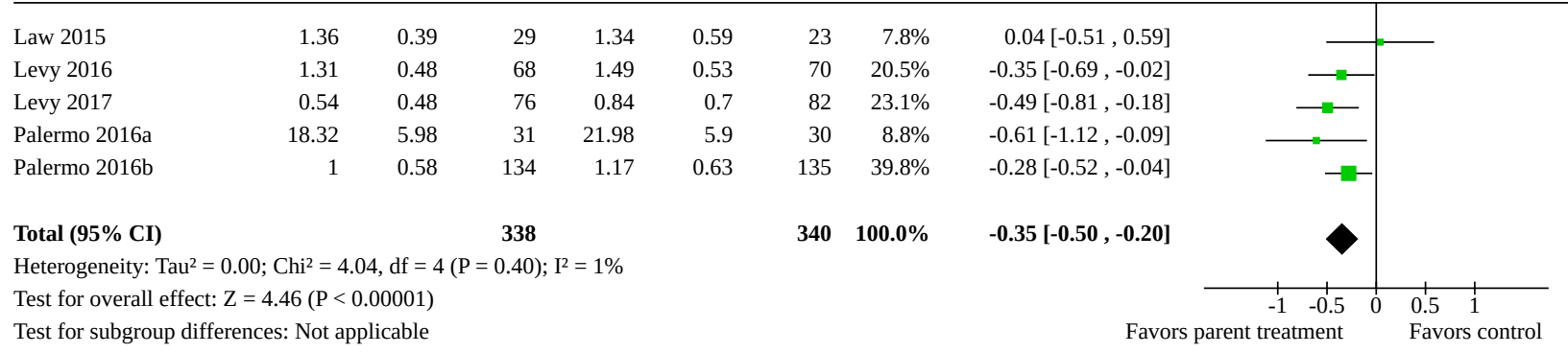

Analysis 6.2. Comparison 6: Chronic pain conditions follow-up, Outcome 2: Parent mental health

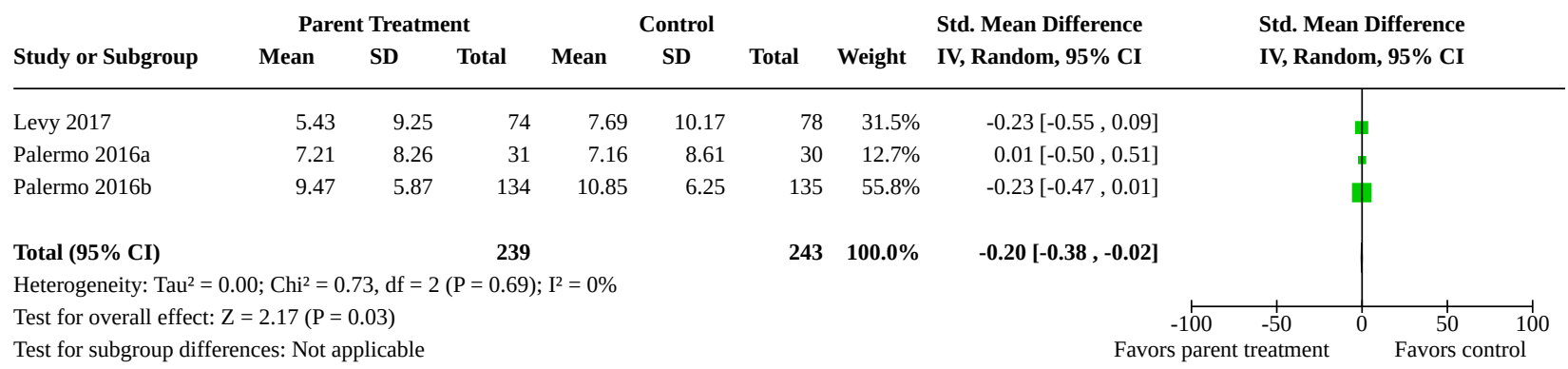

\section{Analysis 6.3. Comparison 6: Chronic pain conditions follow-up, Outcome 3: Child behavior/disability}

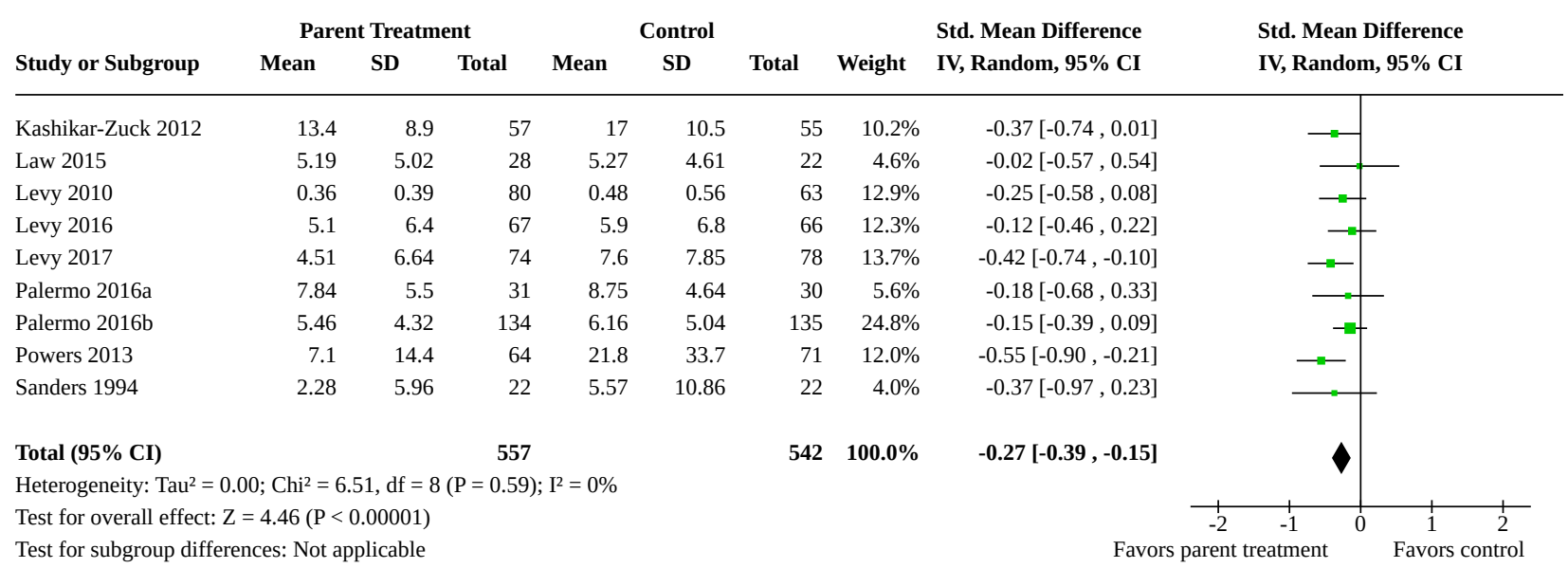


Analysis 6.4. Comparison 6: Chronic pain conditions follow-up, Outcome 4: Child mental health

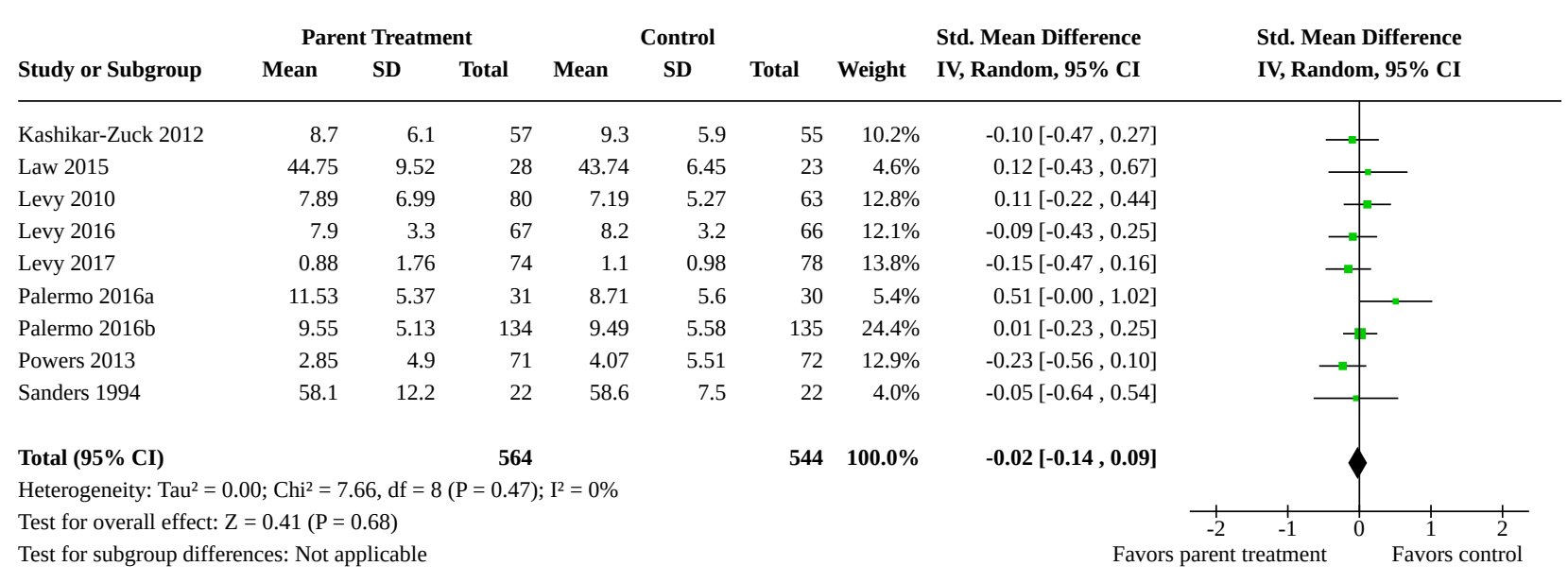

Analysis 6.5. Comparison 6: Chronic pain conditions follow-up, Outcome 5: Child symptoms

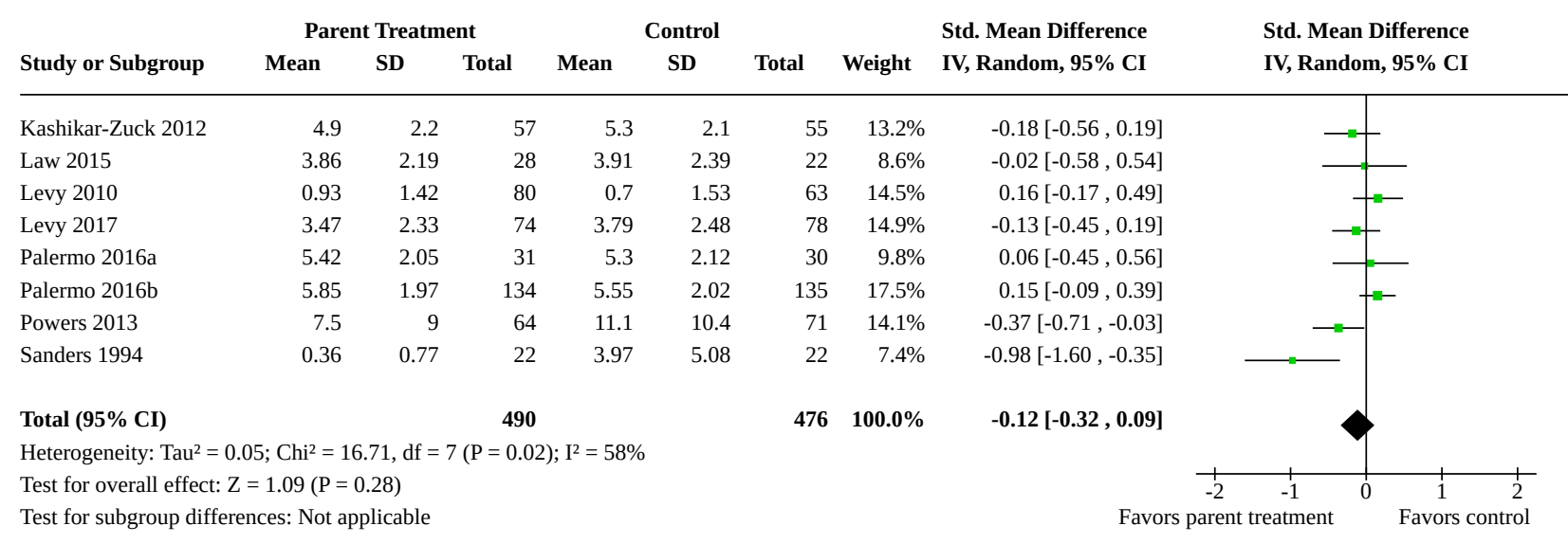

\section{Comparison 7. Diabetes post-treatment}

\begin{tabular}{|c|c|c|c|c|}
\hline $\begin{array}{l}\text { Outcome or subgroup } \\
\text { title }\end{array}$ & No. of studies & $\begin{array}{l}\text { No. of partici- } \\
\text { pants }\end{array}$ & Statistical method & Effect size \\
\hline 7.1 Parenting behavior & 5 & 338 & $\begin{array}{l}\text { Std. Mean Difference (IV, Random, 95\% } \\
\mathrm{Cl} \text { ) }\end{array}$ & $-1.39[-2.41,-0.38]$ \\
\hline 7.2 Parent mental health & 3 & 211 & $\begin{array}{l}\text { Std. Mean Difference (IV, Random, 95\% } \\
\mathrm{CI})\end{array}$ & $-0.24[-0.90,0.42]$ \\
\hline 7.3 Child mental health & 6 & 467 & $\begin{array}{l}\text { Std. Mean Difference (IV, Random, 95\% } \\
\mathrm{CI} \text { ) }\end{array}$ & $-0.09[-0.40,0.21]$ \\
\hline 7.4 Child symptoms & 13 & 1339 & $\begin{array}{l}\text { Std. Mean Difference (IV, Random, 95\% } \\
\mathrm{Cl} \text { ) }\end{array}$ & $-0.02[-0.25,0.21]$ \\
\hline 7.5 Family functioning & 9 & 701 & $\begin{array}{l}\text { Std. Mean Difference (IV, Random, 95\% } \\
\mathrm{CI})\end{array}$ & $-0.15[-0.31,0.01]$ \\
\hline
\end{tabular}


Analysis 7.1. Comparison 7: Diabetes post-treatment, Outcome 1: Parenting behavior

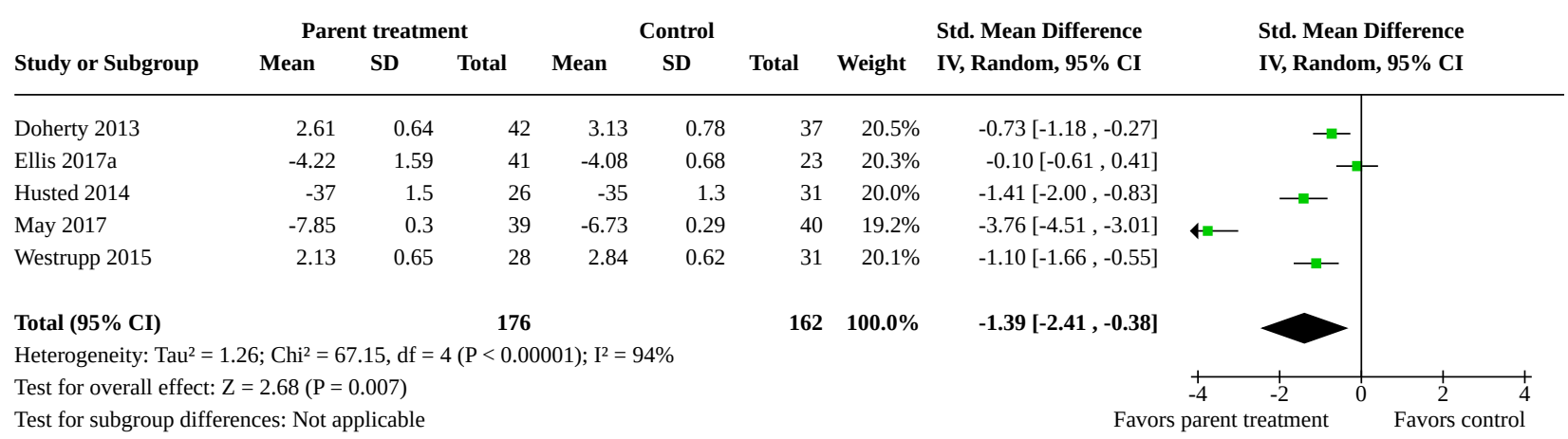

Analysis 7.2. Comparison 7: Diabetes post-treatment, Outcome 2: Parent mental health

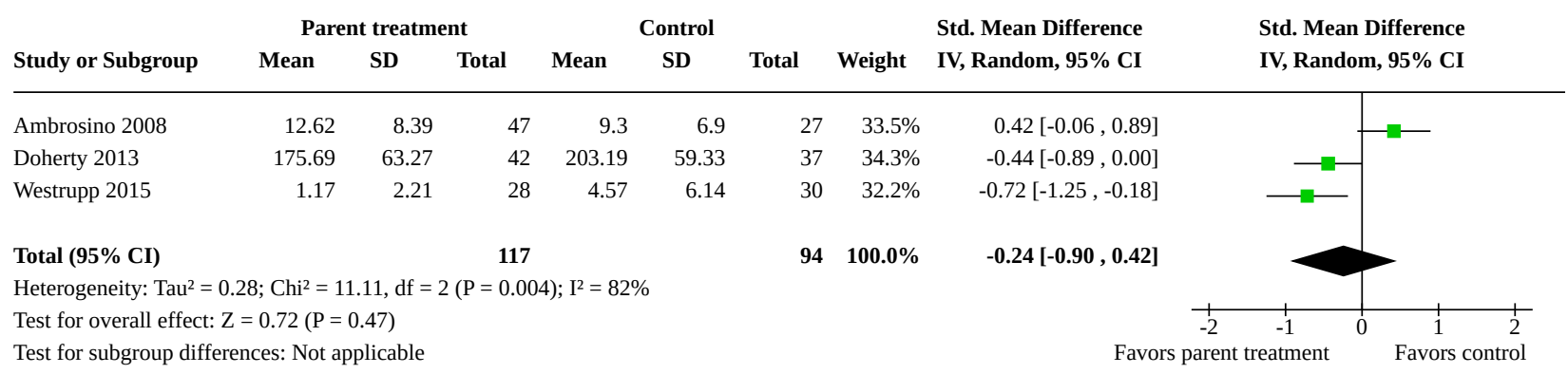

Analysis 7.3. Comparison 7: Diabetes post-treatment, Outcome 3: Child mental health

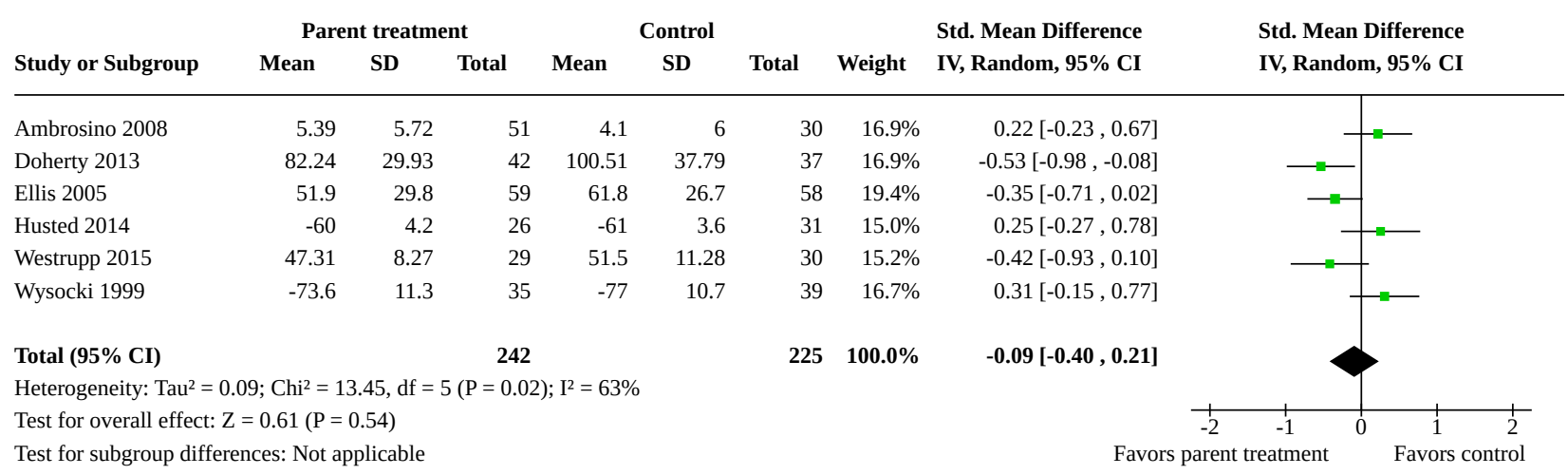




\begin{tabular}{lllll}
\hline $\begin{array}{l}\text { Outcome or subgroup } \\
\text { title }\end{array}$ & No. of studies & $\begin{array}{l}\text { No. of partici- } \\
\text { pants }\end{array}$ & Statistical method & Effect size \\
\hline 8.5 Family functioning & 2 & 158 & $\begin{array}{l}\text { Std. Mean Difference (IV, Random, 95\% } \\
\text { Cl) }\end{array}$ & $0.11[-0.23,0.44]$ \\
\hline
\end{tabular}

Analysis 8.1. Comparison 8: Diabetes follow-up, Outcome 1: Parenting behavior

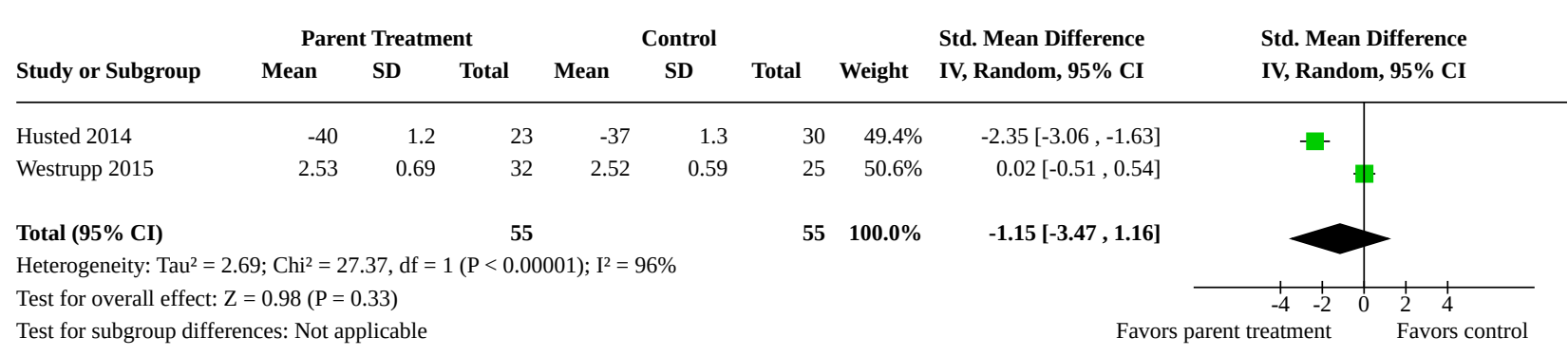

\section{Analysis 8.2. Comparison 8: Diabetes follow-up, Outcome 2: Parent mental health}

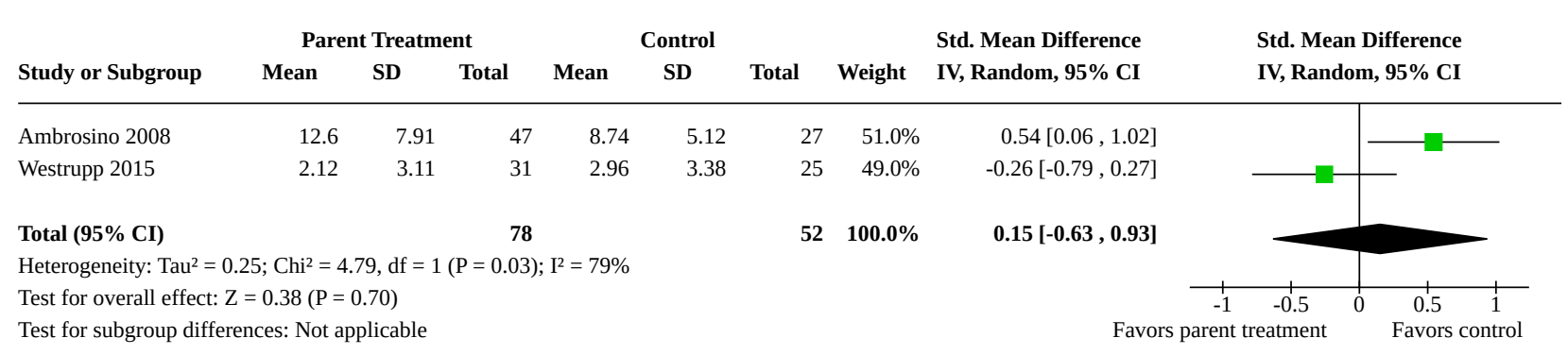

Analysis 8.3. Comparison 8: Diabetes follow-up, Outcome 3: Child mental health

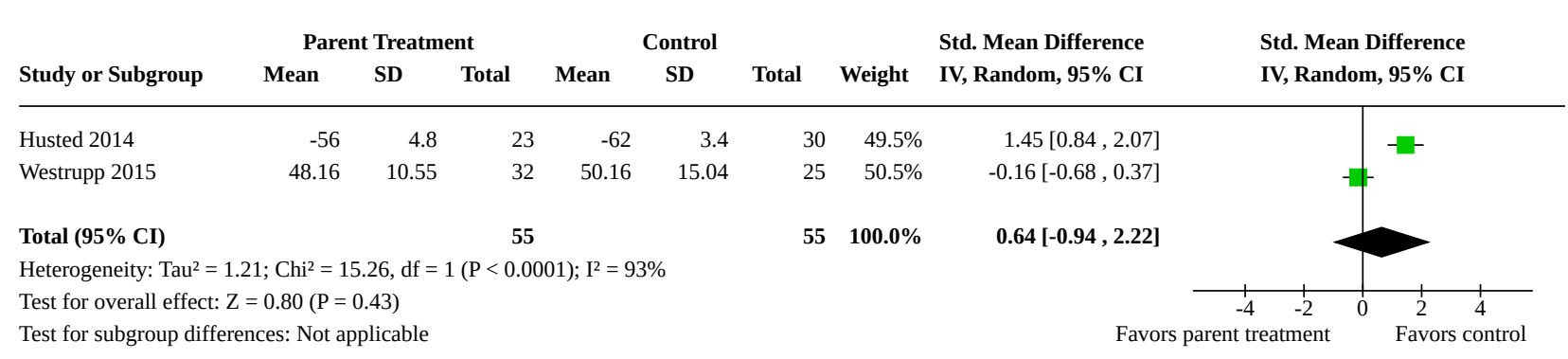


Analysis 8.4. Comparison 8: Diabetes follow-up, Outcome 4: Child symptoms

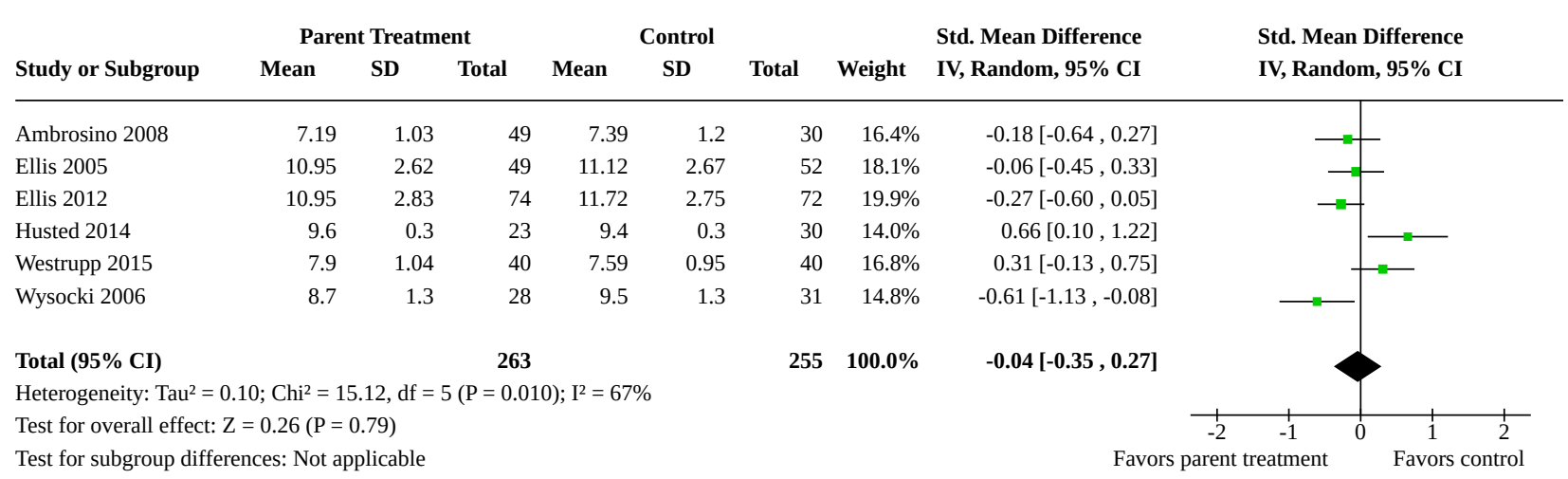

\section{Analysis 8.5. Comparison 8: Diabetes follow-up, Outcome 5: Family functioning}

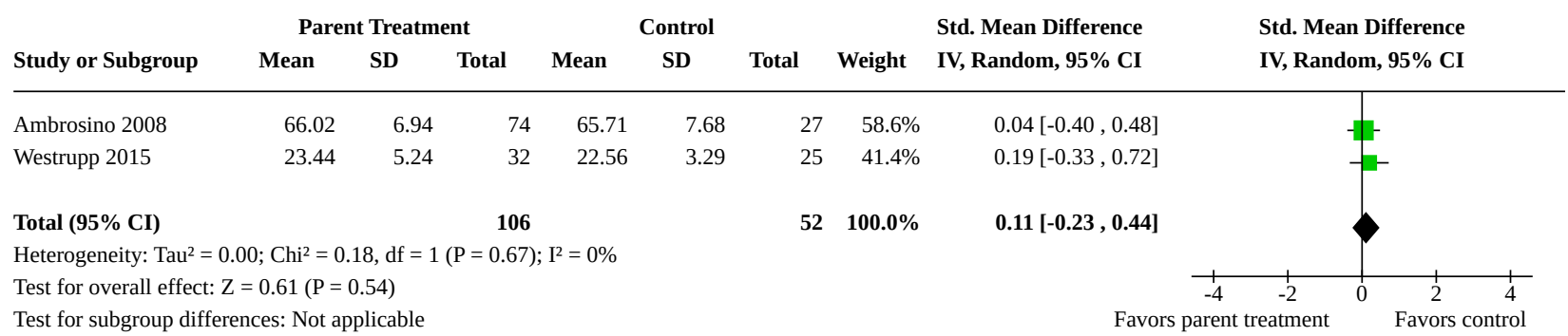

\section{Comparison 9. Skin diseases post-treatment}

\begin{tabular}{llllll}
\hline $\begin{array}{l}\text { Outcome or subgroup } \\
\text { title }\end{array}$ & No. of studies & $\begin{array}{l}\text { No. of partici- } \\
\text { pants }\end{array}$ & Statistical method & Effect size \\
\hline 9.1 Parenting behavior & 1 & 77 & $\begin{array}{l}\text { Std. Mean Difference (IV, Random, 95\% } \\
\text { Cl) }\end{array}$ & $-0.06[-0.51,0.39]$ \\
\hline 9.2 Child mental health & 1 & 75 & Mean Difference (IV, Random, 95\% CI) & $1.01[-12.08,14.10]$ \\
\hline 9.3 Child symptoms & 1 & 72 & $\begin{array}{l}\text { Std. Mean Difference (IV, Random, 95\% } \\
\text { CI) }\end{array}$ & $-0.42[-0.89,0.05]$ \\
\hline 9.4 Family functioning & 1 & 77 & $\begin{array}{l}\text { Std. Mean Difference (IV, Random, 95\% } \\
\text { CI) }\end{array}$ & $0.05[-0.40,0.50]$ \\
\hline
\end{tabular}


Analysis 9.1. Comparison 9: Skin diseases post-treatment, Outcome 1: Parenting behavior

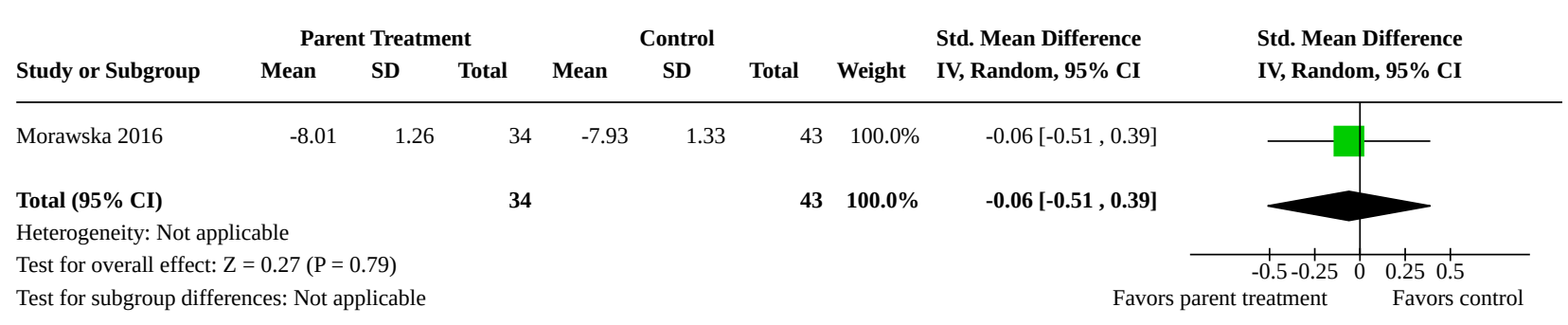

Analysis 9.2. Comparison 9: Skin diseases post-treatment, Outcome 2: Child mental health

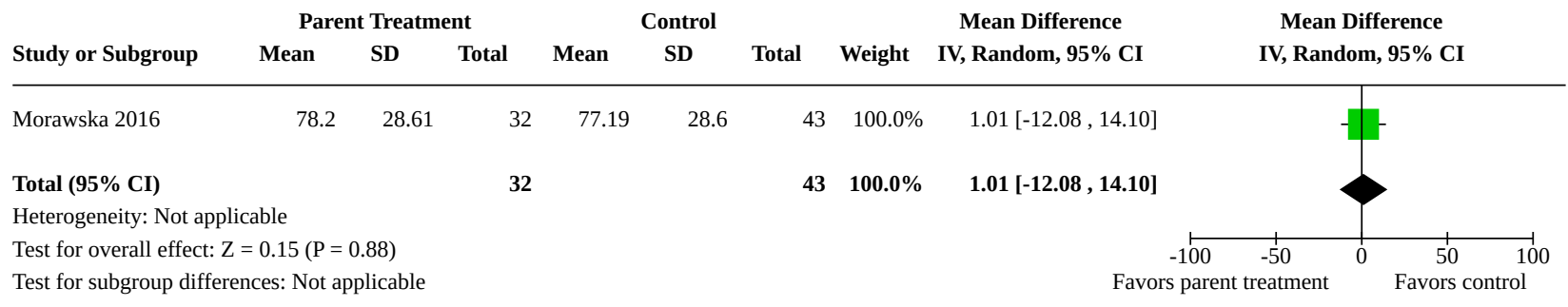

\section{Analysis 9.3. Comparison 9: Skin diseases post-treatment, Outcome 3: Child symptoms}

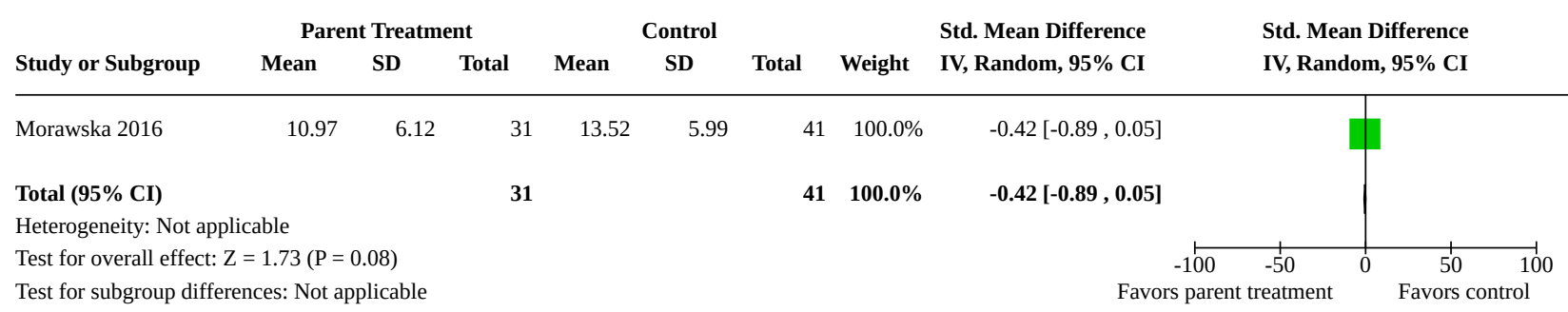

\section{Analysis 9.4. Comparison 9: Skin diseases post-treatment, Outcome 4: Family functioning}

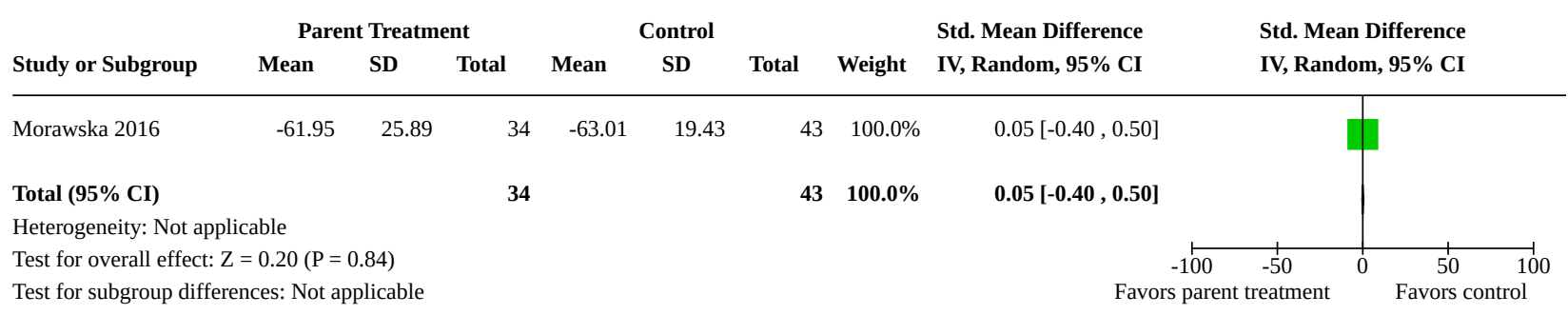

Comparison 10. Skin diseases follow-up

\begin{tabular}{lllll}
\hline $\begin{array}{l}\text { Outcome or subgroup } \\
\text { title }\end{array}$ & No. of studies & $\begin{array}{l}\text { No. of partici- } \\
\text { pants }\end{array}$ & Statistical method & Effect size \\
\hline 10.1 Parenting behavior & 1 & 69 & $\begin{array}{l}\text { Std. Mean Difference (IV, Random, 95\% } \\
\text { Cl) }\end{array}$ & $-0.03[-0.51,0.44]$ \\
\hline
\end{tabular}




\begin{tabular}{llllll}
\hline $\begin{array}{l}\text { Outcome or subgroup } \\
\text { title }\end{array}$ & No. of studies & $\begin{array}{l}\text { No. of partici- } \\
\text { pants }\end{array}$ & Statistical method & Effect size \\
\hline 10.2 Child mental health & 1 & 69 & Mean Difference (IV, Random, 95\% Cl) & $-10.90[-22.99,1.19]$ \\
\hline 10.3 Child symptoms & 1 & 70 & $\begin{array}{l}\text { Std. Mean Difference (IV, Random, 95\% } \\
\text { Cl) }\end{array}$ & $-0.48[-0.96,-0.01]$ \\
\hline 10.4 Family functioning & 1 & 70 & $\begin{array}{l}\text { Std. Mean Difference (IV, Random, 95\% } \\
\text { Cl) }\end{array}$ & $-0.19[-0.66,0.28]$ \\
\hline
\end{tabular}

Analysis 10.1. Comparison 10: Skin diseases follow-up, Outcome 1: Parenting behavior

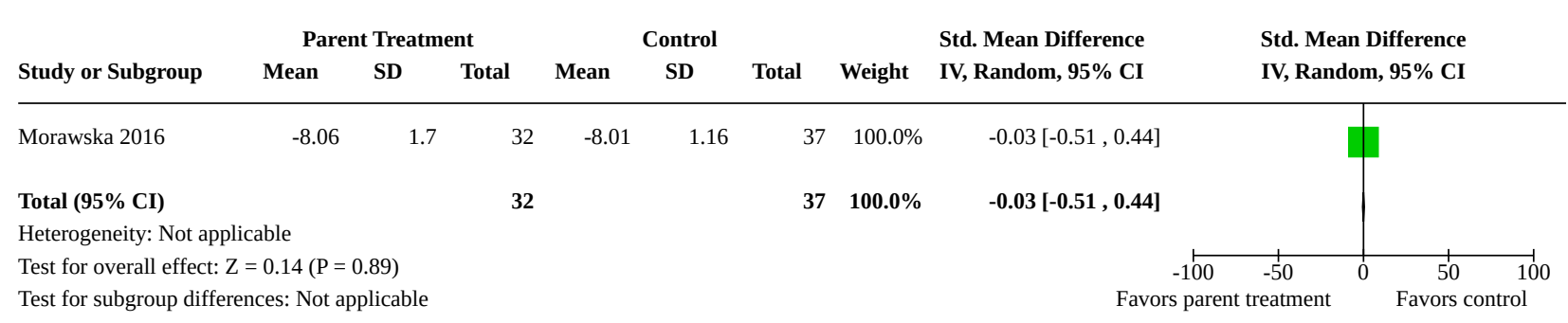

Analysis 10.2. Comparison 10: Skin diseases follow-up, Outcome 2: Child mental health

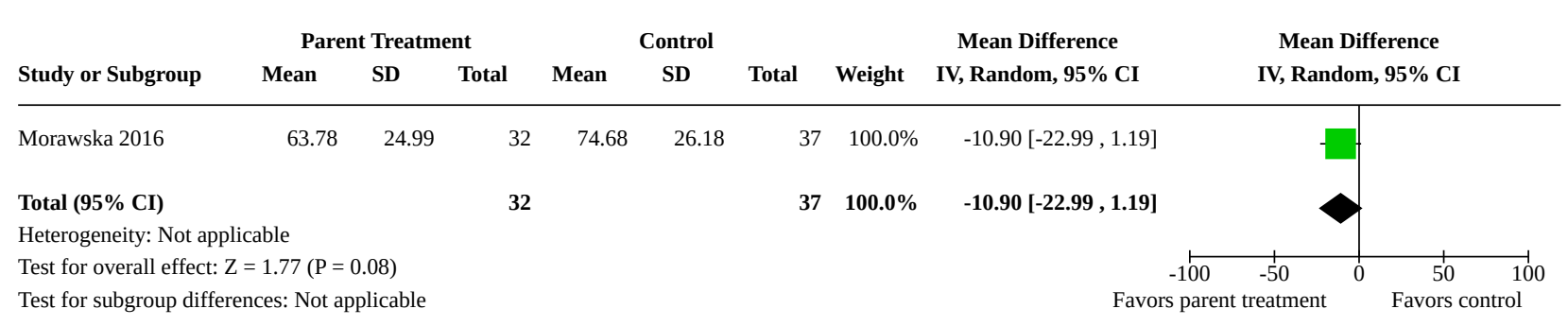

Analysis 10.3. Comparison 10: Skin diseases follow-up, Outcome 3: Child symptoms

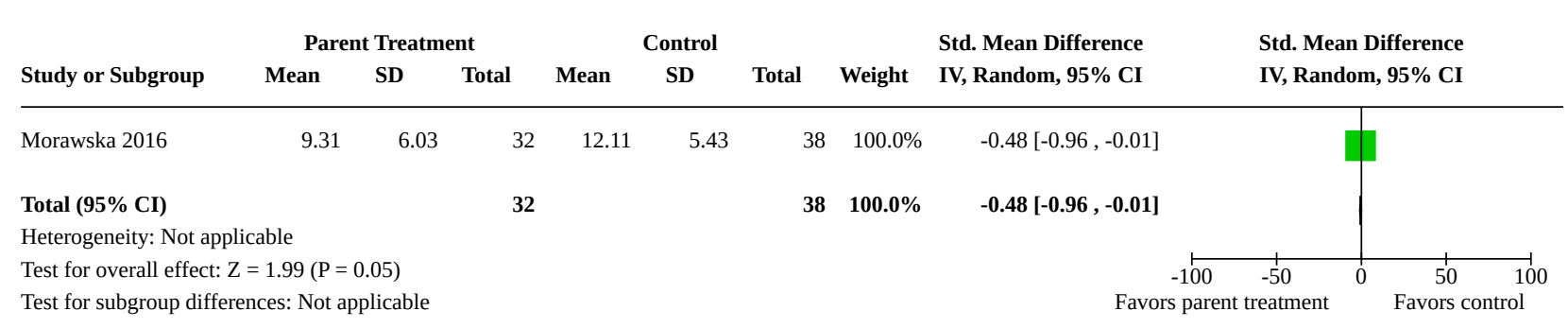


Analysis 10.4. Comparison 10: Skin diseases follow-up, Outcome 4: Family functioning

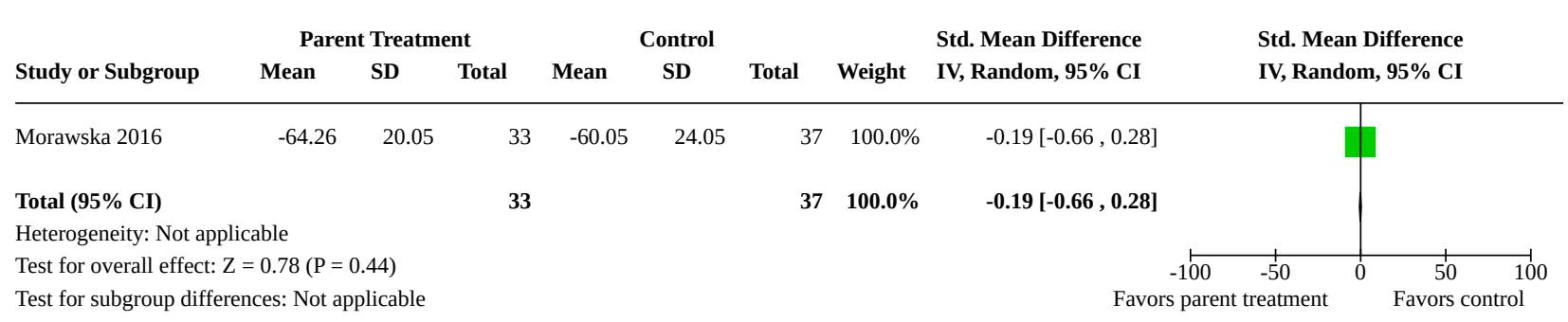

\section{Comparison 11. Traumatic brain injury post-treatment}

\begin{tabular}{|c|c|c|c|c|}
\hline $\begin{array}{l}\text { Outcome or subgroup ti- } \\
\text { tle }\end{array}$ & No. of studies & $\begin{array}{l}\text { No. of partici- } \\
\text { pants }\end{array}$ & Statistical method & Effect size \\
\hline 11.1 Parenting behavior & 3 & 254 & $\begin{array}{l}\text { Std. Mean Difference (IV, Random, 95\% } \\
\mathrm{Cl} \text { ) }\end{array}$ & $-0.74[-1.25,-0.22]$ \\
\hline 11.2 Parent mental health & 2 & 165 & $\begin{array}{l}\text { Std. Mean Difference (IV, Random, 95\% } \\
\mathrm{CI} \text { ) }\end{array}$ & $-0.51[-0.87,-0.16]$ \\
\hline $\begin{array}{l}11.3 \text { Child behavior/dis- } \\
\text { ability }\end{array}$ & 1 & 121 & $\begin{array}{l}\text { Std. Mean Difference (IV, Random, 95\% } \\
\mathrm{CI} \text { ) }\end{array}$ & $-0.08[-0.44,0.28]$ \\
\hline 11.4 Child mental health & 3 & 251 & $\begin{array}{l}\text { Std. Mean Difference (IV, Random, 95\% } \\
\mathrm{Cl} \text { ) }\end{array}$ & $-0.43[-0.69,-0.18]$ \\
\hline 11.5 Family functioning & 1 & 121 & $\begin{array}{l}\text { Std. Mean Difference (IV, Random, 95\% } \\
\mathrm{Cl} \text { ) }\end{array}$ & $-0.23[-0.59,0.12]$ \\
\hline
\end{tabular}

\section{Analysis 11.1. Comparison 11: Traumatic brain injury post-treatment, Outcome 1: Parenting behavior}

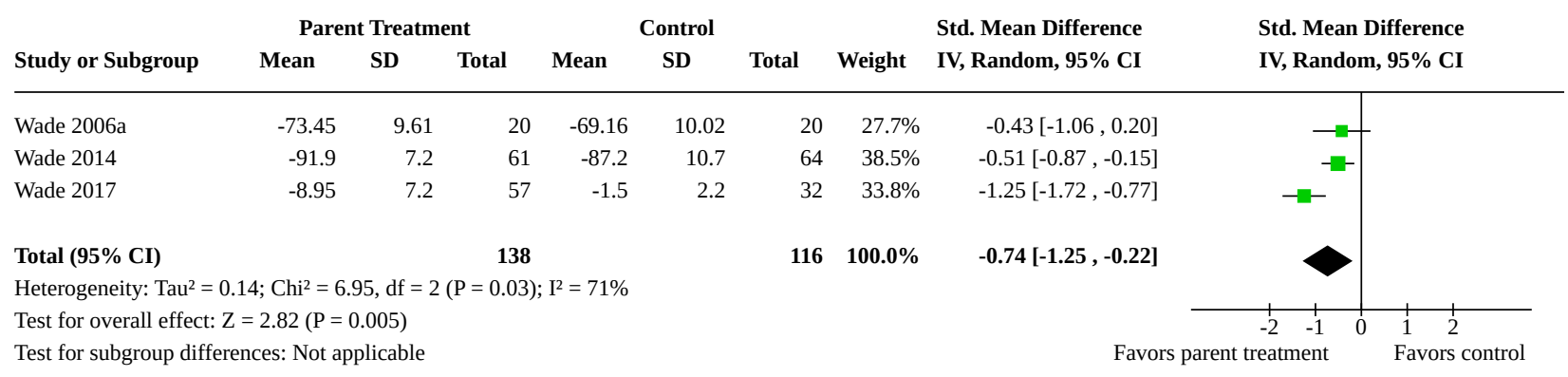


Analysis 11.2. Comparison 11: Traumatic brain injury post-treatment, Outcome 2: Parent mental health

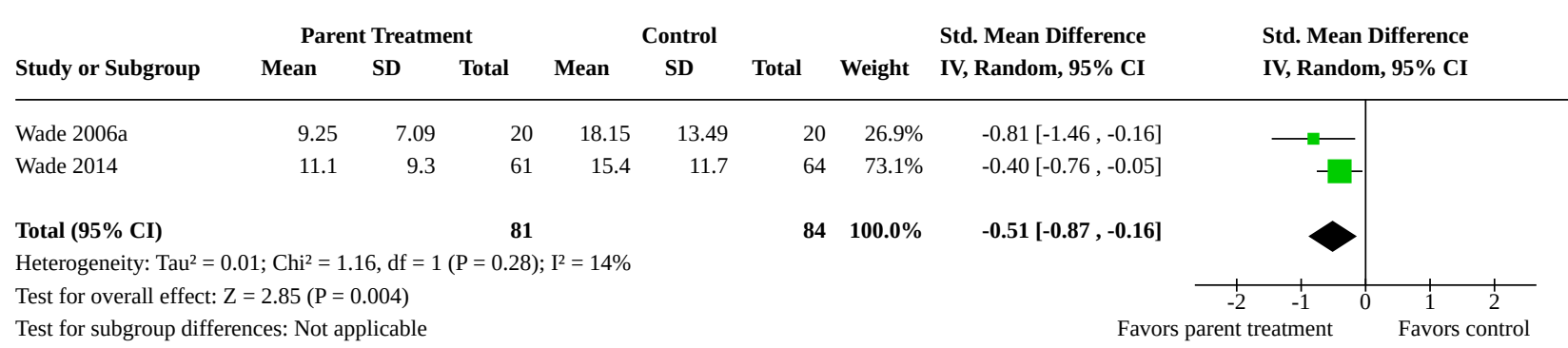

Analysis 11.3. Comparison 11: Traumatic brain injury post-treatment, Outcome 3: Child behavior/disability

\begin{tabular}{|c|c|c|c|c|c|c|c|c|c|}
\hline & & Tre & & & ontrol & & & Std. Mean Difference & Std. Mean Difference \\
\hline Study or Subgroup & Mean & SD & Total & Mean & SD & Total & Weight & IV, Random, 95\% CI & IV, Random, 95\% CI \\
\hline
\end{tabular}

$\begin{array}{llllllllll}\text { Wade } 2014 & 43 & 39.42 & 60 & 46.07 & 38.18 & 61 & 100.0 \% & -0.08[-0.44,0.28]\end{array}$

Total (95\% CI)

60

$61 \quad 100.0 \%$

$-0.08[-0.44,0.28]$

Heterogeneity: Not applicable

Test for overall effect: $\mathrm{Z}=0.43(\mathrm{P}=0.67)$

Test for subgroup differences: Not applicable

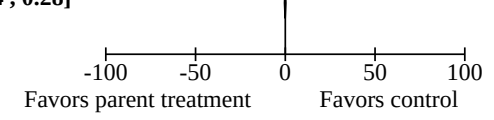

\section{Analysis 11.4. Comparison 11: Traumatic brain injury post-treatment, Outcome 4: Child mental health}

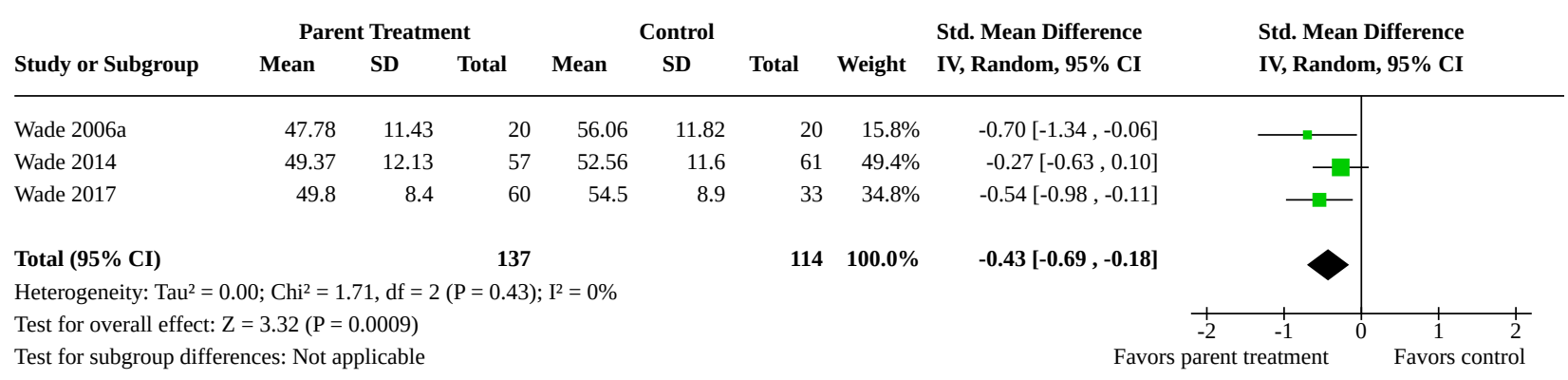

Analysis 11.5. Comparison 11: Traumatic brain injury post-treatment, Outcome 5: Family functioning

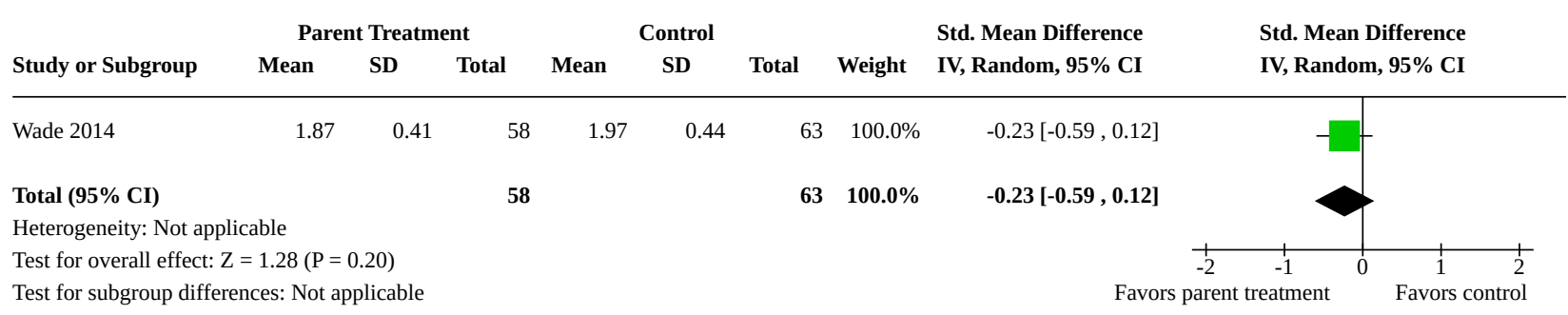


Comparison 12. Traumatic brain injury follow-up

\begin{tabular}{|c|c|c|c|c|}
\hline $\begin{array}{l}\text { Outcome or subgroup ti- } \\
\text { tle }\end{array}$ & No. of studies & $\begin{array}{l}\text { No. of partici- } \\
\text { pants }\end{array}$ & Statistical method & Effect size \\
\hline 12.1 Parenting behavior & 1 & 113 & $\begin{array}{l}\text { Std. Mean Difference (IV, Random, 95\% } \\
\mathrm{CI} \text { ) }\end{array}$ & $-0.34[-0.72,0.03]$ \\
\hline 12.2 Parent mental health & 1 & 113 & $\begin{array}{l}\text { Std. Mean Difference (IV, Random, 95\% } \\
\text { CI) }\end{array}$ & $-0.08[-0.45,0.29]$ \\
\hline $\begin{array}{l}12.3 \text { Child behavior/dis- } \\
\text { ability }\end{array}$ & 1 & 105 & $\begin{array}{l}\text { Std. Mean Difference (IV, Random, 95\% } \\
\mathrm{Cl} \text { ) }\end{array}$ & $0.04[-0.35,0.42]$ \\
\hline 12.4 Child mental health & 1 & 98 & $\begin{array}{l}\text { Std. Mean Difference (IV, Random, 95\% } \\
\mathrm{CI})\end{array}$ & $-0.12[-0.52,0.28]$ \\
\hline 12.5 Family functioning & 1 & 101 & $\begin{array}{l}\text { Std. Mean Difference (IV, Random, 95\% } \\
\mathrm{Cl} \text { ) }\end{array}$ & $-0.17[-0.56,0.23]$ \\
\hline
\end{tabular}

\section{Analysis 12.1. Comparison 12: Traumatic brain injury follow-up, Outcome 1: Parenting behavior}

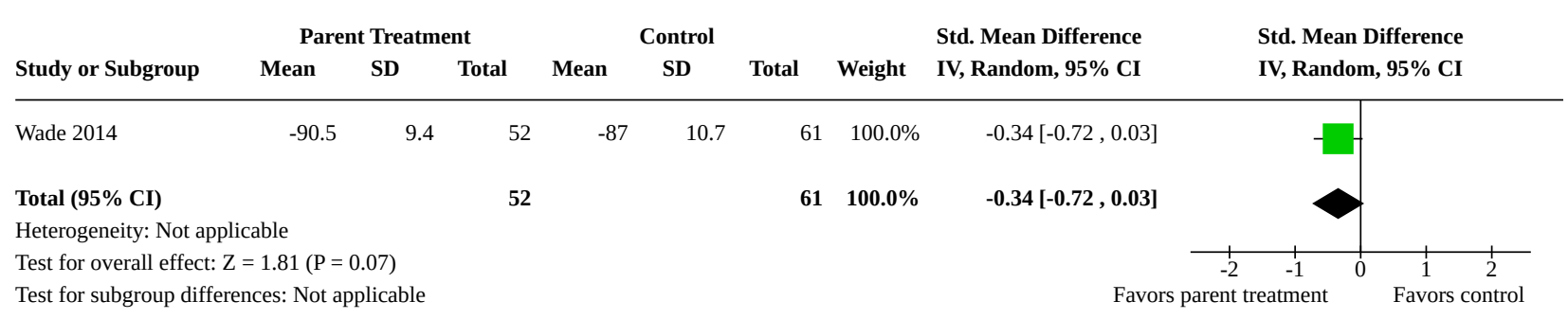

Analysis 12.2. Comparison 12: Traumatic brain injury follow-up, Outcome 2: Parent mental health

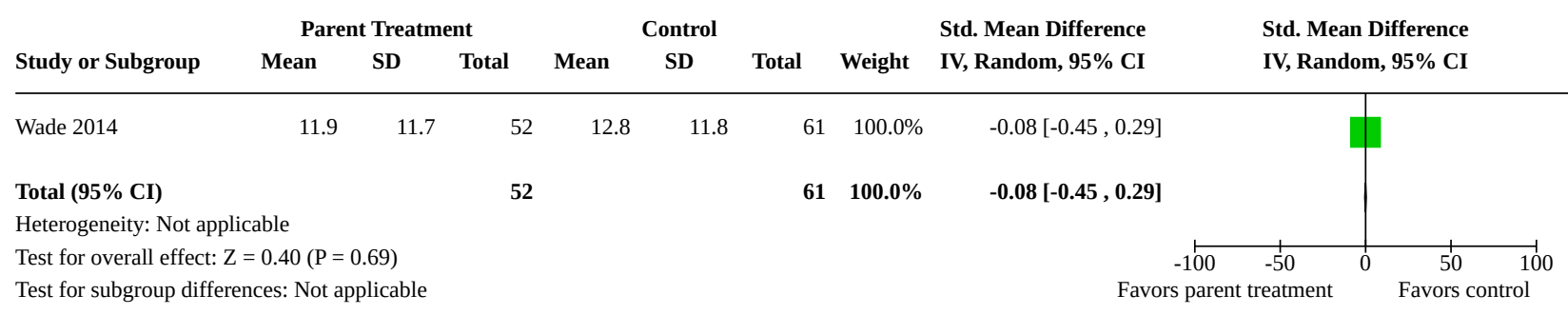

\section{Analysis 12.3. Comparison 12: Traumatic brain injury follow-up, Outcome 3: Child behavior/disability}

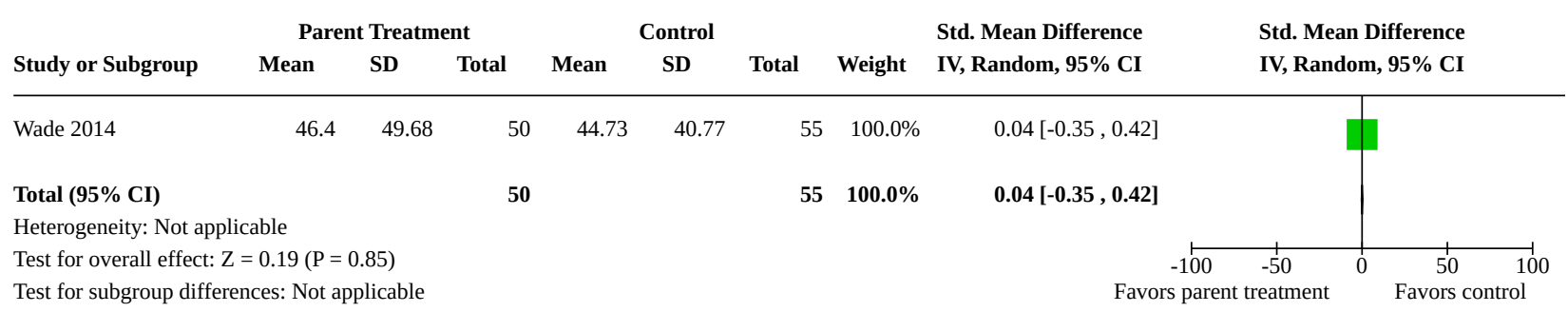


Analysis 12.4. Comparison 12: Traumatic brain injury follow-up, Outcome 4: Child mental health

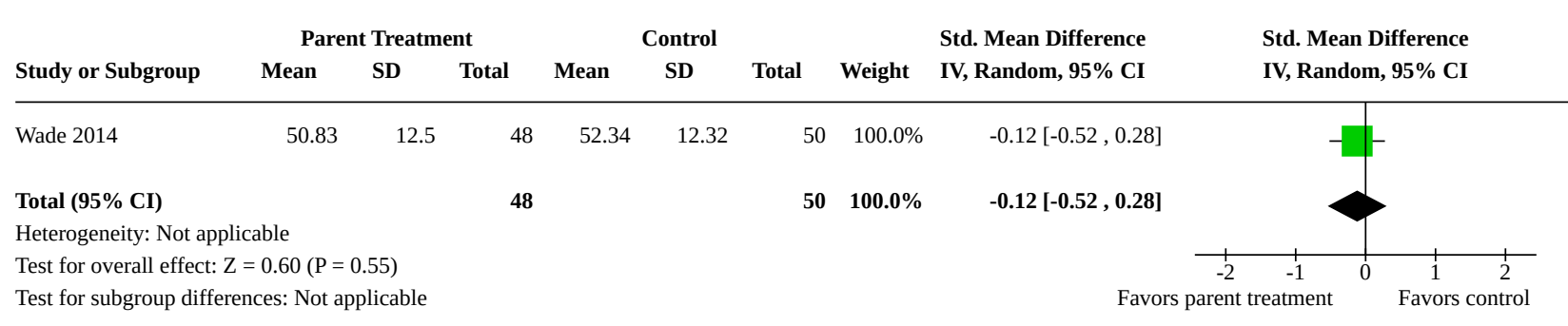

\section{Analysis 12.5. Comparison 12: Traumatic brain injury follow-up, Outcome 5: Family functioning}

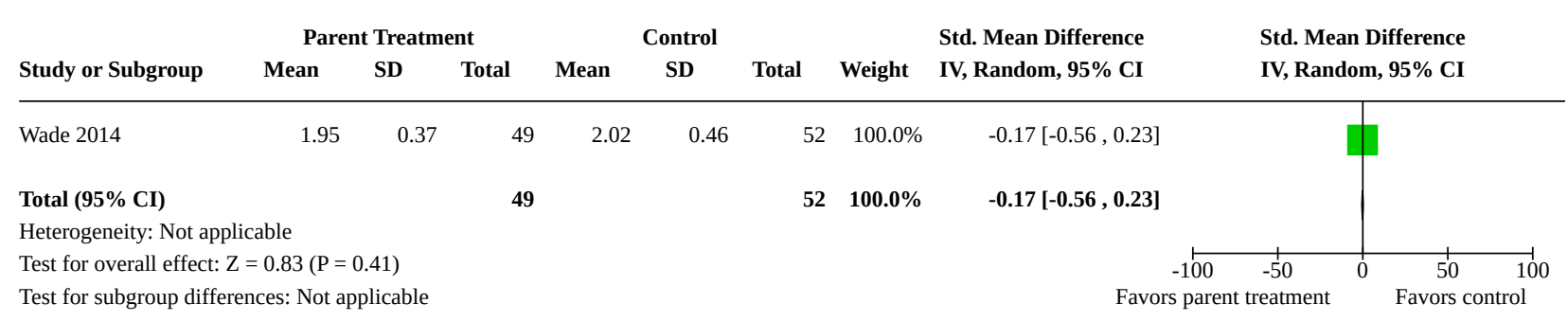

\section{Comparison 13. Cognitive-behavioral therapy post-treatment}

\begin{tabular}{|c|c|c|c|c|}
\hline $\begin{array}{l}\text { Outcome or subgroup } \\
\text { title }\end{array}$ & No. of studies & $\begin{array}{l}\text { No. of partici- } \\
\text { pants }\end{array}$ & Statistical method & Effect size \\
\hline 13.1 Parenting behavior & 9 & 1040 & $\begin{array}{l}\text { Std. Mean Difference (IV, Random, 95\% } \\
\mathrm{CI} \text { ) }\end{array}$ & $-0.45[-0.68,-0.21]$ \\
\hline 13.1.1 Active control & 8 & 992 & $\begin{array}{l}\text { Std. Mean Difference (IV, Random, 95\% } \\
\mathrm{Cl} \text { ) }\end{array}$ & $-0.50[-0.74,-0.26]$ \\
\hline 13.1.2 Waitlist control & 1 & 48 & $\begin{array}{l}\text { Std. Mean Difference (IV, Random, 95\% } \\
\mathrm{CI} \text { ) }\end{array}$ & $0.08[-0.49,0.65]$ \\
\hline $\begin{array}{l}\text { 13.2 Parent mental } \\
\text { health }\end{array}$ & 8 & 811 & $\begin{array}{l}\text { Std. Mean Difference (IV, Random, 95\% } \\
\mathrm{CI} \text { ) }\end{array}$ & $-0.19[-0.41,0.03]$ \\
\hline 13.2.1 Active control & 8 & 811 & $\begin{array}{l}\text { Std. Mean Difference (IV, Random, 95\% } \\
\mathrm{CI} \text { ) }\end{array}$ & $-0.19[-0.41,0.03]$ \\
\hline $\begin{array}{l}13.3 \text { Child behavior/dis- } \\
\text { ability }\end{array}$ & 10 & 1236 & $\begin{array}{l}\text { Std. Mean Difference (IV, Random, 95\% } \\
\mathrm{CI} \text { ) }\end{array}$ & $-0.22[-0.35,-0.08]$ \\
\hline 13.3.1 Active control & 8 & 1093 & $\begin{array}{l}\text { Std. Mean Difference (IV, Random, 95\% } \\
\mathrm{CI} \text { ) }\end{array}$ & $-0.18[-0.31,-0.05]$ \\
\hline 13.3.2 Waitlist control & 2 & 143 & $\begin{array}{l}\text { Std. Mean Difference (IV, Random, 95\% } \\
\mathrm{CI} \text { ) }\end{array}$ & $-0.47[-0.97,0.04]$ \\
\hline $\begin{array}{l}13.4 \text { Child mental } \\
\text { health }\end{array}$ & 15 & 1786 & $\begin{array}{l}\text { Std. Mean Difference (IV, Random, 95\% } \\
\mathrm{CI} \text { ) }\end{array}$ & $-0.08[-0.19,0.03]$ \\
\hline
\end{tabular}




\begin{tabular}{lllll}
\hline $\begin{array}{l}\text { Outcome or subgroup } \\
\text { title }\end{array}$ & No. of studies & $\begin{array}{l}\text { No. of partici- } \\
\text { pants }\end{array}$ & Statistical method & Effect size \\
\hline 13.4.1 Active control & 13 & 1637 & $\begin{array}{l}\text { Std. Mean Difference (IV, Random, 95\% } \\
\text { Cl) }\end{array}$ & $-0.09[-0.21,0.02]$ \\
\hline 13.4.2 Waitlist control & 2 & 149 & $\begin{array}{l}\text { Std. Mean Difference (IV, Random, 95\% } \\
\text { Cl) }\end{array}$ & $0.06[-0.27,0.38]$ \\
\hline 13.5 Child symptoms & 13 & 1434 & $\begin{array}{l}\text { Std. Mean Difference (IV, Random, 95\% } \\
\text { Cl) }\end{array}$ & $-0.38[-0.71,-0.06]$ \\
\hline 13.5.1 Active control & 11 & & $\begin{array}{l}\text { Std. Mean Difference (IV, Random, 95\% } \\
\text { Cl) }\end{array}$ & $-0.15[-0.32,0.02]$ \\
\hline 13.5.2 Waitlist control & 2 & 1291 & $\begin{array}{l}\text { Std. Mean Difference (IV, Random, 95\% } \\
\text { Cl) }\end{array}$ & $-1.70[-3.94,0.55]$ \\
\hline 13.6 Family functioning & 5 & 143 & $\begin{array}{l}\text { Std. Mean Difference (IV, Random, 95\% } \\
\text { Cl) }\end{array}$ & $-0.11[-0.35,0.13]$ \\
\hline
\end{tabular}

\section{Analysis 13.1. Comparison 13: Cognitive-behavioral therapy post-treatment, Outcome 1: Parenting behavior}

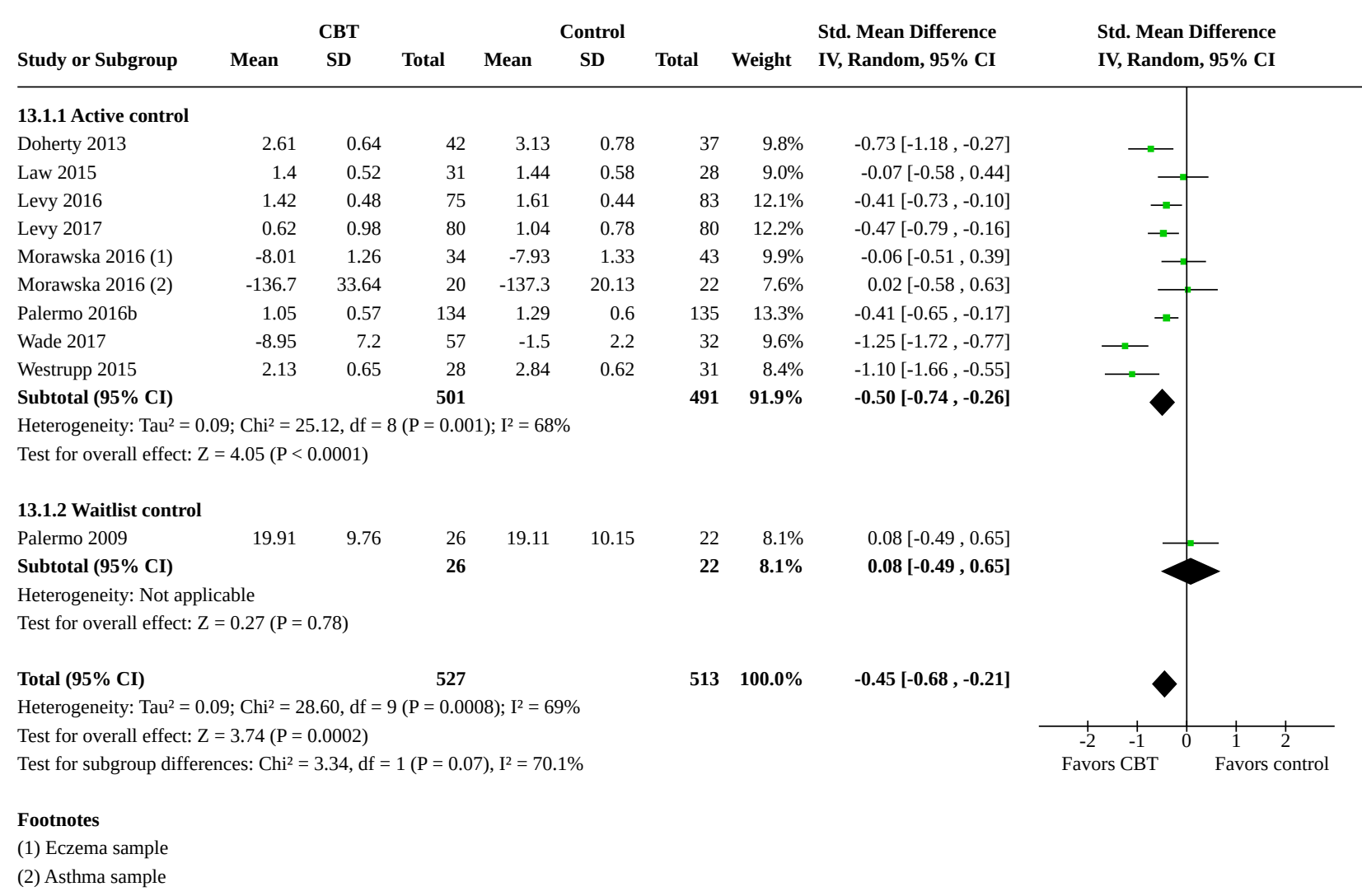


Analysis 13.2. Comparison 13: Cognitive-behavioral therapy post-treatment, Outcome 2: Parent mental health

\begin{tabular}{|c|c|c|c|c|c|c|c|c|c|}
\hline & & CBT & & & ontrol & & & Std. Mean Difference & Std. Mean Difference \\
\hline Study or Subgroup & Mean & SD & Total & Mean & SD & Total & Weight & IV, Random, 95\% CI & IV, Random, 95\% CI \\
\hline
\end{tabular}

\subsubsection{Active control}

Ambrosino 2008

Doherty 2013

$12.62 \quad 8.39$

Hoekstra-Weebers 1998

$\begin{array}{rr}12.62 & 8.39 \\ 175.69 & 63.27\end{array}$

8.39
63.27

$\begin{array}{rrr}47 & 9.3 & 6.9 \\ 42 & 203.19 & 59.33\end{array}$

$27 \quad 11.4 \%$

$0.42[-0.06,0.89]$

Levy 2017

$\begin{array}{rr}46.9 & 10.7\end{array}$

$42 \quad 203.19$

59.33

$37 \quad 12.2 \%$

Palermo 2016b

$5.34 \quad 13.29$

$80 \quad 10.68$

13.5
11.99

$10.22 \quad 5.96$

$134 \quad 11.15$

11.99
6.48

$21 \quad 8.4 \%$

Stehl 2009

$42.05 \quad 15.54$

42.35

6.48
15.22

$80 \quad 16.5 \%$

Tsitsi 2017

$11.7 \quad 8.15$

$\begin{array}{ll}39 & 13.33\end{array}$

8.38

Westrupp 2015

$1.17 \quad 2.21$

$\begin{array}{lll}28 & 4.57 & 6.14\end{array}$

$135 \quad 19.3 \%$

$38 \quad 12.1 \%$

$25 \quad 10.0 \%$

Subtotal (95\% CI)

418

$30 \quad 10.1 \%$

$393100.0 \%$

$-0.44[-0.89,0.00]$

$0.12[-0.49,0.73]$

$-0.42[-0.73,-0.11]$

$-0.15[-0.39,0.09]$

$-0.02[-0.47,0.43]$

$-0.19[-0.73,0.34]$

$-0.72[-1.25,-0.18]$

Heterogeneity: $\mathrm{Tau}^{2}=0.05 ; \mathrm{Chi}^{2}=14.88, \mathrm{df}=7(\mathrm{P}=0.04) ; \mathrm{I}^{2}=53 \%$

Test for overall effect: $\mathrm{Z}=1.70(\mathrm{P}=0.09)$

Total (95\% CI)

418

Heterogeneity: $\mathrm{Tau}^{2}=0.05 ; \mathrm{Chi}^{2}=14.88, \mathrm{df}=7(\mathrm{P}=0.04) ; \mathrm{I}^{2}=53 \%$

Test for overall effect: $\mathrm{Z}=1.70(\mathrm{P}=0.09)$

Test for subgroup differences: Not applicable

IV, Random, 95\% CI

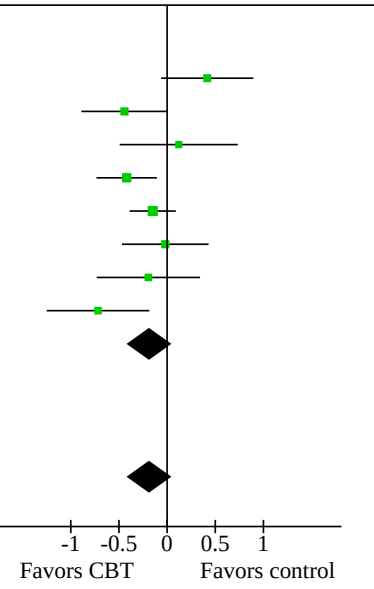

\section{Analysis 13.3. Comparison 13: Cognitive-behavioral therapy post-treatment, Outcome 3: Child behavior/disability}

\begin{tabular}{|c|c|c|c|c|c|c|c|c|}
\hline \multirow[b]{2}{*}{ Study or Subgroup } & \multicolumn{3}{|c|}{ CBT } & \multicolumn{3}{|c|}{ Control } & \multicolumn{2}{|r|}{ Std. Mean Difference } \\
\hline & Mean & SD & Total & Mean & SD & Total & Weight & IV, Random, 95\% CI \\
\hline \multicolumn{9}{|l|}{ 13.3.1 Active control } \\
\hline Kashikar-Zuck 2012 & 16.7 & 8.7 & 57 & 19.8 & 9.4 & 55 & $9.8 \%$ & $-0.34[-0.71,0.03]$ \\
\hline Law 2015 & 4.83 & 4.78 & 20 & 4.86 & 4.4 & 37 & $5.3 \%$ & $-0.01[-0.55,0.54]$ \\
\hline Levy 2010 & 0.56 & 0.54 & 83 & 0.55 & 0.48 & 75 & $12.7 \%$ & $0.02[-0.29,0.33]$ \\
\hline Levy 2016 & 5.6 & 5.7 & 80 & 7.3 & 8.2 & 78 & $12.7 \%$ & $-0.24[-0.55,0.07]$ \\
\hline Levy 2017 & 5.51 & 8.14 & 80 & 7.65 & 10.44 & 80 & $12.8 \%$ & $-0.23[-0.54,0.08]$ \\
\hline Palermo 2016b & 5.68 & 4.38 & 134 & 5.65 & 4.69 & 135 & $17.8 \%$ & $0.01[-0.23,0.25]$ \\
\hline Powers 2013 & 15.5 & 17.4 & 64 & 29.6 & 42.2 & 71 & $11.2 \%$ & $-0.43[-0.77,-0.08]$ \\
\hline Sanders 1994 & 2.39 & 7.15 & 22 & 7.56 & 13.74 & 22 & $4.5 \%$ & $-0.46[-1.06,0.14]$ \\
\hline Subtotal (95\% CI) & & & 540 & & & 553 & $86.8 \%$ & $-0.18[-0.31,-0.05]$ \\
\hline
\end{tabular}

Heterogeneity: $\mathrm{Tau}^{2}=0.00 ; \mathrm{Chi}^{2}=8.07, \mathrm{df}=7(\mathrm{P}=0.33) ; \mathrm{I}^{2}=13 \%$

Test for overall effect: $\mathrm{Z}=2.65(\mathrm{P}=0.008)$

13.3.2 Waitlist control

$\begin{array}{lrrrrrrrr}\text { Bonnert } 2017 & 1.04 & 1.05 & 44 & 1.31 & 1.07 & 51 & 8.6 \% & -0.25[-0.66,0.15] \\ \text { Palermo 2009 } & 3.6 & 2.86 & 26 & 6.62 & 4.76 & 22 & 4.6 \% & -0.77[-1.36,-0.18] \\ \text { Subtotal (95\% CI) } & & & \mathbf{7 0} & & & \mathbf{7 3} & \mathbf{1 3 . 2 \%} & \mathbf{- 0 . 4 7}[-\mathbf{0 . 9 7}, \mathbf{0 . 0 4}]\end{array}$

Subtotal (95\% CI)

70

$73 \quad 13.2 \%$

$-0.47[-0.97,0.04]$

Test for overall effect: $\mathrm{Z}=1.82(\mathrm{P}=0.07)$

Total (95\% CI)

610

$626 \quad 100.0 \%$

$-0.22[-0.35,-0.08]$

Heterogeneity: $\mathrm{Tau}^{2}=0.01 ; \mathrm{Chi}^{2}=11.99, \mathrm{df}=9(\mathrm{P}=0.21) ; \mathrm{I}^{2}=25 \%$

Test for overall effect: $\mathrm{Z}=3.15(\mathrm{P}=0.002)$

Test for subgroup differences: $\mathrm{Chi}^{2}=1.21, \mathrm{df}=1(\mathrm{P}=0.27), \mathrm{I}^{2}=17.0 \%$

Std. Mean Difference

IV, Random, 95\% CI 
Analysis 13.4. Comparison 13: Cognitive-behavioral therapy post-treatment, Outcome 4: Child mental health

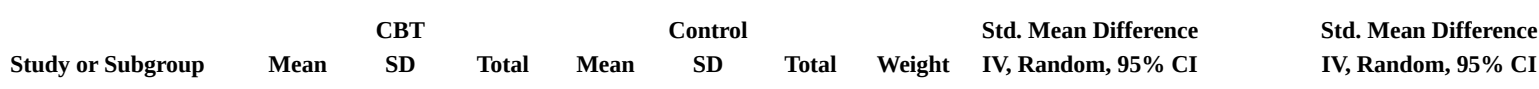

\begin{tabular}{|c|c|c|c|c|c|c|c|c|}
\hline \multicolumn{9}{|l|}{ 13.4.1 Active control } \\
\hline Ambrosino 2008 & 5.39 & 5.72 & 51 & 4.1 & 6 & 30 & $4.9 \%$ & $0.22[-0.23,0.67]$ \\
\hline Doherty 2013 & 82.24 & 29.93 & 42 & 100.51 & 37.79 & 37 & $4.9 \%$ & $-0.53[-0.98,-0.08]$ \\
\hline Kashikar-Zuck 2012 & 9.9 & 6.2 & 57 & 11.8 & 5.8 & 57 & $6.8 \%$ & $-0.31[-0.68,0.06]$ \\
\hline Law 2015 & 46.3 & 10.03 & 27 & 47.48 & 9.5 & 23 & $3.4 \%$ & $-0.12[-0.68,0.44]$ \\
\hline Levy 2010 & 9.97 & 6.16 & 84 & 8.35 & 5.73 & 84 & $9.1 \%$ & $0.27[-0.03,0.57]$ \\
\hline Levy 2016 & 7.6 & 7.1 & 80 & 8.8 & 7.6 & 78 & $8.7 \%$ & $-0.16[-0.47,0.15]$ \\
\hline Levy 2017 & 1.09 & 1.88 & 154 & 1.28 & 1.07 & 81 & $10.7 \%$ & $-0.11[-0.38,0.15]$ \\
\hline Morawska 2016 (1) & 78.62 & 28.61 & 34 & 77.19 & 28.6 & 43 & $4.9 \%$ & $0.05[-0.40,0.50]$ \\
\hline Morawska 2016 (2) & 47.3 & 28.23 & 20 & 48.5 & 24.64 & 22 & $2.9 \%$ & $-0.04[-0.65,0.56]$ \\
\hline Palermo 2016b & 9.71 & 5.1 & 134 & 9.32 & 5.37 & 135 & $12.4 \%$ & $0.07[-0.16,0.31]$ \\
\hline Powers 2013 & 4.6 & 5.6 & 71 & 5.56 & 5.83 & 72 & $8.1 \%$ & $-0.17[-0.50,0.16]$ \\
\hline Sanders 1994 & 57.5 & 11.5 & 22 & 58.1 & 5.8 & 22 & $3.0 \%$ & $-0.06[-0.66,0.53]$ \\
\hline Wade 2017 & 49.37 & 12.13 & 57 & 52.56 & 11.6 & 61 & $7.0 \%$ & $-0.27[-0.63,0.10]$ \\
\hline Westrupp 2015 & 47.31 & 8.27 & 29 & 51.5 & 11.28 & 30 & $3.9 \%$ & $-0.42[-0.93,0.10]$ \\
\hline Subtotal (95\% CI) & & & 862 & & & 775 & $90.6 \%$ & $-0.09[-0.21,0.02]$ \\
\hline
\end{tabular}

Heterogeneity: $\mathrm{Tau}^{2}=0.01 ; \mathrm{Chi}^{2}=17.49, \mathrm{df}=13(\mathrm{P}=0.18) ; \mathrm{I}^{2}=26 \%$

Test for overall effect: $\mathrm{Z}=1.55(\mathrm{P}=0.12)$

\subsubsection{Waitlist control}

\begin{tabular}{|c|c|c|c|c|c|c|c|c|}
\hline Bonnert 2017 & 25.23 & 16.23 & 47 & 22.62 & 16.31 & 54 & $6.2 \%$ & $0.16[-0.23,0.55]$ \\
\hline Palermo 2009 & 58.96 & 13.1 & 26 & 61.59 & 18.67 & 22 & $3.3 \%$ & $-0.16[-0.73,0.41]$ \\
\hline
\end{tabular}

Heterogeneity: $\mathrm{Tau}^{2}=0.00 ; \mathrm{Chi}^{2}=0.84, \mathrm{df}=1(\mathrm{P}=0.36) ; \mathrm{I}^{2}=0 \%$

Test for overall effect: $\mathrm{Z}=0.34(\mathrm{P}=0.74)$

Total (95\% CI)

935

Heterogeneity: Tau $^{2}=0.01 ; \mathrm{Chi}^{2}=18.96, \mathrm{df}=15(\mathrm{P}=0.22) ; \mathrm{I}^{2}=21 \%$

Test for overall effect: $\mathrm{Z}=1.41(\mathrm{P}=0.16)$

Test for subgroup differences: $\mathrm{Chi}^{2}=0.72, \mathrm{df}=1(\mathrm{P}=0.40), \mathrm{I}^{2}=0 \%$

\section{Footnotes}

(1) Eczema group

(2) Asthma group
V, Random, 95\% CI

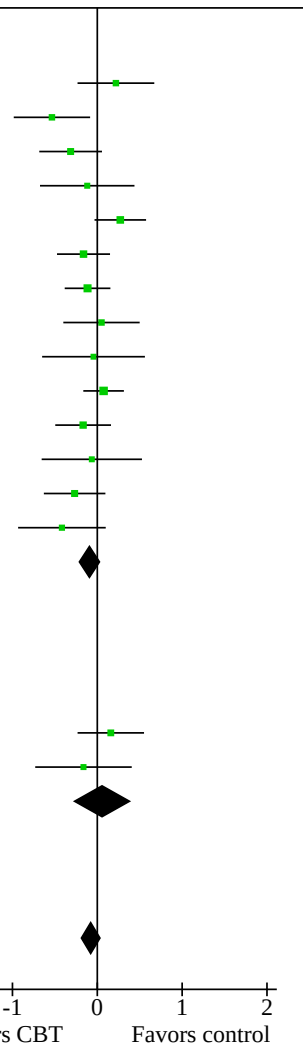


Analysis 13.5. Comparison 13: Cognitive-behavioral therapy post-treatment, Outcome 5: Child symptoms

\begin{tabular}{|c|c|c|c|c|c|c|c|c|c|}
\hline & & CBT & & & ontr & & & Std. Mean Difference & Std. Mean Difference \\
\hline Study or Subgroup & Mean & SD & Total & Mean & SD & Total & Weight & IV, Random, 95\% CI & IV, Random, 95\% CI \\
\hline
\end{tabular}

\begin{tabular}{|c|c|c|c|c|c|c|c|c|}
\hline \multicolumn{9}{|l|}{ 13.5.1 Active control } \\
\hline Ambrosino 2008 & 7.04 & 1.29 & 51 & 7.3 & 1.23 & 30 & $7.6 \%$ & $-0.20[-0.66,0.25]$ \\
\hline Kashikar-Zuck 2012 & 5.3 & 2.3 & 57 & 6 & 1.9 & 57 & $8.0 \%$ & $-0.33[-0.70,0.04]$ \\
\hline Laffel 2003 & 8.2 & 1.1 & 50 & 8.7 & 1.5 & 50 & $7.9 \%$ & $-0.38[-0.77,0.02]$ \\
\hline Law 2015 & 4.63 & 2.14 & 40 & 4.7 & 2.23 & 37 & $7.6 \%$ & $-0.03[-0.48,0.42]$ \\
\hline Levy 2010 & 1.64 & 2.02 & 83 & 1.25 & 1.75 & 75 & $8.2 \%$ & $0.20[-0.11,0.52]$ \\
\hline Levy 2017 & 3.99 & 2.22 & 80 & 4.57 & 2.28 & 80 & $8.2 \%$ & $-0.26[-0.57,0.05]$ \\
\hline Morawska 2016 (1) & 10.97 & 6.12 & 31 & 13.52 & 5.99 & 41 & $7.5 \%$ & $-0.42[-0.89,0.05]$ \\
\hline Palermo 2016b & 5.87 & 2.05 & 134 & 5.59 & 2.15 & 135 & $8.5 \%$ & $0.13[-0.11,0.37]$ \\
\hline Powers 2013 & 9.8 & 9.8 & 64 & 14.5 & 9.8 & 71 & $8.1 \%$ & $-0.48[-0.82,-0.13]$ \\
\hline Sanders 1994 & 3.27 & 8.33 & 22 & 6.67 & 7.04 & 22 & $6.8 \%$ & $-0.43[-1.03,0.17]$ \\
\hline Westrupp 2015 & 7.94 & 0.85 & 41 & 7.71 & 0.85 & 40 & $7.7 \%$ & $0.27[-0.17,0.71]$ \\
\hline Subtotal (95\% CI) & & & 653 & & & 638 & $86.1 \%$ & $-0.15[-0.32,0.02]$ \\
\hline
\end{tabular}

Heterogeneity: $\mathrm{Tau}^{2}=0.04 ; \mathrm{Chi}^{2}=22.06, \mathrm{df}=10(\mathrm{P}=0.01) ; \mathrm{I}^{2}=55 \%$

$0.15[-0.32,0.02]$

Test for overall effect: $\mathrm{Z}=1.78(\mathrm{P}=0.08)$

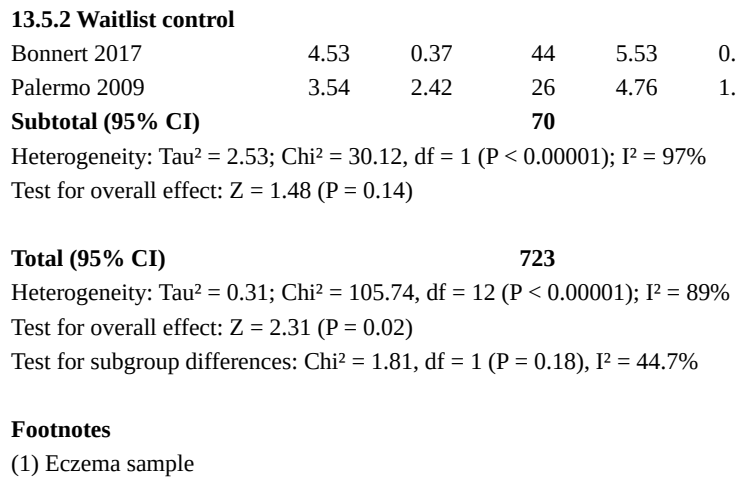

(1) Eczema sample
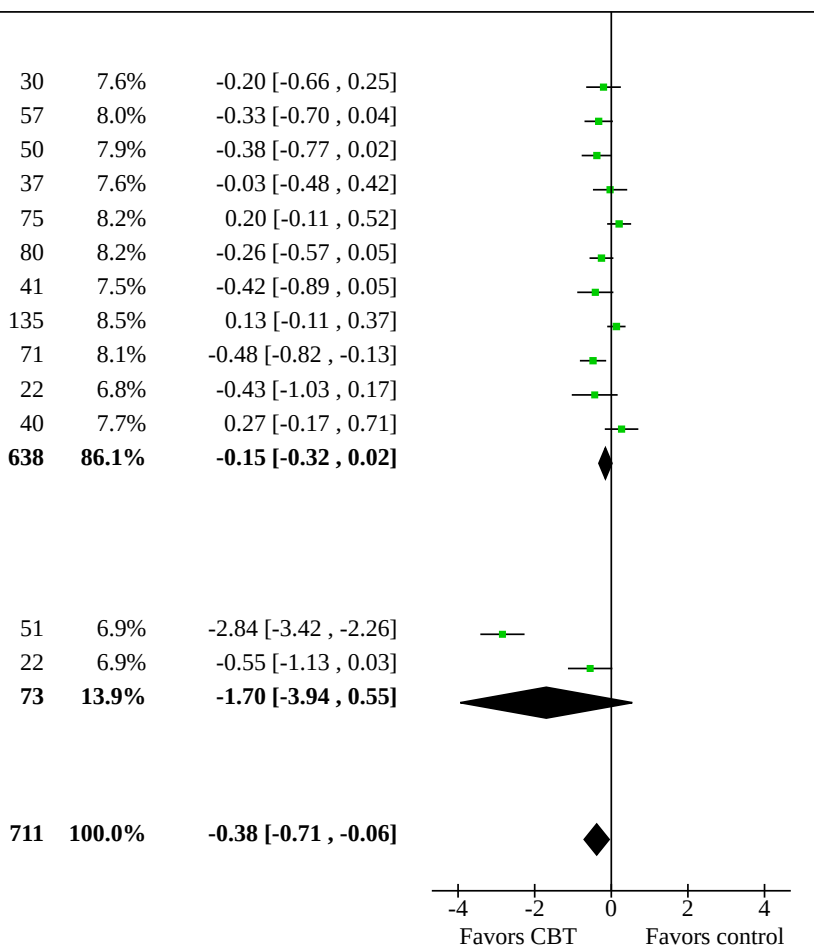

Analysis 13.6. Comparison 13: Cognitive-behavioral therapy post-treatment, Outcome 6: Family functioning

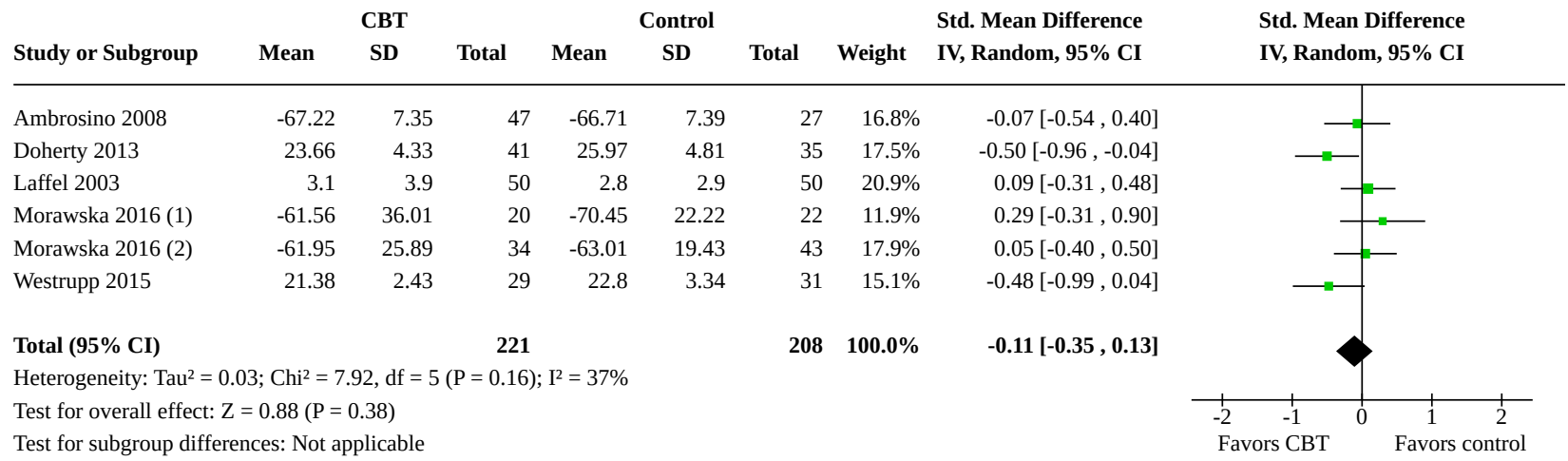

Footnotes

(1) Asthma sample

(2) Eczema sample 
Comparison 14. Cognitive-behavioral therapy follow-up

\begin{tabular}{|c|c|c|c|c|}
\hline $\begin{array}{l}\text { Outcome or subgroup } \\
\text { title }\end{array}$ & No. of studies & $\begin{array}{l}\text { No. of partici- } \\
\text { pants }\end{array}$ & Statistical method & Effect size \\
\hline 14.1 Parenting behavior & 6 & 743 & $\begin{array}{l}\text { Std. Mean Difference (IV, Random, 95\% } \\
\mathrm{CI})\end{array}$ & $-0.26[-0.42,-0.11]$ \\
\hline $\begin{array}{l}14.2 \text { Parent mental } \\
\text { health }\end{array}$ & 5 & 592 & $\begin{array}{l}\text { Std. Mean Difference (IV, Random, 95\% } \\
\mathrm{CI})\end{array}$ & $-0.07[-0.34,0.20]$ \\
\hline $\begin{array}{l}14.3 \text { Child behavior/dis- } \\
\text { ability }\end{array}$ & 8 & 1038 & $\begin{array}{l}\text { Std. Mean Difference (IV, Random, 95\% } \\
\mathrm{Cl} \text { ) }\end{array}$ & $-0.28[-0.40,-0.15]$ \\
\hline 14.4 Child mental health & 10 & 1244 & $\begin{array}{l}\text { Std. Mean Difference (IV, Random, 95\% } \\
\mathrm{CI} \text { ) }\end{array}$ & $-0.07[-0.19,0.04]$ \\
\hline 14.5 Child symptoms & 10 & 1136 & $\begin{array}{l}\text { Std. Mean Difference (IV, Random, 95\% } \\
\mathrm{CI} \text { ) }\end{array}$ & $-0.13[-0.32,0.06]$ \\
\hline 14.6 Family functioning & 3 & 201 & $\begin{array}{l}\text { Std. Mean Difference (IV, Random, 95\% } \\
\mathrm{Cl} \text { ) }\end{array}$ & $-0.04[-0.32,0.24]$ \\
\hline
\end{tabular}

\section{Analysis 14.1. Comparison 14: Cognitive-behavioral therapy follow-up, Outcome 1: Parenting behavior}

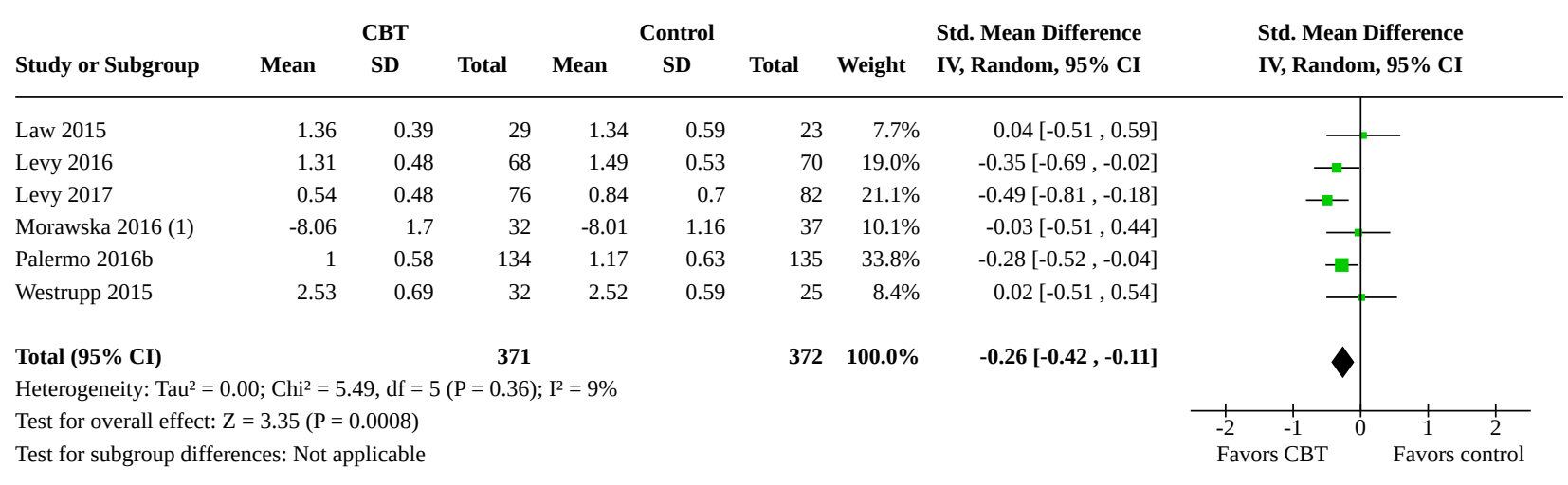

Footnotes

(1) Eczema sample

\section{Analysis 14.2. Comparison 14: Cognitive-behavioral therapy follow-up, Outcome 2: Parent mental health}

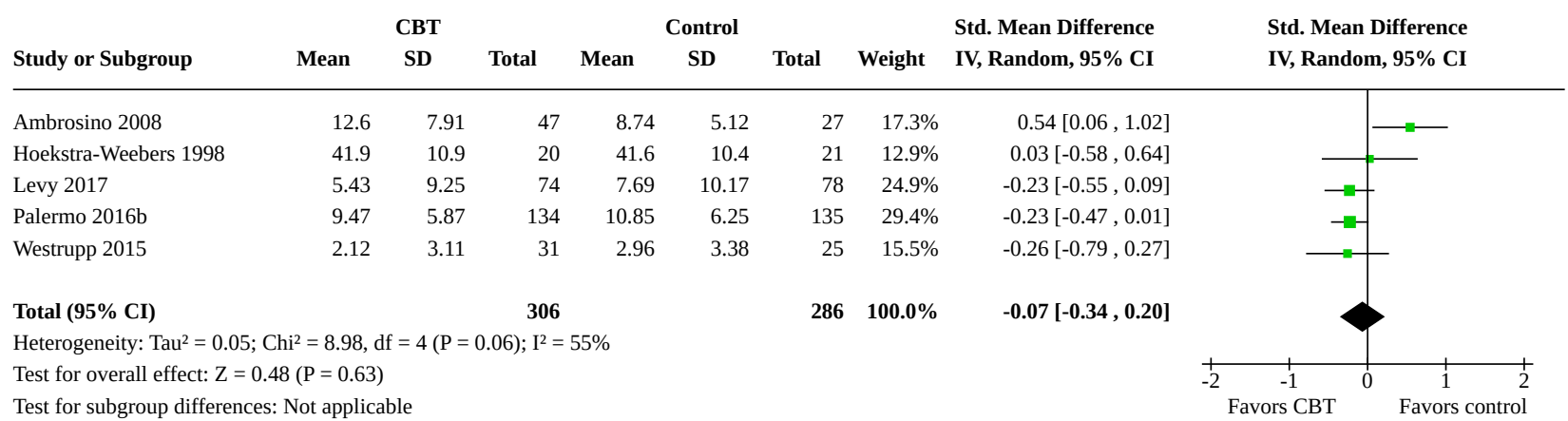


Analysis 14.3. Comparison 14: Cognitive-behavioral therapy follow-up, Outcome 3: Child behavior/disability

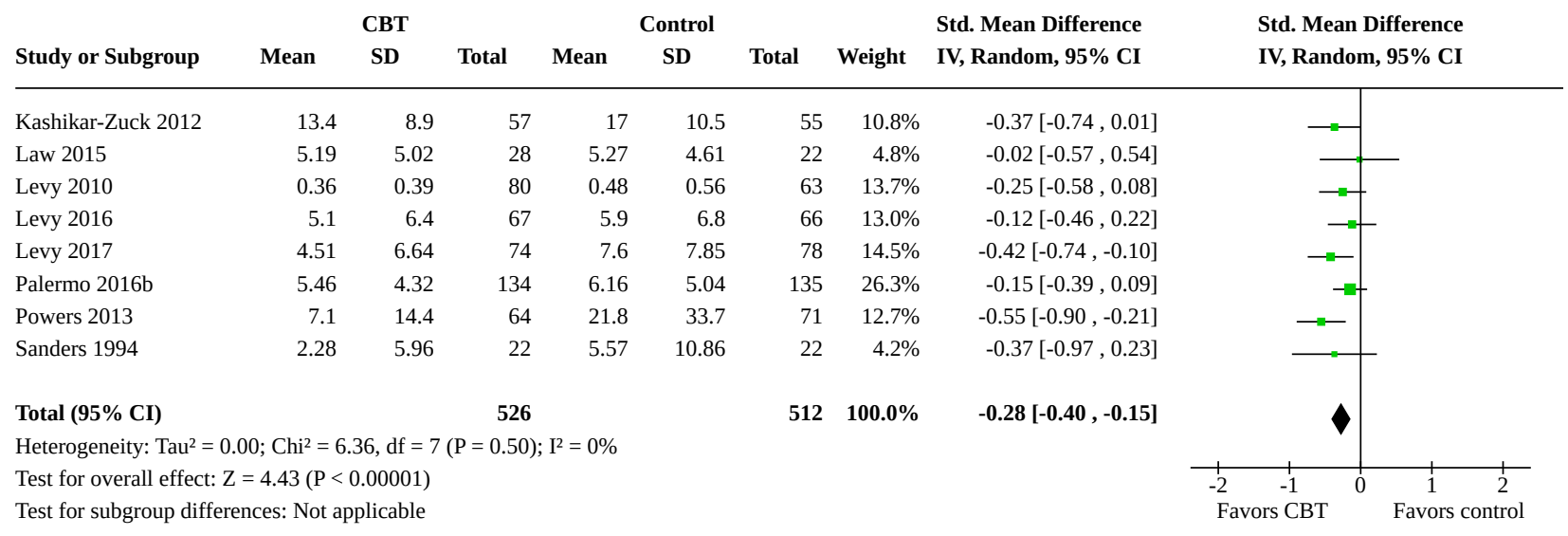

Analysis 14.4. Comparison 14: Cognitive-behavioral therapy follow-up, Outcome 4: Child mental health

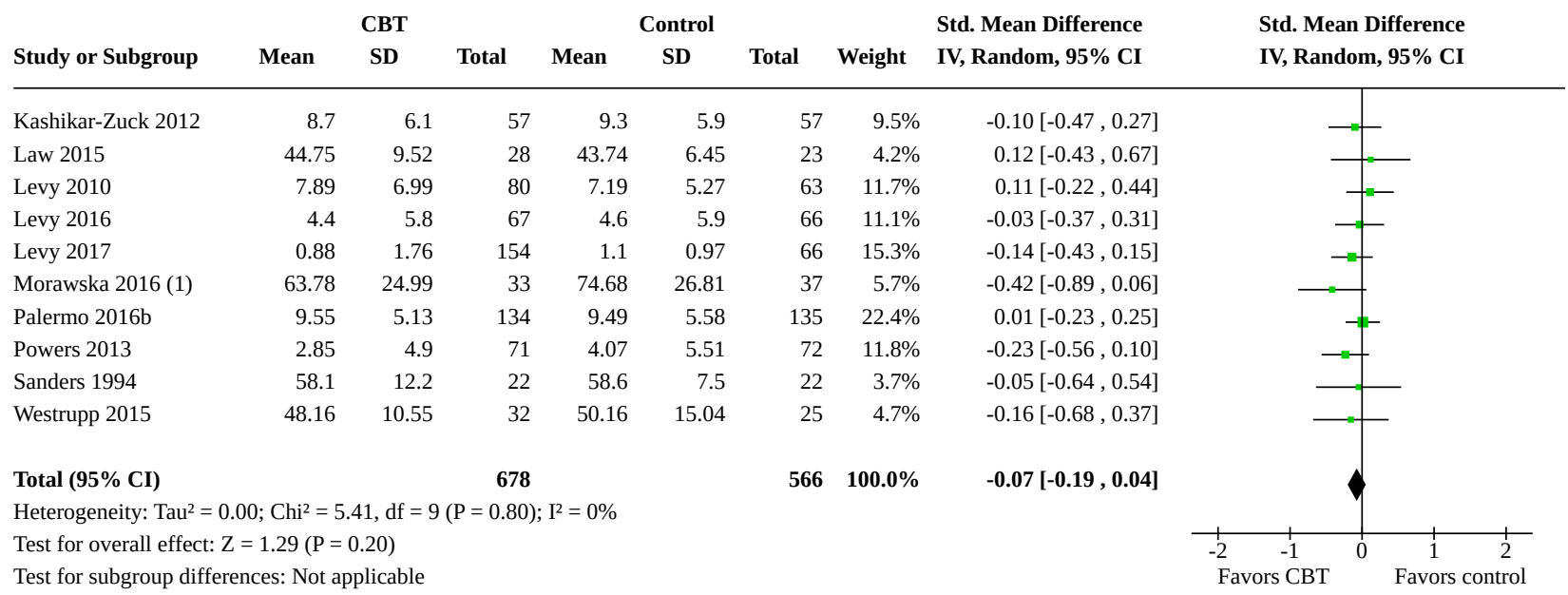

Footnotes

(1) Eczema group 
Analysis 14.5. Comparison 14: Cognitive-behavioral therapy follow-up, Outcome 5: Child symptoms

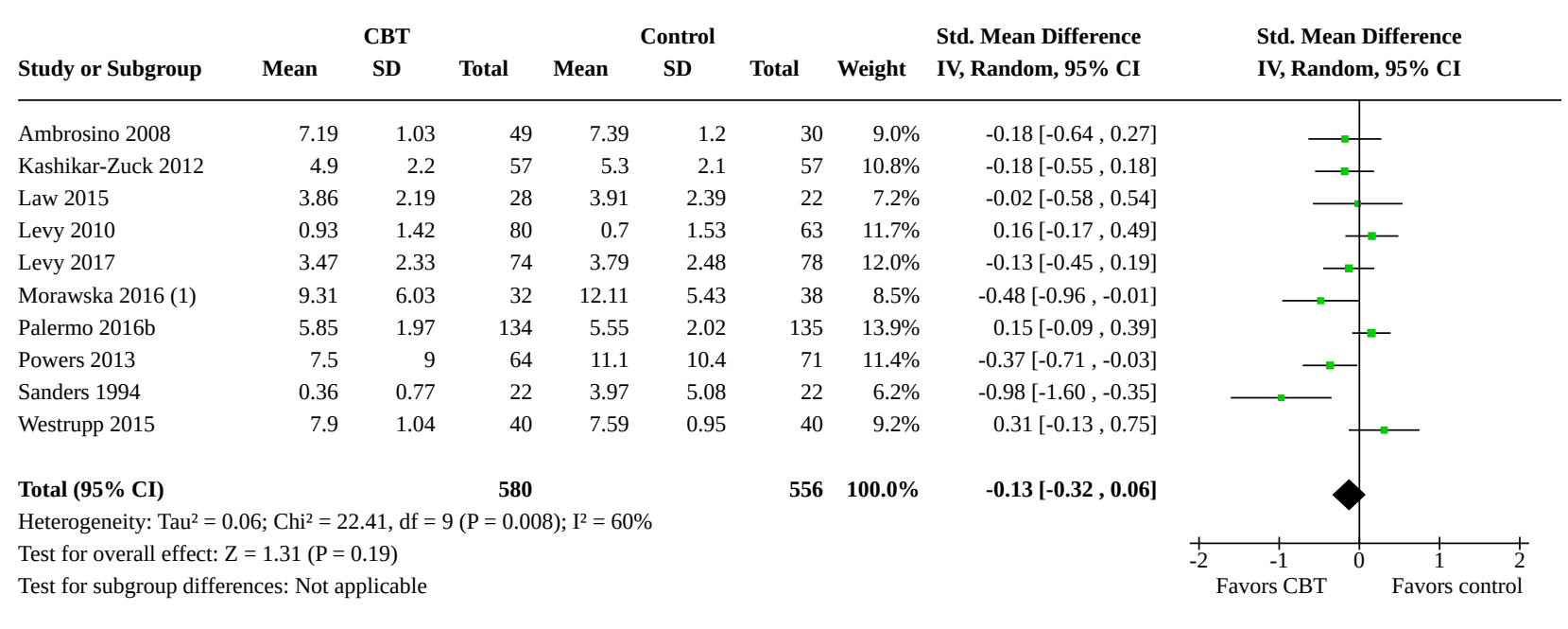

Footnotes

(1) Eczema sample

Analysis 14.6. Comparison 14: Cognitive-behavioral therapy follow-up, Outcome 6: Family functioning

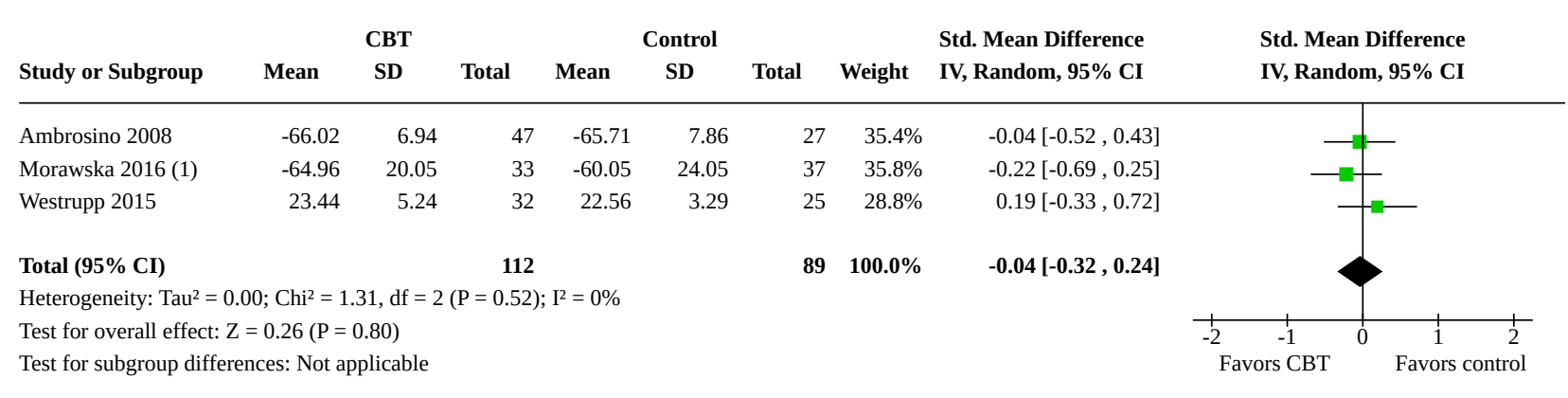

Footnotes

(1) Eczema sample

\section{Comparison 15. Family therapy post-treatment}

\begin{tabular}{lllll}
\hline $\begin{array}{l}\text { Outcome or subgroup } \\
\text { title }\end{array}$ & No. of studies & $\begin{array}{l}\text { No. of partici- } \\
\text { pants }\end{array}$ & Statistical method & Effect size \\
\hline $\begin{array}{l}15.1 \text { Parent mental } \\
\text { health }\end{array}$ & 1 & 65 & $\begin{array}{l}\text { Std. Mean Difference (IV, Random, 95\% } \\
\text { Cl) }\end{array}$ & $-0.76[-1.27,-0.26]$ \\
\hline 15.2 Child mental health & 1 & 74 & Mean Difference (IV, Fixed, 95\% CI) & $3.40[-1.63,8.43]$ \\
\hline 15.3 Child symptoms & 3 & 197 & $\begin{array}{l}\text { Std. Mean Difference (IV, Random, 95\% } \\
\text { Cl) }\end{array}$ & $-0.18[-0.77,0.40]$ \\
\hline 15.4 Family functioning & 3 & 197 & $\begin{array}{l}\text { Std. Mean Difference (IV, Random, 95\% } \\
\text { CI) }\end{array}$ & $-0.34[-0.89,0.21]$ \\
\hline
\end{tabular}


Analysis 15.1. Comparison 15: Family therapy post-treatment, Outcome 1: Parent mental health

\begin{tabular}{|c|c|c|c|c|c|c|c|c|c|}
\hline & \multicolumn{3}{|c|}{ Family Therapy } & \multicolumn{3}{|c|}{ Control } & \multicolumn{2}{|r|}{ Std. Mean Difference } & Std. Mean Difference \\
\hline Study or Subgroup & Mean & SD & Total & Mean & SD & Total & Weight & IV, Random, 95\% CI & IV, Random, 95\% CI \\
\hline
\end{tabular}

$\begin{array}{lllllllll}\text { Yeh } 2016 & 202.12 & 25.93 & 34 & 222.03 & 25.57 & 31 & 100.0 \% & -0.76[-1.27,-0.26]\end{array}$

Total (95\% CI)

34

$31 \quad 100.0 \% \quad-0.76[-1.27,-0.26]$

Heterogeneity: Not applicable

Test for overall effect: $\mathrm{Z}=2.96(\mathrm{P}=0.003)$

Test for subgroup differences: Not applicable

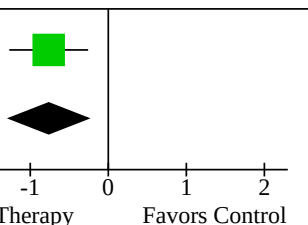

Analysis 15.2. Comparison 15: Family therapy post-treatment, Outcome 2: Child mental health

\begin{tabular}{|c|c|c|c|c|c|c|c|c|c|}
\hline & \multicolumn{3}{|c|}{ Family Therapy } & \multicolumn{3}{|c|}{ Control } & \multicolumn{2}{|r|}{ Mean Difference } & Mean Difference \\
\hline Study or Subgroup & Mean & SD & Total & Mean & SD & Total & Weight & IV, Fixed, 95\% CI & IV, Fixed, 95\% CI \\
\hline
\end{tabular}

\begin{tabular}{llllllllll}
\hline Wysocki 1999 & -73.6 & 11.3 & 35 & -77 & 10.7 & 39 & $100.0 \%$ & $3.40[-1.63,8.43]$
\end{tabular}

Total (95\% CI)

35

$39 \quad 100.0 \% \quad 3.40[-1.63,8.43]$

Heterogeneity: Not applicable

Test for overall effect: $\mathrm{Z}=1.33(\mathrm{P}=0.19)$

Test for subgroup differences: Not applicable

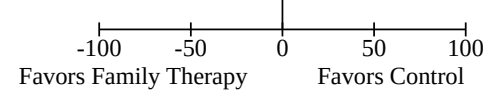

Analysis 15.3. Comparison 15: Family therapy post-treatment, Outcome 3: Child symptoms

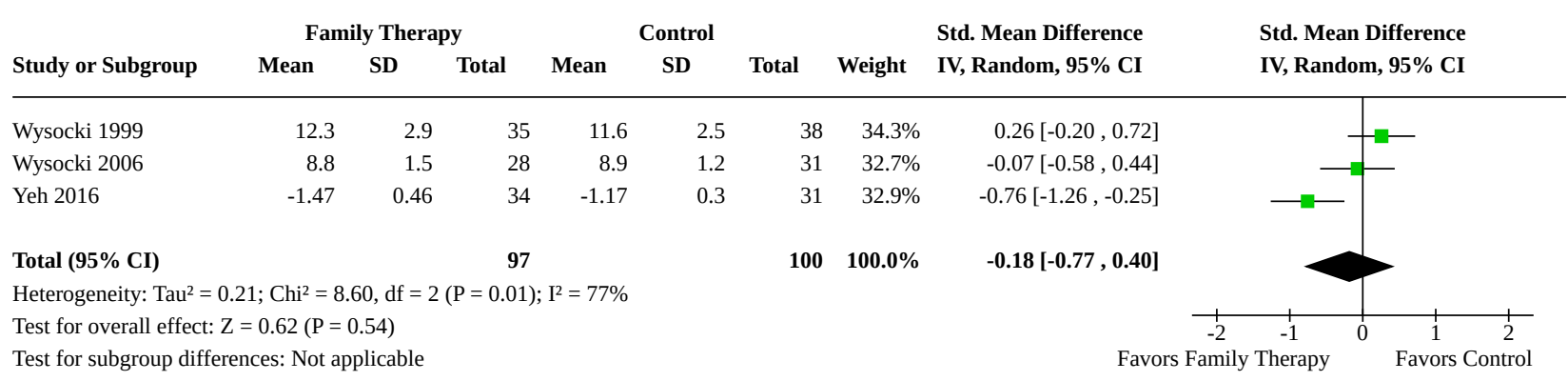

\section{Analysis 15.4. Comparison 15: Family therapy post-treatment, Outcome 4: Family functioning}

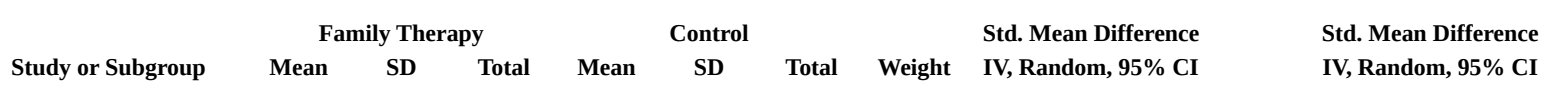

\begin{tabular}{lrrrr}
\hline Wysocki 1999 & 50.2 & 6.7 & 35 & 51.4 \\
Wysocki 2006 & 50 & 6.7 & 28 & 49.6 \\
Yeh 2016 & -49.44 & 3.14 & 34 & -44.68 \\
& & \\
Total (95\% CI) & $\mathbf{9 7}$ \\
Heterogeneity: Tau & $=0.17$; Chi ${ }^{2}=7.40, \mathrm{df}=2(\mathrm{P}=0.02) ; \mathrm{I}^{2}=73 \%$ \\
Test for overall effect: Z = 1.22 (P = 0.22) \\
Test for subgroup differences: Not applicable
\end{tabular}

$\begin{array}{rrrr}5.6 & 38 & 34.6 \% & -0.19[-0.65,0.27] \\ 6.1 & 31 & 32.7 \% & 0.06[-0.45,0.57] \\ 6.79 & 31 & 32.7 \% & -0.90[-1.42,-0.39] \\ & & & \\ & \mathbf{1 0 0} & \mathbf{1 0 0 . 0 \%} & \mathbf{- 0 . 3 4}[-\mathbf{0 . 8 9}, \mathbf{0 . 2 1}]\end{array}$

Test for subgroup differences: Not applicabl

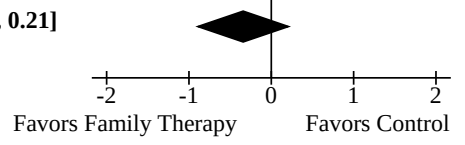


Comparison 16. Family therapy follow-up

\begin{tabular}{lllll}
\hline $\begin{array}{l}\text { Outcome or subgroup ti- } \\
\text { tle }\end{array}$ & No. of studies & $\begin{array}{l}\text { No. of partici- } \\
\text { pants }\end{array}$ & Statistical method & Effect size \\
\hline 16.1 Parent mental health & 1 & 65 & $\begin{array}{l}\text { Std. Mean Difference (IV, Random, } \\
95 \% \text { CI) }\end{array}$ & $-1.30[-1.83,-0.76]$ \\
\hline 16.2 Child symptoms & 2 & 124 & $\begin{array}{l}\text { Std. Mean Difference (IV, Random, } \\
95 \% \text { Cl) }\end{array}$ & $-0.48[-1.12,0.15]$ \\
\hline 16.3 Family functioning & 1 & 65 & $\begin{array}{l}\text { Std. Mean Difference (IV, Random, } \\
95 \% \text { Cl) }\end{array}$ & $-2.71[-3.39,-2.02]$ \\
\hline
\end{tabular}

Analysis 16.1. Comparison 16: Family therapy follow-up, Outcome 1: Parent mental health

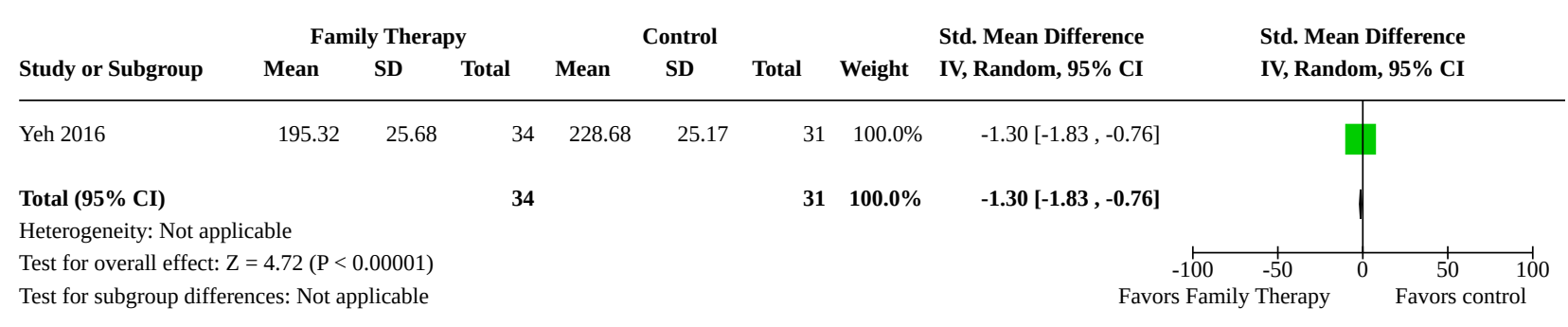

\section{Analysis 16.2. Comparison 16: Family therapy follow-up, Outcome 2: Child symptoms}

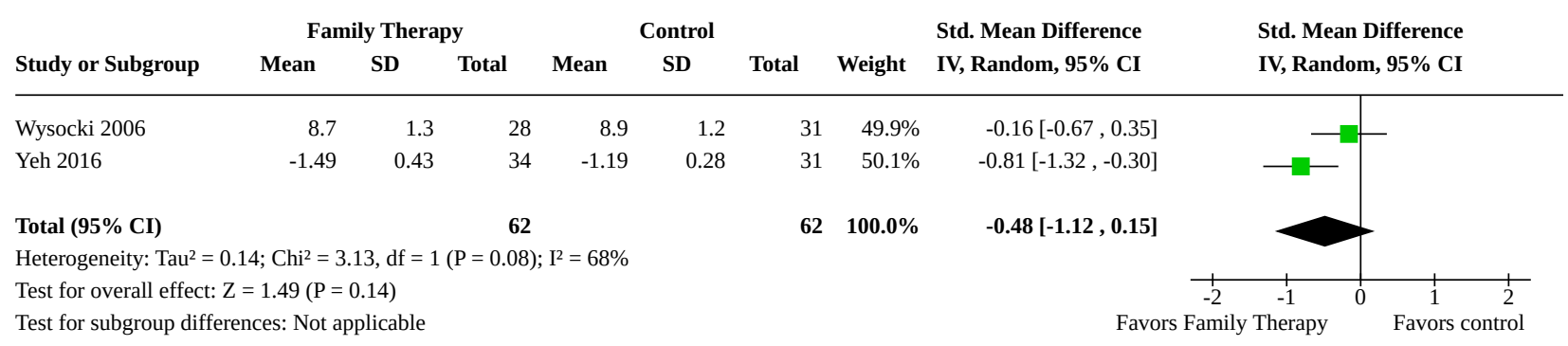

\section{Analysis 16.3. Comparison 16: Family therapy follow-up, Outcome 3: Family functioning}

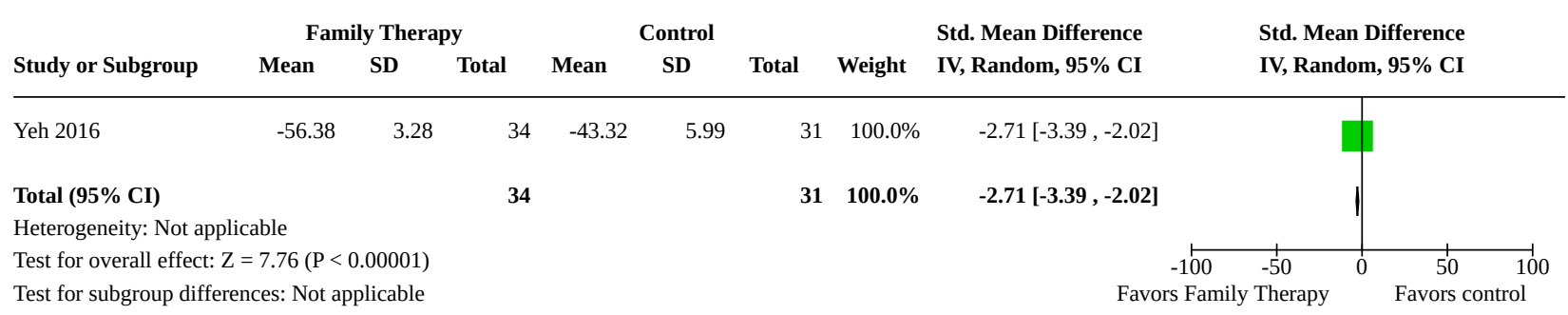


Comparison 17. Motivational interviewing post-treatment

\begin{tabular}{lllll}
\hline $\begin{array}{l}\text { Outcome or subgroup } \\
\text { title }\end{array}$ & No. of studies & $\begin{array}{l}\text { No. of partici- } \\
\text { pants }\end{array}$ & Statistical method & Effect size \\
\hline 17.1 Parenting behavior & 2 & 143 & $\begin{array}{l}\text { Std. Mean Difference (IV, Random, 95\% } \\
\text { Cl) }\end{array}$ & $-1.92[-5.50,1.66]$ \\
\hline 17.2 Child symptoms & 2 & 122 & $\begin{array}{l}\text { Std. Mean Difference (IV, Random, 95\% } \\
\text { Cl) }\end{array}$ & $-0.18[-0.82,0.46]$ \\
\hline 17.3 Family functioning & 2 & 143 & $\begin{array}{l}\text { Std. Mean Difference (IV, Random, 95\% } \\
\text { Cl) }\end{array}$ & $-0.22[-0.66,0.21]$ \\
\hline
\end{tabular}

Analysis 17.1. Comparison 17: Motivational interviewing post-treatment, Outcome 1: Parenting behavior

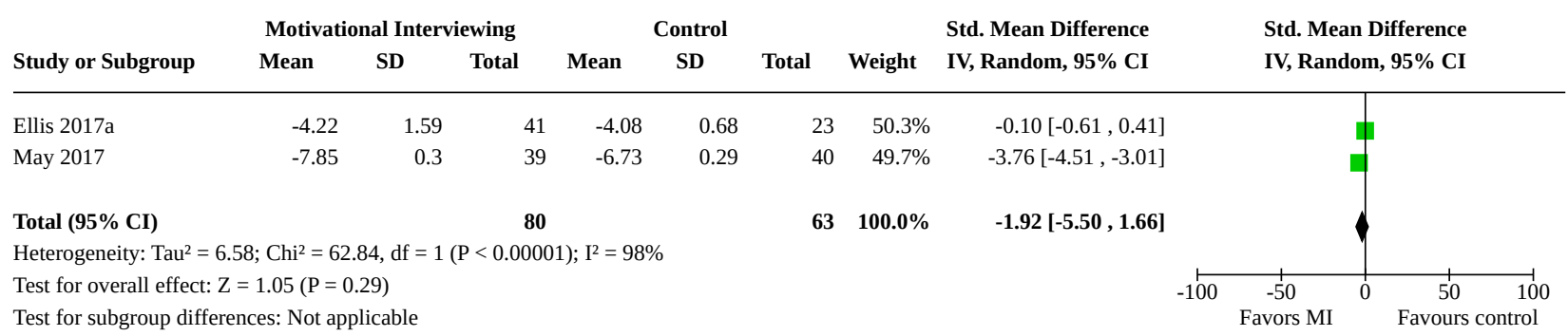

\section{Analysis 17.2. Comparison 17: Motivational interviewing post-treatment, Outcome 2: Child symptoms}

\begin{tabular}{|c|c|c|c|c|c|c|c|c|c|c|}
\hline \multirow[b]{2}{*}{ Study or Subgroup } & \multicolumn{3}{|c|}{ Motivational Interviewing } & \multicolumn{3}{|c|}{ Control } & \multirow[b]{2}{*}{ Weight } & \multirow{2}{*}{$\begin{array}{l}\text { Std. Mean Difference } \\
\text { IV, Random, } 95 \% \text { CI }\end{array}$} & \multirow{2}{*}{$\begin{array}{l}\text { Std. Mean Difference } \\
\text { IV, Random, } 95 \% \text { CI }\end{array}$} & \\
\hline & Mean & SD & Total & Mean & SD & Total & & & & \\
\hline Ellis 2017a & 10.04 & 1.79 & 41 & 11.04 & 2.23 & 23 & $49.9 \%$ & $-0.50[-1.02,0.01]$ & & \\
\hline Mayer-Davis 2015 & 9.7 & 1.5 & 29 & 9.5 & 1.2 & 29 & $50.1 \%$ & $0.15[-0.37,0.66]$ & & \\
\hline Total (95\% CI) & & & 70 & & & 52 & $100.0 \%$ & $-0.18[-0.82,0.46]$ & & \\
\hline \multicolumn{11}{|c|}{ Heterogeneity: $\mathrm{Tau}^{2}=0.14 ; \mathrm{Chi}^{2}=3.04, \mathrm{df}=1(\mathrm{P}=0.08) ; \mathrm{I}^{2}=67 \%$} \\
\hline \multirow{2}{*}{\multicolumn{5}{|c|}{ Test for overall effect: $\mathrm{Z}=0.55(\mathrm{P}=0.58)$}} & & & & & $-2 \quad-1$ & 2 \\
\hline & & & & & & & & & Favors MI & ontrol \\
\hline
\end{tabular}

\section{Analysis 17.3. Comparison 17: Motivational interviewing post-treatment, Outcome 3: Family functioning}

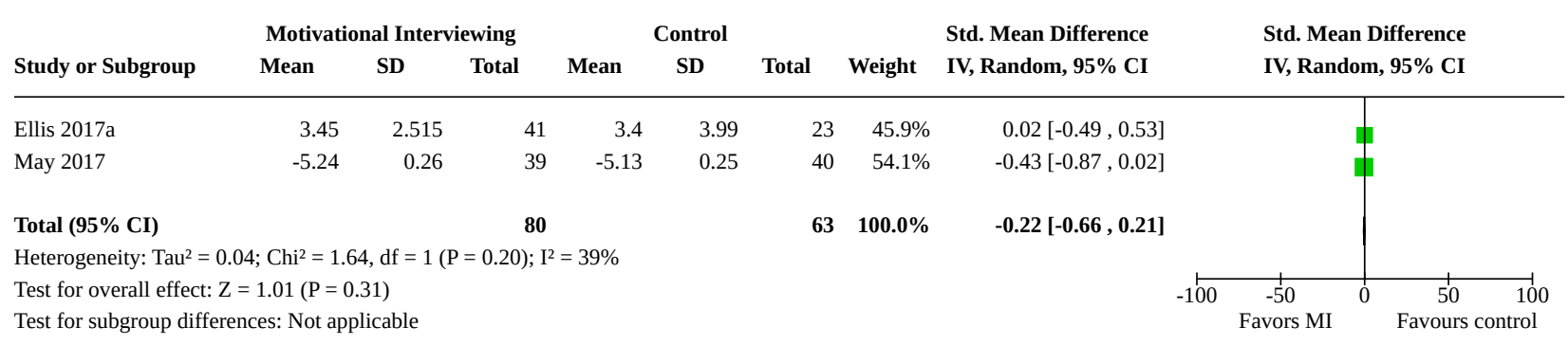


Comparison 18. Multisystemic therapy post-treatment

\begin{tabular}{lllll}
\hline $\begin{array}{l}\text { Outcome or subgroup } \\
\text { title }\end{array}$ & No. of studies & $\begin{array}{l}\text { No. of partici- } \\
\text { pants }\end{array}$ & Statistical method & Effect size \\
\hline 18.1 Parenting behavior & 1 & 167 & $\begin{array}{l}\text { Std. Mean Difference (IV, Random, 95\% } \\
\text { Cl) }\end{array}$ & $-0.17[-0.47,0.14]$ \\
\hline 18.2 Child mental health & 1 & 117 & $\begin{array}{l}\text { Std. Mean Difference (IV, Random, 95\% } \\
\text { Cl) }\end{array}$ & $-0.35[-0.71,0.02]$ \\
\hline 18.3 Child symptoms & 4 & 477 & $\begin{array}{l}\text { Std. Mean Difference (IV, Random, 95\% } \\
\text { Cl) }\end{array}$ & $-0.18[-0.45,0.08]$ \\
\hline
\end{tabular}

Analysis 18.1. Comparison 18: Multisystemic therapy post-treatment, Outcome 1: Parenting behavior

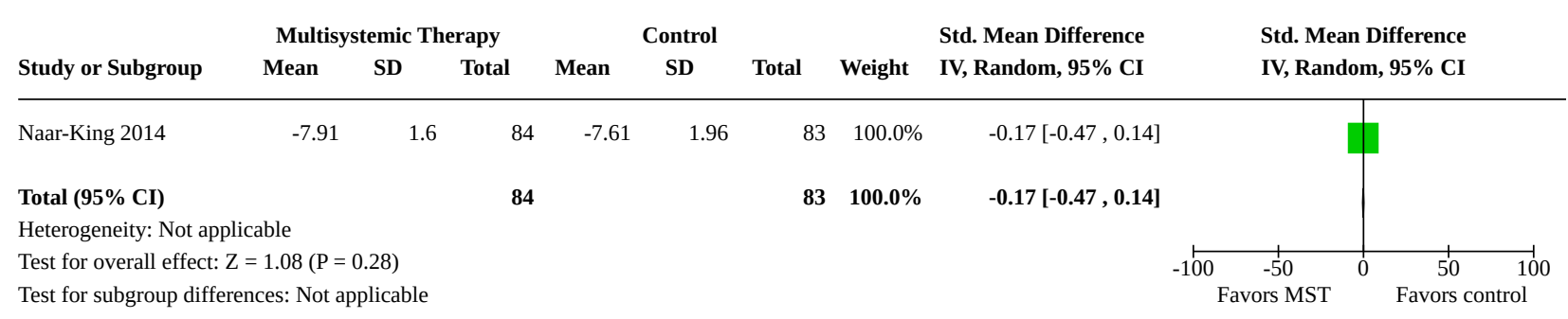

Analysis 18.2. Comparison 18: Multisystemic therapy post-treatment, Outcome 2: Child mental health

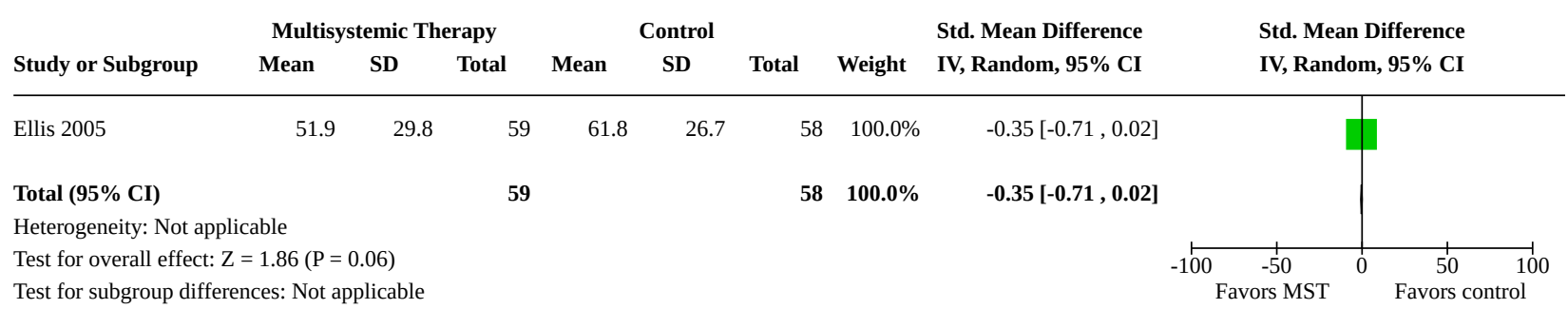

\section{Analysis 18.3. Comparison 18: Multisystemic therapy post-treatment, Outcome 3: Child symptoms}

\begin{tabular}{|c|c|c|c|c|c|c|c|c|c|c|}
\hline \multirow[b]{2}{*}{ Study or Subgroup } & \multicolumn{3}{|c|}{ Multisystemic Therapy } & \multicolumn{3}{|c|}{ Control } & \multirow[b]{2}{*}{ Weight } & \multirow{2}{*}{$\begin{array}{l}\text { Std. Mean Difference } \\
\text { IV, Random, 95\% CI }\end{array}$} & \multirow{2}{*}{\multicolumn{2}{|c|}{$\begin{array}{l}\text { Std. Mean Difference } \\
\text { IV, Random, } 95 \% \text { CI }\end{array}$}} \\
\hline & Mean & SD & Total & Mean & SD & Total & & & & \\
\hline Ellis 2005 & 10.72 & 2.59 & 59 & 11.29 & 2.3 & 58 & $26.0 \%$ & $-0.23[-0.59,0.13]$ & -1 & \\
\hline Ellis 2012 & 10.41 & 2.45 & 74 & 11.54 & 2.5 & 72 & $28.5 \%$ & $-0.45[-0.78,-0.13]$ & -- & \\
\hline Ellis 2017b & 11.03 & 2.1 & 23 & 11.39 & 2.12 & 24 & $15.1 \%$ & $-0.17[-0.74,0.41]$ & $\longrightarrow$ & \\
\hline Naar-King 2014 & -2.24 & 0.6 & 84 & -2.3 & 0.58 & 83 & $30.5 \%$ & $0.10[-0.20,0.40]$ & - & \\
\hline Total (95\% CI) & & & 240 & & & 237 & $100.0 \%$ & $-0.18[-0.45,0.08]$ & & \\
\hline \multicolumn{11}{|c|}{ Heterogeneity: $\mathrm{Tau}^{2}=0.04 ; \mathrm{Chi}^{2}=6.04, \mathrm{df}=3(\mathrm{P}=0.11) ; \mathrm{I}^{2}=50 \%$} \\
\hline \multirow{2}{*}{\multicolumn{5}{|c|}{$\begin{array}{l}\text { Test for overall effect: } \mathrm{Z}=1.36(\mathrm{P}=0.17) \\
\text { Test for subgroup differences: Not applicable }\end{array}$}} & & & & -2 & -1 & 2 \\
\hline & & & & & & & & & ors MST & rol \\
\hline
\end{tabular}


Comparison 19. Multisystemic therapy follow-up

\begin{tabular}{lllll}
\hline Outcome or subgroup title & No. of studies & $\begin{array}{l}\text { No. of partici- } \\
\text { pants }\end{array}$ & Statistical method & Effect size \\
\hline 19.1 Child symptoms & 2 & 247 & $\begin{array}{l}\text { Std. Mean Difference (IV, Random, } \\
95 \% \text { Cl) }\end{array}$ & $-0.19[-0.44,0.06]$ \\
\hline
\end{tabular}

Analysis 19.1. Comparison 19: Multisystemic therapy follow-up, Outcome 1: Child symptoms

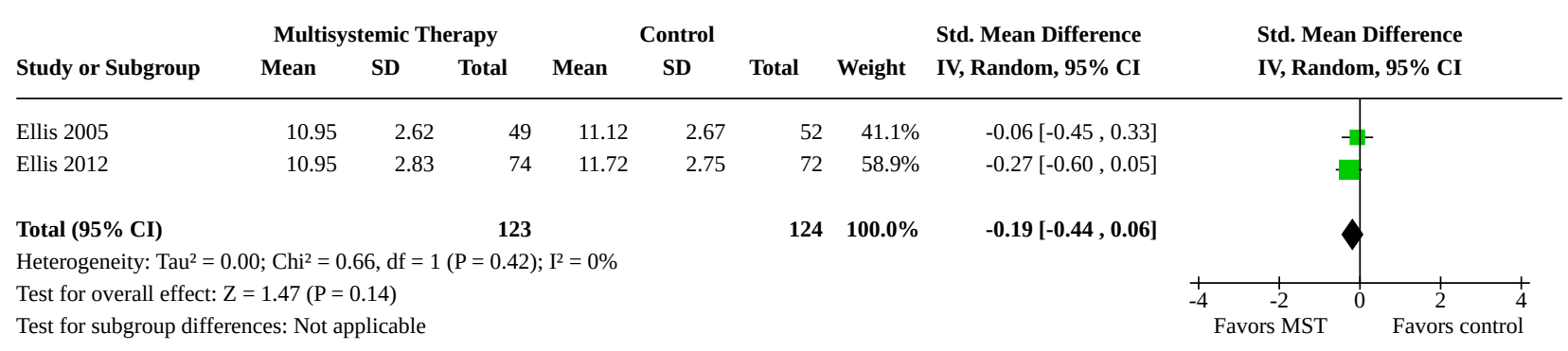

Comparison 20. Problem-solving therapy post-treatment

\begin{tabular}{|c|c|c|c|c|}
\hline $\begin{array}{l}\text { Outcome or subgroup ti- } \\
\text { tle }\end{array}$ & No. of studies & $\begin{array}{l}\text { No. of partici- } \\
\text { pants }\end{array}$ & Statistical method & Effect size \\
\hline 20.1 Parenting behavior & 7 & 947 & $\begin{array}{l}\text { Std. Mean Difference (IV, Random, 95\% } \\
\text { CI) }\end{array}$ & $-0.39[-0.64,-0.13]$ \\
\hline 20.2 Parent mental health & 6 & 891 & $\begin{array}{l}\text { Std. Mean Difference (IV, Random, 95\% } \\
\text { CI) }\end{array}$ & $-0.30[-0.45,-0.15]$ \\
\hline $\begin{array}{l}20.3 \text { Child behavior/dis- } \\
\text { ability }\end{array}$ & 3 & 247 & $\begin{array}{l}\text { Std. Mean Difference (IV, Random, 95\% } \\
\text { Cl) }\end{array}$ & $0.08[-0.18,0.33]$ \\
\hline 20.4 Child mental health & 4 & 276 & $\begin{array}{l}\text { Std. Mean Difference (IV, Random, 95\% } \\
\text { CI) }\end{array}$ & $-0.12[-0.50,0.25]$ \\
\hline 20.5 Child symptoms & 5 & 679 & $\begin{array}{l}\text { Std. Mean Difference (IV, Random, 95\% } \\
\text { CI) }\end{array}$ & $0.25[-0.23,0.72]$ \\
\hline 20.6 Family functioning & 2 & 237 & $\begin{array}{l}\text { Std. Mean Difference (IV, Random, 95\% } \\
\text { CI) }\end{array}$ & $-0.15[-0.41,0.10]$ \\
\hline
\end{tabular}


Analysis 20.1. Comparison 20: Problem-solving therapy post-treatment, Outcome 1: Parenting behavior

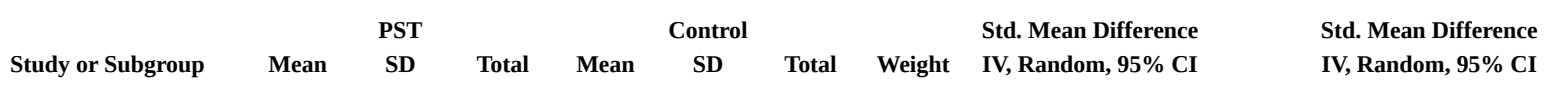

\begin{tabular}{lrrrrrrrr}
\hline Husted 2014 & -37 & 1.5 & 26 & -35 & 1.3 & 31 & $10.4 \%$ & $-1.41[-2.00,-0.83]$ \\
Palermo 2016a & 21.93 & 5.02 & 31 & 21.15 & 7.33 & 30 & $12.2 \%$ & $0.12[-0.38,0.63]$ \\
Sahler 2002 & -72.85 & 14.48 & 33 & -71.32 & 13.49 & 40 & $13.2 \%$ & $-0.11[-0.57,0.35]$ \\
Sahler 2005 & -14.33 & 2.54 & 189 & -13.59 & 2.39 & 195 & $20.4 \%$ & $-0.30[-0.50,-0.10]$ \\
Sahler 2013 & -14.58 & 2.61 & 97 & -13.74 & 2.78 & 110 & $18.3 \%$ & $-0.31[-0.58,-0.04]$ \\
Wade 2006a & -73.45 & 9.61 & 20 & -69.16 & 10.02 & 20 & $9.6 \%$ & $-0.43[-1.06,0.20]$ \\
Wade 2014 & -91.9 & 7.2 & 61 & -87.2 & 10.7 & 64 & $16.0 \%$ & $-0.51[-0.87,-0.15]$ \\
& & & & & & & &
\end{tabular}

Heterogeneity: $\mathrm{Tau}^{2}=0.07 ; \mathrm{Chi}^{2}=18.26, \mathrm{df}=6(\mathrm{P}=0.006) ; \mathrm{I}^{2}=67 \%$

Test for overall effect: $\mathrm{Z}=2.99(\mathrm{P}=0.003)$

Test for subgroup differences: Not applicable

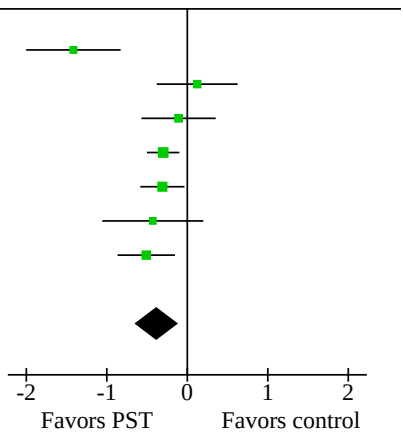

Analysis 20.2. Comparison 20: Problem-solving therapy post-treatment, Outcome 2: Parent mental health

\begin{tabular}{|c|c|c|c|c|c|c|c|c|}
\hline \multirow[b]{2}{*}{ Study or Subgroup } & \multirow[b]{2}{*}{ Mean } & \multicolumn{2}{|l|}{ PST } & \multicolumn{3}{|c|}{ Control } & \multicolumn{2}{|r|}{ Std. Mean Difference } \\
\hline & & SD & Total & Mean & SD & Total & Weight & IV, Random, 95\% CI \\
\hline Palermo 2016a & 7.87 & 5.82 & 31 & 9.33 & 8.51 & 30 & $8.3 \%$ & $-0.20[-0.70,0.30]$ \\
\hline Sahler 2002 & 80.76 & 38.81 & 33 & 98.1 & 48.5 & 40 & $9.6 \%$ & $-0.39[-0.85,0.08]$ \\
\hline Sahler 2005 & 10.74 & 8.8 & 191 & 13.87 & 9.66 & 194 & $37.5 \%$ & $-0.34[-0.54,-0.14]$ \\
\hline Sahler 2013 & 12.14 & 10.4 & 97 & 12.86 & 9.66 & 110 & $24.0 \%$ & $-0.07[-0.34,0.20]$ \\
\hline Wade 2006a & 9.25 & 7.09 & 20 & 18.15 & 13.49 & 20 & $5.2 \%$ & $-0.81[-1.46,-0.16]$ \\
\hline Wade 2014 & 11.1 & 9.3 & 61 & 15.4 & 11.7 & 64 & $15.6 \%$ & $-0.40[-0.76,-0.05$ \\
\hline
\end{tabular}

Heterogeneity: $\mathrm{Tau}^{2}=0.01 ; \mathrm{Chi}^{2}=5.82, \mathrm{df}=5(\mathrm{P}=0.32) ; \mathrm{I}^{2}=14 \%$

Test for overall effect: $\mathrm{Z}=3.93(\mathrm{P}<0.0001)$

Test for subgroup differences: Not applicable

Std. Mean Difference

IV, Random, 95\% CI

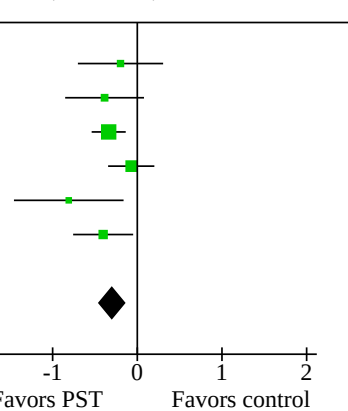

Analysis 20.3. Comparison 20: Problem-solving therapy post-treatment, Outcome 3: Child behavior/disability

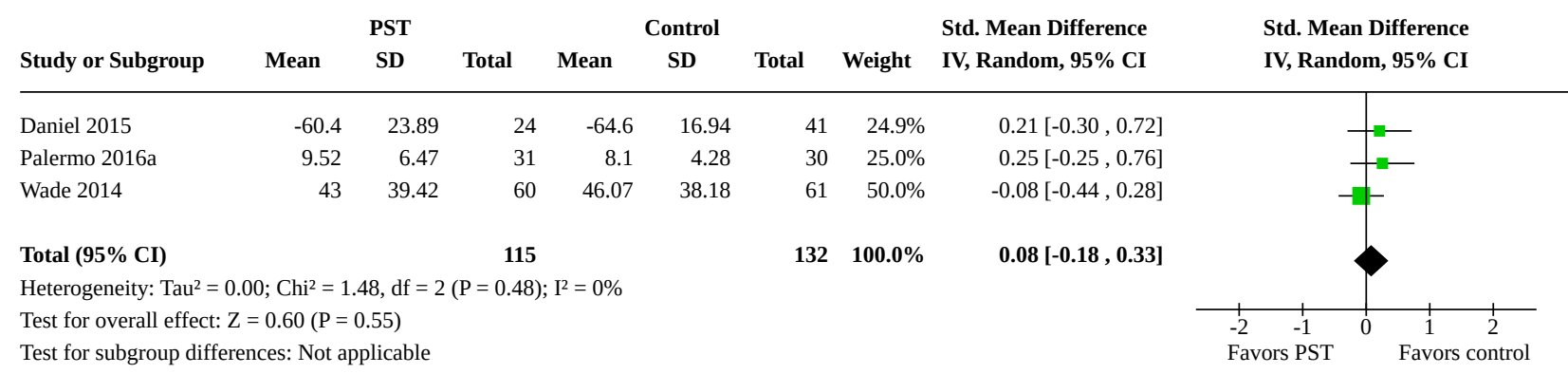


Analysis 20.4. Comparison 20: Problem-solving therapy post-treatment, Outcome 4: Child mental health

\begin{tabular}{|c|c|c|c|c|c|c|c|c|c|}
\hline Study or Subgroup & Mean & $\begin{array}{l}\text { PST } \\
\text { SD }\end{array}$ & Total & Mean & $\begin{array}{l}\text { introl } \\
\text { SD }\end{array}$ & Total & Weight & $\begin{array}{l}\text { Std. Mean Difference } \\
\text { IV, Random, } 95 \% \text { CI }\end{array}$ & $\begin{array}{l}\text { Std. Mean Difference } \\
\text { IV, Random, 95\% CI }\end{array}$ \\
\hline Husted 2014 & -60 & 4.2 & 26 & -61 & 3.6 & 31 & $24.0 \%$ & $0.25[-0.27,0.78]$ & \\
\hline Palermo 2016a & 12.03 & 5.13 & 31 & 11.2 & 5.37 & 30 & $24.9 \%$ & $0.16[-0.35,0.66]$ & - \\
\hline Wade 2006a & 47.78 & 11.43 & 20 & 56.06 & 11.82 & 20 & $19.5 \%$ & $-0.70[-1.34,-0.06]$ & \\
\hline Wade 2014 & 49.37 & 12.13 & 57 & 52.56 & 11.6 & 61 & $31.7 \%$ & $-0.27[-0.63,0.10]$ & 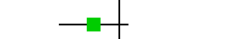 \\
\hline Total (95\% CI) & & & 134 & & & 142 & $100.0 \%$ & $-0.12[-0.50,0.25]$ & \\
\hline \multicolumn{10}{|c|}{ Heterogeneity: Tau $^{2}=0.08 ;$ Chi $^{2}=6.88, \mathrm{df}=3(\mathrm{P}=0.08) ; \mathrm{I}^{2}=56 \%$} \\
\hline \multicolumn{9}{|c|}{ Test for overall effect: $\mathrm{Z}=0.63(\mathrm{P}=0.53)$} & $-1 \quad-0.5$ \\
\hline \multicolumn{9}{|c|}{ Test for subgroup differences: Not applicable } & vors PST \\
\hline
\end{tabular}

Analysis 20.5. Comparison 20: Problem-solving therapy post-treatment, Outcome 5: Child symptoms

\begin{tabular}{|c|c|c|c|c|c|c|c|c|c|}
\hline & & PST & & & ontr & & & Std. Mean Difference & Std. Mean Difference \\
\hline Study or Subgroup & Mean & SD & Total & Mean & SD & Total & Weight & IV, Random, 95\% CI & IV, Random, 95\% CI \\
\hline
\end{tabular}

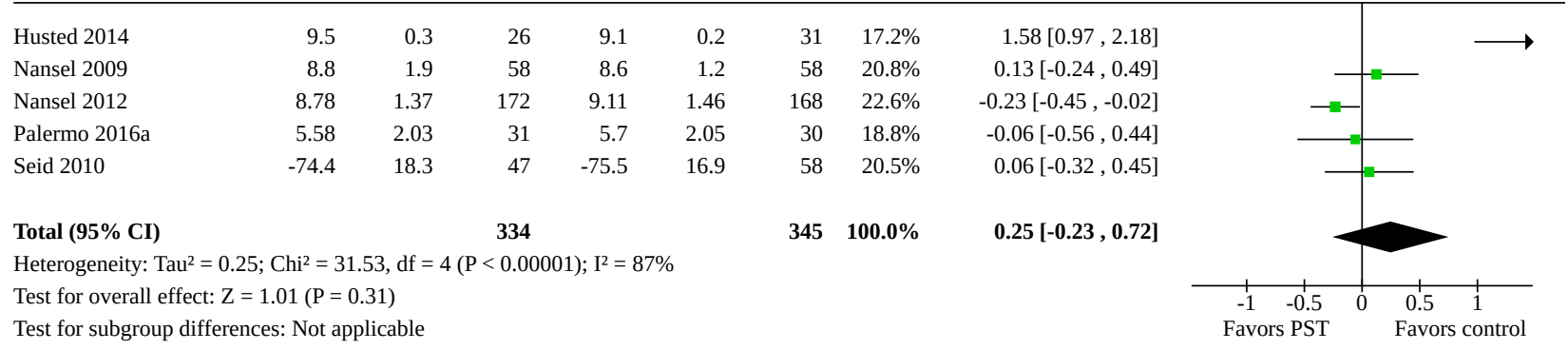

\section{Analysis 20.6. Comparison 20: Problem-solving therapy post-treatment, Outcome 6: Family functioning}

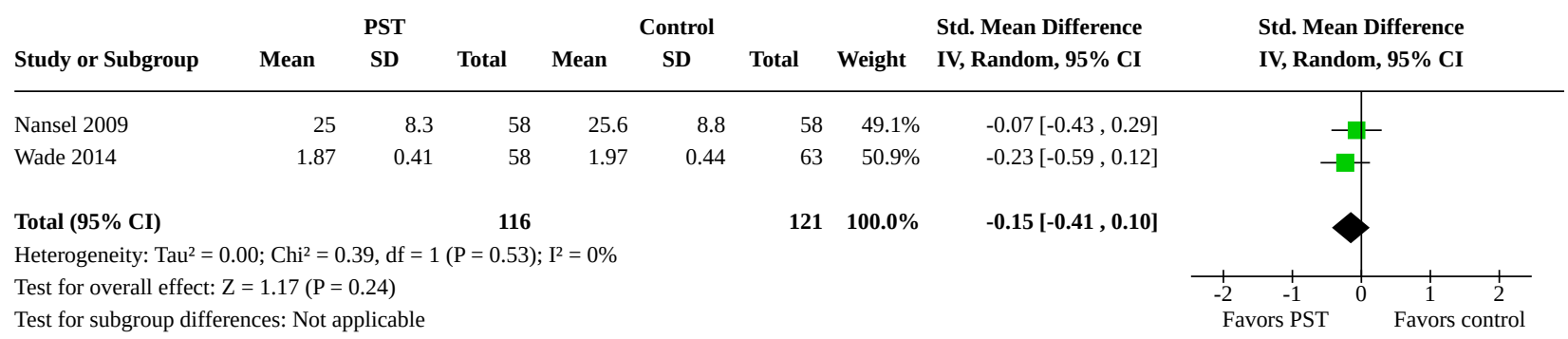

Comparison 21. Problem-solving therapy follow-up

\begin{tabular}{lllll}
\hline $\begin{array}{l}\text { Outcome or subgroup ti- } \\
\text { tle }\end{array}$ & No. of studies & $\begin{array}{l}\text { No. of partici- } \\
\text { pants }\end{array}$ & Statistical method & Effect size \\
\hline 21.1 Parenting behavior & 6 & 852 & $\begin{array}{l}\text { Std. Mean Difference (IV, Random, 95\% } \\
\text { Cl) }\end{array}$ & $-0.54[-0.94,-0.14]$ \\
\hline 21.2 Parent mental health & 5 & 800 & $\begin{array}{l}\text { Std. Mean Difference (IV, Random, 95\% } \\
\text { Cl) }\end{array}$ & $-0.21[-0.35,-0.07]$ \\
\hline $\begin{array}{l}21.3 \text { Child behavior/dis- } \\
\text { ability }\end{array}$ & 2 & 166 & $\begin{array}{l}\text { Std. Mean Difference (IV, Random, 95\% } \\
\text { Cl) }\end{array}$ & $-0.04[-0.35,0.26]$ \\
\hline
\end{tabular}




\begin{tabular}{lllll}
\hline $\begin{array}{l}\text { Outcome or subgroup ti- } \\
\text { tle }\end{array}$ & No. of studies & $\begin{array}{l}\text { No. of partici- } \\
\text { pants }\end{array}$ & Statistical method & Effect size \\
\hline 21.4 Child mental health & 3 & 212 & $\begin{array}{l}\text { Std. Mean Difference (IV, Random, 95\% } \\
\text { Cl) }\end{array}$ & $0.59[-0.28,1.46]$ \\
\hline 21.5 Child symptoms & 3 & 210 & $\begin{array}{l}\text { Std. Mean Difference (IV, Random, 95\% } \\
\text { Cl) }\end{array}$ & $0.25[-0.08,0.59]$ \\
\hline 21.6 Family functioning & 1 & 101 & $\begin{array}{l}\text { Std. Mean Difference (IV, Random, 95\% } \\
\text { Cl) }\end{array}$ & $-0.17[-0.56,0.23]$ \\
\hline
\end{tabular}

\section{Analysis 21.1. Comparison 21: Problem-solving therapy follow-up, Outcome 1: Parenting behavior}

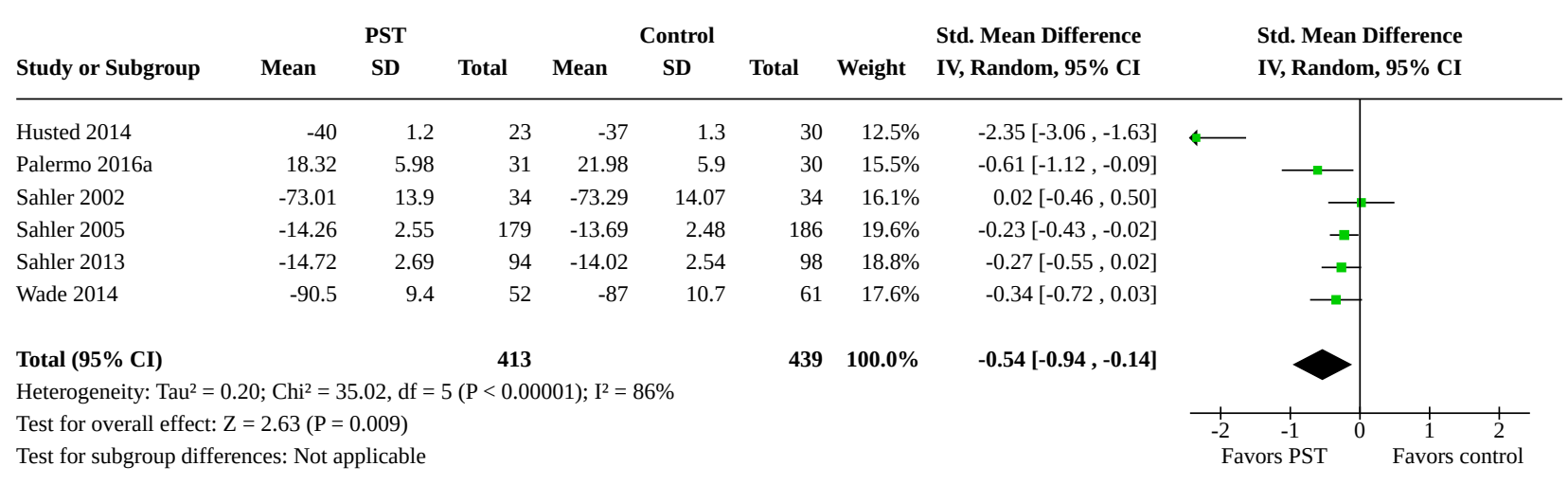

\section{Analysis 21.2. Comparison 21: Problem-solving therapy follow-up, Outcome 2: Parent mental health}

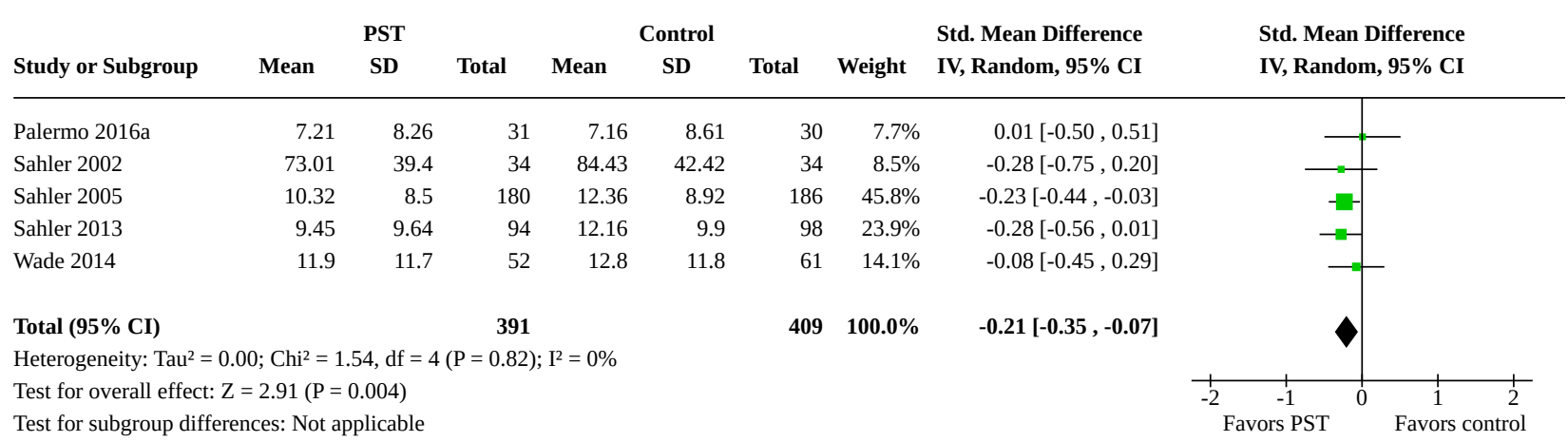


Analysis 21.3. Comparison 21: Problem-solving therapy follow-up, Outcome 3: Child behavior/disability

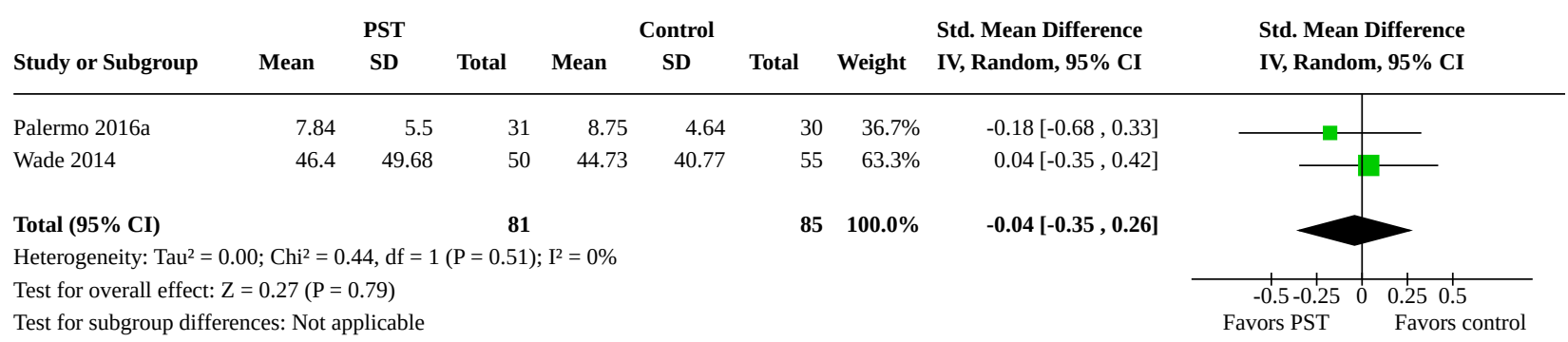

\section{Analysis 21.4. Comparison 21: Problem-solving therapy follow-up, Outcome 4: Child mental health}

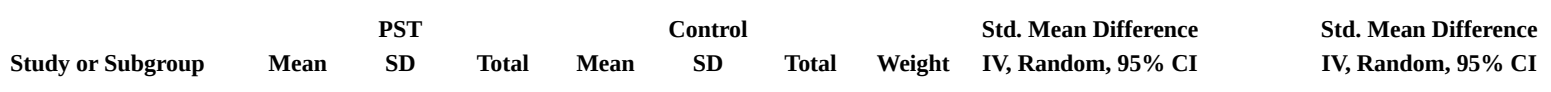

\begin{tabular}{|c|c|c|c|c|c|c|c|c|}
\hline Husted 2014 & -56 & 4.8 & 23 & -62 & 3.4 & 30 & $31.7 \%$ & $1.45[0.84,2.07]$ \\
\hline Palermo 2016a & 11.53 & 5.37 & 31 & 8.71 & 5.6 & 30 & $33.3 \%$ & $0.51[-0.00,1.02]$ \\
\hline Wade 2014 & 50.83 & 12.5 & 48 & 52.34 & 12.32 & 50 & $34.9 \%$ & $-0.12[-0.52,0.28]$ \\
\hline Total (95\% CI) & & & 102 & & & 110 & $100.0 \%$ & $0.59[-0.28,1.46]$ \\
\hline
\end{tabular}

Heterogeneity: Tau $^{2}=0.52 ; \mathrm{Chi}^{2}=18.10, \mathrm{df}=2(\mathrm{P}=0.0001) ; \mathrm{I}^{2}=89 \%$

Test for overall effect: $\mathrm{Z}=1.32(\mathrm{P}=0.19)$

Test for subgroup differences: Not applicable

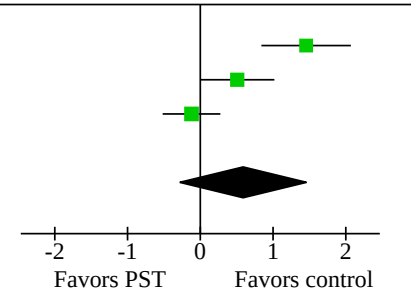

Analysis 21.5. Comparison 21: Problem-solving therapy follow-up, Outcome 5: Child symptoms

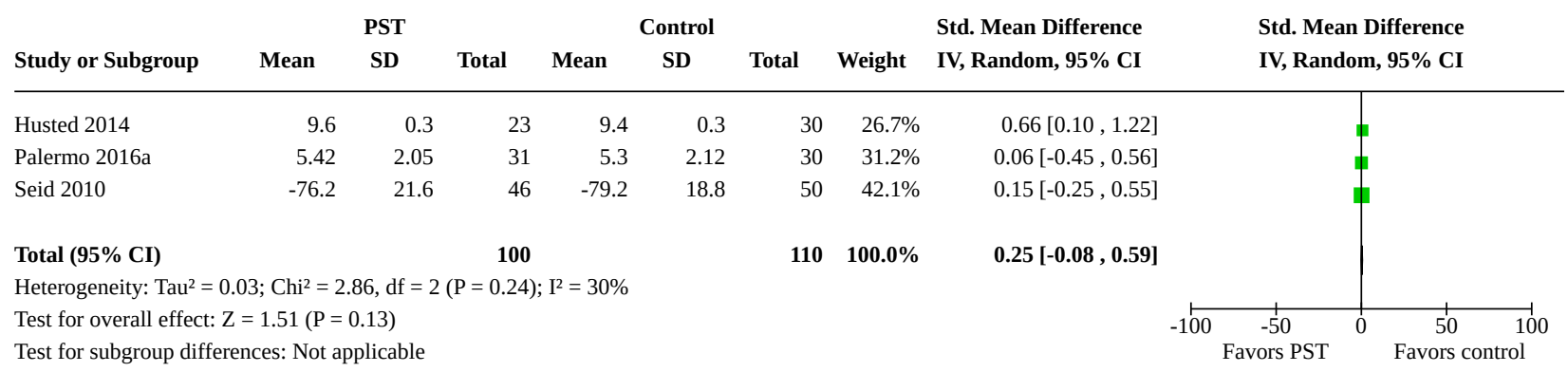

Analysis 21.6. Comparison 21: Problem-solving therapy follow-up, Outcome 6: Family functioning

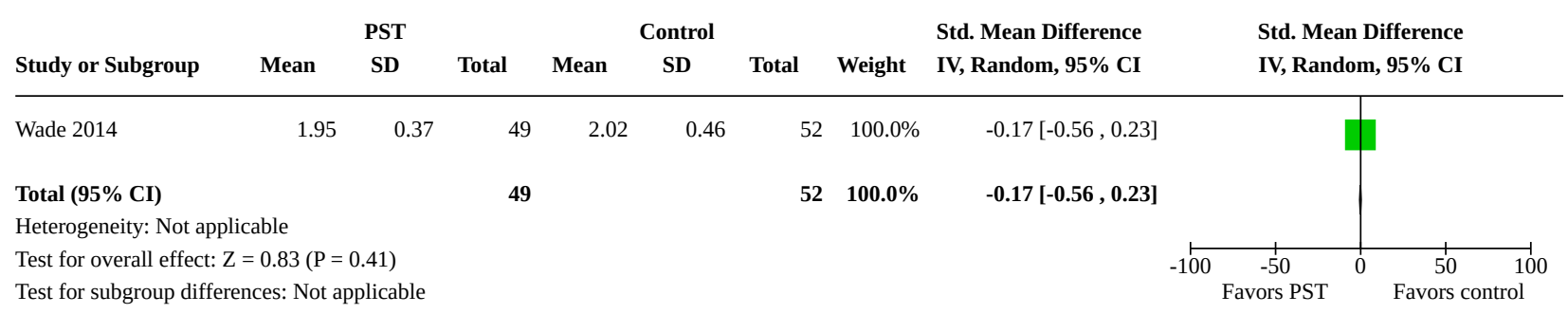




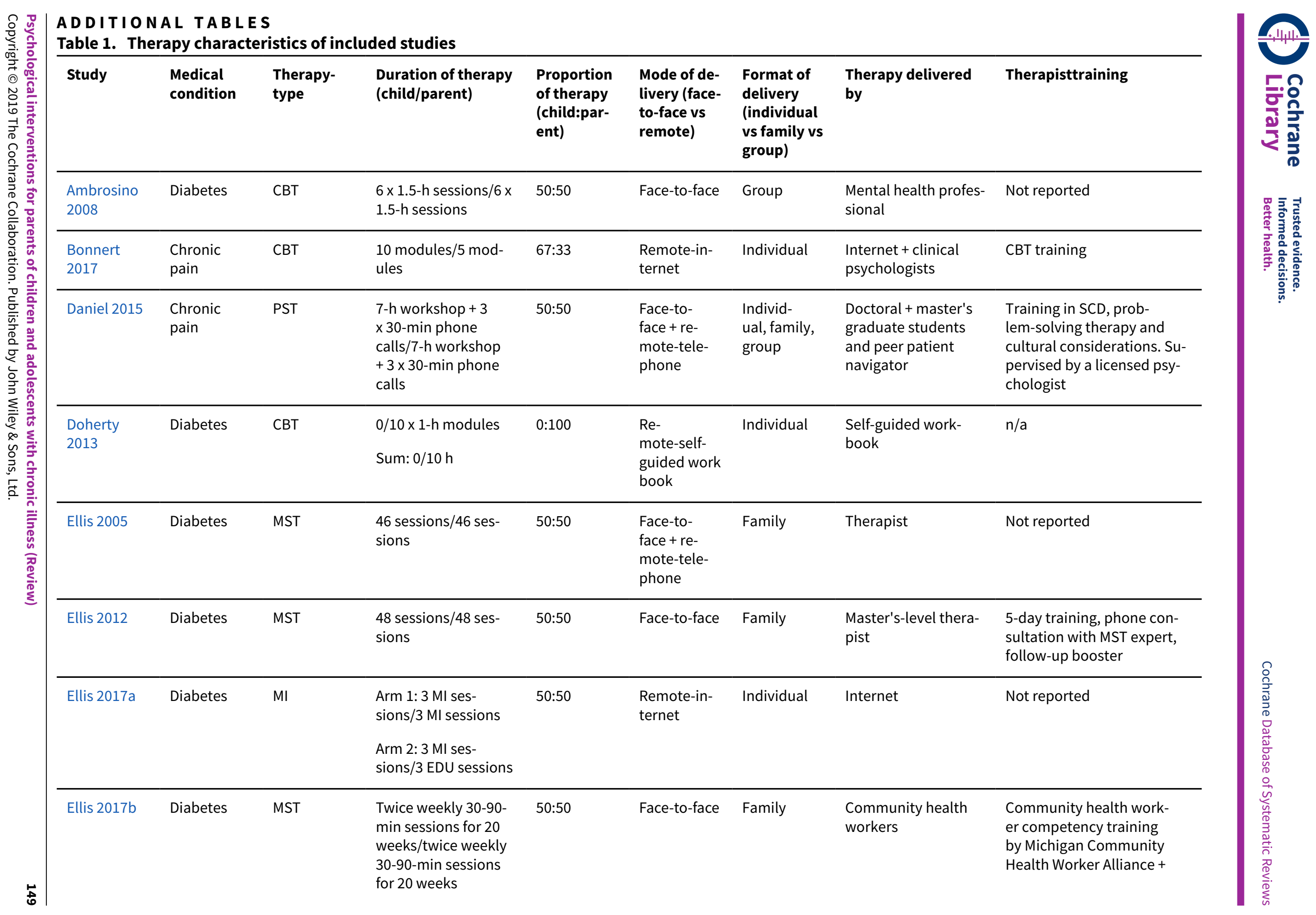




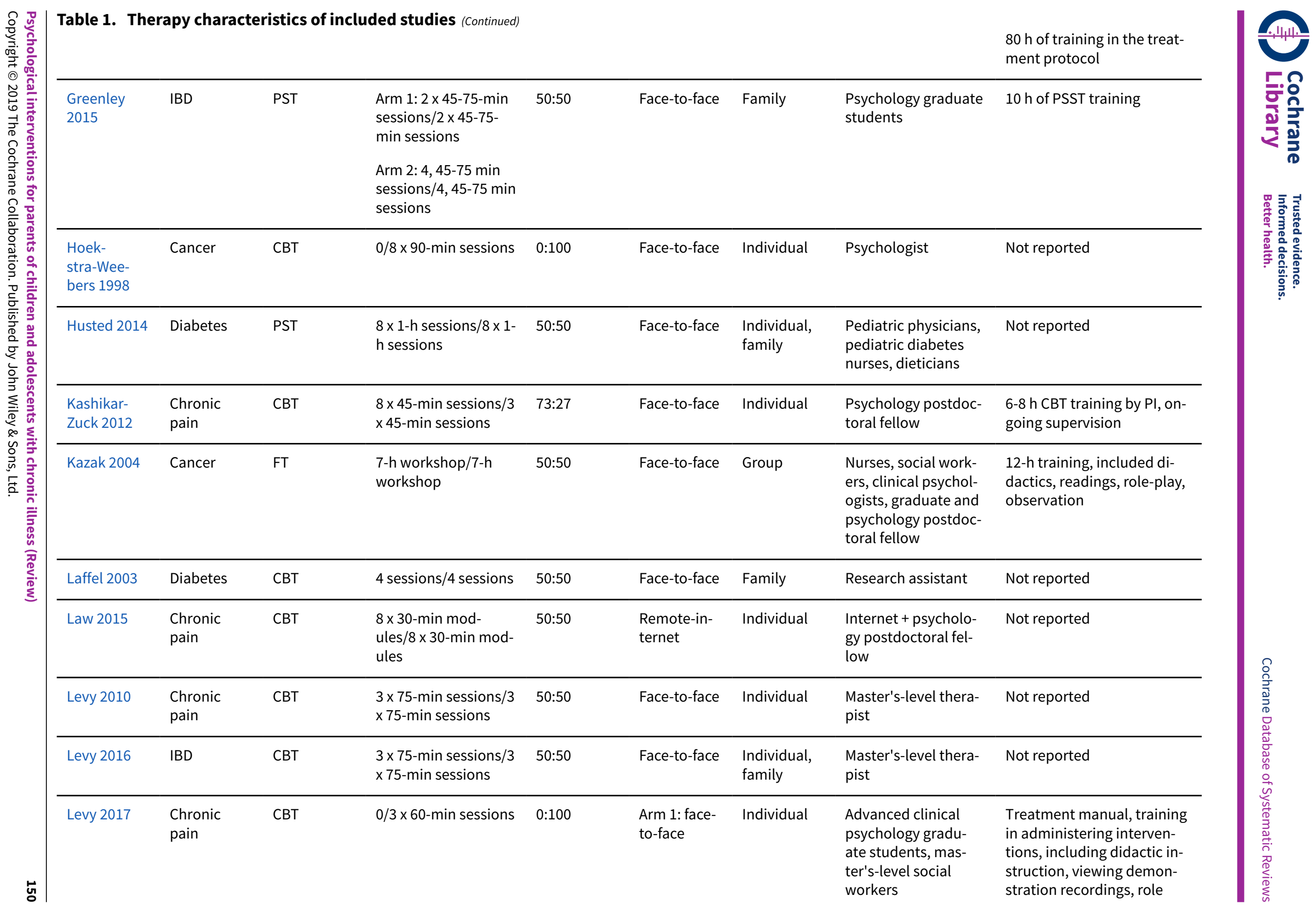




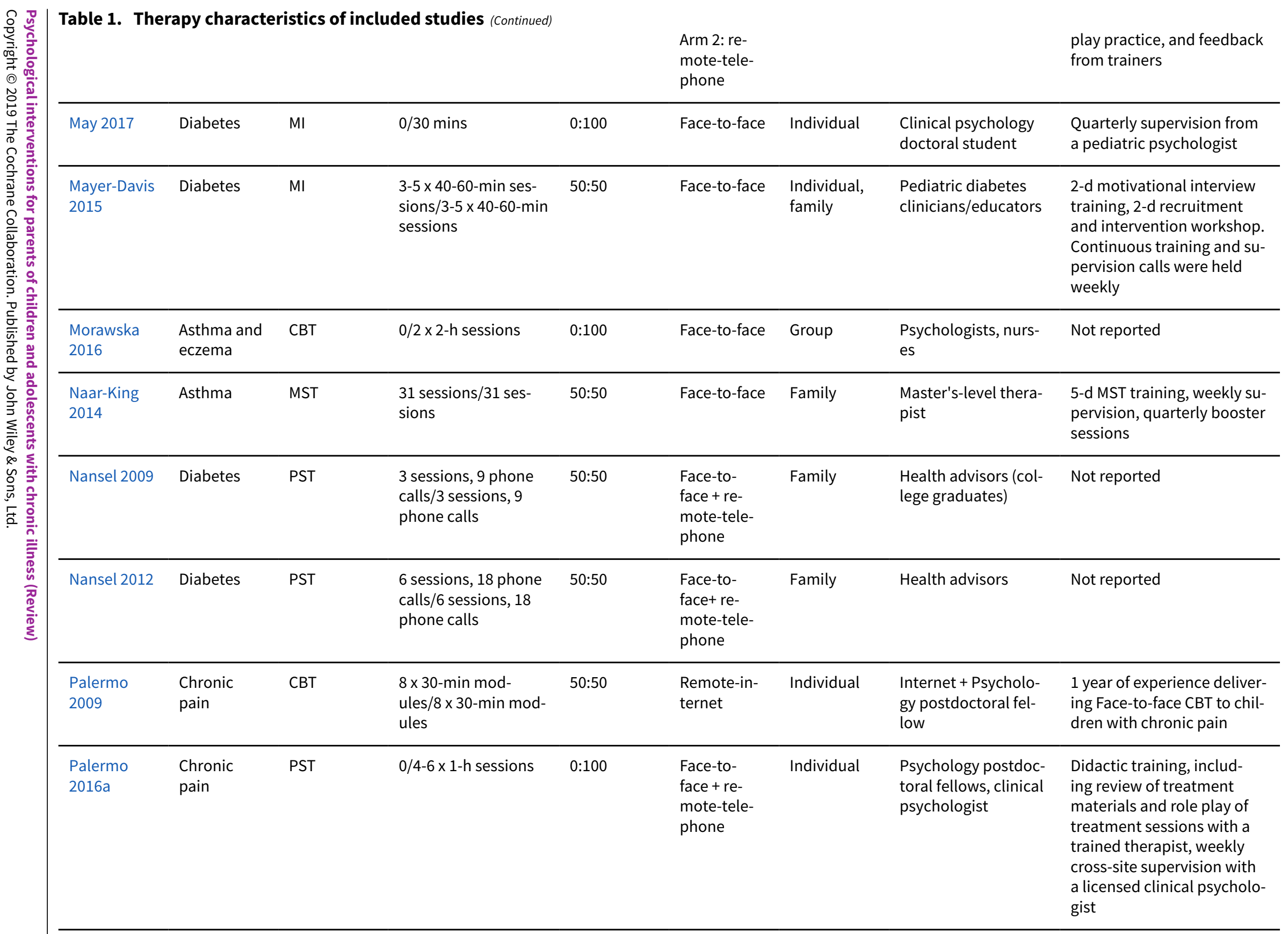




\begin{tabular}{|c|c|c|c|c|c|c|c|c|}
\hline $\begin{array}{l}\text { Palermo } \\
2016 b\end{array}$ & $\begin{array}{l}\text { Chronic } \\
\text { pain }\end{array}$ & CBT & $\begin{array}{l}8 \times 30-\text { min mod- } \\
\text { ules } / 8 \times 30-\text { min mod- } \\
\text { ules }\end{array}$ & $50: 50$ & $\begin{array}{l}\text { Remote-in- } \\
\text { ternet }\end{array}$ & Individual & $\begin{array}{l}\text { Internet + master's } \\
\text { degree- or PhD-level } \\
\text { psychology postdoc- } \\
\text { toral fellow }\end{array}$ & $\begin{array}{l}\text { Online coach manual + stan- } \\
\text { dard series training tasks in- } \\
\text { cluding readings, role play, } \\
\text { and supervision by first au- } \\
\text { thor }\end{array}$ \\
\hline Powers 2013 & $\begin{array}{l}\text { Chronic } \\
\text { pain }\end{array}$ & CBT & $\begin{array}{l}8 \times 1-h \text { sessions }+5 \\
\text { booster sessions } / 3 \\
\times 1-h \text { sessions }+5 \\
\text { booster sessions }\end{array}$ & $73: 27$ & Face-to-face & Individual & $\begin{array}{l}\text { Postdoctoral psy- } \\
\text { chology fellows }\end{array}$ & $\begin{array}{l}\text { Trained and supervised by } \\
\text { a licensed clinical psycholo- } \\
\text { gist with specialized experi- } \\
\text { ence in pain management }\end{array}$ \\
\hline Robins 2005 & $\begin{array}{l}\text { Chronic } \\
\text { pain }\end{array}$ & CBT & $\begin{array}{l}5 \times 40 \text {-min sessions } / 3 \\
\times 40 \text {-min sessions }\end{array}$ & $63: 37$ & Face-to-face & Individual & $\begin{array}{l}\text { Pre-doctoral psy- } \\
\text { chology intern, post- } \\
\text { doctoral psychology } \\
\text { fellow }\end{array}$ & Not reported \\
\hline Sahler 2002 & Cancer & PST & $0 / 8 \times 1$-h sessions & $0: 100$ & $\begin{array}{l}\text { Face-to- } \\
\text { face+ re- } \\
\text { mote-tele- } \\
\text { phone }\end{array}$ & Individual & $\begin{array}{l}\text { Master's-level thera- } \\
\text { pist, psychology doc- } \\
\text { toral candidate }\end{array}$ & $\begin{array}{l}\text { 3-d workshop, regular su- } \\
\text { pervision }\end{array}$ \\
\hline Sahler 2005 & Cancer & PST & $0 / 8 \times 1$-h sessions & $0: 100$ & Face-to-face & Individual & Not reported & Not reported \\
\hline Sahler 2013 & Cancer & PST & $0 / 8 \times 1$-h sessions & $0: 100$ & Face-to-face & Individual & $\begin{array}{l}\text { Psychology graduate } \\
\text { students }\end{array}$ & $\begin{array}{l}\text { Group training, weekly indi- } \\
\text { vidual supervision }\end{array}$ \\
\hline $\begin{array}{l}\text { Sanders } \\
1994\end{array}$ & $\begin{array}{l}\text { Chronic } \\
\text { pain }\end{array}$ & CBT & $\begin{array}{l}6 \times 50 \text {-min sessions } / 6 \\
\times 50 \text {-min sessions }\end{array}$ & $50: 50$ & Face-to-face & Individual & $\begin{array}{l}\text { Clinical psycholo- } \\
\text { gists }\end{array}$ & Not reported \\
\hline Seid 2010 & Asthma & PST & $\begin{array}{l}11 \times 60-\text { min ses- } \\
\text { sions } / 11 \text { x 60-min } \\
\text { sessions }\end{array}$ & $50: 50$ & Face-to-face & Family & $\begin{array}{l}\text { Master's-level health } \\
\text { educator }\end{array}$ & $\begin{array}{l}\text { 2-week training including } \\
\text { didactics, role play, obser- } \\
\text { vation. Weekly supervision }\end{array}$ \\
\hline Stark 2005 & $\begin{array}{l}\text { Chronic } \\
\text { pain }\end{array}$ & $\mathrm{BI}$ & $\begin{array}{l}4 \times 90 \text {-min sessions } / 4 \\
x \\
90 \text {-min sessions }\end{array}$ & $50: 50$ & Face-to-face & Group & $\begin{array}{l}\text { Parents: PhD psy- } \\
\text { chologist. } \\
\text { Children: postdoc- } \\
\text { toral fellow, research } \\
\text { assistant }\end{array}$ & $\begin{array}{l}\text { Review of treatment materi- } \\
\text { als, role play, weekly super- } \\
\text { vision }\end{array}$ \\
\hline Stehl 2009 & Cancer & CBT & $\begin{array}{l}0 / 3 \times 45 \text {-min sessions } \\
+3 \text { boosters }\end{array}$ & $0: 100$ & $\begin{array}{l}\text { Face-to- } \\
\text { face + Re- } \\
\text { mote-CD- }\end{array}$ & Individual & $\begin{array}{l}\text { Psychology fellows, } \\
\text { psychology intern, } \\
\text { master's-level psy- }\end{array}$ & $\begin{array}{l}18 \mathrm{~h} \text { of didactic and experi- } \\
\text { ential training, weekly su- } \\
\text { pervision }\end{array}$ \\
\hline
\end{tabular}




\begin{tabular}{|c|c|c|c|c|c|c|c|c|}
\hline & & & & & $\begin{array}{l}\text { ROM + tele- } \\
\text { phone }\end{array}$ & & $\begin{array}{l}\text { chologist, doctor- } \\
\text { al-level nurse }\end{array}$ & \\
\hline Tsitsi 2017 & Cancer & CBT & $\begin{array}{l}0 / 3 \times 25 \text {-min sessions } \\
+3 \text { weeks of daily } \\
\text { practice }\end{array}$ & $0: 100$ & Remote-CD & Individual & $\begin{array}{l}\text { Digital media player } \\
+ \text { research assistant }\end{array}$ & Not reported \\
\hline Wade 2006a & $\mathrm{TBI}$ & PST & $\begin{array}{l}\text { 8-14 modules + video } \\
\text { conferences/8-14 } \\
\text { modules + video con- } \\
\text { ferences }\end{array}$ & $50: 50$ & $\begin{array}{l}\text { Remote-in- } \\
\text { ternet }+ \\
\text { teleconfer- } \\
\text { ence }\end{array}$ & Family & $\begin{array}{l}\text { Internet + clinical } \\
\text { psychology graduate } \\
\text { student }\end{array}$ & $\begin{array}{l}\text { 2-month } \\
\text { training, weekly supervi- } \\
\text { sion, treatment manual }\end{array}$ \\
\hline Wade 2014 & TBI & PST & $\begin{array}{l}8-12 \text { modules }+ \\
6 \text { video confer- } \\
\text { ences } / 8-12 \text { mod- } \\
\text { ules }+6 \text { video confer- } \\
\text { ences }\end{array}$ & $50: 50$ & $\begin{array}{l}\text { Remote-in- } \\
\text { ternet + } \\
\text { videocon- } \\
\text { ference }\end{array}$ & Family & $\begin{array}{l}\text { Internet + clinical } \\
\text { psychologists }\end{array}$ & Not reported \\
\hline Wade 2017 & $\mathrm{TBI}$ & CBT & $\begin{array}{l}\text { I-InTERACT Program } \\
=10-14 \text { modules, } \\
\text { weekly video confer- } \\
\text { ence } \\
\text { I-InTERACT Express } \\
=7 \text { modules, weekly } \\
\text { video conference }\end{array}$ & $50: 50$ & $\begin{array}{l}\text { Remote-in- } \\
\text { ternet }+ \\
\text { videocon- } \\
\text { ference }\end{array}$ & Individual & $\begin{array}{l}\text { Licensed psychol- } \\
\text { ogists, postdoctor- } \\
\text { al fellow, advanced } \\
\text { clinical psychology } \\
\text { graduate students }\end{array}$ & $\begin{array}{l}\text { Treatment manual }+3-d \\
\text { training, weekly supervision } \\
\text { and fidelity checklists }\end{array}$ \\
\hline $\begin{array}{l}\text { Westrupp } \\
2015\end{array}$ & Diabetes & CBT & $0 / 10 \times 1$-h sessions & $0: 100$ & Face-to-face & Individual & Clinical psychologist & Not reported \\
\hline $\begin{array}{l}\text { Wysocki } \\
1999\end{array}$ & Diabetes & FT & $\begin{array}{l}10 \text { sessions/10 ses- } \\
\text { sions }\end{array}$ & $50: 50$ & Face-to-face & Family & Clinical psychologist & Not reported \\
\hline $\begin{array}{l}\text { Wysocki } \\
2006\end{array}$ & Diabetes & FT & $\begin{array}{l}12 \text { sessions/12 ses- } \\
\text { sions }\end{array}$ & $50: 50$ & Face-to-face & Family & $\begin{array}{l}\text { Clinical psychologist, } \\
\text { social worker }\end{array}$ & Not reported \\
\hline Yeh 2016 & Asthma & FT & $\begin{array}{l}4 \times 50 \text {-min sessions } / 4 \\
\times 50 \text {-min sessions }\end{array}$ & $50: 50$ & Face-to-face & Family & Not reported & Not reported \\
\hline
\end{tabular}

BI: Behavioral intervention; CBT: cognitive-behavioural therapy; FT: family therapy; MI: Motivational Interviewing; MST: multisystemic therapy; PI: principal investigator; PSST: problem-solving skills training; PST: problem-solving therapy; TBI: traumatic brain injury 
Table 2. Intervention content and therapy classification of included studies

\begin{tabular}{ll}
\hline Author & Therapy summary \\
\hline Ambrosino 2008 & $\begin{array}{l}\text { Coping skills training. Parents and children received training in communi- } \\
\text { cation skills, social problem solving, recognizing links between thoughts/ } \\
\text { feelings/behaviors, stress management and conflict resolution. The focus of } \\
\text { this intervention was to improve participants' general ability to manage daily } \\
\text { problems, and did not directly address diabetes management }\end{array}$
\end{tabular}

Therapy type

CBT

Bonnert 2017 Exposure-based internet-CBT. Using an internet program, families received

Chronic pain training in using exposure exercises to reduce symptom-fear and avoidance (e.g. eating symptom-provoking foods and avoiding symptom-reducing behavior, rest). Parent modules focused on operant training, communication skills, problem solving, and relapse prevention. Children received psychoeducation and training in exposure exercises

Daniel 2015

Doherty 2013

Diabetes
Families Taking Control. Using a full-day (7-h) weekend workshop at the hospital for children, their primary parents, and school-age siblings. The intervention was based on a problem-solving framework. Families received psychoeducation, an introduction of the problem-solving model, and goal identification. Parents and children received training in applying problem-solving to school challenges. Following the workshop, families had 3 booster phone call sessions to support skills implementation
Triple P Positive Parenting Program. Using a self-directed workbook, parents received training in goal setting, using behavioral contracts to increase desirable behavior and manage problem behavior, monitoring effectiveness of behavior plans and amending where necessary, strategies for dealing with risky behavior, and maintenance planning. A tip sheet was also provided, which illustrated application of workbook skills to address common challenges among families of children with diabetes
PST

MT. Families received an intensive, family- and community-based interven tion designed to target problems related to adherence to diabetes treatment across the multiple systems within which the child and their family operated. A variety of psychological interventions were employed depending on individual need, including CBT, parent training and behavioral family systems therapy

\section{Ellis 2012}

Diabetes
MST. Families received an intensive, family-centered, community-based intervention designed for adolescents with poor-self management of diabetes. Parent intervention included education about diabetes care, operant training, and communication skills training. Peer intervention included enlisting the support of peers to support regimen adherence. School interventions included problem solving with school personnel to monitor, support and communicate with the family regarding the adolescent's diabetes care and regimen adherence. Strategies were also developed to support the adolescent's regimen adherence in community settings, and to promote a positive working relationship with healthcare providers. Adolescent interventions focused on improving diabetes care skills and increasing motivation for completing diabetes care
MST ing using CIAS, a flexible internet-based interactive software that delivers mo-

Ellis 2017a

Diabetes tivational content via a life-like animated narrator that speaks, moves, points, and displays emotional responses as appropriate. The parent intervention included 4 strategies: 1) Engagement via the narrator's communication of empathy and optimism, 2) Focusing the parent on the potential value of parental monitoring of diabetes via psychoeducation, 3) Evoking change talk and commitment language by eliciting the parent's views regarding monitoring diabetes care, and 4) Planning through optional goal setting activities. The ado- 
Table 2. Intervention content and therapy classification of included studies (Continued)

lescent intervention mirrored the parent intervention with content that was focused on motivating the adolescent to complete their own diabetes management

Ellis 2017b

Diabetes
REACH for Control. Parents and children received motivational interviewing using CIAS, a flexible internet-based interactive software that delivers motivational content via a life-like animated narrator that speaks, moves, points, and displays emotional responses as appropriate. The parent intervention included four strategies: 1) engagement via the narrator's communication of empathy and optimism; 2) focusing the parent on the potential value of parental monitoring of diabetes via psychoeducation; 3) evoking change talk and commitment language by eliciting the parent's views regarding monitoring diabetes care; and 4) planning through optional goal-setting activities. The adolescent intervention mirrored the parent intervention with content that was focused on motivating the adolescent to complete their own diabetes management
MST

PST to address adherence barriers. PSST skills included developing a positive problem outlook, formulating a clear and specific problem definition, brainstorming possible solutions, choosing the best solution, and formulating a solution implementation plan

\section{Hoekstra-Weebers 1998 Intervention program for parents of pediatric cancer patients. Parents re- ceived education regarding the potential impact of the child's illness on the Cancer child and family as well as training in emotional expression, cognitive restruc- turing, problem-focused coping skills, communication and assertiveness skills. Children did not receive any intervention}

$\begin{array}{ll}\text { Husted } 2014 & \begin{array}{l}\text { Guided self-determination-youth. Children and parents received training in } \\ \text { shared decision-making and mutual, dynamic problem solving }\end{array} \\ \text { Diabetes } & \text { shing }\end{array}$
version of the Coping Skills Training program evaluated in Kashikar-Zuck 2005. Parents received operant training with a focus on encouraging independent pain management, maintaining a normal routine, avoiding status checks and increasing their child's use of coping skills learned in the program. Children received education about behavioral pain management as well as training in progressive muscle relaxation, distraction, activity pacing, using self statements, problem solving and relapse prevention strategies

$\begin{array}{ll}\text { Kazak 2004 } & \text { Surviving Cancer Competently Intervention Programme (SCCIP). Families } \\ & \text { received education about the link between thoughts, feelings and behaviors } \\ \text { and training in cognitive restructuring. Families also participated in discussion } \\ \text { groups about the ways cancer has affected their family, recognizing and re- } \\ \text { sponding to distress in other family members, and acknowledging and accept- } \\ \text { ing their cancer experience }\end{array}$

Laffel 2003

Diabetes
Teamwork intervention. Parents and children received training in communicating about diabetes and sharing blood glucose results with family members, the need for teamwork between parents and children in diabetes management during adolescence, managing family members' responses to the child's blood glucose levels, sharing diabetes management with family members, and using a diary to help problem solve high and low blood glucose levels 
Table 2. Intervention content and therapy classification of included studies (Continued) Chronic pain

\begin{tabular}{ll}
\hline Levy 2010 & Social learning and cognitive-behavioural therapy. Children and parents re- \\
ceived pain education in addition training in deep breathing, progressive mus- \\
cle relaxation, imagery, operant strategies, cognitive restructuring and relapse \\
prevention strategies
\end{tabular}

Levy 2016

IBD

Levy 2017
Chronic pain

Social learning and CBT. Children and parents received instruction in cognitive-behavioural coping strategies of relaxation, stress management, and cognitive restructuring. Parents received training in operant strategies
CBT

CBT

Social learning and CBT. Parents received training in cognitive restructuring operant training, and skills maintenance strategies. Children did not receive any intervention. Treatment was delivered in person or via telephone

\begin{tabular}{ll}
\hline May 2017 & Feedback intervention. Parents received in vivo observation of communica- \\
tion skills while discussing a problem in diabetes care with their child. Using \\
motivational interviewing, the interventionist provided individualized feed- \\
back to parents on their use of person-centered communication skills
\end{tabular}

Mayer-Davis 2015

Diabetes

Flexible Lifestyles for Youth intervention (FL3X). Families received an intervention that is framed through $\mathrm{MI}$ and includes training in problem-solving and elements of behavioral family systems therapy

\begin{abstract}
Morawska 2016
Asthma and eczema

Positive Parenting for Healthy Living. Parents received training in strategies to prevent and manage problem behaviors and ensure that medical recommendations were implemented appropriately. Topics included continuing regular activities, having realistic expectations, reducing stress, helping siblings cope, condition-specific management steps, involving the child, communicating with parents, keeping track of symptoms, being prepared for emergencies, causes of behavior problems in children with chronic illness, and operant training. Children did not receive any intervention
\end{abstract}

MI

MI

Naar-King $2014 \quad$ Multisystemic therapy adapted for health care settings (MST-HC). Adolescents received training in asthma education. Parents received operant train-

Asthma ing, communication skills training, and problem solving to develop family routines around the adolescent's asthma care. School interventions included strategies to support communication between the family and the school and increasing accessibility of medications to youths while in school. Strategies were also developed to support a positive relationship between the family and healthcare providers

\begin{tabular}{ll}
\hline Nansel 2009 & WE`CAN Intervention. Parents and children jointly selected a goal for the \\
child's diabetes management and developed a plan to address this problem \\
Diabetes \\
using the WE*CAN process: W - work together to set goals, E - explore possible \\
barriers and solutions, $\mathrm{C}$ - choose the best solutions, $\mathrm{A}$ - act on your plan, $\mathrm{N}$ - \\
note the results
\end{tabular}

Diabetes

Palermo 2009
Chronic pain

\begin{abstract}
Web-based Management of Adolescent Pain (Web-MAP). Using an internet program, parents received education about chronic pain and training in recognizing stress and negative emotions, operant strategies, modeling, sleep hygiene and lifestyle, communication and relapse prevention. Children received education about chronic pain and training in recognizing stress and negative emotions, deep breathing and relaxation, distraction, cognitive skills, sleep hygiene and lifestyle, staying active and relapse prevention
\end{abstract}


Table 2. Intervention content and therapy classification of included studies (Continued)
Palermo 2016a
Problem-solving skills training. This intervention is a modified version of the problem-solving skills training intervention evaluated in Sahler 2002. Parents
Chronic pain condition received problem solving using the Bright IDEAS framework including using a positive problem-solving orientation, problem definition and formulation (Identify the problem), generation of alternative solutions (Determine the op- tions), decision-making (Evaluate options), solution implementation (Act), and verification (See if it worked). Children did not receive any intervention
(Mixed pain conditions)

PST

Web-based Management of Adolescent Pain-2 (Web-MAP2). This intervention is a modified version of the Web-based Management of Adolescent Pain (Web-MAP) intervention evaluated in Palermo 2009. Using an internet program, children and parents received education about chronic pain, training in behavioral and cognitive coping skills, instruction in increasing activity participation and healthy lifestyle habits, and education about pain behaviors and parental operant and communication strategies

\begin{tabular}{ll}
\hline Powers 2013 & CBT intervention. This treatment was based on the CBT intervention evaluat- \\
ed in Kashikar-Zuck 2012, modified to include biofeedback for relaxation train- \\
ing. Children and parents received the intervention
\end{tabular}

Robins 2005 Short-term CBT. Children and parents received education about pain and stress as well as training in deep breathing, imagery, relaxation and operant Chronic pain strategies. Children also received training in tracking the antecedents and consequences of pain episodes and cognitive restructuring
CBT CBT PST framework: Be optimistic about solving problems, Identify the problem, Determine options, Evaluate options and choose one, Act and See if it worked. Children did not receive any intervention

\begin{tabular}{lll}
\hline Sahler 2005 & PSST. See Sahler 2002 & PST \\
Cancer & &
\end{tabular}

\begin{tabular}{lll}
\hline Sahler 2013 & PSST. See Sahler 2002 & PST \\
\hline
\end{tabular}

Cancer

Sanders 1994

Chronic pain

\section{Seid 2010}

Asthma

Problem-solving skills training + care co-ordination. Parents received inhome asthma education, referrals to community resources, co-ordination with medical providers and problem-solving training using the Bright IDEAS framework (see Sahler 2002 above). The intervention targeted caregivers although children were encouraged to participate.
Cognitive-behavioral family intervention. Parents received education about behavioral pain management, operant training and relapse prevention. Children received education about behavioral pain management, muscle relaxation, deep breathing, imagery, cognitive restructuring, distraction and relapse prevention
CBT

PST

BI. Parents received nutrition education and operant training focused on grad-

BI ually increasing their child's calcium intake. Children received nutrition education and participated in a practice meal during each session where operant techniques were used to motivate children to reach their calcium goals during the meal
Surviving Cancer Competently Intervention Programme - newly diagnosed (SCCIP-ND). Parents received education about the link between Stehl 2009 Cancer 
Table 2. Intervention content and therapy classification of included studies (Continued)

cussion of beliefs about the role cancer will play in the family's future. Parents also watched a CD-ROM of other parents of children with cancer discussing their experiences and responses to diagnosis. Children did not receive any intervention

\section{Tsitsi 2017 \\ Cancer \\ Combination of progressive muscle relaxation and guided imagery. Par- ents received training in progressive muscle relaxation and guided imagery. Children did not receive any intervention}

Wade $2006 a$

TBI

Family problem-solving intervention. Using an internet program and teleconferencing, families received training in problem solving, communication, behavior management skills and relapse prevention. Families could also com-

CBT plete supplemental sessions if needed on stress management, working with the school, sibling concerns, anger management, pain management and marital communication

Wade 2014

$\mathrm{TB}$
Wade 2017

$\mathrm{TB}$

$\begin{array}{ll}\text { Westrupp } 2015 & \text { Triple P Positive Parenting. Parents received training in skills designed to } \\ \text { Diabetes } & \text { promote children's competence and development, and in skills to help man- } \\ & \text { age misbehavior. Children did not receive any intervention }\end{array}$

Wysocki 1999

Diabetes

Wysocki 2006

Diabetes
Behavioral Family Systems Therapy (BFST). Families received training in problem-solving skills, communication skills and cognitive restructuring as well as functional and structural family therapy interventions targeting family systems issues that may have interfered with effective problem-solving and communication skills
Behavioral Family Systems Therapy for Diabetes (BFST-D). This interven-
Counselor-Assisted Problem Solving (CAPS). Using a combination of faceto-face, internet program, and videoconferencing, families received training in problem solving using the ABCDE framework (Aim, Brainstorm, Choose, Do it and Evaluate). Families also received communication skills training. Children were taught a self-regulation heuristic (Stop, Monitor, Appraise, Reflect, Try). Optional modules were also available targeting communication skills, parent self-care, social skills, after high school, sibling issues, pain management, sleep, and memory
I-InTERACT Program. I-Interact provided parenting skills training and strategies for behavior management through online modules and videoconferencing meetings with a trained therapist. Skills training included consequence-focused and antecedent behavior management, and psychoeducation about the effects of TBI on child development.

I-InTERACT Express. The express program provided an abbreviated parent training intervention delivered through online modules and videoconferencing with a trained therapist that focused on developing a warm, responsive parent-child relationship and providing consistent discipline
PST

CBT

CBT

$\begin{array}{ll}\text { Yeh } 2016 & \begin{array}{l}\text { Asthma Family Empowerment Program (AFEP). Based on a family systems } \\ \text { approach, AFEP aimed to help families maintain equilibrium by identifying } \\ \text { problems and trying solutions by themselves. Families were provided with ed- }\end{array} \\ \text { Asthma } & \text { proms }\end{array}$
problems and trying solutions by themselves. Families were provided with edtion is a revised version of the BFST intervention evaluated in Wysocki 1999. Families received training in problem solving, communication skills and cognitive restructuring as well as functional and structural family therapy interventions targeting family systems issues related to effective problem solving and communication. Diabetes-specific adaptations included targeting two or more barriers to diabetes management in treatment, training in behavioral contracting, education in how to improve diabetic control based on data from self-monitoring of blood glucose levels, simulation of living with diabetes by parents for 1 week, and involvement of peers/teachers/extended family in treatment as needed 
Table 2. Intervention content and therapy classification of included studies (Continued) ucation about asthma and condition management, support for positive coping behaviors, and resources to help manage the condition. Study therapists encouraged families to address problems themselves, including making decisions for actionable changes and choosing solutions through family discussions

BFST-D: Behavioral Family Systems Therapy for Diabetes; BI: behavioral intervention; CBT: cognitive-behavioural therapy; FT: family therapy; IBS: irritable bowel syndrome; MST: multisystemic therapy; PST: problem-solving therapy; TBI: traumatic brain injury

\section{A P P E N D I C E S}

\section{Appendix 1. Search strategies}

\section{CENTRAL (CRSO)}

\#1 MESH DESCRIPTOR Psychotherapy EXPLODE ALL TREES

\#2 MESH DESCRIPTOR Problem Solving EXPLODE ALL TREES

\#3 psychotherap*:TI,AB,KY

\#4 ((cogniti* or family or behavior ${ }^{\star}$ or behaviour ${ }^{\star}$ or psychological $\left.{ }^{\star}\right)$ adj5 (intervention* or treatment* or therap*)):TI,AB,KY

\#5 ((problem* adj5 solv*)):TI,AB,KY

\#6 CBT:TI,AB,KY

\#7 \#1 OR \#2 OR \#3 OR \#4 OR \#5 OR \#6

\#8 MESH DESCRIPTOR Parents EXPLODE ALL TREES

\#9 MESH DESCRIPTOR Family EXPLODE ALL TREES

\#10 MESH DESCRIPTOR Caregivers

\#11 ((parent ${ }^{\star}$ or mother ${ }^{\star}$ or father ${ }^{\star}$ or family or families or caregiver ${ }^{\star}$ or care-giver $\left.\left.{ }^{\star}\right)\right): \mathrm{TI}, \mathrm{AB}, \mathrm{KY}$

\#12 \#8 OR \#9 OR \#10 OR \#11

\#13 MESH DESCRIPTOR Child EXPLODE ALL TREES

\#14 MESH DESCRIPTOR Infant EXPLODE ALL TREES

\#15 MESH DESCRIPTOR Adolescent EXPLODE ALL TREES

\#16 ((child* or infant $^{\star}$ or adolesc ${ }^{\star}$ or baby or babies or toddler* or teenager ${ }^{\star}$ or youth $\left.\left.{ }^{\star}\right)\right): T I, A B, K Y$

\#17 \#13 OR \#14 OR \#15 OR \#16

\#18 MESH DESCRIPTOR Pain EXPLODE ALL TREES

\#19 MESH DESCRIPTOR Complex Regional Pain Syndromes EXPLODE ALL TREES

\#20 MESH DESCRIPTOR Rheumatic Diseases EXPLODE ALL TREES

\#21 MESH DESCRIPTOR Neoplasms EXPLODE ALL TREES

\#22 MESH DESCRIPTOR Diabetes Mellitus EXPLODE ALL TREES

\#23 MESH DESCRIPTOR Asthma EXPLODE ALL TREES

\#24 MESH DESCRIPTOR Brain Injuries EXPLODE ALL TREES 
\#25 MESH DESCRIPTOR Inflammatory Bowel Diseases EXPLODE ALL TREES

\#26 MESH DESCRIPTOR Anemia, Sickle Cell EXPLODE ALL TREES

\#27 MESH DESCRIPTOR Skin Diseases EXPLODE ALL TREES

\#28 MESH DESCRIPTOR Genital Diseases, Female EXPLODE ALL TREES

\#29 MESH DESCRIPTOR Menstruation Disturbances EXPLODE ALL TREES

\#30 ((pain* or headache*)):TI,AB,KY

\#31 ((rheumat* or arthriti* or fibromyalgia)):TI,AB,KY

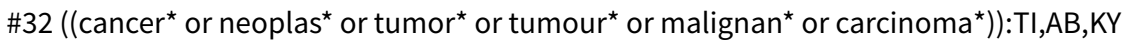

\#33 diabet*:TI,AB,KY

\#34 asthma*:TI,AB,KY

\#35 ((brain adj5 (trauma* or injur $\left.\left.\left.{ }^{\star}\right)\right)\right): \mathrm{TI}, \mathrm{AB}, \mathrm{KY}$

\#36 ((bowel ${ }^{\star}$ adj5 inflammatory adj5 (condition* or disease* or illness $\left.\left.{ }^{\star}\right)\right)$ ):TI,AB, KY

\#37 ((sickle cell adj5 (disease* or disorder ${ }^{\star}$ or anemia*))):TI,AB,KY

\#38 (((skin adj5 (disease* or disorder $\left.\left.{ }^{\star}\right)\right)$ or eczema $\left.\left.{ }^{\star}\right)\right): \mathrm{TI}, \mathrm{AB}, \mathrm{KY}$

\#39 (((gynecologic* or gynaecologic $\left.{ }^{\star}\right)$ adj5 (disease* or disorder $\left.\left.\left.{ }^{\star}\right)\right)\right): \mathrm{TI}, \mathrm{AB}, \mathrm{KY}$

\#40 dysmenorrh*:TI,AB,KY

\#41 endometriosis:TI,AB,KY

\#42 MESH DESCRIPTOR Chronic Disease

\#43 (((chronic* ${ }^{\star}$ or longterm or long-term) adj5 (condition* or ill* or disease $\left.\left.\left.{ }^{\star}\right)\right)\right): T I, A B, K Y$

\#44 \#18 OR \#19 OR \#20 OR \#21 OR \#22 OR \#23 OR \#24 OR \#25 OR \#26 OR \#27 OR \#28 OR \#29 OR \#30 OR \#31 OR \#32 OR \#33 OR \#34 OR \#35 OR \#36 OR \#37 OR \#38 OR \#39 OR \#40 OR \#41 OR \#42 OR \#43

\#45 \#7 AND \#12 AND \#17 AND \#44

\#46 01/07/2014 TO 25/04/2017:CD

\#47 \#45 AND \#46

\section{MEDLINE (OVID)}

1 exp Psychotherapy/

2 Problem Solving/

3 psychotherap ${ }^{\star} \cdot \mathrm{mp}$.

$4\left(\left(\right.\right.$ cogniti $^{\star}$ or family or behavior $^{\star}$ or behaviour $^{\star}$ or psychological $\left.^{\star}\right)$ adj5 (intervention* ${ }^{\star}$ or treatment ${ }^{\star}$ or therap $\left.\left.{ }^{\star}\right)\right) . \mathrm{mp}$

5 (problem adj5 solv*).mp.

6 CBT.mp.

7 or/1-6

8 exp Parents/

9 exp Family/

10 Caregivers/ 
11 (parent $^{\star}$ or mother ${ }^{\star}$ or father ${ }^{\star}$ or family or families or caregiver ${ }^{\star}$ or care-giver $\left.^{\star}\right) . \mathrm{mp}$.

12 or/8-11

13 exp Child/

14 exp Infant/

15 Adolescent/

16 (child $^{\star}$ or infant ${ }^{\star}$ or adolesc ${ }^{\star}$ or baby or babies or toddler ${ }^{\star}$ or teenager ${ }^{\star}$ or youth $\left.{ }^{\star}\right) . \mathrm{mp}$.

17 or/13-16

18 exp Pain/

19 exp Complex Regional Pain Syndromes/

20 exp Rheumatic Diseases/

21 exp Neoplasms/

22 exp Diabetes Mellitus/

23 exp Asthma/

24 exp Brain Injuries/

25 exp Inflammatory Bowel Diseases/

26 exp Anemia, Sickle Cell/

27 exp Skin Diseases/

28 exp Genital Diseases, Female/

29 exp menstruation disturbances/

30 (pain* or headache $^{\star}$ ).mp.

31 (rheumat* or arthriti* or fibromyalgia).mp.

32 (cancer* or neoplas ${ }^{\star}$ or tumor ${ }^{\star}$ or tumour ${ }^{\star}$ or malignan* or carcinoma $\left.^{\star}\right)$.mp.

33 diabet $^{\star} . \mathrm{mp}$.

34 asthma*.mp.

35 (brain adj5 (trauma* or injur $\left.\left.{ }^{\star}\right)\right) \cdot m p$.

36 (bowel $^{\star}$ adj5 inflammatory adj5 (condition* or disease* or illness*)).mp.

37 (sickle cell adj5 (disease* or disorder* or anemia*)).mp.

38 ((skin adj5 (disease* or disorder $\left.\left.{ }^{\star}\right)\right)$ or eczema*).mp.

39 ((gynecologic ${ }^{\star}$ or gynaecologic $\left.{ }^{\star}\right) \operatorname{adj} 5$ (disease* or disorder $\left.\left.{ }^{\star}\right)\right) . \mathrm{mp}$.

40 dysmenorrh*.mp.

41 endometriosis.mp.

42 Chronic Disease/

43 ((chronic* or longterm or long-term) adj5 (condition* or ill* or disease*)).mp.

44 or/18-43

45 randomized controlled trial.pt.

Psychological interventions for parents of children and adolescents with chronic illness (Review) 
46 controlled clinical trial.pt.

47 randomized.ab.

48 placebo.ab.

49 drug therapy.fs.

50 randomly.ab.

51 trial.ab.

52 groups.ab.

5345 or 46 or 47 or 48 or 49 or 50 or 51 or 52

54 exp animals/ not humans.sh.

5553 not 54

567 and 12 and 17 and 44 and 55

$57\left(201203^{\star}\right.$ or $201204^{\star}$ or $201205^{\star}$ or $201206^{\star}$ or $201207^{\star}$ or $201208^{\star}$ or $201209^{\star}$ or $201210^{\star}$ or $201011^{\star}$ or $201212^{\star}$ or $2013^{\star}$ or $\left.2014^{\star}\right) . e d$.

5856 and 57

\section{Embase (OVID)}

1 exp Psychotherapy/

2 Problem Solving/

3 psychotherap ${ }^{\star} . \mathrm{mp}$.

$4\left(\left(\right.\right.$ cogniti $^{\star}$ or family or behavior ${ }^{\star}$ or behaviour ${ }^{\star}$ or psychological $\left.{ }^{\star}\right)$ adj5 (intervention* or treatment $^{\star}$ or therap $\left.\left.^{\star}\right)\right) . \mathrm{mp}$

5 (problem adj5 solv*).mp.

6 CBT.mp.

7 or/1-6

8 exp Parents/

9 exp Family/

10 Caregivers/

11 (parent $^{\star}$ or mother ${ }^{\star}$ or father $^{\star}$ or family or families or caregiver ${ }^{\star}$ or care-giver ${ }^{\star}$ ).mp.

12 or/8-11

$13 \exp$ Child/

14 exp Infant/

15 Adolescent/

16 (child $^{\star}$ or infant $^{\star}$ or adolesc ${ }^{\star}$ or baby or babies or toddler ${ }^{\star}$ or teenager ${ }^{\star}$ or youth $\left.{ }^{\star}\right) . \mathrm{mp}$.

17 or $/ 13-16$

18 exp Pain/

19 exp Complex Regional Pain Syndromes/

20 exp Rheumatic Diseases/

21 exp Neoplasms/

Psychological interventions for parents of children and adolescents with chronic illness (Review) 
22 exp Diabetes Mellitus/

23 exp Asthma/

24 exp Brain Injuries/

25 exp Inflammatory Bowel Diseases/

26 exp Anemia, Sickle Cell/

27 exp Skin Diseases/

28 exp Genital Diseases, Female/

29 exp menstruation disturbances/

30 (pain* or headache $\left.^{\star}\right) \cdot \mathrm{mp}$.

31 (rheumat* ${ }^{\star}$ or arthriti* or fibromyalgia).mp.

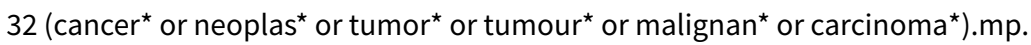

33 diabet $^{\star} . \mathrm{mp}$.

34 asthma*.mp.

35 (brain adj5 (trauma* or injur $\left.\left.{ }^{\star}\right)\right) . m p$.

36 (bowel $^{\star}$ adj5 inflammatory adj5 (condition* or disease* or illness $\left.{ }^{\star}\right)$ ).mp.

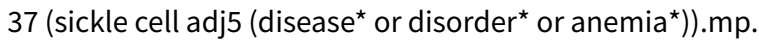

38 ((skin adj5 (disease* or disorder $\left.\left.{ }^{\star}\right)\right)$ or eczema*).mp.

39 ((gynecologic ${ }^{\star}$ or gynaecologic $\left.{ }^{\star}\right)$ adj5 (disease* or disorder $\left.\left.{ }^{\star}\right)\right) . m p$.

40 dysmenorrh*.mp.

41 endometriosis.mp.

42 Chronic Disease/

43 ((chronic* or longterm or long-term) adj5 (condition* or ill or disease*)).mp.

44 or/18-43

45 random\$.tw.

46 factorial\$.tw.

47 crossover\$.tw.

48 cross over\$.tw.

49 cross-over\$.tw.

50 placebo\$.tw.

51 (doubl\$ adj blind\$).tw.

52 (singl\$ adj blind\$).tw.

53 assign\$.tw.

54 allocat\$়.tw.

55 volunteer\$.tw.

56 Crossover Procedure/

Psychological interventions for parents of children and adolescents with chronic illness (Review) 
57 double-blind procedure.tw.

58 Randomized Controlled Trial/

59 Single Blind Procedure/

60 or/45-59

61 (animal/ or nonhuman/) not human/

6260 not 61

637 and 12 and 17 and 44 and 62

$64\left(201203^{\star}\right.$ or $201204^{\star}$ or $201205^{\star}$ or $201206^{\star}$ or $201207^{\star}$ or $201208^{\star}$ or $201209^{\star}$ or $201210^{\star}$ or $201011^{\star}$ or $201212^{\star}$ or $2013^{\star}$ or $\left.2014^{\star}\right) . \mathrm{dd}^{\circ}$

6563 and 64

66 limit 65 to embase

\section{PsycINFO (OVID)}

1 exp Psychotherapy/

2 Problem Solving/

3 psychotherap ${ }^{\star} . \mathrm{mp}$.

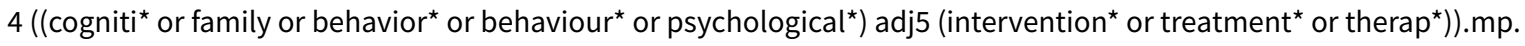

5 (problem adj5 solv*).mp.

6 CBT.mp.

7 or $/ 1-6$

8 exp Parents/

9 exp Family/

10 Caregivers/

11 (parent $^{\star}$ or mother $^{\star}$ or father ${ }^{\star}$ or family or families or caregiver ${ }^{\star}$ or care-giver ${ }^{\star}$ ).mp.

12 or/8-11

13 (child $^{\star}$ or infant ${ }^{\star}$ or adolesc ${ }^{\star}$ or baby or babies or toddler ${ }^{\star}$ or teenager ${ }^{\star}$ or youth ${ }^{\star}$ ).mp.

14 exp Pain/

15 exp Rheumatoid Arthritis/

16 exp Neoplasms/

17 exp Diabetes Mellitus/

18 exp Asthma/

19 exp traumatic brain injury/

20 exp Sickle Cell Disease/

21 exp skin disorders/

22 exp gynecological disorders/

23 (pain* or headache $^{\star}$ ).mp.

24 (rheumat* ${ }^{\star}$ or arthriti* or fibromyalgia).mp.

Psychological interventions for parents of children and adolescents with chronic illness (Review) 
25 (cancer $^{\star}$ or neoplas ${ }^{\star}$ or tumor ${ }^{\star}$ or tumour ${ }^{\star}$ or malignan ${ }^{\star}$ or carcinoma* $) . m p$.

26 diabet $^{\star} . \mathrm{mp}$.

27 asthma*.mp.

28 (brain adj5 (trauma* or injur $\left.\left.{ }^{\star}\right)\right) \cdot \mathrm{mp}$.

29 (bowel $^{\star}$ adj5 inflammatory adj5 (condition* or disease* or illness $\left.{ }^{\star}\right)$ ).mp.

30 (sickle cell adj5 (disease* or disorder $^{\star}$ or anemia*)).mp.

31 ((skin adj5 (disease* or disorder $\left.\left.^{\star}\right)\right)$ or eczema*).mp.

$32\left(\left(\right.\right.$ gynecologic $^{\star}$ or gynaecologic $\left.{ }^{\star}\right) \operatorname{adj5}\left(\right.$ disease $^{\star}$ or disorder $\left.\left.{ }^{\star}\right)\right) . \mathrm{mp}$.

33 dysmenorrh*.mp.

34 endometriosis.mp.

35 ((chronic* or longterm or long-term) adj5 (condition* or ill* or disease*)).mp.

36 or/14-35

377 and 12 and 13 and 36

\section{8 clinical trials/}

39 (randomis* or randomiz ${ }^{\star}$.tw.

40 (random\$ adj3 (allocat\$ or assign\$)).tw.

41 ((clinic\$ or control\$) adj trial\$).tw.

42 ((singl\$ or doubl\$ or trebl\$ or tripl\$) adj3 (blind\$ or mask\$)).tw.

43 (crossover\$ or "cross over\$").tw.

44 random sampling/

45 Experiment Controls/

46 Placebo/

47 placebo\$.tw.

48 exp program evaluation/

49 treatment effectiveness evaluation/

50 ((effectiveness or evaluat\$) adj3 (stud\$ or research\$)).tw.

51 or/38-50

5237 and 51

53 limit 52 to yr="2014 -Current"

\section{Appendix 2. Search results $(2012,2014)$}

2012 search results: we conducted the initial search from inception to June 2012. We extracted a total of 114 papers to identify whether they met the full inclusion criteria; we found 107 papers in the initial search, and a further 7 studies later in an updated search before publication. Of these 114 papers, we found 99 from the search of databases, 6 papers from the citation search, 4 papers from reference searches and 5 papers from authors of included studies. We deemed 35 studies (45 papers) to meet the inclusion criteria for the review, whilst we excluded 61 studies (69 papers).

2014 search results: the updated search identified studies from March 2012 to July 2014 . We identified 418 abstracts in the database search and we read these for inclusion; we excluded 376 . We identified 16 papers in the updated search that met the inclusion criteria, 3 of 
which we identified as follow-up papers of already included studies. Therefore, we included 13 new studies in this update, adding to the 35 previously included studies. We excluded one previously included study (Grey 2011), as it combined data with another study already included in this review and would inflate the results if included. Therefore, in total there were 60 included papers and 47 included studies.

\section{WHAT'S NEW}

\begin{tabular}{lll}
\hline Date & Event & Description \\
\hline 14 June 2021 & Review declared as stable & Stabilised until 2023. See Published notes. \\
\hline
\end{tabular}

\section{H I S T O R Y}

Protocol first published: Issue 2, 2012

Review first published: Issue 8, 2012

\begin{tabular}{|c|c|c|}
\hline Date & Event & Description \\
\hline 30 September 2019 & Amended & Clarification added to Declarations of interest. \\
\hline 9 April 2019 & Amended & $\begin{array}{l}\text { Comma deleted in ongoing study reference (Ellis 2017b) and au- } \\
\text { thor Carcone formatted correctly in Ellis 2017a. }\end{array}$ \\
\hline 8 September 2018 & $\begin{array}{l}\text { New citation required and conclusions } \\
\text { have changed }\end{array}$ & $\begin{array}{l}\text { Eligibility criteria were changed so that only studies with more } \\
\text { than } 20 \text { participants per treatment arm post-treatment were in- } \\
\text { cluded. We added } 21 \text { new studies and removed } 23 \text { studies with } \\
\text { fewer than } 20 \text { participants. There is now a total of } 44 \text { studies } \\
\text { with } 4697 \text { participants at post-treatment. Our conclusions have } \\
\text { changed from the last update in } 2015 \text {. }\end{array}$ \\
\hline 8 September 2018 & New search has been performed & We conducted an updated search from July 2014 to July 2018. \\
\hline 1 July 2014 & $\begin{array}{l}\text { New citation required but conclusions } \\
\text { have not changed }\end{array}$ & $\begin{array}{l}\text { Conclusions of the review have not altered from the original } \\
\text { version in } 2012 \text {. Three 'Summary of findings' tables have been } \\
\text { added for this review. }\end{array}$ \\
\hline 1 July 2014 & New search has been performed & $\begin{array}{l}\text { An updated search from March } 2012 \text { to July } 2014 \text { was conducted } \\
\text { and } 13 \text { new studies were added to the review. }\end{array}$ \\
\hline
\end{tabular}

\section{CONTRIBUTIONS OF AUTHORS}

EL oversaw authoring of the manuscript, was responsible for the methodology, obtained studies, searched reference lists, selected studies for inclusion, extracted data, entered data into Review Manager 5 (RevMan 5; Review Manager 2014), interpreted the analyses, drafted the review, and will update the review in the future.

EF obtained studies, searched reference lists, selected studies for inclusion, extracted data and entered data into RevMan 5, interpreted the analyses, drafted the review, and will update the review in the future.

CE was responsible for the methodology, interpreted the analyses, drafted the final manuscript, and will update the review in the future.

TP arbitrated the selection of studies, interpreted the analyses, drafted the final manuscript, and will update the review in the future.

\section{DECLARATIONS OF INTEREST}

EL: none known; EL is a pediatric psychologist and provides clinical service to children and adolescents with chronic pain. EL is an author on three studies included in this review (Law 2015; Palermo 2016a; Palermo 2016b), and was not involved in data extraction or assessments 
of these studies. During the completion of this work, EL received salary support from the National Institutes of Health/National Institute of Neurological Disorders and Stroke (Grant number K23NS089966, PI: Law).

EF: none known.

CE: none known; CE is an author on one study included in this review (Palermo 2016a), and was not involved in data extraction or assessments of this study. Since CE is an author as well as the PaPaS Co-ordinating Editor at the time of writing, we acknowledge the input of Phil Wiffen who acted as Sign Off Editor for this review. CE had no input into the editorial decisions or processes for this review.

TP: none known; TP is an author on four studies included in this review (Law 2015; Palermo 2009; Palermo 2016a; Palermo 2016b), and was not involved in data extraction or assessments of these studies. During the completion of this work, TP received salary support from the National Institutes of Health/National Institute of Child Health, Behavior and Development (K24HD060068, PI: Palermo).

\section{SOURCES OF SUPPORT}

\section{Internal sources}

- University of Bath, UK

\section{External sources}

- National Institutes of Health/National Institutes for Child Health and Human Development, USA Grant number: K24HD060068 (PI: Palermo)

- National Institutes of Health/National Institute of Neurological Disorders and Stroke, USA Grant number: K23NS089966 (PI: Law)

\section{DIFFERENCES BETWEEN PROTOCOL AND REVIEW}

From the 2014 update, we included GRADE assessments for the quality of evidence. We removed concordance ratings and quality of evidence using the Yates scale, following Cochrane guidance (Schünemann 2011).

Differences between protocol and 2012 review publication:

- Language throughout the protocol has been altered to improve the flow and increase the accuracy.

- The tense of the language used in the methodology has been changed to past in line with Cochrane guidelines.

- Measures of treatment effect: this section has been added to provide a clearer description of intended analyses.

- The order of the four main analyses has been re-worded for a clearer understanding of the analysis plan. Parent outcomes have been listed before child outcomes as this is the focus of the review. Appendices were added for other search strategies.

- Assessment of risk of bias in included studies: this has been expanded to include a fuller description.

Differences between 2012 and 2014 updated publication:

- Quality of studies (Yates 2005), was deleted. Quality of evidence included using GRADE ratings.

- Consistency between aims, measures, and results removed for this updated review.

Differences between 2014 and 2018 updated publication:

- Updated the Background to include relevant citations published since the last update.

- Studies that included fewer than 20 participants/arm were excluded for this update.

- We renamed 'painful conditions', 'chronic pain conditions'.

- Inflammatory bowel diseases are combined with chronic pain conditions in this update.

- We included studies that combined psychological interventions with pharmacological interventions, given the relevance of pharmacological treatments for children with chronic medical conditions.

- We added Methods sections that were missing from prior versions of this review: 'Unit of analysis issues; Assessment of reporting biases; Sensitivity analysis.

- Assessment of heterogeneity: we now clarify that assessment of heterogeneity will be conducted for analyses with at least 10 studies per Cochrane guidance (Deeks 2017).

- Measures of treatment effect: we reworded this section to reduce redundancy with information provided in How the intervention might work (no methods were changed).

- Assessment of risk of bias in included studies: we revised this section to improve clarity and readability. We also made two changes to our methods: 1) for reporting bias, we rated studies as high risk if data were not fully reported in the manuscript even if study 
authors provided these data on request; previously we rated this as unclear risk, 2) for attrition bias, we rated studies as unclear risk if insufficient data were provided to make a judgement (e.g. the study reported attrition but not differences between completers versus non-completers); previously we rated this as high risk.

- Data synthesis: we revised language to describe GRADE ratings to reflect current recommendations (no methods were changed).

- Subgroup analysis and investigation of heterogeneity: we revised our methods for subgroup analysis and investigation of heterogeneity and now focus on a single subgroup analysis: comparing intervention effects for studies with a wait-list control condition versus an active control condition. We chose to focus on this single subgroup analysis for the following reasons: 1 ) visual inspection indicated this may have contributed to heterogeneity, 2) the originally planned analyses were redundant with the primary aims of this review, and 3) this review includes a large number of primary analyses and as such we wanted to present a maximum of one subgroup analysis per Cochrane guidance (Deeks 2017).

\section{NOTES}

\section{Assessed for updating in 2021}

In June 2021 we did not identify any potentially relevant studies likely to change the conclusions. Therefore, this review has now been stabilised following discussion with the authors and editors. The review will be reassessed for updating in two years. If appropriate, we will update the review before this date if new evidence likely to change the conclusions is published, or if standards change substantially which necessitate major revisions. Should the review require updating, we will seek a new author team to complete it.

\section{NDEX TERMS}

\section{Medical Subject Headings (MeSH)}

Chronic Disease [*psychology]; Cognitive Behavioral Therapy; Family Relations; Family Therapy; Motivational Interviewing; Parenting [psychology]; Parents [ ${ }^{*}$ psychology]; Problem Solving; Psychotherapy [ ${ }^{\star}$ methods]; Randomized Controlled Trials as Topic

\section{MeSH check words}

Adolescent; Child; Child, Preschool; Humans; Infant 